Portland State University

PDXScholar

\title{
An Evaluation of Moderating Influences of Employee Proactive Personality: Empowerment and Political Skill
}

Deborah Kaylee Ford

Portland State University

Follow this and additional works at: https://pdxscholar.library.pdx.edu/open_access_etds Let us know how access to this document benefits you.

\section{Recommended Citation}

Ford, Deborah Kaylee, "An Evaluation of Moderating Influences of Employee Proactive Personality: Empowerment and Political Skill" (2011). Dissertations and Theses. Paper 515.

https://doi.org/10.15760/etd.515

This Dissertation is brought to you for free and open access. It has been accepted for inclusion in Dissertations and Theses by an authorized administrator of PDXScholar. Please contact us if we can make this document more accessible: pdxscholar@pdx.edu. 
An Evaluation of Moderating Influences of Employee Proactive Personality:

Empowerment and Political Skill

by

Deborah Kaylee Ford

A dissertation submitted in partial fulfillment of the requirements for the degree of

Doctor of Philosophy

in

Applied Psychology

Dissertation Committee:

Donald M. Truxillo, Chair

Talya N. Bauer

Berrin Erdogan

Leslie B. Hammer

Cynthia D. Mohr

Portland State University

(C)2011 


\begin{abstract}
An action-orientation within the workplace is often sought out by organizations as a source for competitive advantage. Organizational leaders are increasingly reliant on independently driven employees that will take action without being instructed to do so. Toward this effort, proactive personality has become increasingly popular within the literature as a personality trait associated with an employee's propensity to take charge of situations and demonstrate initiative to make a positive impact.

In identifying potential variables that will moderate the effects of proactive personality, a highly relevant construct is empowerment. Proactive personality is thought of as a trait, whereas empowerment can be thought of as the contextual counterpart. In this study, I research both psychological empowerment as an employee interpretation of organizational conditions, such as feelings of selfefficacy, control, and flexibility for action (Arnold, Arad, Rhoades, \& Drasgow, 2000) and structural empowerment as the influence of situational workplace context (Kanter, 1977).

Despite the theoretical overlap between proactive personality and empowerment, very little has been done to integrate or investigate these variables together to evaluate their relative influences on important outcomes. Given that limited concentration has been focused on boundary conditions of proactive personality, employee political skill is hypothesized as a moderator that will encourage the attainment of important organizational outcomes (i.e., job task
\end{abstract}


Action Orientation ii performance, job satisfaction) and minimize negative outcomes (i.e., occupational stress and strain) from proactive personality and empowerment.

This study is a more complete investigation of proactive personality that not only provides a meaningful theoretical examination, but also informs applied practice. Despite a number of theoretical links between proactive personality and empowerment, the two constructs have been investigated in isolation from one another. Therefore, the relationship between empowerment and political skill is largely unknown. It is unclear whether empowerment and political skill are both necessary to realize optimal results or whether being high on both leads to exponentially better outcomes.

This study included 252 nurses from union organizations in Oregon, Florida, and Missouri that registered and were invited to participate (53\%). They were surveyed across two points in time, 176 participated at Time 1 and Time 2 and 76 participated in only Time 1. Results did not show support for my hypotheses that improvements would be observed for those high on any two research variables: proactive personality, empowerment, and political skill. However, results consistently support a compensatory model. In general, task performance, perceived effectiveness, and satisfaction with quality of care improved when nurses were high on either proactive personality or empowerment (either structural or psychological). Those high on either proactive personality or political skill had higher levels of task performance and satisfaction with quality of care. Similarly, those high on either structural empowerment or political skill had higher levels of task performance and satisfaction with quality of care. Only when a nurse was low 
Action Orientation iii

on both variables in the model did they show reduced benefits.

Several clear practical solutions are readily apparent based on study results. Given that empowerment can be manipulated within an organizational culture and proactive personality can be integrated with selection systems, the results are important for organizational leaders and organizational development consultants. Similarly, this research adds greatly to the literature on political skill, an area that is relatively new. By examining the moderating influence of political skill, this adds to the theoretical advancement of the three constructs while also informing practitioners regarding potential selection, training, and organizational design. Political skill has been seen as an attribute with the capacity to change over time with training, experience, and mentoring (Ferris, Perrewé, Anthony, \& Gilmore, 2000). Therefore, the practical implications for organizations are clearly evident. Further, given that both proactive personality and empowerment have received limited evaluation into their boundary conditions, an evaluation of potential moderators helps advance into the understanding of the processes related to action within the workplace. 


\section{Dedication}

Action Orientation iv

I am dedicating this dissertation to my grandmother, Mary D'amico. She has been my supporter and champion throughout my life. She is a source of my inspiration and my strength. 


\section{Acknowledgements}

I would like to acknowledge the financial support I received from the Society for Industrial and Organizational Psychology, the Personnel Testing Counsel of Northern California, and CPS Human Resource Services.

In addition, I would like to thank the organizations that facilitated with data collection efforts. These included the Oregon Nurses Association, the Oregon Center for Nursing, the Florida Nurses Association, and the Missouri Nurses Association.

I would like to recognize the leadership and support of my committee. My Committee Chairs, Donald Truxillo and Talya Bauer, were indispensible in making this dissertation successful. Berrin Erdogan, Cynthia Mohr, and Leslie Hammer provided detailed feedback and insightful additions throughout. I would like to especially acknowledge Cynthia Mohr for all of her support during data collection.

Finally I would like to thank my research assistants Roxana Gutierrez and Layla Mansfield for the energy, commitment, and attention to detail they provided throughout the project.

In the end, I found it a pleasure to work with each of these individuals and organizations. 
Abstract $\quad$ i

Dedication $\quad$ iv

Acknowledgements $\quad \mathrm{V}$

List of Tables viii

List of Figures $\quad$ xi

CHAPTER 1 1

RESEARCH PURPose

Potential Limitations to Proactive Personality and Empowerment 4

Political Skill as a Potential Moderator 5

Contributions of the Research 5

$\begin{array}{lr}\text { CHAPTER } 2 & 9\end{array}$

Literature Review: Proactive Personality 9

Proactive vs. Reactive $\quad 10$

Proactivity as a Process 11

$\begin{array}{ll}\text { Theoretical Foundations } & 11\end{array}$

$\begin{array}{ll}\text { Proactive Personality } & 13\end{array}$

$\begin{array}{ll}\text { Proactive Behavior } & 14\end{array}$

Relationship Between Proactive Personality and Outcome Variables 15

$\begin{array}{ll}\text { CHAPTER } 3 & 21\end{array}$

LITERATURE REVIEW: EMPOWERMENT 21

Structural Versus Psychological Empowerment 22

Facets of Psychological Empowerment 24

Structural Empowerment $\quad 26$

Relationship Between Empowerment and Organizational Outcomes 27

The Relationship Between Empowerment and Proactive Personality 36

$\begin{array}{ll}\text { CHAPTER } 4 & 40\end{array}$

Literature ReVIEW: Political Skill $\quad 40$

The Construct of Political Skill 44

Political Skill as a Moderator of Action-Orientation 46

Political Skill and Proactivity 49

Political Skill and Empowerment 56

$\begin{array}{ll}\text { CHAPTER } 5 & 62\end{array}$

METHOD $\quad 62$

Occupation Sample $\quad 62$

Study History and Modifications. 65

$\begin{array}{ll}\text { Recruitment } & 67\end{array}$

Respondent Characteristics $\quad 68$ 
Data Collection Design

Action Orientation vii

Measures

71

Control Variables

71

77

Chapter 6

83

RESULTS

83

Respondents vs. Non-Respondents $\quad 83$

Analyses

84

Additional Research Questions

96

Interactions with Autonomy

98

CHAPTER 7

105

DISCUSSION

105

Two-Way Interactions

106

Three-Way Interactions

112

Implications for Research

114

Implications for Practice

116

Potential Limitations and Future Research Directions

119

Conclusion

124

REFERENCES

202

Appendix: Scale Items

231 


\section{List of Tables}

Table 1. Overview of Measure by Source and Data Collection Timing 125

Table 2. Means, Standard Deviations, Reliability Estimates, and Correlations for Study

Variables

Table 3. Regression Analyses Testing Proactive Personality and Psychological Empowerment Interaction with Task Performance

Table 4. Regression Analyses Testing Proactive Personality and Structural Empowerment Interaction with Task Performance .............................................................. 131

Table 5. Regression Analyses Testing Proactive Personality and Psychological Empowerment Interaction with Perceived Effectiveness

Table 6. Regression Analyses Testing Proactive Personality and Structural Empowerment Interaction with Perceived Effectiveness.

Table 7. Regression Analyses Testing Proactive Personality and Psychological Empowerment Interaction with Job Satisfaction

Table 8. Regression Analyses Testing Proactive Personality and Structural Empowerment Interaction with Job Satisfaction. 135

Table 9. Regression Analyses Testing Proactive Personality and Psychological Empowerment Interaction with Satisfaction with Quality of Care.

Table 10. Regression Analyses Testing Proactive Personality and Structural Empowerment Interaction with Satisfaction with Quality of Care.

Table 11. Regression Analyses Testing Proactive Personality and Psychological Empowerment Interaction with Stress

Table 12. Regression Analyses Testing Proactive Personality and Structural Empowerment Interaction with Stress ....

Table 13. Regression Analyses Testing Proactive Personality and Psychological Empowerment Interaction with Emotional Exhaustion....

Table 14. Regression Analyses Testing Proactive Personality and Structural Empowerment Interaction with Emotional Exhaustion...

Table 15. Regression Analyses Testing Proactive Personality and Psychological Empowerment Interaction with Strain

Table 16. Regression Analyses Testing Proactive Personality and Structural Empowerment Interaction with Strain 
Action Orientation ix

Table 17. Regression Analyses Testing Proactive Personality and Political Skill Interaction with Task Performance

Table 18. Regression Analyses Testing Proactive Personality and Political Skill Interaction with Perceived Effectiveness.

Table 19. Regression Analyses Testing Proactive Personality and Political Skill Interaction with Job Satisfaction

Table 20. Regression Analyses Testing Proactive Personality and Political Skill Interaction with Satisfaction with Quality of Care ....

Table 21. Regression Analyses Testing Proactive Personality and Political Skill Interaction with Stress. 148

Table 22. Regression Analyses Testing Proactive Personality and Political Skill Interaction with Emotional Exhaustion

Table 23. Regression Analyses Testing Proactive Personality and Political Skill Interaction with Strain

Table 24. Regression Analyses Testing Psychological Empowerment and Political Skill Interaction with Task Performance

Table 25. Regression Analyses Testing Structural Empowerment and Political Skill Interaction with Task Performance

Table 26. Regression Analyses Testing Psychological Empowerment and Political Skill Interaction with Perceived Effectiveness.

Table 27. Regression Analyses Testing Structural Empowerment and Political Skill Interaction with Perceived Effectiveness.

Table 28. Regression Analyses Testing Psychological Empowerment and Political Skill Interaction with Job Satisfaction

Table 29. Regression Analyses Testing Structural Empowerment and Political Skill Interaction with Job Satisfaction

Table 30. Regression Analyses Testing Psychological Empowerment and Political Skill Interaction with Satisfaction with Quality of Care .....

Table 31. Regression Analyses Testing Structural Empowerment and Political Skill Interaction with Satisfaction with Quality of Care ....

Table 32. Regression Analyses Testing Psychological Empowerment and Political Skill Interaction with Stress.

Table 33. Regression Analyses Testing Structural Empowerment and Political Skill Interaction with Stress. 
Table 34. Regression Analyses Testing Psychological Empowerment and Political Skill Interaction with Emotional Exhaustion

Table 35. Regression Analyses Testing Proactive Personality and Structural Empowerment Interaction with Emotional Exhaustion.

Table 36. Regression Analyses Testing Psychological Empowerment and Political Skill Interaction with Strain.

Table 37. Regression Analyses Testing Structural Empowerment and Political Skill Interaction with Strain

Table 38. Summary Table of Observed Significant Main Effects and Interactions 165

Table 39. Regression Analyses Testing Proactive Personality, Structural Empowerment, and Political Skill Interaction with Job Task Performance.

Table 40. Regression Analyses Testing Proactive Personality, Structural Empowerment, and Political Skill Interaction with Satisfaction with Quality of Care.

Table 41. Regression Analyses Testing Proactive Personality, Political Skill, with Decision-Making Autonomy Interaction with Job Task Performance 168

Table 42. Regression Analyses Testing Proactive Personality, Structural Empowerment, with Decision-Making Autonomy Interaction with Job Satisfaction

Table 43. Regression Analyses Testing Proactive Personality, Political Skill, with Decision-Making Autonomy Interaction with Job Satisfaction.

Table 44. Regression Analyses Testing Proactive Personality, Structural Empowerment, and Work-Methods Autonomy Interaction with Emotional Exhaustion

Table 45. Regression Analyses Testing Proactive Personality, Psychological Empowerment, and Work-Methods Autonomy Interaction with Emotional Exhaustion....

Table 46. Regression Analyses Testing Proactive Personality, Psychological Empowerment, and Work-Methods Autonomy Interaction with Strain.... 
List of Figures

Action Orientation $\mathrm{xi}$

Figure 1. Model of Relationships between Proactive Personality, Empowerment and Political Skill....

Figure 2. Model of Empowerment as Moderator of Proactive Personality-Outcome Relationships 175

Figure 3. Model of Political Skill as Moderator of Proactive Personality-Outcome Relationships 176

Figure 4. Model of Political Skill as Moderator of Empowerment-Outcome Relationships 177

Figure 5. Proactive Personality by Psychological Empowerment with Job Task Performance 178

Figure 6. Proactive Personality by Psychological Empowerment with Perceived Effectiveness 179

Figure 7. Proactive Personality by Structural Empowerment with Job Task Performance 180

Figure 8. Proactive Personality by Structural Empowerment with Perceived Effectiveness 181

Figure 9. Proactive Personality by Psychological Empowerment with Satisfaction Quality of Care. 182

Figure 10. Proactive Personality by Structural Empowerment with Satisfaction with Quality of Care 183

Figure 11. Proactive Personality by Political Skill with Job Task Performance 184

Figure 12. Proactive Personality by Political Skill with Satisfaction with Quality of Care 185

Figure 13. Structural Empowerment by Political Skill with Job Task Performance ...... 186

Figure 14. Proactive Personality, Structural Empowerment, and Political Skill with Job

Task Performance

Figure 15. Proactive Personality, Structural Empowerment, and Political Skill with Satisfaction with Quality of Care. 188

Figure 16. Proactive Personality, Political Skill, and Decision-Making Autonomy with Job Task Performance. 189

Figure 17. Proactive Personality, Structural Empowerment, and Decision-Making Autonomy with Job Satisfaction 190 
Action Orientation xii

Figure 18. Proactive Personality, Political Skill, and Decision-Making Autonomy with Job Satisfaction

Figure 19. Proactive Personality, Structural Empowerment, and Work Methods Autonomy with Emotional Exhaustion.

Figure 20. Proactive Personality, Psychological Empowerment, and Work Methods Autonomy with Emotional Exhaustion.

Figure 21. Proactive Personality, Psychological Empowerment, and Work Methods Autonomy with Strain...

Figure 22. Psychological Empowerment by Political Skill with Job Task Performance 195

Figure 23. Psychological Empowerment by Political Skill with Perceived Effectiveness

Figure 24. Core Self Evaluation by Political Skill with Job Satisfaction 197

Figure 25. Core Self Evaluation by Political Skill with Satisfaction with Quality of Care 198

Figure 26. Conscientiousness by Political Skill with Job Satisfaction 199

Figure 27. Conscientiousness by Political Skill with Satisfaction with Quality of Care 200 Figure 28. Conscientiousness by Political Skill with Strain.... 201 


\section{CHAPTER 1}

Action Orientation 1

\section{RESEARCH PURPOSE}

Given that industries are currently struggling to survive in an ever more vast, volatile, and global market, it is not surprising that organizations rely on employees to maintain a competitive edge. During a period highlighted with ongoing technological advances, an organization's human capital is often the key strategic component to simply being a viable competitor and integral to being an industry leader.

Skilled workers who are willing and able to undertake broader roles are integral for organizations to stay competitive and to cope with dynamic environments (Parker, 1998). Two prominent concepts from divergent vantage points have emerged within organizational research to explain motivational forces that promote an employee action: employee proactive personality (Bateman \& Crant, 1993), which is proposed as a stable individual difference variable, and empowerment (Conger \& Kanungo, 1988), which is promoted as a contextual variable or a perception of one's organizational context. Although psychological empowerment is undeniably related to an employee's disposition, it is largely driven by an employee's perception of their work and workplace (Thomas \& Velthouse, 1990). Some empowerment researchers focus on social-structural factors, but much of the attention has been placed on psychological factors (Liden, Wayne, \& Sparrowe, 2000). The psychological view of empowerment emphasizes a psychological state based on perceptions of meaningfulness, competence, selfdetermination, and impact (Conger \& Kanungo, 1988; Spreitzer, 1995b; Thomas \& Velthouse, 1990). To provide a holistic evaluation, I collected both psychological and structural empowerment for examination. Although there are slight distinctions between 
Action Orientation 2

the two constructs, the theoretical rationale for processes do not differ so there is one set of hypotheses.

Campbell (2000) notes that a number of organizational initiatives which promote employee role expansion including organizational empowerment are primarily focused on promoting employee action. Empowerment tends to focus on external, organizationally induced sources of motivation, while proactive personality examines the employee's disposition. The proactivity and empowerment literatures have considerable overlap both conceptually and theoretically, yet an integration of these two concepts to examine their relative influence and their relationships to one another is largely absent. Both empowerment and proactive personality deal with employees taking charge to change their workplaces in a positive manner. Both constructs emphasize the role of "personal control" as a mechanism for explaining positive outcomes. As further evidence for the relatedness between these two constructs, one must only look at descriptions of the dimensions of empowerment, which are thought to produce the proactive essence of employee empowerment (Spreitzer, Kizilos, \& Nason, 1997). Finally, in an integrative model of proactive behaviors (Crant, 2000), proactive personality is seen as an important individual difference variable that contributes to one's propensity to take initiative, but contextual antecedents to proactive behaviors are reminiscent of empowerment (e.g., management support, situational cues, organizational culture). This suggests that these two constructs may be closely linked.

Despite their considerable theoretical overlap, we know little regarding the relationship between employee proactive personality and empowerment. For instance, does empowerment act as a substitute for proactivity or vice versa? Do empowerment 
Action Orientation 3

and proactive personality work in an additive fashion, such that the possession of proactive personality within an empowering workplace creates even greater performance gains or exponentially higher levels of optimal organizational outcomes? Is a minimum level of either proactivity or empowerment necessary to realize beneficial organizational outcomes? In the research, I seek to first and foremost examine these and other questions regarding the relationships between employee proactive personality and organizational empowerment, while detailing the empirical and theoretical linkages between these two literatures.

The research design attempts to examine literatures from two related constructs to provide a more integrative examination of the interplay between both individual attributes (i.e., proactive personality) and perceptions of context (i.e., empowerment). Additionally, the research provides a meaningful examination of a potential boundary condition (i.e., political skill) that can be used to provide valuable guidance to practitioners in terms of their approach to selection and/or training methodology. Finally, the research examines how proactive personality affects a range of important organizational outcomes, including task performance, perceived effectiveness, job satisfaction, satisfaction with quality of care, occupational stress, emotional exhaustion and occupational strain, and how the effects of proactive personality are moderated by empowerment and political skill. Increasingly, the public is expecting organizations to expand their level of responsibility to include employee concerns and needs (Liedtka, 1999); therefore, stress and health outcomes are an important avenue for future research related to proactivity and empowerment. Given that both proactivity and empowerment may involve an employee going out on a limb to make changes that are not obviously 
needed, it could be that an employee's levels of stress and strain could be impacted. As such, it is essential that outcomes selected for investigation not only include the traditionally positive outcomes such as job performance and job satisfaction, but also negative outcomes such as occupational stress and strain.

Potential Limitations to Proactive Personality and Empowerment

Modern organizations need flexible employees who go beyond narrow task requirements and demonstrate personal initiative (Hertog \& Beischak, 2007). This is particularly true for occupations that are considered socially laden in that they require higher levels of interpersonal interaction, collaboration, and opportunities for negotiation and coordination with others within the workplace (Bing, Minor, Davison, \& Novicevic, 2009). Given that organizations are becoming increasingly decentralized and team oriented, socially laden job activities are emerging more and more in organizations across a number of industries.

Yet there remains significant risk in engaging in proactive acts. Organizations that empower or seek out employees with proactive qualities cannot realize the benefits without the likelihood of some unpredicted and unexpected outcomes. Both proactive personality and empowerment have been espoused as a positive influence for a number of beneficial organizational outcomes, yet very few have questioned or examined the boundary conditions. The promotion of action-oriented behaviors does not guarantee that they are deployed in an effective manner (e.g., Erdogan \& Bauer, 2005). I examined a potential moderator that would add significant breadth to both the field of proactive personality and research dedicated to empowerment. Social competence, in particular political skill, is a likely important and necessary condition to realizing optimal results, 
and essential for minimizing the potential negative repercussions.

Political Skill as a Potential Moderator

Political skill is thought to impact performance, effectiveness, and career success via important factors such as social astuteness, positioning, and savvy reasoning (Mintzberg, 1983). Politically skilled individuals are thought to combine social astuteness with the capacity to adjust their behavior to different changing demands (Ferris et al., 2007). They are able to win over others and control the responses of others by inspiring support and trust, as well as projecting a sense of genuineness of intentions.

Given that the effectiveness of proactive behaviors is heavily dependent on how proactive employees are evaluated by others (Grant \& Ashford, 2008), this tendency for politically skilled individuals to inspire trust and support would appear to be a necessary skill for ensuring optimal outcomes. Conversely, it is expected that those who engage in proactive behaviors that challenge the status quo and upset the balance and flow of activities without political skill will be met with opposition. As noted by Grant and Ashford, proactive behaviors that are perceived as unethical, self-serving, or causing harm will lead to punishments.

Contributions of the Research

In an effort to bridge related fields of research, I examined the commonalities and distinctions between empowerment and employee proactive personality. Further, I evaluated political skill as a primary moderator for proactive personality and empowerment with important organizational outcomes. As discussed later, I include multiples measures of each outcome variable: job performance, job satisfaction, and occupational strain. I include one general scale of each construct and then a second more 
Action Orientation 6

specific measure. The inclusion of multiple measures for these constructs will provide a more comprehensive examination of these outcomes. Figure 1 provides a holistic illustration of the hypothesized model to be tested within this research. As seen in the figure, both proactive personality and empowerment are thought to have main effects on employee job performance, job satisfaction, occupational stress and occupational strain. Empowerment is shown as a moderator between proactive personality and organizational outcomes. Political skill is illustrated as a moderator within the model. Specifically, it was expected that the relationships between employee proactive personality and empowerment with important outcome variables will vary depending on the degree to which an employee possesses political skill. For example, an employee with higher levels of proactive personality will realize greater task performance results when they possess higher levels of political skill. Similarly, a proactive employee will be expected to experience greater levels of occupational stress and strain when they possess little to no political skill. The research offers three meaningful contributions to organizational literature.

First, by bridging work related to empowerment and employee proactive personality, I am able to create meaningful motivational linkages between conceptually overlapping fields. This provides a meaningful theoretical extension for the proactive personality nomological network. The study examines the interaction between proactive personality and empowerment to ascertain the unique contributions of each and the relationship between them in predicting important organizational outcomes.

Second, the research also addresses the call by researchers to examine the potential negative aspects of proactive personality (e.g., Chan, 2006) and empowerment 
Action Orientation 7

(e.g., Campbell, 2000). The existing literature has predominantly focused on the main effects of proactive personality and empowerment without considering the moderators in the prediction of important organizational outcomes. Any theory must 1) describe the constructs of interest, 2) describe how the constructs are related, 3) articulate mediating processes that explain the mechanisms at play, and finally 4) explain the boundary conditions regarding how changes in the context (i.e., who, where, or when) affect the causal system (e.g., Bacharach, 1989; Feldman, 2004; Whetten, 1989). This study provides greater depth to the proactive personality theoretical literature that has primarily investigated the direct relationships between proactive personality and important organizational outcomes, while neglecting potential moderators (see Chan, 2006; Erdogan \& Bauer, 2005 for exceptions). Additionally, it examines a moderator that is contextual (i.e., empowerment) and a moderator that is linked to an individual employee's capability (i.e., political skill).

Similarly, empowerment researchers have repeatedly suggested that political type skills and prowess are necessary for realizing optimal results from empowerment programs (Bookman \& Morgan, 1988; Hardy \& Leiba-O'Sullivan, 1998). Yet the empirical investigations between empowerment and political skill are non-existent despite the existence of research suggesting that organizational empowerment programs often fail (e.g., Barker, 1993; Brown, 1992; Eccles, 1993). Therefore, the research offers theoretical rationale for explaining the potential moderator of political skill between empowerment and key outcomes.

Finally, the implication from the research offers considerable practical value to organizational consultants and leaders. Literature related to empowerment is largely 
Action Orientation 8 centered on organizational change interventions aimed at enhancing an employee's sense of control and efficacy. Therefore, a moderating relationship between empowerment and proactive personality would inform selection methods, job redesign, and/or culture change. Organizations may seek to remove perceived employee barriers within the workplace, select employees that have higher levels of proactive personality, or train managers to promote empowerment within the workforce. Similarly, if political skill were identified as a moderator for both proactive personality and empowerment, several practical insights can provide sound insight for organizational practitioners. Political skill could be added to a selection battery. Additionally, because political skill is by definition a skill, it can be improved with intense training and coaching. Political skill is thought to improve with greater experience and exposure to various situations. For example, developmental assessment centers that emphasize coaching and employee development could prove effective in enhancing an employee's political skill.

In this dissertation, I first provide a detailed examination of the defining characteristics for the proactive personality construct. Second, I outline empowerment while highlighting theoretical links to proactive personality as a potential moderator. Finally, I delineate how political skill would be a likely moderating variable for both proactive personality and empowerment. Included in subsequent chapters are details related to data collection, recruitment, data analysis, and implications of the research initiative. 


\section{CHAPTER 2}

Action Orientation 9

\section{Literature ReView: Proactive Personality}

Frese and Fray (2001) emphasize that the global competition associated with $21^{\text {st }}$ century jobs require greater levels of resourcefulness and innovation. Given that individual employees vary in their propensity to take action in an effort to change their environment (Chan, 2006), proactive personality is thought to be the individual trait that explains whether an individual is inclined to act as a positive influence (Bateman \& Crant, 1993) by engaging in a number of behaviors that can range from personal initiative, feedback seeking, and taking charge. Proactive behaviors are an employee's attempt to actively promote positive change to their work setting. To elaborate on the distinguishing characteristics of proactivity, it is important to highlight the contrast with passivity and clarify its relationship to custodial behaviors.

Individuals who are highly involved and committed as independent contributors to the organization with initiative and a sense of responsibility are characterized as proactive employees (Campbell, 2000). Literature related to employee proactivity emerged as part of a movement to address the limited portrayal of employees as passive and reactive entities within the workplace. In contrast to the behavioral tradition that views employees as respondents to stimuli in their environment (Lewin, 1936), a number of constructs have emerged that promote employees as individuals who affect, shape, expand and mitigate the experiences in their life (Grant \& Ashford, 2008) including topics such as adaptive performance (e.g., Pulakos, Arad, Donovan, \& Plamondon, 2000), feedback-seeking (e.g., Ashford \& Cummings, 1983), and a central premise for this research, employee proactivity (e.g., Crant, 2000). 
Proactive vs. Reactive

As highlighted by Parker and Collins (2010), dictionary definitions of proactivity emphasize "acting in anticipation of future problems, needs or changes" (Merriam Webster, 2008) and "controlling a situation by causing something to happen rather than waiting to respond to it after it happens" (Princeton University, 2003). In defining proactive behavior, Crant (2000) specifies that proactive behaviors encompass actions taken by employees to improve current circumstances. However, this action must involve challenging the status quo rather than passively adapting to present conditions.

Grant and Ashford (2008) define proactive behaviors as "anticipatory action that employees take to impact themselves and/or their environments", which is largely consistent with other researchers (e.g., Parker, Williams, \& Turner, 2006). Grant and Ashford's definition was formulated in an attempt to distinguish proactive behaviors from more general motivated behavior under the premise that proactive behavior includes acting in advance and the intention of impact, which differentiates it from reactive and passive behavior. For instance, adaptive performance (Pulakos et al., 2000) focuses on adapting to change and the modification of behaviors to meet the demands of new situations, whereas portrayals of proactive behavior emphasize initiating change (e.g., Frese \& Fray, 2001; Griffin, Neal, \& Parker, 2007).

Responsive behavior is passive in nature, which is counter to the dominant theme of proactivity within the proactivity literature (cf. Grant \& Ashford, 2008). Proactivity requires forethought, anticipation, and planning. Thus, creative solutions to unforeseen environmental changes would be considered reactive by nature and not inclusive under the domain of proactivity. Despite the adaptive nature of applying creative solutions to 
Action Orientation 11

organizational dilemmas, it would not be considered proactive due to the reactionary response to a problem.

Proactivity as a Process

It is important to note that proactivity is not by nature extra-role, as once thought (e.g., Van Dyne, Cummings, \& McLean Parks, 1995). Proactivity is a process that can be applied to either in-role or extra-role activities (Grant \& Ashford, 2008). And therefore, it is of greater importance that the employee identifies opportunities to anticipate, strategize, and act to impact the environment or oneself (Parker et al., 2006). In an effort to build a stronger theoretical foundation for the study of proactive behavior, Grant and Ashford (2008) outline proactivity as a process applied to actions through anticipation, planning, and striving to create an impact. Within the evolution of proactive behavior, researchers have often married the topic of proactivity with the concepts of in-role and extra-role behaviors (e.g., Crant, 2000; Frese \& Fray, 2001; Parker et al., 2006). Yet the concept of extra-role behaviors has been noted as a vague and unclear classification and often dependent on how an individual defines their role (Morrison, 1994). In delineating their framework for explaining the proactive behavior as a process, Grant and Ashford (2008) argue that proactive behaviors can be both in-role and extra-role. This has been supported by other proactivity scholars (e.g., Crant, 2000). Rather the emphasis in defining proactive behavior is dependent on whether the employee anticipates, plans for, and attempts to create a future outcome that has impact on the self or the environment (Parker et al., 2006).

Theoretical Foundations

The basic concept that individuals shape their environments and are fore-active 
Action Orientation 12

and not simply counteractive (Bandura, 1986) provides the underlying logic for research on proactive personality (Bateman \& Crant, 1993). Both reciprocal determinism (Bandura, 1997) and self-regulation theory (Kanfer, 1970) are mechanisms used to explain proactive tendencies. Bandura's (1997) concept of reciprocal determinism suggests that employees are not only products of their social systems, but also producers and influencers. As such, the viewpoint that individuals create their environments is a central premise for explaining elements of proactive personality (Bandura, 1977; Bateman \& Crant, 1993). This perspective highlights the complex set of processes that lead individuals to select, interpret and change situations (Terborg, 1981). The proactive dimension of behavior is linked to an employee's need to manipulate and control their work settings (Langer, 1983) and proactive personality is the personal dispositional variable that is a dominant corollary for proactive behavior (Bateman \& Crant, 1993). Self-regulation theory (Kanfer, 1970) proposes that self-regulation guides goaldirected activities in spite of challenges and failures (Karoly, 1993). Frese and Fray (2001) note that elements of proactive behaviors (i.e., personal initiative) are also discussed in self-regulation elements including, self-setting goals, proactive approaches, and persistence in spite of barriers (Bandura, 1991; Karoly, 1993). Proactivity has been studied in primarily two ways - as a personality trait and a set of relatively enduring expressions of reoccurring proactive behaviors. Next, I review the literature that has advanced these two streams of research. As is expected, the interplay between proactive personality and proactive behaviors has been explored and is included within this overview. 
Proactive Personality

Individuals can be active rather than passive in their role-making process (Graen, 1976) and they can create ecological change in their environments (Weick, 1979). Workers can passively withdraw or actively try to change working conditions as they adapt to dissatisfying work environments (Hirschman, 1970). Bateman and Crant (1993) define proactive personality as the relatively stable tendency to effect environmental change. Proactive personality is the relatively stable tendency to effect environmental change that differentiates people based on the extent to which they take action to change their environment (Bateman \& Crant, 1993). Crant (1995) expands on this definition by describing high proactive personality individuals as relatively unconstrained by situational forces and able to effect environmental change. An individual with a highly proactive personality will identify opportunities, take action, and persevere until they bring about meaningful change (Frese \& Fray, 2001).

Proactive personality is thought to be a compound variable (Hough, 2003), which means it is comprised of basic personality traits that do not all covary and is rooted in people's needs to manipulate and control their environment (Langer, 1983; White, 1959). Research supports proactive personality as a conceptually and empirically distinct construct from the Five Factor Model (FFM) personality traits (e.g., Major, Turner, \& Fletcher, 2006). In addition, proactive personality has been shown to be correlated with need for achievement and need for dominance, but not locus of control (Bateman \& Crant, 1993).

In terms of the difference between those high and low on proactivity, it might be well demonstrated via the active versus passive distinction. If an individual identifies 
Action Orientation 14

opportunities and acts on them and is persistent in the face of obstacles, they would be characterized as possessing a proactive personality (Seibert, Crant, \& Kraimer, 1999). Less proactive individuals would act in reaction to environmental changes and passively adapt to circumstances rather than change them.

Proactive Behavior

Proactive behavior is an "active performance concept" (Frese \& Fray, 2001) that has been examined in a number of ways. The manifestations of proactive behavior are phenomenon-driven, but despite inherent interrelatedness they have grown rapidly and largely in isolation (Grant \& Ashford, 2008). For instance, personal initiative is an attribute that describes an employee who is innovative, uses a proactive approach, and remains persistent to overcoming difficulties that arise in the pursuit of goals (Frese, Fay, Hilburger, Leng, \& Tag, 1997; Frese, Kring, Soose, \& Zempel, 1996). A person who has personal initiative is self-starting, proactive, able to overcome barriers, and acts in concert with organizational goals. Similarly, the constructive concept of employee voice has been studied as an operationalization of proactivity. It involves employees' behaviors to speak out and challenge the status quo with the intent of improving the situation (LePine \& Van Dyne, 1998). Taking charge is a manifestation of proactivity that specifically focuses on improving how work is executed (Morrison \& Phelps, 1999). Other constructs that fall under the proactive behavior umbrella include: task revision (Staw \& Boettger, 1990), role innovation (Schein, 1971), selling critical issues to leaders (Dutton \& Ashford, 1993), and initiating role expansions (Parker, Wall, \& Jackson, 1997).

Construct differentiation. Because proactivity did not emerge as an integrated 
Action Orientation 15

research theme (Crant, 2000), as noted above, a proliferation of related constructs have been studied by researchers under the auspices of proactive behaviors. In an effort to provide some integration across proactive behaviors that have been investigated, Parker and Collins (2010) used empirical data to clarify the differences, similarities, and interrelationships among operationalized proactive behaviors. They were able to show that each of the proactive behaviors in their study is empirically distinguishable. Further, the authors hypothesized and supported a hierarchical structure that included 1) proactive work behavior (e.g., taking charge, voice, individual innovation, problem prevention), 2) proactive person-environment (PE) fit behavior (e.g., feedback inquiry, feedback monitoring, job change negotiation, career initiative), and 3) proactive strategic behavior (e.g. strategic scanning, issue selling credibility, issue selling willingness). This structure is organized according to the intended target of impact and provides a parsimonious conceptualization of proactive behaviors for research questions targeted at examining relationships with broader constructs (Parker \& Collins, 2010).

Relationship Between Proactive Personality and Outcome Variables

Researchers dedicated to understanding the factors linked to a healthy and productive workplace have recently identified that employee proactivity promotes important organizational outcomes, including employee participation in organizational initiatives (Parker, 1998), career success (e.g., Erdogan \& Bauer, 2005; Seibert et al., 1999; Seibert, Kraimer, \& Crant, 2001), newcomer adaptation (e.g., Ashford \& Black, 1996; Chan \& Schmitt, 2000; Morrison, 1993), leadership effectiveness (e.g., Bateman \& Crant, 1993), innovation (e.g., Kickul \& Guidry, 2002), as well as employee and work team performance (e.g., Crant, 1995; Kirkman \& Rosen, 1999). In one attempt to 
Action Orientation 16 quantify the value added for employee proactivity, Seibert and colleagues (Seibert et al., 1999) found that a one-point increase in proactive personality was associated with an $\$ 8,677$ increase in yearly salary after controlling for demographics (e.g., gender, ethnicity), human capital (e.g., education, experience), motivational variables (e.g., hours worked, desire for upward mobility), organizational variables (e.g., number of employees, private vs. public) and industry variables (e.g., type of industry, metropolitan area). In the present study, I focus on task performance, job satisfaction, and occupational stress and strain as important outcome variables that cover the broad spectrum of factors that contribute to organizational and individual effectiveness and well-being. Although strain can be conceptualized as cognitive strain (e.g., memory impairments, distractions) or physical strain (e.g., fatigue, stomach ache, elevated blood pressure), I will refer to affective strain, which includes such things as emotional exhaustion and irritability. I will simply refer to strain throughout this dissertation, but am researching affective strain in particular. Next, I will present an overview of the relationship between employee proactivity and the outcome variables in greater detail.

Task performance. A greater understanding for the contingencies within work environments can emerge when employees exert control over their work and anticipate changes. Bell and Staw (1989) note that employees can change their roles, procedures, task assignments, and even exert influence over decisions affecting their pay, promotions, and distribution of other organizational rewards. Proactive personality is associated with an individual's propensity to seek out information and opportunities while maintaining a self-starting style for their work activities (Crant, 2000). It is because of these tendencies that proactivity is linked to various manifestations of organizational performance, 
including newcomer socialization and adaptation (Ashford \& Black, 1996; Chan \& Schmitt, 2000; Morrison, 1993), sales performance (e.g., Crant, 1995), innovation (e.g., Kickul \& Guidry, 2002; Seibert et al., 2001), career success (e.g., Seibert et al., 1999; Seibert et al., 2001), and team performance (Kirkman \& Rosen, 1999).

In research dedicated to examining those variables that enhance a newcomer's effectiveness, studies have shown that proactive individuals are more likely to seek out task information and organizational norms and politics (e.g., Ashford \& Black, 1996; Bauer, Bodner, Erdogan, Truxillo, \& Tucker, 2007). Additionally, proactive individuals engage in feedback seeking (Ashford \& Tsui, 1991), which is linked to higher performance. Outside of the newcomer area of research, Crant (1995) explored the links between proactivity and performance within a sample of real estate agents. He found that those with high scores on proactive personality had higher sales than individuals with relatively lower levels of proactive personality. He suggested that those proactively inclined identified more opportunities for sales and followed through with potential homebuyers more than less proactive agents. In an empirical test of potential mediating mechanisms, Thompson (2005) tested a theoretical linkage between proactive personality and performance that used the social capital perspective (Lin, 2001). He proposed that resources within the social structure are accessed and/or mobilized purposefully to enhance performance. Resources can include social capital, such as networks. Employees with proactive personalities are thought to develop strong networks, enact their environment, and garner support to leverage in the pursuit of their self directed objectives (Thompson, 2005). Finally, meta-analytic research conducted by Bodner, Cadiz, Drown, and McCune (2009) showed a mean effect size estimate for the relationship between 
proactive personality and supervisor ratings of job performance of .21, $\mathrm{z}=7.51, p<.001$.

Based on the integrative review of proactivity conducted by Crant (2000), behaviors that are proactive were described as "taking initiative in improving current circumstances or creating new ones" (p. 436). In his review, Crant put forth an integrative model that included outcome variables, such as higher levels of job performance and success. In line with this promotive and progressive performance path, employee proactivity is associated with participation in organizational initiatives (Parker, 1998), entrepreneurial behaviors (Becherer \& Maurer, 1999), and leadership effectiveness (Bateman \& Crant, 1993; Crant \& Bateman, 2000).

Job satisfaction. Proactive individuals take action to improve, rather than adapt to situations as they occur (Crant, 2000). It is thought that proactive individuals are more satisfied because they remove obstacles that prevent satisfaction, develop new ideas, have greater understanding of organizational politics, and update their skills (Erdogan \& Bauer, 2005). They identify opportunities for change and growth, act on those opportunities, and persist in their efforts until change has occurred. These activities are thought to promote greater levels of satisfaction based on their general promotive and adaptive qualities. In support for the linkage to job satisfaction, proactive personality has been associated with intrinsic career success (job and career satisfaction) by a number of researchers (e.g., Erdogan \& Bauer, 2005; Seibert et al., 1999; Seibert et al., 2001).

Bodner et al. (2009) suggest proactive individuals will make every effort to either alter the environment so that it suits them, or find a new environment that is more pleasing when they find themselves in a situation that is displeasing to them. Using this rationale, they proposed and supported meta-analytically that proactive individuals are 
Action Orientation 19

likely to experience higher levels of job satisfaction. Bodner and colleagues found a mean effect size of .19, which was significantly different from zero, supporting the relationship between proactive personality and job satisfaction.

Based on this meta-analytic empirical results and theoretical rational, I propose that proactive personality will be related to job satisfaction. Proactive individuals are not inclined to adapt to situations that do not fill their needs, when they find themselves in a job that they are not satisfied with, they will make efforts to change their current circumstances to make them more satisfying.

Occupational stress and strain. Individual differences exist in an employee's propensity to experience occupational stress and strain. In support of this premise, personality has been found to be capable of mitigating a number of health conditions, including arthritic disease (Smith \& Zauntra, 2002). Employees are able to adapt differently to the environment, which can impact stress levels (Parkes, 1990, 1994). As proposed by Parker and Sprigg (1999), proactive personality can play a substantive roll in the theoretical Job Demands-Control Model of occupational stress and strain (Karasek, 1979). Proactive personality has been argued to play a significant role in buffering stress and strain (Harvey, Blouin, \& Stout, 2006). Stress buffering is thought to be attributed to a general hardiness and strong character associated with some employees that help them deal and overcome stressful events (Jex \& Beehr, 1991).

Similarly, Aspinwall and Taylor (1997) propose that an individual's proactive tendencies to cope will mitigate the negative responses to potential stressors. Given that the premise of the demands-control model focuses on the autonomy of the work environment allowing employees to work independently to manage the demands that 
Action Orientation 20

occur (Karasek, 1979), it seems logical that an individual's internal proactivity inclinations may shape one's willingness to take such action with or without the situational consent (Parker \& Sprigg, 1999).

In describing elements of proactive employees, Bateman and Crant (1993) outline several attributes theoretically linked to one's ability to deal effectively with the struggles that will occur within the work setting. For instance, the authors specify that proactive individuals can be unconstrained by situational forces and initiate environmental change. Proactive employees will take advantage of opportunities, take action, and persevere through change. Proactive coping is when employees take advanced action to avoid potentially stressful events by helping to prevent or modify the event to ameliorate negative reactions (Aspinwall \& Taylor, 1997). In contrast to those with lower levels of proactive personality that have difficulty identifying and/or monopolizing opportunities for change, highly proactive employees are thought to endure their circumstances (Bateman \& Crant, 1993). In support of this theoretical argument, Parker and Sprigg (1999) found empirical support for a significant negative relationship between proactive personality and occupational strain.

While proactive personality is linked to a number of organizational outcomes (e.g., Bodner et al., 2009; Erdogan \& Bauer, 2005; Parker \& Sprigg, 1999), other variables will likely act as moderators for the expression of an employee's proactive personality (e.g., empowerment) and the success associated with proactive personality (e.g., political skill). In the next chapter, I will show the overwhelming overlap between the concept of proactive personality and empowerment. Further, I will explain how empowerment will likely act as a moderator for proactive personality. 
Action Orientation 21

\section{CHAPTER 3}

\section{LITERATURE REVIEW: EMPOWERMENT}

The dynamic complexity associated with jobs has helped advance the construct of empowerment because of empowerment's emphasis on flexibility (Wilkinson, 1998). Empowerment promoted within an organization is thought to enlarge employees' roles in an effort to tap into employees' natural sense of responsibility. Empowerment ideas and rhetoric largely emerged during the upsurge of employee involvement that dominated the 1980s. The empowerment literature contrasts with the Taylorized and/or bureaucratic workplaces that are thought to alienate workers (Wilkinson, 1998). Empowerment is thought to encourage an employee's participation within the organization, including involvement in decision-making. Undeniably the research dedicated to empowerment programs emerged from organizational programs that promoted participative management and employee involvement (Spreitzer et al., 1997). As proposed by Conger and Kanungo (1988), empowerment is "a process of enhancing feelings of self-efficacy among organizational members through the identification of conditions that foster powerlessness and through their removal of both formal organizational practices and informal techniques of providing efficacy information" (p. 474). Put more simply, empowerment is associated with the redistribution of power in an effort to generate involvement, commitment, and enhanced employee contribution (Wilkinson, 1998).

In general, empowerment has been proposed to facilitate participative behavior in organizations (Conger \& Kanungo, 1988) by encouraging employees to reach their full potential and promoting adaptive employee performance as a result of reduced bureaucratic hurdles that hinder responsiveness (Ahearne, Mathieu, \& Rapp, 2005; 
Action Orientation 22

Spreitzer, 1995b). Academics and practitioners have thought of empowerment as a means for providing decision-making authority to lower levels within the organization while simultaneously enriching employee lives (Liden et al., 2000). An important reason for the inclusion of empowerment within this study is the conceptual and theoretical overlap with proactivity mechanisms. By examining the constructs of empowerment with proactive personality, I will be able to closely examine the interplay of these two constructs on important organizational outcomes.

Structural Versus Psychological Empowerment

When examining proactive personality within an organizational setting, contextual characteristics of the organization become highlighted. Indeed, organizational culture and climate is an obvious consideration when evaluating the moderating influences of proactive personality. Research dedicated to macro organizational culture and climate adds significant depth of exploration (Katz \& Kahn, 1978). Culture and climate is thought to represent how participants experience and make sense of the organization (Schneider, 2000). Culture and climate research focuses on both understanding psychological phenomena in organizations and the shared meaning and shared understanding of the organizational context. Schneider (2000) describes climate as a experientially based description of what people see and report happening to them in an organizational situation.

Psychological empowerment is often studied at the individual level and nonaggregaged. However, empowerment is seen as a cognitive state that is derived from the context and results in increased intrinsic task motivation (Thomas \& Velthouse, 1990). Some researchers have focused on social-structural factors and others have emphasized 
the perceptional or psychological factors (Liden et al., 2000). One camp views empowerment in terms of practices "involving the delegation of responsibility down the hierarchy so as to give employees increased decision-making authority in respect to execution of their primary work tasks" (Leach, Wall, \& Jackson, 2003, p. 28). Others view empowerment as a psychological state based on perceptions of meaningfulness, competence, self-determination, and impact (Conger \& Kanungo, 1988; Spreitzer, 1995b; Thomas \& Velthouse, 1990). In this study, I will investigate both structural and psychological empowerment. Psychological empowerment is an employee interpretation of organizational conditions, such as feelings of self-efficacy, control, and flexibility for action (Arnold et al., 2000). Psychological empowerment has received the most amount of research attention, but because it is being modeled in this study as an individual's perception of their environment it is not considered a direct representation of the context or culture. Structural empowerment focuses on employees' perceptions of the actual work environment conditions, rather than how they interpret this information psychologically (Kanter, 1977).

Although psychological empowerment and structural empowerment appear quite similar, a clear distinction exists. Structural empowerment is the perception of empowering conditions in the workplace, whereas psychological empowerment is an employees' psychological interpretation of work conditions (Laschinger, Finegan, Shamian, \& Wilk, 2004). As demonstrated by Laschinger and colleagues (Laschinger et al., 2004; Laschinger, Finegan, Shamian, \& Wilk, 2001), psychological empowerment represents a reaction of employees to structural empowerment conditions, which represents a true measure of the employee's context. 
Facets of Psychological Empowerment

In order to provide greater detail related to an individual's psychological empowerment, I explicate the four cognitive components that make up empowerment. These dimensions are not viewed as predictors or outcomes, but rather the core of psychological empowerment (Thomas \& Velthouse, 1990). Conceptual work argues that each dimension adds a unique facet to the experience of psychological empowerment (Thomas \& Velthouse, 1990). This "gestalt" view of psychological empowerment is supported in research conducted by Spreitzer (1995a) that shows the dimensions combine to form an overall experience of psychological empowerment in the workplace. Importantly, these four dimensions of psychological empowerment are prescribed to "reflect a proactive, rather than passive, orientation to one's work role" (Spreitzer et al., 1997), which highlights the consistency with views of proactive personality. Together competence, self-determination, meaningfulness, and impact serve to promote employee active engagement in organizational functioning, which is thought to translate into substantial gains for individuals and organizations alike.

Competence. Competence is closely aligned with the concept of self-efficacy that is thought to possess a strong relationship to performance (Locke, 1991). The research literature suggests that self-efficacy, or perceived personal competence, is linked to various indicators of performance effectiveness (Gist \& Mitchell, 1992; Locke, Frederick, Lee, \& Bobko, 1984). Further, self-efficacy is positively related to motivation mechanisms (e.g., initiating behaviors, effort, and persistence), which affect job performance (Bandura, 1977).

Employees will have feelings of inadequacy if they do not have confidence in 
Action Orientation 25

their abilities (Spreitzer et al., 1997). Competence is consistent with self-efficacy (Gist, 1987) and analogous to concepts of social cognitive theory (Bandura, 1977). An employee's belief that they have the skills and abilities necessary to perform is the core idea of competence (Spreitzer et al., 1997). This facet of psychological empowerment has been linked to effectiveness, work satisfaction, and job-related strain (Spreitzer et al., 1997).

Self-determination. The essence of self-determination is an employee's view of whether they are the origin of their actions (Spreitzer et al., 1997). This dimension of psychological empowerment was originally referred to as choice and defined by its involvement with the causal responsibility for a person's actions (Thomas \& Velthouse, 1990). In Spreitzer's (1995b) scale development process, he renamed Thomas and Velthouse's (1990) dimension of choice as self-determination. The concepts of personal control and proactive personality (Bateman \& Crant, 1993) have been linked to selfdetermination (Spreitzer et al., 1997), which highlights again the conceptual overlap between psychological empowerment and proactivity.

Meaningfulness. Meaning is thought to serve as the "engine" of psychological empowerment because of its ability to energize employees (Spreitzer et al., 1997). The fit between an employee's needs and the work role with emphasis on values, beliefs, and behaviors is central to the meaningfulness component of psychological empowerment (Brief \& Nord, 1990). It is related to an employee's perceived value for requisite job tasks. Lower levels of meaning have been linked to apathy at work and lower job satisfaction (Thomas \& Velthouse, 1990).

Impact. Impact reflects and employee's perception that they are influencing work 
Action Orientation 26

processes to make a difference (Thomas \& Velthouse, 1990). While the selfdetermination component of psychological empowerment focuses on an individual's sense of control over work processes, the impact dimension is distinct by emphasizing an employee's sense of control over organizational outcomes (Spreitzer et al., 1997).

\section{Structural Empowerment}

Kanter (1977) introduced the concept of how a situational context can either constrain or encourage behaviors in the workplace. She proposed that "power" can be derived from the job context when an employee has: 1) access to resources, information, and support necessary to carry out tasks, and 2) the ability to get cooperation in doing what is necessary (Kanter, 1979). She delineates the formal and informal organizational features that can either lead to powerlessness or empowerment. Kanter proposes that when an employee is empowered, the system can be productive; whereas when power is removed, the system is bogged down. In support of this notion, structural empowerment has been effective in predicting a number of organizational outcomes including organizational commitment (e.g., Laschinger \& Finegan, 2005; McDermott, Laschinger, \& Shamian, 1996), trust (e.g., Laschinger \& Finegan, 2005), stress (e.g., Laschinger et al., 2001), and job satisfaction (e.g., Laschinger \& Finegan, 2005; Laschinger et al., 2004; Laschinger et al., 2001).

Kanter (1979) illustrates power as an employee's ability to mobilize resources to accomplish tasks. She puts forth that access to lines of information; support, resources, and opportunity to learn and grow are integral sources of structural empowerment. Both formal and informal systems of organizations are thought to provide sources of power for employees. Organizational lines of power are thought to be derived from: 1) lines of 
Action Orientation 27

supply: employees have the capacity to obtain resources (e.g., money, rewards, prestige); 2) lines of information: employees are "in the know" of formal and informal information; and 3) Lines of support: employees have discretion or can exercise judgment (Kanter, 1979).

Both formal and informal powers are thought to support the above-mentioned lines of power (Kanter, 1979). Positive relationships among superiors, peers, and subordinates are thought to result in alliances that lead to informal power (Laschinger et al., 2004). Whereas, an employee's formal power is derived from characteristics of the position. For instance, jobs that have high levels of flexibility, discretion in how work is accomplished, and positions that are highly visible would be considered powerful. Similarly, formal power is provided to positions that are central to the overall purpose of the organization (Laschinger et al., 2004).

\section{Relationship Between Empowerment and Organizational Outcomes}

The premise behind various management tactics, including empowerment and proactivity, is the emphasis of productivity from the workforce, autonomy, and high trust relationships. Both psychological and structural empowerment are linked to a number of meaningful organizational outcomes including work satisfaction (e.g., Laschinger et al., 2004; Liden et al., 2000), performance (e.g., Alge, Ballinger, Tangirala, \& Oakley, 2006; Liden et al., 2000; Spreitzer et al., 1997), supervisor and coworker satisfaction (e.g., Robert, Probst, Martocchio, Drasgow, \& Lawler, 2000), organizational citizenship behaviors (OCBs; e.g., Alge et al., 2006) and strain (e.g., Laschinger et al., 2001; Salancik \& Pfeffer, 1978; Spreitzer et al., 1997).

As part of this research, I examine four important outcome variables that provide 
Action Orientation 28

a diverse examination of important and well-researched organizational concerns: task performance, job satisfaction, occupational stress, and strain, which together represent broad inclusion of variables that have clear connections to overall effectiveness for individuals and organizations.

Task performance. Empowerment research has been proposed to facilitate organizations in dealing with the struggles with the competitive environment that often necessitates downsizing (Thomas \& Velthouse, 1990). It is thought to help motivate workers that are relied upon to complete the work of those that have been laid off (Brockner \& Wiesenfeld, 1993). By reducing dependencies that make work difficult to complete and delegating power and authority, empowerment is proposed to enhance performance (Conger \& Kanungo, 1988; Kanter, 1977). Empowerment is thought to improve overall organizational performance under the assumption that employees closer to the work situation will have greater opportunities to contribute to organizational success by suggesting improvements that are not as readily obvious to management (Wilkinson, 1998). Additionally, the need for control systems are expected to be greatly reduced which is thought to enhance efficiency (Wilkinson). When employees are empowered it is easier for them to accomplish more because they have the tools and they are highly motivated (Kanter, 1979).

Structural empowerment can be thought to motivate employee drive, while simultaneously providing the resources and support necessary to be successful. Theoretically, growth need strength is a mechanism that can explain the relationship between job design and quality work as an outcome (Hackman \& Oldham, 1980). Principles of employee autonomy and skill variety that are central to structural 
empowerment theories are aligned with the job characteristics model (Hackman \& Oldham, 1980).

Empowering workplaces are espoused to be non-bureaucratic and participationoriented; the empowering work context is thought to send a message to employees that they are empowered to deal effectively with clients, obstacles, etc. (Bowen \& Lawler, 2006). Dean and Bowen (1994) point out that non-managerial employees can make important contributions to organizations when they have the power and necessary preparation. It is expected that structural empowerment, like psychological empowerment, will serve to enhance performance outcomes.

Researchers posit that empowerment is successful in enhancing employee involvement, which in turn boosts performance (e.g., Bowen \& Lawler, 2006; Kanter, 1979; Laschinger, Wilk, Cho, \& Greco, 2009; Lawler III, 1986). Indeed, Kanter (1977) conceptualizes structural empowerment as the existence of social structures in the work context that enable employees to accomplish their work in meaningful ways. She argues that employees are empowered to accomplish their work when they have access to necessary information, resources, and support and are provided discretion to complete tasks.

In their seminal work, Conger and Kanungo (1988) delineate the linkage between psychological empowerment and an individual's belief in their own self-efficacy. They specify that personal efficacy stems from one's internal need-states, such as selfdetermination (Deci \& Ryan, 1985), a dimension of psychological empowerment. By encouraging open communication and facilitating goal-setting (Conger \& Kanungo, 1988), empowerment enhances ownership, responsibility, capability, and ultimately 
performance (Hardy \& Leiba-O'Sullivan, 1998).

Action Orientation 30

Spreitzer and colleagues (1997) note that both cognitive and motivational forces can be used to explain the relationship between the self-determination dimension of psychological empowerment and performance effectiveness. Based on the cognitive perspective, employees are thought to be more equipped than supervisors with regard to work knowledge and information and are therefore better positioned to identify and resolve obstacles, as well as plan and schedule work to achieve optimal job performance (Cooke, 1994). Because employees tend to know which behaviors and task strategies are most effective, the autonomy and self-determination elements of empowerment will likely contribute to higher levels of performance and effectiveness.

Spreitzer and colleagues (1997) suggest that the impact dimension of psychological empowerment would be related to performance based on the logic that an employee who believes they have an impact within their workplace will be seen as more effective (Ashforth, 1989). Employees that are continuously solicited for ideas that are later implemented will likely engage in their work and be more effective on the job than those with little to no influence with their workplace (Ashforth, 1990). In support of this, empirical results from Spreitzer et al. (1997) found that impact was related to work effectiveness.

Researchers have associated the competence dimension of psychological empowerment with self-efficacy (Bandura, 1986), which has been proposed to have a strong affect on employee performance (Locke, 1991) and has been shown to be positively related to a variety of work-related performance measures (Gist \& Mitchell, 1992). In short, psychological empowerment is thought to improve self-efficacy 
Action Orientation 31

(Bandura, 1986) and counter feelings of powerlessness (Hardy \& Leiba-O'Sullivan, 1998). In turn, self-efficacy has been linked repeatedly to effective performance (Vroom, 1964). Empirical research conducted by Spreitzer and colleagues (1997) supports an association between the psychological empowerment dimension of competence and work effectiveness.

Although the relationship between self-efficacy and performance has been largely debated (e.g., Bandura \& Locke, 2003; Vancouver, 2000; Vancouver, Thompson, \& Williams, 2001), recent research suggests when looking between individuals rather than within individuals, higher levels of self-efficacy is associated with greater levels of performance (Yeo \& Neal, 2006). Given this evidence, the methodological design used dictates the expected relationship between self-efficacy and performance.

Job satisfaction. Traditionally, disenfranchised groups of employees experience oppression that would encourage them to take action to change their conditions (Hardy \& Leiba-O'Sullivan, 1998). During the quality of work life movement (e.g., Blau \& Alba, 1982), empowerment emerged as a relevant construct as it was thought to enhance employee satisfaction and intrinsic motivation (Spreitzer et al., 1997).

Employees often value many of the principles of structural empowerment including autonomy, variety and challenge, relaxed controls, and opportunities for personal initiative (Hardy \& Leiba-O'Sullivan, 1998; Kanter, 1977). Empowerment, from such acts as participative decision-making, is thought to enhance employee commitment to organizational goals, increase job satisfaction, and reduce turnover (Wilkinson, 1998). Indeed research has linked both psychological and structural empowerment to job satisfaction in longitudinal examinations (e.g., Laschinger et al., 2009). 
Action Orientation 32

In drawing ties between the dimensions of psychological empowerment and job satisfaction, Spreitzer and colleagues (1997) suggest linkages from each of the empowerment dimensions to job satisfaction. With regard to the meaning dimension of psychological empowerment, they outline its relationship to the idea of personal value fulfillment (Locke, 1976) within the job satisfaction literature. Indeed, the value one places to the meaning of their job requirements is a long standing notion within theories dedicated to work satisfaction (Herzberg, 1966). Put simply, it is expected that a sense of meaning will result in increased motivation and satisfaction. Empirical results show support for the linkage between the meaning dimension of empowerment and work satisfaction (e.g., Spreitzer et al., 1997).

Similarly, Spreitzer and colleagues (1997) draw a linkage between the empowerment dimension of impact and job satisfaction given that a lack of opportunity for impact is negatively related to work satisfaction (Ashforth, 1989). Essentially, individuals feel a need to shape their environments, have a sense of control, and ultimately contribute as a valuable member. Therefore, having an impact on one's work seems to be a logical contribution to an employee's sense of satisfaction with work life.

The competence dimension of psychological empowerment is thought to be related to job satisfaction based on its close association with the concept of self-efficacy (Spreitzer et al., 1997). It is believed that employees possessing a sense of work-related competence will likely feel more satisfied. Research supports that feelings of competence are related to intrinsic motivation (e.g., Harackiewicz, Sansone, \& Manderlink, 1985). Gist (1987) proposes that self-efficacy relates to satisfaction from previous successes and feelings of personal causation, which enhances intrinsic motivation. 
Action Orientation 33

In concert with the underlying mechanism of intrinsic motivation, Spreitzer and colleagues (1997) further propose that the self-determination component of psychological empowerment affects satisfaction through its relationship with intrinsic motivation (Deci \& Ryan, 1985). The autonomy elements of the job are thought to lead to perceptions of empowerment and facilitate the reception of intrinsic rewards from work (Thomas \& Velthouse, 1990), which is proposed to fulfill self-determination and result in work satisfaction (e.g., Conger \& Kanungo, 1988; Spreitzer et al., 1997). A number of researchers have empirically supported the link between personal control and work satisfaction (e.g., Liden et al., 2000; Thomas \& Tymon, 1994). Further, Spreitzer et al. (1997) found some support that the self-determination dimension of empowerment is related to work satisfaction.

Occupational stress and strain. The transactional concept (Liedtka, 1999) of occupational stress and strain emphasizes that a transaction occurs between the individual and the environment including the individual's perceptions, expectations, interpretations, and coping responses. Structural empowerment theorists suggest that when power is withheld from employees, they are thought to feel disenfranchised (e.g., Kanter, 1979), which can be distressful. Theoretical linkages between empowerment and occupational stress and strain use the underlying premise of the transactional concept as a theme for explaining mechanisms.

The Job Characteristics Model (Hackman \& Oldham, 1975) emphasizes several components that are reminiscent of psychological empowerment subscales: meaning, self-determination, impact, and competence. The enrichment job characteristic is a core factor in making employees satisfied and able to minimize stress and strain. Each of the 
Action Orientation 34

four subscales of psychological empowerment might be thought to provide greater enrichment to one's job. Task identity is associated with an individual's ability to see work from beginning to end. The opportunity to see a project or task through fruition is thought to provide greater meaning to one's work rather than a piece meal approach to job design, which is clearly consistent with the meaning subscale of psychological empowerment and potentially the impact component. When work is seen as important it is thought that the job shows high levels of task significance, which is directly in line with the concept of meaning within the psychological empowerment literature. Skill variety indicates that the job allows employees to perform different tasks. The opportunity to receive feedback is another work characteristic that is seen to help employees. Finally, the concept of autonomy emphasizes an employee's control and discretion for how to conduct the job, which is a central premise of both psychological and structural empowerment. Similarly, the core tenets of structural empowerment of resources, autonomy, and discretion are in clear concert with the Job Characteristics Model (Dean \& Bowen, 1994).

The Job Demand-Control Model (Karasek, 1979; van der Doef \& Maes, 1999) proposes that stress and strain can result from high levels of responsibility without accompanying authority. The model suggests that active jobs in which demands are balanced by high decision latitude will be least likely associated with stress or strain (Nelson \& Simmons, 2003). The relaxed controls associated with both psychological and structural empowerment are thought to help employees cope with the ambiguity, complexity, and change associated with the dynamic corporate environment (Thomas \& Velthouse, 1990) by offering employees greater personal control over their own work 
Action Orientation 35

(Spreitzer et al., 1997). Meta-analytic research has found overwhelming support for the relationship between perceived control, such as participation and autonomy, and stress (Spector, 1986). Results show that perceived control is associated with decreased physical symptoms and emotional distress. Similarly a number of studies link structural empowerment with reduced occupational stress and strain (Hatcher \& Laschinger, 1996; Laschinger et al., 2001).

Additionally, Spreitzer and colleagues (1997) propose theoretical relationships with dimensions of psychological empowerment (i.e., meaning, competence, selfdetermination, and impact) and occupational stress and strain. They found support for linkages between strain and the dimensions of meaning and competence. Empirical research supports that the dimension of competence (or self-efficacy) is linked to lowered amount of strain on the job. Researchers have found that competence is related to lower levels of strain in managers and self-efficacy is linked to psychological health (e.g., Gecas, 1989; Thomas \& Tymon, 1994). Therefore, employees with higher perceptions of their abilities feel significantly less strain on the job (Spreitzer et al., 1997).

Spreitzer et al. (1997) also postulate that the empowerment dimension of impact is related to occupational stress and strain. In support of this, Thomas and Tymon (1994) found that impact was strongly related to reduced stress. Similarly, research related to universal learned helplessness, which has been seen as synonymous with the psychological empowerment dimension of impact, supports a linkage to occupational stress and strain. Research conducted by Abramson, Seligman, and Teasdale (1978) found that universal learned helplessness can lead to dampened ability to recognize opportunities, reduced motivation, and depressed affect. Similarly, in a review of 
Action Orientation 36

previous research, Martinko and Gardner (1982) report that universal learned helplessness is related to depression, anxiety, frustration, and hostility.

Given that the self-determination dimension of psychological empowerment is linked conceptually to ideas of autonomy and that researchers have found that autonomy reduces strain (Matteson \& Ivancevich, 1987; Sutton \& Kahn, 1987), it suggests that the self-determination dimension of empowerment will contribute to lower levels of occupational stress and strain (Spreitzer et al., 1997). An individual's belief that control can be exercised at any time is important to reduce strain more so than control over the stressors (Parker, 2003).

The Relationship Between Empowerment and Proactive Personality

Although proactive behaviors have been investigated within the literature, there is little agreement on how best to conceptualize or measure them (Crant, 2000).

Researchers have focused on personal traits (e.g., proactive personality, Bateman \& Crant, 1993), while at times employee action is conceptualized to emerge from the context (e.g., empowerment, Conger \& Kanungo, 1988). Now that I have overviewed both concepts of empowerment and proactive personality, it becomes increasingly clear that the two concepts are intertwined both conceptually and theoretically. Figure 2 provides a pictorial overview of the hypothesized relationship between proactive personality and empowerment for the first four hypotheses that are outlined next.

I evaluate whether proactive personality and empowerment will interact in such a way that performance is enhanced when there are high levels of both. Researchers suggest that empowerment works because employees that are prone to go beyond the call of duty will take risks and pursue new opportunities to benefit the organization when they 
are delegated power (e.g., Burke, 1986; Lawler, 1992). Thus, empowerment practices might be implemented with the idea that only subsets of employees will be encouraged to take action. Therefore, those employees that go beyond the call of duty might be necessary for realizing the optimal consequences associated with the empowering organizational context. Empowerment is modeled as a moderator of the proactive personality-performance relationship. Even though I hypothesize that empowerment will act as a moderator of proactive personality, obviously it is also possible to interpret proactive personality as the moderator. In other words, high levels of proactive personality may act as a substitute for lower levels of empowerment in the context.

Hypothesis 1: The positive relationship between proactive personality and task performance will be stronger when empowerment is high than when empowerment is low.

There is reason to believe that the interaction between empowerment and proactive personality will combine in complex ways when hypothesizing about occupational stress, strain, and job satisfaction. Empowerment is thought to be critical and necessary when subordinates feel powerless (Conger \& Kanungo, 1988); however, it may be expected that proactive individuals would be less inclined to possess feelings of helplessness or powerlessness (e.g., Parker \& Sprigg, 1999). This suggests that an interaction will likely exist between proactive personality and empowerment in the prediction of job satisfaction, occupational stress, and strain. Yet, the interplay between empowerment and proactive personality may be more complex. Those employees with high levels of proactive personality may experience high levels of occupational stress and strain and lower levels of job satisfaction when they are working within an organizational context with very low levels of empowerment. On the other hand, those with moderate 
levels of proactivity may not experience so severe a reaction.

The Discrepancy Concept suggests that stress will result when there is an incongruity between an individual's desires and the environment (Edwards, 1992). Therefore, I would expect that an employee possessing a proactive personality would find it stressful and/or unsatisfying to be confined within an environment that discourages an action-orientation. Similarly, the Job Demand-Control Model (Karasek, 1979) suggests that employees lacking in job decision latitude will experience stress and strain.

However, it is realistic to expect that individual personality differences in proactivity will show a stronger reaction to being unempowered. Given the aforementioned theory and rationale, it is expected that empowerment and proactive personality will interact in such a way that high levels of proactivity with lower levels of empowerment will result in the lowest levels of job satisfaction and highest levels of stress and strain.

Hypothesis 2: Proactive personality and empowerment will interact to affect job satisfaction. The relationship between proactive personality and satisfaction will be positive under conditions of high empowerment, but the relationship will be negative under conditions of low empowerment.

Hypothesis 3: Proactive personality and empowerment will interact to affect occupational stress. The relationship between proactive personality and occupational stress will be negative under conditions of high empowerment, but the relationship will be positive under conditions of low empowerment.

Hypothesis 4: Proactive personality and empowerment will interact to affect occupational strain. The relationship between proactive personality and occupational strain will be negative under conditions of high empowerment, but the relationship will 
be positive under conditions of low empowerment.

Now that I have laid out the similarities between proactive personality and empowerment while explaining how we might expect these two constructs to influence organizational outcomes when examined together, it is important to investigate the boundary conditions to action-oriented behaviors emerging from empowerment and proactive personality. Excitement regarding proactive personality and empowerment is largely perceived and promoted as universally beneficial with little speculation as to potentially detrimental consequences that could be present. Therefore, practitioners often hire employees with proactive personality or implement programs meant to enhance empowerment with the expectation of optimal results, while little emphasis is being placed on where problems may occur. In the following chapter I will outline why political skill will be a critical proficiency that employees need to realize the optimal results from proactive behaviors. 


\section{CHAPTER 4}

\section{Literature ReVIEW: Political Skill}

A number of practitioners and academics alike have come to challenge the "gocentric" premise that intelligence is a major (and potentially only) predictor of performance and instead embrace the importance of social influence (Ahearn, Ferris, Hochwarter, Douglas, \& Ammeter, 2004). In line with these thoughts, the importance of persuading, influencing, and controlling others is thought of as important for employees to be effective in navigating the diverse roles confronted in a modern organization (Mintzberg, 1983). People change their conditions and social positioning intentionally in thoughtful ways (Buss, 1987), which includes selection, evocation, and manipulation. Individual differences influence the environments in which employees interact, the responses they elicit from others, and the way they attempt to alter or change others (Caldwell \& Burger, 1997).

Although empowerment and proactivity have been espoused for numerous organizational outcomes (e.g., Bodner et al., 2009; Chen, Kirkman, Kanfer, Allen, \& Rosen, 2007; Parker \& Collins, 2010; Parker, 1998; Seibert et al., 1999; Spreitzer, 1995a; Spreitzer et al., 1997; Thomas \& Tymon, 1994; Thompson, 2005), there remain opportunities to investigate moderating effects of factors including social competence, such as political skill. Actions resulting from empowerment or proactive personality may be met with mixed results in the workplace. Role demands may add complication and difficulty to the job (Campbell, 2000). The problem is no longer whether the organization can find procedures and techniques for motivating individuals to take on a new action-orientation that expands their role, but "whether and under what 
Action Orientation 41 circumstances they are prepared to live with the increased unpredictability if employees do accept them" (Campbell, p. 53).

In discussions related to social influence, constructs have emerged to address the theme of "political arenas" that characterize organizations (Ammeter, Douglas, Gardner, Hochwarter, \& Ferris, 2002; Mintzberg, 1983). Literature examining the nature of politics has had a long history that includes such topics as power (e.g., French \& Raven, 1959), influence tactics (e.g., Yukl \& Falbe, 1990; Yukl \& Tracey, 1992), and political skill (Pfeffer, 1981). Political skill emerged as a meaningful concept that deals with the quality with which one is adept at interpersonal influence and information management (Ferris \& Judge, 1991). Political skill has been defined by a number of scholars (e.g., Ferris, Treadway, et al., 2005; Mintzberg, 1983) as "the ability to effectively understand others at work and to use such knowledge to influence others to act in ways that enhance one's personal and/or organizational objectives" (Ferris, Davidson, \& Perrewe, 2005, p. 127).

Although these skills are not seen as integral to the execution of a job, they are promoted as fundamentally critical to performance and survival in the dynamic and complex organization of today (Harvey \& Novicevic, 2004). As noted in the literature, jobs are unlikely to be able to specify all of the possible work situations an employee may confront; therefore, it is beneficial to have employees that exercise sound judgment when faced with atypical work situations (Campbell, 2000). Employee political skill will enable an employee to anticipate and act in a fashion that would mirror that of their manager's views, which has been proposed by Campbell as an integral component of realizing optimal results. 
Action Orientation 42

Politically skilled individuals are socially astute with the capacity to adjust to changing situational demands effectively (Ferris et al., 2007). They select effective influence strategies and evoke the appropriate behaviors to effectively manipulate and shape their environments. As a result of their ability to read situations and acquire tacit knowledge, politically skilled employees are thought to possess enhanced perceived control in concert with an intuitive savvy and comprehension for the organizational context (Ahearn et al., 2004). They are able to appear sincere, inspire support, exude self-confidence, develop trust, and influence others (Ferris et al., 2007).

Despite the long heritage, only recently has empirical research been dedicated to the examination of political skill. Research suggests that political skill is generally related to workplace interactions (Ferris, Davidson, et al., 2005; Ferris et al., 2000; Ferris, Treadway, et al., 2005). Specifically, it has translated as a meaningful determinant for a number of organizational success indicators, such as performance ratings (e.g., Bing et al., 2009; Ferris, Davidson, et al., 2005; Semadar, Robins, \& Ferris, 2006) and team performance (Ahearn et al., 2004). Additionally, Treadway et al. (2004) have supported a relationship between political skill and trust, job satisfaction, perceived organizational support, and lack of organizational cynicism.

As cited by Ahearn and colleagues (2004), research on the convergent validity reported by Ferris and colleagues (Ferris et al., 1999) shows that political skill has modest association with self-monitoring $(r=.13$ and $\mathrm{r}=.21, p<.01$, in two samples), positive affectivity $(r=.36, p<.001)$, extraversion $(r=.28, p<.01)$, empathy $(r=.28, p<.01)$, understanding events $(r=.30, p<.001)$, conscientiousness $(r=.25, p<.01)$, and delay of gratification $(r=.32, p<.01)$. In comparison to other social effectiveness measures, 
empirical research found that political skill was the most related to managerial performance appraisals (Semadar et al., 2006). Additionally, discriminant validity evidence is shown by Ferris and colleagues (Ferris et al., 1999) in a non-significant correlation between political skill and general intelligence $(r=-.08, n s)$.

Both proactivity and empowerment are thought to act as internal and external motivators to encourage action, stimulate effort, and promote engagement within the organization workforce. Because managers may find employee initiative and judgment to be dysfunctional (Campbell, 2000), political skill is meaningful in evaluating the effectiveness and proper implementation of these behaviors. It has been suggested that promotion of independent action among employees may not always lead to optimal outcomes (Chan, 2006). Organizational scholars recognize that to be successful within an organizational setting, individuals must possess the will as well as political skill (e.g., Mintzberg, 1983; Pfeffer, 1981). In an effort to bridge efforts within the proactivity, empowerment, and political skill theoretical and empirical research, this study seeks to address not only direct effects, but the moderating relationships among these variables, which has been somewhat lacking in empirical investigations.

Both proactivity and empowerment are espoused as optimal elements for promoting engagement in the organization via decision-making, employee participation, and action. Both literatures emphasize that when employees are provided discretion with regard to their work, important decisions can be made at any level of the organization (e.g., Crant, 2000; Parker et al., 1997; Robert et al., 2000). Yet there is little dedicated attention to the necessary condition for empowerment or proactivity to be successful. Some researchers suggest that unintended consequences can emerge from empowerment 
initiatives with employees who do not possess the proper skills or training (e.g., Wilkinson, 1998). In an effort to investigate possible contingent factors, I examine political skill as a potential moderator in determining the relative influence of empowerment and proactive personality.

\section{The Construct of Political Skill}

The political skill construct is postulated to be multidimensional, including the four facets of social astuteness, interpersonal influence, networking ability, and apparent sincerity (Ferris et al., 2007). I will next overview each of these facets.

Social astuteness. The social astuteness dimension of political skill is conceptually overlapping with the idea of being sensitive to others (Pfeffer, 1992). Essentially, those with social astuteness will be able to interpret the behaviors of others, understand social situations, and be seen as ingenious in dealing with others. This facet of political skill will likely be integral to employee proactive endeavors, as it will affect an employee's ability to gauge the best timing and methods for initiating change. Reading coworkers, supervisors, and clients will be a necessary skill to effective implementation of proactive actions because change is a sensitive endeavor that is not likely to be received with open arms by most.

Interpersonal influence. Interpersonal influence is a facet of political skill that involves one's ability to adapt and calibrate themselves to different contexts in order to influence others. Those with interpersonal influence are unassuming and convincing which is conceptually similar to Pfeffer's (1992) term of “flexibility” (Ferris et al., 2007), noted as one's ability to adapt. Since taking action will require buy-in from key players and others within the workplace, the power for influence is a beneficial skill for proactive 
endeavors. This facet will likely improve an employee's ability to gain necessary cooperation and support from organizational stakeholders when taking action within the organization.

Networking ability. Networking ability suggests that politically skilled individuals will be able to develop relationships and contacts that are valuable for obtaining interpersonal and organizational gains (Ferris, Davidson, et al., 2005). Beneficial alliances and coalitions make politically skilled individuals more adept in taking advantage of opportunities (Ferris, Davidson, et al.). Given that change is rarely possible without the support of others, proactivity requires not just a champion for such change, but a support network to garner respect, influence, and legitimization. Therefore, those proactive or empowered employees will be more effective in their advancements to the degree that they are able to network with key organizational players to promote their efforts.

Apparent sincerity. Finally, apparent sincerity is a dimension of political skill that helps in the building of confidence and trust. This facet focuses on the importance of perceived intentions, integrity, sincerity, and authenticity. Those that are politically skilled will likely be able to engage in proactive behaviors in a manner that disguises personal motives so as to be interpreted by others as genuine (Ferris, Davidson, et al., 2005; Ferris, Treadway, et al., 2005). Although this construct may seem negative, it does not suggest that motives are negative. Because suggesting change within the organization has a potential to be evaluated with skepticism, employees initiating action may be seen as self-promoting or disingenuous. In order to garner the required support from others, an employee will need to be effective in portraying the sincerity of their cause. 
Action Orientation 46

Political skill and social effectiveness. Despite the clear association between

political skill and social effectiveness constructs, such as self-monitoring, interpersonal acumen, social skill, functional flexibility and social intelligence, political skill has been shown to be conceptually distinct based on its dedication to the interactions at work and one's ability to use his or her knowledge of others to attain their objectives (e.g., Ferris, Perrewé, \& Douglas, 2002; Ferris et al., 2007; Harris, Kacmar, Zivnuska, \& Shaw, 2007). Researchers speculate that the overlap would not be expected to be greater than modestsized relationships (Ferris et al., 2002). Further, some empirical support suggests there is a differentiation between self-monitoring from political skill (Ferris, Treadway, et al., 2005). Therefore, I would expect that political skill is related, but not redundant with social effectiveness constructs.

Political Skill as a Moderator of Action-Orientation

The vast majority of theoretical discussion and empirical investigation associated with political skill has been dedicated to the main effects, despite its likely moderating role on proactive personality and empowerment. Given that an assessment of anticipated consequences is at the crux of effective proactive behavior implementation (e.g., issue selling, voice), I test political skill as an essential component to realizing the positive outcomes of proactivity. Both social influence theory (Levy, Collins, \& Nail, 1998) and social information theory (Salancik \& Pfeffer, 1978) can be used to explain why political skill will moderate the proactive personality-outcome relationships and organizational empowerment-outcome relationships.

Social influence theory (Levy et al., 1998) has been used to explain the positive factors of political skill (Harris et al., 2007) and helps to explain the moderating 
Action Orientation 47

mechanism of political skill in either attenuating or enhancing potential organizational outcome relationships resulting from political skill or empowerment. Social influence has been defined by Levy, Collins, and Nail (1998) as “any situation in which an influencee's thoughts, feelings, or behaviors are affected by the actual, implied, or imagined presence or actions of one or more influences" (p. 733). Social influence theory (Levy et al., 1998) helps explain how individuals can be persuaded to change their views and decisions. Further, it postulates that characteristics of an individual are important for explaining one's effectiveness to influence others and therefore provides a theoretical explanation for understanding the moderating mechanism of political skill with proactive personality.

Political skill is linked to an employee's capacity to change situations (Ferris, Treadway, et al., 2005). Because political skill encompasses one's ability to "combine social astuteness with the capacity to adjust their behavior to different and changing situational demands in a manner that appears to be sincere, inspires support and trust, and effectively influences and controls the responses of others" (Ferris et al., 2007, p. 291), it stands to reason that engaging in proactive behaviors with little to no political skill may result in negative consequences.

Similarly, social information theory (Salancik \& Pfeffer, 1978) provides a theoretical background for explaining why political skill is an important element for promoting the effective implementation of proactive tendencies in a delicate organizational social environment. Identifying key processes that contribute to an employee's success in influencing others during such times of high competition for scarce organizational resources is crucial (Harris et al., 2007). Employees may have opportunities to scan, survey, analyze and shape their work environments with the 
Action Orientation 48

potential to improve the current state of affairs. Individual dispositions, such as proactive personality, or contextual forces, such as psychological empowerment, may encourage action or inaction. Organizations could look to promote these actions by selecting proactive employees and/or promoting empowerment within the workplace, but considering the importance of social information processing, it may behoove organizations to consider an employee's political skill to implement changes in the most functional and effective manner.

A model of social information processing includes three general activities of reading, generating, and applying (Topping, Bremner, \& Holmes, 2000). Employees must interpret social cues, determine a suitable response, and effectively execute selected behaviors in order to achieve positive outcomes within social situations. Political skill is postulated to be a crucial component to ensuring that behaviors resulting from either proactive behavior or empowerment are appropriately selected to match the context and implemented successfully. Support for the sensitive nature of proactive personality within the workplace is shown within the research conducted by Chan (2006). He found that situational judgment proficiency moderates the relationship between proactive personality and important organizational outcomes. Chan (2006) argues that proactive employees who are ineffective in their ability to judge or respond to the demands of the situation will potentially act in a counterproductive fashion. He suggests that when challenging the status quo an individual must be able to "accurately identify, understand, and effectively respond to the practical demands and constraints of the situation" (p. 476).

As evidence for the calculations that are likely to occur naturally when deciding 
Action Orientation 49

to take initiative, Ashford et al. (1998) argue that employees will be less likely to engage in proactive issue selling if they fear that doing so will harm their image. Proactive attempts may be seen as "rocking the boat". Thus, individuals should strategize implementation tactics and contingency plans prior to engaging in proactive behaviors. Consequently, one's ability to effectively diagnose the situation and respond in a savvy manner will determine whether these proactive behaviors are met with opposition or support. For instance, Harris and colleagues (Harris et al., 2007) found that politically skilled employees who engage in higher levels of impression management were seen as better performers, whereas those with low levels of political skill were seen less positively. Most likely, politically skilled employees are more capable in diagnosing the situation and selecting an influence tactic that will be most effective, as expected by social influence theory (Levy et al., 1998).

Political Skill and Proactivity

Despite the potential delicacy regarding the implementation of proactivity within the workplace, a dearth of research is dedicated to identifying the boundary conditions to positive outcomes. Research has not yet fully examined the potential negative consequences of poorly implemented proactivity within the workplace. Noteworthy exceptions include work conducted by Erdogan and Bauer (2005) and Chan (2006). Erdogan and Bauer (2005) examined person-organization fit ( $\mathrm{P}-\mathrm{O}$ fit) and person-job fit ( $\mathrm{P}-\mathrm{J}$ fit) as moderators of the relationship between proactive personality and intrinsic career success (job and career satisfaction). They found that proactive personality was positively related to job satisfaction only for individuals with high $\mathrm{P}-\mathrm{O}$ fit in one sample. Also, proactive personality was positively related to career satisfaction only for 
Action Orientation 50

individuals with high $\mathrm{P}-\mathrm{O}$ fit and for individuals with high $\mathrm{P}-\mathrm{J}$ fit.

Chan (2006) found situational judgment proficiency as an integral component to understanding the relationship between proactivity and important organizational outcomes. He hypothesized that highly proactive individuals who are not effective in judging or responding to situational demands would develop unrealistic expectations for their supervisors and work situation. Using an applied sample of rehabilitation employees, he found that poor situational judgment proficiency resulted in a negative relationship between proactive personality and important work perceptions (procedural justice, perceived supervisor support, and social integration) and outcomes (job satisfaction, affective organizational commitment, and job performance).

The limited dedication to understanding the potential moderators between proactivity behaviors and important organizational outcomes signifies a substantial gap that this study addresses. As seen in the feedback seeking literature, there may be potential costs based on proactivity to an employee's image (Ashford, Blatt, \& VandeWalle, 2003). Research suggests that frequent interest in positive feedback can hurt perceptions of employee effectiveness (e.g., Ashford \& Tsui, 1991).

Although performance is in part determined by intelligence, hard work, and proactivity, factors of social astuteness, positioning and savvy play an important role (Kolodinsky, Hochwarter, \& Ferris, 2004) in determining an employee's effectiveness in the "political arenas" of organizations (e.g., Mintzberg, 1983; Pfeffer, 1981). Attentiveness to social cues, as characterized by political skill, will enhance the optimal effects promoted by proactive personality.

By definition, proactive employees are inclined to engage and change their work 
Action Orientation 51

context; but, organizational research shows that people tend to dislike changes, and they usually greet changes with skepticism (Begley, 1998). Batemen and Crant (1993) note that not all proactive behaviors are favorable and desirable and that misguided attempts at proactivity can have detrimental consequences. Grant and Ashford (2008) emphasize that proactivity involves expending additional effort, challenging the status quo, and deviating from assigned tasks, reified norms, accepted practices, and existing routines, which suggests that mixed effects and unintended consequences are likely to occur for employees, teams, and organizations. Employees may look to shape their social environment in a way that is conducive to their own success on the job and network building, a key to political skill (Ferris, Davidson, et al., 2005). This is one way to facilitate the effective implementation of proactivity within the workforce. Toward their goals, employees possessing both political skill and proactive personality may create allies to support personal initiatives to promote their agenda. They associate with those of position and power to better serve their goals. Together political skill and proactive personality may be a special combination of initiative, know-how, and social prowess to enhance the success of organizational change that requires a certain amount of delicacy. Indeed, political skill may be the very difference between a dysfunctional implementation of proactivity within the workplace and a well-orchestrated change endeavor.

As evidence for the need for delicacy, Chan (2006) found that proactive personality is positively associated with work-relevant criteria when situational judgment proficiency is high, but is negatively associated with the criterion when situational judgment proficiency is low. Similar to the finding that agreeableness is a necessary component to realizing the positive benefits of conscientiousness to work outcomes 
Action Orientation 52

(Witt, Burke, Barrick, \& Mount, 2002), I investigate whether political skill is a necessary factor in realizing the optimal work outcomes associated with proactive personality. Figure 3 provides a pictorial overview of the expected relationship between proactive personality and political skill in the prediction of task performance, job satisfaction, and occupational stress and strain. This figure covers Hypotheses 5 though 8, which are presented next.

\section{Political skill as moderator of proactive personality-task performance}

relationship. The application of an action-orientation within an organization may require a vast amount of delicacy then what is alluded to in the literature. For instance Frese and Fray (2001) suggest that personal effort, one type of proactive behavior, may be perceived as being tiring and strenuous. Supervisors of high-personal initiative individuals may think of these employees as rebellious because they do not necessarily accept suggestions or orders without requesting a rationale. Proactive individuals may be less likely to do things just because it is the way they have always been done. As noted by Frese and Fray, every proactive act makes changes, which can cause unease in others and be uncomfortable for organizational members. Moreover, I have already highlighted that these behaviors emerge in anticipation of unforeseen problems; thus, the perceived call to action by others in the organization will be less clear than if the action were reactive to an existing dilemma.

Favorable impressions of employees will likely result when they are sensitive to contextual cues when engaging in proactive behavior (Detert \& Burris, 2007). Therefore, subjective evaluations of an individual's overall performance will likely incorporate a rater's evaluation of an employee's sensitivity to contextual cues (Wayne, 1995). Indeed, 
Action Orientation 53

scholars propose that top performers are skilled at monitoring their environment and adapting their behaviors using self-presentation tactics (Snyder \& Copeland, 1989). Therefore, an individual's degree of proactivity will be enhanced when they also possess the political skills to be influential in creating effective organization change that is well perceived.

Anecdotal accounts suggest that misguided behaviors can result from proactivity within the workplace which costs the organization time and money (Campbell, 2000). There may be a tendency for organizations to promote initiative within the workplace and yet punish such actions later because they are not acceptable, this has been termed an "initiative paradox" (Campbell, 2000). It is expected that those who act in ways that are not aligned with the organizational goals will receive little reward from their engagement in initiatives (Erdogan \& Bauer, 2005). Erdogan and Bauer found empirical results that suggest that those who have "congruence with organizational values may engage in proactive efforts that are more consistent with organizational values. Leading to greater success in furthering their job and career objectives" (p. 882). Based on the arguments presented above, the following hypothesis is proposed.

Hypothesis 5: Proactive personality and political skill will interact to affect task performance. The relationship between proactive personality and task performance will be positive when an employee has high levels of political skill, but the relationship will be negative when the employee has low levels of political skill.

Political skill as moderator of proactivity-job satisfaction relationship. Proactive individuals tend to demonstrate a number of behaviors that may be deemed favorable by managers. For instance, they are more likely to engage in information and feedback 
seeking (Ashford \& Tsui, 1991) and they excel at identifying opportunities for change and growth. Similarly, politically skilled individuals are thought to exemplify a number of behaviors that allow them to be received warmly by others, including managers. Politically skilled individuals are thought to be intuitively savvy with regard to selecting behaviors that fit the context (Ferris et al., 2000), they are seen as being great compromisers that develop and use social networks (Blass \& Ferris, 2007), and they demonstrate higher levels of social capability (Bing et al., 2009).

It is possible that leader-member exchange (Liden \& Graen, 1980) may serve to explain the mechanism for why proactive personality and political skill will interact in the prediction of job satisfaction relationship. Proactive individuals that show political skill in their efforts may be provided greater levels of delegation by their supervisors and experience more positive leader-member exchanges, which may in turn lead to higher levels of job satisfaction (e.g., Gerstner \& Day, 1997; Graen \& Uhl-Gien, 1995; Liden \& Graen, 1980). Given this rationale, the following hypothesis describes the relationship between proactive personality and political skill in the prediction of job satisfaction.

Hypothesis 6: Proactive personality and political skill will interact to affect job satisfaction. The relationship between proactive personality and job satisfaction will be positive when an employee has high levels of political skill, but the relationship will be negative when the employee has low levels of political skill.

\section{Political skill as moderator of proactivity-occupational stress and strain} relationship. Although proactive personality has been touted and supported as a buffer for dealing with occupational stress and strain (e.g., Harvey et al., 2006; Parker \& Sprigg, 1999), it has also been found to accentuate stress at times (Harvey et al., 2006). Affective 
Action Orientation 55

types of conflict and stress are thought to be potentially more damaging than task or cognitive sources of conflict and has been linked to deteriorating performance and satisfaction (De Dreu \& Weingart, 2003). Harvey et al. (2006) suggest that the goaldirected and steadfast attempts by those high on proactive personality to resolve issues in their environment will lead to stress and frustration when they encounter interpersonal conflict. It is believed that proactive employees will perceive conflict as an obstacle to the achievement of goals, which will result in cynicism, avoidance, or counter-effort (Amason, 1996). Harvey and colleagues (2006) have found some support for this notion in young workers.

Given that politically skilled individuals are socially astute and have the capacity to adjust to changing situational demands (Ferris et al., 2007), appear sincere, inspire support, exude self-confidence, develop trust, and influence others (Ferris et al., 2007), they are better able to avoid interpersonal conflicts that might occur with others when acting proactively. These individuals garner useful resources or connections, develop and use social networks, and are seen as "adroit negotiators and as the brokers of compromise" (Blass \& Ferris, 2007, p. 10). This political skill trait will be particularly essential given that other employees may think of proactive acts as unnecessary.

In a meta-analysis conducted by Bing et al. (2009) political skill was shown to be of greater importance to accomplishing one's tasks at work in socially laden settings (e.g., working closely within teams to accomplish one's work). Politically skilled individuals were shown to be better able to perform successfully and it is suggested that these positive accomplishments lead to reducing stress levels. Politically skilled individuals are able to read situations, acquire tacit knowledge, and exhibit enhanced 
Action Orientation 56

perceived control in concert with an intuitive savvy and comprehension for the organizational context (Ahearn et al., 2004). This skill will help alleviate potential stressors associated with improperly implemented proactive behaviors and mitigate possible interpersonal conflicts that can arise. As such, the following hypotheses are presented.

Hypothesis 7: Proactive personality and political skill will interact to affect occupational stress. The relationship between proactive personality and occupational stress will be negative when an employee has high levels of political skill, but the relationship will be positive when the employee has low levels of political skill.

Hypothesis 8: Proactive personality and political skill will interact to affect occupational strain. The relationship between proactive personality and occupational strain will be negative when an employee has high levels of political skill, but the relationship will be positive when the employee has low levels of political skill. Political Skill and Empowerment

Researchers have come to recognize the political dynamics inherent within management empowerment interventions (Hardy \& Leiba-O'Sullivan, 1998). Empowerment has been thought of as "a spectrum of political activity" (Bookman \& Morgan, 1988, p. 4). The interplay between political skill and empowerment has been suggested in the literature for some time, but little dedicated discussion or empirical examination has been conducted. Figure 4 provides a pictorial overview of the expected relationship between empowerment and political skill in the prediction of task performance, job satisfaction, and occupational stress and strain. This figure covers Hypotheses 9 though 12 . 
Action Orientation 57

At one time literature took the universalistic approach in regarding empowerment as optimal in all circumstances and organizational contexts (Wilkinson, 1998). However, recent research suggests that not all employees will flourish within an empowering context. Hardy and Leiba-O’Sullivan (1998) emphasize that when managers provide employees with greater access to resources, they may need greater cultural norms to reduce the likelihood that employees will use their newly acquired power in an adversarial way. Undeniably growing evidence shows that empowerment programs at times fail to meet employee and manager expectations (e.g., Barker, 1993; Brown, 1992; Eccles, 1993). For instance, salespersons with lower self-efficacy and experience (i.e., technologic expertise) were shown to benefit from less empowering leaders (Mathieu, Ahearne, \& Taylor, 2007). Similarly, Ahearn and colleagues (Ahearne et al., 2005) found that employee readiness (i.e., knowledge and experience) was important for realizing the beneficial impact of empowerment on employee self-efficacy and adaptability. These results suggest that the role of empowerment does not act uniformly across employees. Thus, the investigation of theoretically informed moderating variables to explain variance can provide meaningful information for selection and organizational development efforts.

The potential role of political skill in the success of organizational empowerment is evident. For instance, Hardy and Leiba-O'Sullivan (1998) call attention to a critical assumption of empowerment programs that all employees will be aware of their grievances and act upon them by participating in decision-making. They emphasize that employees must have the prowess to be cognizant of the contextual pertinence of resources they possess and deploy them appropriately and point out that the term "politics" has been used to describe power mobilization (e.g., Pettigrew, 1973). 
Action Orientation 58

Business empowerment practices has emphasized both the economic and political resources necessary to impact outcomes (Hardy \& Leiba-O'Sullivan, 1998). Given that empowerment is thought to unleash employees' potential by allowing them to act adaptively to situations, there is potential that ill-equipped employees will not realize the benefits of empowerment. Kizilos (1990) suggests that organizations dream of energetic and dedicated workers who undertake action, but only when "appropriate;" take risks, but are not reckless; volunteer ideas, but only brilliant ones; engage in problem solving, but never make mistakes; and exercise their voice, but do not ruffle any feathers. Although not likely to avoid all unforeseen risks associated with empowerment action behaviors, political skill offers greater assurance that empowerment will result in greater success.

Social information processing theory (Salancik \& Pfeffer, 1978) supports the premise that political skill is a necessary condition for ensuring that empowered employees are able to take initiative with organizational decision-making in an effective manner. Employee political skill will be integral to ensuring that employees are able to navigate the organizational environment well. Employees exist in a power context (e.g., Knights, 1992), such that they will need to discern opportunities for role-expansion and recognition, but also be astute to understanding when and how to engage the appropriate players. Actually, in addition to greater sense of pride and self-efficacy, empowerment will also offer greater levels of economic and political influence (Hardy \& LeibaO'Sullivan, 1998). Empowerment within the workplace will provide employees power and access to resources within the political system, which allows employees the opportunity to change the status quo (e.g., Kizilos, 1990). Therefore, an employee's political skill will be integral to their likelihood of effectively utilizing said power and 
appropriately navigating the political landscape. In the delicate social context of organizational decision-making, there are opportunities for employees to inadvertently step on the toes of coworkers and supervisors. So, it will be important for employees to exercise control with delicacy. As such, political skill is hypothesized as an important moderator.

Hypothesis 9: Empowerment and political skill will interact to affect task performance. The relationship between empowerment and task performance will be positive when an employee has high levels of political skill, but the relationship will be negative when the employee has low levels of political skill.

Similarly, political skill and empowerment will interact in the prediction of job satisfaction, occupational stress, and strain. Because an individual's identity is largely determined and/or influenced by one’s job (Hulin, 2002; Judge \& Hulin, 1993). Work can provide substantial meaning including sources for relationships outside the family, obligatory activity, autonomy, opportunities to develop skills and creativity, purpose in life, feelings of self-worth and self esteem, as well as income and security (Hulin, 2002). When one occupies a job for which they feel that they are constrained (i.e., lack of empowerment) and/or performing inadequately (i.e., lack of political skill when taking initiative), it is easy to imagine that many of these meaningful sources of identity could be threatened.

Undeniably employees can develop a sense of helplessness if they feel that they possess a need to act politically without any opportunities (i.e., high political skill with low levels of empowerment). Additionally, I can see employees struggling with the challenges presented to them by an organization when they possess little social prowess 
Action Orientation 60 to implement change with great success, which is expected of them (i.e., high levels of empowerment with low levels of political skill). Therefore, I expect that at the very least a moderate amount of dissatisfaction would emerge from these situations.

Additionally, employee occupational stress and strain would likely emerge under routine failures. Although empowerment can be linked to greater control and less stress and strain, it is true that with greater responsibility, forms of stress and strain can result. Empowerment researchers advocate activities such as setting attainable goals, offering forms of mentorship for vicarious learning, providing encouragement and feedback, and providing emotional support to offset stress and anxiety and enhance positive forms of emotional arousal (Thomas \& Velthouse, 1990). Although empowerment is thought to help employees cope with adversity (Conger \& Kanungo, 1988), Hardy and LeibaO’Sullivan (1998) emphasize the power play and political dynamics that underlies business empowerment practices that are necessary considerations for proper implementation.

All in all, these three outcomes (i.e., job satisfaction, stress and strain) are important because I feel that the mismatch between organizational empowerment and employee political skill could lead to detrimental effects for the employee and the organization over time. Therefore, the following three hypotheses are presented to review the potential negative consequences that are likely to emerge when either an employee is asked to act when they do not possess the skill necessary for proper implementation or when an employee has the desire to change their context without any discretion to do so.

Hypothesis 10: Political skill will moderate the relationship between empowerment and job satisfaction. The relationship between empowerment and job 
Action Orientation 61

satisfaction will be positive when an employee has high levels of political skill, but the relationship will be negative when an employee has low levels of political skill.

Hypothesis 11: Political skill will moderate the relationship between empowerment and occupational stress. The relationship between empowerment and occupational stress will be negative when an employee has high levels of political skill, but the relationship will be positive when an employee has low levels of political skill.

Hypothesis 12: Political skill will moderate the relationship between empowerment and occupational strain. The relationship between empowerment and occupational strain will be negative when an employee has high levels of political skill, but the relationship will be positive when an employee has low levels of political skill. 
CHAPTER 5

METHOD

Occupation Sample

Because behavioral expression of the constructs within this study is essential, I targeted an occupation that is socially laden, requires social influence and networking tactics, and often allows for autonomous working conditions. Additionally, I sought out an occupation that would likely encourage engagement by occupants to solve problems, offer suggestions for enhancing work processes, and in general lend itself to critical thinking. I used O*NET ratings to gather systematic evaluations for linkages to the constructs of interest. O*NET is a US Federal government database that provides professionally gathered ratings for occupations across a variety of categories and dimensions. Included in this database are a number of job analysis ratings related to social skills, including coordination, instructing, negotiation, persuasion, service orientation, and social perceptiveness.

The registered nursing occupation is linked to a social interest dimensions that suggests proactivity, empowerment, and political skills are necessary (O*NET, 2008b). The social interest link suggests the nursing profession involves working with, communicating with, and teaching people. A socially laden occupation requires social influence tactics and networking abilities, which is prevalent in the tasks associated with nurses (e.g., coordinate with health care team members to assess, plan, implement, and evaluate patient care plans). Research indicates that political skill is maximally effective within socially laden settings (e.g., Bing et al., 2009; Perrewé, Ferris, Frink, \& Anthony, 2000). Considering that proactivity is most effective in a position that offers high levels 
Action Orientation 63

of autonomy and that political skill is most influential in positions that are socially laden (Bing et al., 2009), the nursing occupation is well-suited for examining the constructs of interest.

Additionally, the more discretion individuals have to act independently and make decisions on their own will affect the degree to which I would expect political skill to moderate both proactive personality and empowerment. Employees provided a greater degree of latitude in carrying out the tasks on their job would likely benefit from greater levels of political skill. A job that requires employees to think critically, problem-solve, and use reasoning to perform effectively will likely be optimal for observing participants acting proactively or organizations encouraging empowerment.

The $\mathrm{O}^{*} \mathrm{NET}(2008 \mathrm{~b})$ ratings suggest that the registered nursing occupation includes inductive reasoning, problem sensitivity, deductive reasoning, and information ordering. The occupation is linked to investigative interest dimensions, which suggest that nurses are frequently involved with ideas and extensive amounts of thinking (O*NET, 2008a). Nurses are often searching for facts and figuring out problems mentally. Work activities include gathering information from relevant sources to determine appropriate courses of action (O*NET, 2008a). Additionally, the occupation is described as requiring a willingness to take on responsibilities and challenges $\left(O^{*} N E T\right.$, 2008b). This type of engagement will likely promote a certain degree of individual processing to evaluate the context and appropriate course of action.

In addition a nursing sample has several unique characteristics that are important to note. According to a report by Lacey and Wright (2009) in the Monthly Labor Review publication put out by the U.S. Bureau of Labor Statistics, more than 581,500 new 
Action Orientation 64

nursing positions will be created through 2018 (a 22.2\% increase). Expectations at this magnitude make nursing the top profession in terms of projected job growth in the U.S. Further, Buerhaus and coauthors (Buerhaus, Auerbach, \& Staiger, 2009) site that despite the easing of the nursing shortage due to the recession, the U.S. nursing shortage is projected to reach 260,000 registered nurses by 2025 . This shortage projection is twice as large as any nursing shortage experienced in the U.S. since the mid-1960s. The researchers point to a rapidly aging workforce as a primary contributor to the projected shortage. The expected downfall of available nurses is partly due to the projected retirement of registered nurses over age 50, which will soon be the largest age group in the nursing workforce (Orlovsky, 2006).

The increasing consumption of health care goods and services indicates the need for continued attention in identifying ways to maximize employee retention and productivity (e.g., job satisfaction and job performance) and minimizing problematic areas for nurses (e.g., work stress, strain, and turnover). Turnover affects staff retention including quality of care, adequacy of staffing, job satisfaction, group cohesion, and job stress (Wells, Roberts, \& Medlin, 2002). Role stress for nurses continues to be an area of great interest to the profession, particularly as stress affects the mental and physical health of nurses, as well as having an economic cost to the community (Cooper, 1998). The information obtained from this research study can be used to support nurses in their roles. Empowerment has been shown to be related to a number of relevant organizational constructs including interactional justice, respect, and organizational trust (Laschinger \& Finegan, 2005). In this study, empowerment is hypothesized to bolster the influences of proactive personality on organizational outcomes. Additionally, a proactive role is 
Action Orientation 65

thought to be necessary for nurses in their decision-making (Hunter, Brace, \& Buckley, 1993; Nolan et al., 1996)

Study History and Modifications.

Recruitment began in August of 2009 with Oregon Nurses Association (ONA), which is the union organization in Oregon. Due to some unexpected complications with the $\mathrm{H} 1 \mathrm{~N} 1$ crisis and a reorganization, the recruitment of ONA was difficult during this time period. In mid-November, I started searching for opportunities with professional nursing union associations in states other than Oregon. However, there little responsiveness from organizations during the holiday season.

After the holidays, I met with ONA on Feb. $19^{\text {th }}, 2010$ and established intent to attend focus group meetings in Bend and Eugene. Unfortunately, these meetings were unable to be scheduled. I met with the nurse executive at OHSU, Jennifer Jacoby, on June $28^{\text {th }}$. She put me in contact with Deborah Elderidge, Director of Quality, Research \& Magnet Program at OHSU, and Barbara Bonnice, their Director of Professional Practice. I met with these two representatives on July $7^{\text {th }}$. During that meeting, the participation of OHSU in the study was potentially questionable. There were several concerns. First, OHSU would not be able send out questionnaires until January or February of 2011. Second, they required that I drop any items that used passive voice. In general, they requested that any items suggesting that the context is responsible for one's behavior to be removed because it is not consistent with their organizational philosophy.

Because the total speed of recruitment for ONA was concerning, I continued recruiting in additional states. This recruitment was conducted for a number of reasons including: 
Action Orientation 66

a) ONA's interest in being involved with other states,

b) the possibility of sampling minorities,

c) providing additional back-up data in the event of lower response rates in any one state.

In my initial recruitment efforts, I targeted union organizations. I requested that union organizations email their members and allow us to attend conferences when they were available. As part of this request, I asked union organizations to send an individualized email outside of their normal e-newsletter. This email included their endorsement and a link to a website where interested participants could answer a few demographic questions and register for potential inclusion into the study. Both the Florida Nurses Association and the Missouri Nurses Association provided this assistance. In addition, the Florida Nurses Association and Oregon Nurses Association invited me to attend conferences to solicit participants.

In general, nested multi-level data with responses from supervisors and employees was difficult to collect for two main reasons. First, in the absence of hospital support, the nurses and supervisors were leery of submitting the names and email addresses for coworkers. Second, when participants were willing to provide the name and email address for their coworkers, I experienced technical difficulties. Some hospitals do not have email addresses for employees. Other hospitals have blocks that will not allow nurses to receive email from outside of the hospital. Based on these obstacles, I concluded that the recruitment strategy was inappropriate. In retrospect, I now believe that targeting large hospitals would have been a better strategy. Matching could have happened seamlessly, and if they had had organizational support, supervisors 
would have felt less fear about rating employees.

I proposed to the committee several modifications occur to the dissertation based on these challenges. The revisions dropped the multi-level design to be replaced with a single-source design with two data collection administrations. In general the hypotheses remained unchanged, except they would be self-report rather than multi-source.

Often alternative measures of variables were collected at Time 1 then Time 2. Psychological empowerment (Spreitzer, 1995) is collected at Time 1, but structural empowerment is measured at Time 2 (Laschinger, 2000). Job satisfaction is measured using a general scale at Time 1 (Judge et al., 1998), but satisfaction with quality of care is collected at Time 2 (Hinshaw, \& Atwood, 1983). Similarly, a general measure of task performance (Williams \& Anderson, 2001) is collected at Time 1, but perceived effectiveness (Shortell et al, 1991) is measured at Time 2. Although not every measure was included in the formal dissertation proposal, I included them in the defense to provide for a more comprehensive and sound research design. All committee members approved these modifications for the final defense.

\section{Recruitment}

A registration website was created for this study. Interested individuals were directed to the study registration website that asked various demographic questions (i.e., age, education, experience, nursing specialty, and position) and allowed individuals an opportunity to specify the email address they prefer to use and a login password. The demographic information collected in the registration allows for comparisons between those that complete the surveys and those that do not. The usernames and passwords 1) allowed participants to save their survey and complete it in different settings (e.g., at work 
Action Orientation 68

or at home), 2) provided security so that multiple users on the same computer are not redirected to another participant's survey, and 3) provided an opportunity for me to review positions and assignments to screen out participants that were not a target in this study (e.g., nurses in a teaching university or nurse executives).

I recruited study participants from nurse unions within Florida, Missouri, and Oregon. As part of this effort, I attended nursing conferences in both Oregon and Florida. Additionally, Missouri Nursing Association and Florida Nursing association sent emails to their union members endorsing the research effort and providing a link to the study registration.

Various incentives were provided to organizations and individual employees to promote completion of the entire research study. The rewards for participants were provided using a lottery process to allow for greater participant counts. Employees were entered into a raffle for completing the surveys. The raffles included 50 visa gift cards worth $\$ 50$ and two worth $\$ 500$. Organizations and participants will be offered study results upon request. Respondent Characteristics

A total of 743 participants registered for inclusion in the study over a six-month period. During screening of registrants, 264 registrants were not qualified for inclusion in this analysis because of their position (academic, nurse executive) or lack of employment. After completing the screening process, 479 registrants were invited to participate in the study. Two hundred and forty-six were from Florida, 123 were from Missouri, and 110 were from Oregon. Of those that were invited, $252(52.61 \%)$ chose to participate. One hundred seventy six completed both time 1 and time 2 surveys (36.74\%), 76 individuals 
Action Orientation 69

completed only the time 1 survey $(15.87 \%)$. For those analyses that included variables collected only at time 1 , the statistical power is calculated at 1.0 when estimating an $\mathrm{R}^{2}$ of .20 , an alpha of .05 , and two predictors. For those analyses that included variables collected at time 1 and time 2 , the statistical power is calculated at .99 when estimating an $\mathrm{R}^{2}$ of .20 , an alpha of .05 , and two predictors.

There was an average of 13.27 years of experience $(\mathrm{SD}=11.93)$ for those that elected to participate in this study. The average age was 42.26 years old $(\mathrm{SD}=11.46)$. The majority of the respondents were Caucasian (88.6\%) females $(87.8 \%)$ with a Bachelor's Degree in nursing (34.3\%). A large proportion of the respondents also had an Associate's Degree in nursing (28.7\%) or a Master's Degree in nursing (14.2\%). The majority of respondents were married $(60.2 \%)$ or divorced $(17.3 \%)$, but $12.6 \%$ claimed that they were single and never married. Most respondents indicated that they work 12hour shifts $(66.5 \%)$ or 8 -hour shifts $(31.5 \%)$, rather than 10-hour shifts $(12.2 \%)$. Further, most respondents worked in a hospital setting (76.4\%), with a small number saying they work in an ambulatory/outpatient clinic/ or medical office $(8.7 \%)$.

In general, the participants in this study are fairly representative of nurses in their states and the US overall. In the US, males made up $6.2 \%$ of the registered nurses (RNs) who were licensed before 2000 and $9.6 \%$ percent of those licensed in 2000 or later (US Department of Health and Human Services, 2010). Nurses from minority racial and ethnic groups represented only $16.8 \%$ of all US nurses in the survey conducted by the US Department of Health and Human Services (2010). Approximately 83\% of RNs were White, non-Hispanic in 2008. Approximately 5\% of RNs reported a racial background of Asian, Native Hawaiian, or Pacific Islander. 
Action Orientation 70

According to the Oregon Health and Science University (2010), men make up approximately $11 \%$ of the nurses. While the Oregon Center for Nursing and the Oregon Healthcare Workforce Institute (2010), 10\% of Oregon nurses are male. Caucasians make up $90 \%$ of the nursing, while $3 \%$ are Asian, $2 \%$ are Hispanic/Latino, $1 \%$ are American Indian/Alaska Native, and 1\% are African American. According to the Florida Center for Nursing (2010), approximately $70 \%$ of the RNs in Florida are Caucasian, $12 \%$ are African American, 8\% are Hispanic, 8\% are Asian, and .2\% are Native American. Females make up $90 \%$ of the population and males make up $10 \%$ in Florida. In Missouri, males make up only $7.5 \%$ of the nursing population (Evangelista \& Sims-Giddens, 2008). Unfortunately, a summary of the ethnic demographic data for nurses in Missouri was not readily available. In conducting a search, I was able to find some ethnic data for those completing a nursing educational graduate degree from University of Missouri - Kansas City. Approximately, 80\% have been Caucasian, 4\% were African American, 4\% were Hispanic, 3\% were Asian, and 1\% have been American Indian. These statistics are somewhat consistent with what is found in the three states sampled in this study. In general, the sample for this dissertation is slightly more Caucasian than the general population.

In looking at variations between respondents from the three sample states, I found no differences. Respondents across states did not differ in their levels of each dependent variable, including perceived effectiveness $\left(F_{(2,173)}=2.60, n s\right)$, quality of care $\left(F_{(2,173)}=\right.$ $1.76, n s)$, job satisfaction $\left(F_{(2,251)}=.73, n s\right)$, strain $\left(F_{(2,251)}=1.53, n s\right)$, emotional exhaustion $\left(F_{(2,251)}=.07, n s\right)$, task performance $\left(F_{(2,250)}=1.35, n s\right)$, and stress $\left(F_{(2,251)}\right.$ $=.72, n s)$. Respondents across states also did not vary on the research variables 
Action Orientation 71

(antecedents and moderators), including proactive personality $\left(F_{(2,250)}=.94, n s\right)$, psychological empowerment $\left(F_{(2,251)}=.26, n s\right)$, structural empowerment $\left(F_{(2,173)}=.11\right.$, $n s)$, and political skill $\left(F_{(2,251)}=.07, n s\right)$.

\section{Data Collection Design}

The data collection for the study involves two administrations, with staff nurses being administered on-line questionnaires at both times. Although the administrations were separated in time, this was not designed as a longitudinal study. Surveys were separated in time to 1) reduce the burden on respondents by allowing for a manageable completion time of surveys and 2) minimize the likelihood of respondents developing an implicit theory for the study questions (Podsakoff, MacKenzie, Lee, \& Podsakoff, 2003), which is hoped to improve the quality of data collected. Participant names were collected to match data from time 1 and time 2 administrations. However, names were removed once all data were collected to protect participant identity and ensure confidentiality of data.

There was approximately a week time difference between measures administered in time 1 and time 2. An overview of the measures is provided in Table 1 . This table provides all information for data collection, including variables not included in the dissertation. All measures are published and validated scales used in prior research. Several scales were abbreviated to remove undue burden from respondents. When scales are modified this is noted below in scale descriptions.

\section{Measures}

Measures administered as part of this study are shown in the Appendix. All research measures originate from published scales that have been validated and used in 
Action Orientation 72

peer-reviewed research. A 7-point Likert scale was used for most measures that ranges from 1 (strongly disagree) to 7 (strongly agree). In those cases where the scale will be modified, this is specified in the description of the scale below.

Antecedents. Proactive personality was assessed using Seibert, Crant, and Kraimer's (1999) shortened version of Bateman and Crant's (1993) scale. This 10-item measure was administered at time 1. A sample item is, "I am always looking for better ways to do things." Reliability for this measure was .89 .

Psychological empowerment was assessed using Spreitzer's (1995b) 12-item measure at time 1. An example item is, "I can decide on my own how to go about doing my work." The reliability index for this measure was .87 . Each of the components of empowerment had adequate reliability with competence having an alpha of .91, meaning having an alpha of .88, self-determination having an alpha of .93, and impact showing and alpha of .92 .

Structural empowerment was assessed using Laschinger and colleagues' (Laschinger, Finegan, Wilk, \& Shamian, 2000) 12-item measure at time 2. A 5-point likert scale was used that targeted frequency that ranged from "none" to "a lot" with the middle point indicating "some". An example item is, "I can decide on my own how to go about doing my work." The reliability index for this measure was .89.

Moderators. Political skill was measured using the 6-item Political Skill Inventory (PSI) developed by Ferris and colleagues (Ferris et al., 1999). This measure was administered at time 1. A sample item is, "It is easy for me to develop good rapport with most people." The internal consistency reliability estimate for the scale was .78.

A 3-item measure of work-methods autonomy designed by Morgeson and 
Humphrey (2006) was collected as a potential moderating variable within the study to better examine the sampling procedures within this study. A sample item is, "This job allows me to make decisions about what methods I use to complete my work." This measure was administered to employee respondents at time 1. The internal consistency coefficient (alpha) was .94.

A 3-item measure of decision-making autonomy designed by Morgeson and Humphrey (2006) was collected as a potential moderating variable within the study to better examine the sampling procedures within this study. A sample item is, "This job allows me to make a lot of decisions on my own." This measure was administered to employee respondents at time 2. The internal consistency coefficient (alpha) was .93.

Outcome measures. The outcomes variables of job task performance, job satisfaction, and occupational stress and strain were measured with validated research measures. In an attempt to provide a more holistic evaluation, I collected multiple measures for each of the outcomes. However, the expected hypotheses are not articulated differently. I do not expect that the relationship will change or vary with different measures of outcomes, but I believe that the collection of these additional measures was warranted due to the complexity and variance in the items from these constructs. Next, I will overview the measures for each of the outcome variables of interest.

Performance was measured using two scales. In-role task performance was measured with a general measure designed by Williams and Anderson (1991). These items were slightly modified to reflect self-evaluations rather than supervisor evaluations. Respondents completed this measure at time 1. This 6-item scale has an observed internal consistency measure of reliability of .89. A sample item is, "I adequately complete 
Action Orientation 74

assigned duties." Additionally, perceived effectiveness was measured at time 2 using a modified version of the five-item scale designed by Shortell and colleagues (Shortell, Rousseau, Gillies, Devers, \& Simons, 1991). Items were slightly reworded to address individuals rather than unit performance. A sample item is, "Given the severity of the patients I treat, my patients experience very good outcomes." The observed internal consistency for this measure was .75 .

Job satisfaction was measured with two scales. A general measure of job satisfaction was assessed with an abbreviated 5-item scale of the original 18-item measured designed by Brayfield and Rothe (1951) that was shortened by Judge and colleagues (Judge, Locke, Durham, \& Kluger, 1998). This scale was administered to employee respondents at time 1 of the data collection. A sample item from this scale is "I feel fairly well satisfied with my present job." The observed reliability for the scale was 91. Additionally, an abbreviated measure of satisfaction with quality of care (Hinshaw \& Atwood, 1983) was administered at time 2. A sample item from this three-item measure is, "Under the circumstances, I was happy with the quality of care I provided." The alpha reliability for this measure was .94 .

A number of different methods exist for the measurement of occupational stress to remain in concert with various models of stress (Spielberger, Vagg, \& Wasala, 2003). I assess general work stress with the 15-item Stress-in-General scale (SIG; Stanton, Balzer, Smith, Parra, \& Ironson, 2001) because it was designed to represent a broadspectrum model of stress reactions. The scale was designed to assess current psychological distress, as it was expected that the symptoms experienced would be similar to the general manifestation of stress. The scale uses a three-point format ("Yes", 
Action Orientation 75

“?', '"No'). Although a three-point response option is unconventional, the scale is standard scale in stress research (Cortina \& Magley, 2003; Lim \& Cortina, 2005). The internal consistency reliability was .84 .

To measure occupational strain, the 7-item Anxiety-Stress Questionnaire designed by House and Rizzo (1972) was administered at time 1. The internal reliability associated with this scale was .87 . This scale provides a broad evaluation of occupational strain. A sample item includes, "My job tends to directly affect my health."

To examine a specific dimension of strain, an 8-item emotional exhaustion scale developed by Ray and Miller (1994) with demonstrated internal reliability $(\alpha=.91)$ was administered at time 1. A sample item is, "I feel emotionally drained from my work."

Factor structure of measures. In an effort to evaluate the relationship among variables and more fully understand the factor structure, I conducted a number of confirmatory factor analyses on constructs that appeared to be similar conceptually and/or highly intercorrelated. First, I tested the factor structure across the Occupational Health Psychology (OHP) measures that were highly intercorrelated: stress, strain, and emotional exhaustion. The standardized regression weights ranged from $.14-.85$ when the three variables were separated. The fit was $\operatorname{good}(C F I=.81 ; R M S E A=.08)$. When I collapsed the OHP variables, the standardized regression weights ranged from .23 - .77. The fit was lowered slightly $(\mathrm{CFI}=.72 ; \mathrm{RMSEA}=.10)$. When stress and emotional exhaustion were collapsed, the standardized regression weights ranged from .19- .81. The fit was slightly below adequate $(\mathrm{CFI}=.77$; RMSEA $=.09)$. Next I checked the factor structure with each factor separate, but I removed items 4 and 5 from stress since these factor loadings were particularly poor. This modification resulted in standardized factor 
Action Orientation 76

loadings that ranged from $.32-.85$. The fit of the model was good $(\mathrm{CFI}=.84$; RMSEA $=$ .08 ). Because items 4 and 5 were both reverse coded items, I next tested the model with all reverse coded items dropped from the stress scale. The standardized regression weights for this model ranged from $.33-.85$. The model fit was comparable to that of the model with just items 4 and 5 dropped $(\mathrm{CFI}=.85$; RMSEA $=.09)$. Finally, I tested the model by dropping all reverse coded items, plus items 1 and 3, which were lower than other factor loadings. The standardized regression weights ranged from $.55-.85$. However, the model fit did not change substantially $(\mathrm{CFI}=.86$; RMSEA $=.09)$. After the committee's review of this analysis, it was determined that I should use the published scales as is and not rerun the analysis with modifications to the OHP scale items.

Additionally, I evaluated the factor structure for my research variables: proactive personality, psychological empowerment, and political skill. First, I tested the factor with each measure separate (i.e., Model 1). The standardized regression weights for this model ranged from $.19-.91$. The model fit was less than adequate $(\mathrm{CFI}=.58$; RMSEA $=$ .15). Next, I tried collapsing proactive personality and political skill to evaluate the impact of these modifications (i.e., Model 2). The standardized regression weights ranged from $.27-.91$. The model fit did not improve, it was actually worse $(\mathrm{CFI}=.51$; RMSEA $=.16)$. I then tested a model with psychological empowerment, proactive personality, and political skill collapsed (i.e., Model 3). The standardized regression weights ranged from $.21-.71$. The model fit did not improve from the original model $(\mathrm{CFI}=.37$; RMSEA $=.18)$. I used the chi-square difference test to evaluate whether there is a statistical difference in these models. The chi-square difference between Model 1 and Model 2 was significant $\left(X^{2}=284.95, p<.01\right)$, indicating that Model 2 fit 
Action Orientation 77

significantly worse than Model 1. Similarly, Model 3 fits significantly worse than Model $1\left(X^{2}=937.49, p<.01\right)$. Finally, I modeled the empowerment subscales separately (meaning, impact, competence, and self-determination) with proactive personality and political skill (Model 4). The standardized regression weights for this model ranged from $.31-.97$. The model fit was adequate $(\mathrm{CFI}=.91 ; \mathrm{RMSEA}=.06)$. Model 4 fits significantly better than Model $1\left(X^{2}=1,471, p<.01\right)$.

In the end, the CFA supported separating psychological empowerment into four dimensions. However, I retained the initial analysis of empowerment as an aggregated measure. The dimensions of empowerment are not seen as predictors or outcomes, but rather the essence of psychological empowerment (Thomas \& Velthouse, 1990). Thomas and Velthouse (1990) argue that each dimension adds unique variance to the experience of psychological empowerment. Competence, self-determination, meaningfulness, and impact are thought to work in concert to promote employee active engagement in organizational functioning. Spreitzer (1995a) supports that the dimensions of empowerment combine to form an overall experience of psychological empowerment . Therefore, I modeled this "gestalt" view of psychological empowerment based on the theoretical propositions proposed by leading psychological empowerment researchers (e.g., Spreitzer, 1995a; Thomas \& Velthouse, 1990).

Control Variables

Control variables by definition are extraneous variables not linked to the hypotheses and theories being tested (Spector \& Brannick, 2010). In selecting control variables, I reviewed literature dedicated to each of the outcome variables of interest to ascertain those predictors that are explicitly related to the outcome variable. Given that I 
Action Orientation 78

have selected dependent variables that cover a broad spectrum of interest and dedication within the field of industrial organizational psychology, the volume of research dedicated to any one of these dependent variables is quite large. Therefore, a general review of meta-analytic findings and typical control variables utilized in other studies related to these dependent variables was conducted to select control variables.

Task performance. Task performance is seen as being a result of motivation, which is a combination of arousal, direction, and intensity (Mitchell \& Daniels, 2003). A number of causal models of performance have emerged in theoretical and empirical research that include cognitive ability, experience, and personality, namely conscientiousness, that affect job performance primarily via their effects on knowledge and skill (Motowidlo, 2003). In a meta-analysis, Hunter (1983) examined the relations between cognitive ability, job knowledge, work sample performance, and supervisor ratings of performance, which supported that ability directly affects job knowledge and skill and that ability affects job performance, through knowledge and skill. Schmidt, Hunter, and Outerbridge (1986) were able to support and extend Hunter's results to include experience as an indirect contributor to supervisor ratings via job knowledge and skill. Therefore, it seems that both experience and ability have an indirect affect on supervisor ratings through their effects on knowledge and skill (Motowidlo, 2003).

Schmidt and Hunter (1998) provided an overarching empirical examination for the role of ability and conscientiousness that summarized the research in this area. They concluded that: 1) individuals that are more intelligent learn job knowledge more quickly and more comprehensively, 2) individuals with more experience have more opportunity to learn job-relevant knowledge and skill, and 3) individuals high on conscientiousness 
Action Orientation 79

exert greater effort and dedicate more time to on-task performance. Therefore, cognitive ability, experience, and conscientiousness are all expected to be causal mechanisms for the affects of ability, opportunity to learn, and motivation to learn (Motowidlo, 2003).

Given that ability testing would be administratively burdensome within the current research design due to time constraints and proctoring requirements, I proposed to control for experience and conscientiousness in hypotheses predicting job task performance. The experience measure is provided in the demographics items and is measured at time 1. Conscientiousness was measured using the 4-item version of the Mini-International Item Personality Pool (Donnellan, Oswald, Brendan, \& Lucas, 2006). This measure was administered to employee respondents within the first data collection administration. Internal reliability estimates for this conscientiousness scale .72, which is comparable to the reliability during the scale validation of .69. A sample item is, "Get chores done right away."

It is important to consider using experience and conscientiousness as potential controls because they are theoretically linked with the research constructs, but not relevant to the questions or theories under investigation. Conscientiousness and experience are potential control variables that can be related to the predictors in the study and the outcomes of task performance and perceived effectiveness. This is a correction for spuriousness (Spector \& Brannick, 2010). More specifically, conscientiousness is linked to empowerment and proactivity in that highly conscientious individuals are described as achievement-striving and persevering (McCrae \& Costa, 1990). These individuals are driven and show high levels of aspiration. This is theoretically linked to proactive personality and empowerment namely through the theories of reciprocal 
Action Orientation 80

determinism (Bandura, 1997) and self-regulation theory (Muraven \& Baumeister, 2000). Related to the ambitious tendencies of conscientiousness, research has also shown that high levels of conscientiousness are associated with greater levels of self-monitoring and social desirability behaviors (Stober, 2001), which is linked theoretically to political skill in its relevance to social influence theory (Levy et al., 1998) and social information theory (Salancik \& Pfeffer, 1978). Experience is a potentially important variable to control for with political skill. Given that political skill is thought to be shaped by exposure to situations and potentially improved over time (Ferris et al., 2000), it is important to consider job experience as a control variable.

Job satisfaction. As noted by Hulin and Judge (2003), the volume of research dedicated to identifying antecedents to job satisfaction is so extensive that it cannot reasonably be discussed within a review chapter dedicated to the topic. However, two primary clusters of variables appear to be evident in the literature: job characteristics and individual dispositional characteristics. Given that empowerment is viewed as an individual perception of one's environment, which incorporates evaluation of one's job characteristics and context, I felt that no additional control variable would be necessary to capture the contextual features linked to job satisfaction. Indeed many of the components of empowerment overlap with aspects of Hackman and Oldham's (1975) job characteristic model.

In terms of dispositional characteristics, employees possessing higher core selfevaluations (Judge \& Bono, 2001) have higher levels of job satisfaction (Connolly \& Viswesvaran, 2000). In general, core self-evaluation shows a stronger relationship to job satisfaction than the Big Five, which was thought to be due to the fact that core-self 
Action Orientation 81

evaluation is more compatible with the broad concept of job satisfaction. This is consistent with the compatibility principle proposed by Fishbein and Ajzen (1974, 1975).

Further, those with higher core self-evaluations may be inclined to take action within the workplace because they have a greater confidence in their own abilities. Controlling for a general personality characteristic related to efficacy is important to isolate the influence of proactive personality and empowerment. It could be that those with a general belief in their own effectiveness may experience psychological empowerment and take advantage of structural empowerment processes to a greater extent than an individual with lower core self-evaluations.

Additionally, higher core self-evaluations may have reciprocal influence with political skill. More specifically, those with high political skill may have higher appraisals of themselves, and those with higher core self-evaluations may be better able to deliver political skills. It is because of these explicit associations that core selfevaluations were included in this study as a control variable.

Therefore, the core self-evaluation measure was incorporated as a control variable within this research effort and was administered in the second data collection administration. The 12-item core self-evaluation scale (CSE) developed by Judge et al. (2003) shows strong internal reliability an alpha of .86. A sample item is, "When I try, I generally succeed."

Occupational stress and strain. As might be expected, occupational stress and strain have been studied extensively within the organizational behavior literature. It has been linked to a number of outcomes including absenteeism (e.g., Cooper, Liukkonen, \& Cartwright, 1996), depression (e.g., Roy \& Steptoe, 1994), and even disabilities (e.g., 
Action Orientation 82

Van der Hek \& Plomp, 1997). Theories of occupational stress and strain largely

emphasize job demands and control (Karasek, 1979), which is the theoretical backdrop for the inclusion of empowerment within this research design. Another model of stress emphasizes the effort-reward imbalance model, which assumes that stress will emerge when there is a lack of reciprocity between costs and rewards (Siegrist, 1996).

Because the empowerment theoretical backdrop of effort-reward imbalance models is closely related to justice theory, I have included justice as a control variables in the hypotheses associated with occupational health and stress. To account for the importance of justice within the workplace, I incorporated measures of procedural and distributive justice using the 11-item scale designed by Colquitt (2001). The organizational justice measures were administered to employee respondents within the second data collection administration. The items from these scales were slightly modified to be as generic as possible. For instance a sample procedural justice items is "My unit's procedures are applied consistently." A sample distributive justice items is, "My outcomes (e.g., performance appraisals, promotions) reflect the effort I have put into my work." The alpha reliability for the procedural justice scale was .90 and the reliability for the distributive justice scale was .98 . 


\section{CHAPTER 6}

\section{RESULTS}

Respondents vs. Non-Respondents

To empirically test whether there were any differences between those who chose to participate and those that did not, two, one-way ANOVAs with age $\left(F_{(1,462)}=2.13\right.$, $n s)$ and years of experience $\left(F_{(1,292)}=.61, n s\right)$ as the dependent variables and survey completion as the grouping variable were conducted. Both these analyses were nonsignificant. Logistic regression analyses were run to see if any appreciable differences existed between those that completed the research survey and those that did not in terms of education, ethnicity, and gender. Education had 10 levels ranging from less than high school to doctorate, with an "other" category option. And ethnicity had 7 levels including Caucasian, African American, Filipino, Hispanic, Native American, Asian/Pacific Islander, and other. I found no distinctions between those that participated and those that did not in terms of gender (Wald statistic $=.92 ; d f=2, n s$ ) and education (Wald statistic $=11.94, d f=6, n s)$, but there were differences seen for ethnicity (Wald statistic $=14.05$, $d f=7, p=.05)$. In terms of response rates, Caucasians chose to participate in the study more than other ethnicities. In calculating the odds ratio for ethnicity, I collapsed the data into two categories, Caucasian and other. Caucasians were almost two times more likely to participate in the study compared to other ethnicities (odd ratio $=1.92)$. However, this is likely due to the low levels of diversity in the entire sample. Only 67 (14\%) individuals were non-Caucasian in the entire sample of registrants, compared to the $406(85 \%)$ Caucasians registrants. Based on this differential finding, I reran all the hypothesized analyses and included ethnicity as a control variable. This made no difference in the 
Action Orientation 84

significant findings.

Analyses

Descriptive statistics. Correlations among research variables are provided in Table 2 to show the interrelatedness of the measures. Means and standard deviations are reported along with alpha reliabilities. There are a number of significant correlations among the research variables. Proactive personality is significantly correlated with job satisfaction $(r=.23, p<.01)$, satisfaction with quality of care $(r=.35, p<.01)$, perceived effectiveness $(r=.37, p<.01)$ and task performance $(r=.41, p<.01)$, but not with strain $(r=-.07, n s)$, emotional exhaustion $(r=-.11, n s)$, and stress $(r=-.09, n s)$. Psychological empowerment is significantly correlated each of the outcome variables including job satisfaction $(r=.62, p<.01)$, satisfaction with quality of care $(r=.40, p<.01)$, strain $(r$ $=-.25, p<.01)$, emotional exhaustion $(r=-.38, p<.01)$, perceived effectiveness $(r=.34$, $p<.01)$, task performance $(r=.30, p<.01)$, and stress $(r=-.32, p<.01)$. Structural empowerment is significantly correlated each of the outcome variables including job satisfaction $(r=.46, p<.01)$, satisfaction with quality of care $(r=.33, p<.01)$, strain $(r$ $=-.26, p<.01)$, emotional exhaustion $(r=-.37, p<.01)$, perceived effectiveness $(r=.34$, $p<.01)$, task performance $(r=.19, p<.05)$, and stress $(r=-.28, p<.01)$. Political skill is significantly correlated each of the outcome variables including job satisfaction $(r=$ $.19, p<.01)$, satisfaction with quality of care $(r=.36, p<.01)$, emotional exhaustion $(r=$ $-.14, p<.05)$, perceived effectiveness $(r=.41, p<.01)$, task performance $(r=.44, p<$ $.01)$, and stress $(r=-.13, p<.05)$.

Age is significantly correlated with tenure $(r=.40, p<.01)$, Florida $(r=.21, p<$ $.01)$, Missouri $(r=-.25, p<.01)$, experience $(r=.73, p<.01)$, full-time experience $(r=$ 
Action Orientation 85 $.75, p<.01)$, proactive personality $(r=.13, p<.05)$, and psychological empowerment $(r$ $=.13, p<.05)$. Experience is significantly correlated with Florida $(r=.29 p<.01)$, Missouri $(r=.26, p<.01)$, education $(r=.24, p<.01)$, tenure $(r=.44, p<.01)$, full-time experience $(r=.86, p<.01)$, and psychological empowerment $(r=.19, p<.05)$. Education is significantly correlated with experience $(r=.24, p<.01)$, psychological empowerment, $(r=.14, p<.05)$, proactive personality $(r=.22, p<.01)$, emotional exhaustion $(r=-.15, p<.05)$, and political skill $(r=.17, p<.01)$. Gender is significantly correlated with Florida $(r=.16, p<.05)$ and Oregon $(r=.13, p<.05)$, such that these two states had more males. Finally, Caucasian is significantly correlated with Missouri ( $r$ $=.20, p<.01)$, such that there were more Caucasians in Missouri than other states.

In reviewing correlations between potential control variables and outcome variables, there were relationships observed for all of the proposed control variables, except experience with performance. As cautioned by Becker (2005), control variables uncorrelated with the dependent variable should be omitted unless there is reason to believe that the control variable is a legitimate suppressor. Type I error can be increased when a control variable is by chance correlated with a predictor and not the criterion. Therefore, experience was excluded as a control variable from analyses to preserve power (Becker, 2005).

Hypothesis testing. Hierarchical regression analyses were used to evaluate the relationship between research variables and outcome variables. Each of the dependent variables (i.e., job satisfaction, perceived effectiveness, quality of care, task performance, stress, strain, and emotional exhaustion) was regressed onto the control variables in the first step with study variables entered in the second step, and interaction terms entered 
Action Orientation 86

into the final step. Following Aiken and West (1991), I centered all variables by standardizing each of the variables prior to calculating the cross products. The relative contribution of these variables was examined by inspecting the standardized regression coefficients $(\beta s)$ and R-squared changes in step three of the regression analysis.

Proactive personality-empowerment interaction. The questions of interest for Hypotheses 1-4 concerns whether empowerment interacts with proactive personality in the prediction of organizational outcomes (e.g., performance, job satisfaction, stress, strain). To investigate Hypothesis 1, the main effect of conscientiousness was entered in the initial step of each analysis as the control variable. Proactive personality and empowerment were entered in Step 2, and the interaction term was entered in Step 3. Analyses were run for both psychological and structural empowerment.

For Hypothesis 1, two indices of performance including a general measure of job task performance and a more context specific measure of perceived effectiveness were regressed onto control variables, proactive personality and empowerment, and the interaction terms. The analyses for Hypothesis 1 are provided in Tables 3-6. Although the results are significant, the observed relationships are not fully consistent with what was hypothesized. Significant interactions between proactive personality and empowerment (psychological and structural) were evident in all four equations predicting job task performance and perceived effectiveness.

First, I found a significant interaction between proactive personality and psychological empowerment in the prediction of job task performance $\left(\Delta R^{2}=.02, \mathrm{~F}_{(1,248)}\right.$ $=4.65, p<.05)$ and perceived effectiveness $\left(\Delta R^{2}=.04, \mathrm{~F}_{(1,171)}=9.86, p<.01\right)$. The nature of these interactions can be seen in Figures 5 and 6, respectively. Regression lines 
were plotted using the standardized values of the variables for high and low levels of psychological empowerment (Cohen \& Cohen, 1983). Second, I found a significant interaction between proactive personality and structural empowerment in the prediction of job task performance $\left(\Delta \mathrm{R}^{2}=.05, \mathrm{~F}_{(1,171)}=11.66, \mathrm{p}<.01\right)$ and perceived effectiveness $\left(\Delta \mathrm{R}^{2}=.02, \mathrm{~F}_{(1,171)}=5.12, \mathrm{p}<.05\right)$. The nature of these interactions can be seen in Figures 7 and 8, respectively.

The same patterns of relationships between empowerment and proactive personality in the prediction of job task performance and perceived effectiveness are evident in the four figures. The relationship between proactive personality and performance outcomes was positive for those with low levels of empowerment, but only moderately positive or flat for those with high levels of empowerment. The figures suggest that being high on either empowerment or proactive personality will lead to higher performance. Being low on both can be detrimental to performance. This would suggest a compensatory model between empowerment and proactive personality. This is in line with theory, but not consistent with the expectation that being high on both proactive personality and empowerment would lead to even greater results.

To investigate Hypothesis 2, that proactive personality would interact with empowerment to affect job satisfaction; the main effect of core self-evaluations was entered in the initial step of each analysis as a control variable. Proactive personality and empowerment were entered in Step 2, and the interaction term was entered in Step 3. Analyses were run for both psychological and structural empowerment.

For Hypothesis 2, two indices of satisfaction including a general measure of job satisfaction and a more context specific measure of satisfaction with quality of care were 
Action Orientation 88

regressed onto control variables, proactive personality, empowerment, and interaction terms. Results for Hypothesis 2 are provided in Tables 7-10. I found a significant interaction between proactive personality and psychological empowerment in the prediction of quality of care $\left(\Delta R^{2}=.04, F_{(1,171)}=9.24, p<.01\right)$, but not general job satisfaction $\left(\Delta R^{2}=.01, F_{(1,171)}=1.93, n s\right)$. Similarly, I found a significant interaction between proactive personality and structural empowerment in the prediction of quality of care $\left(\Delta R^{2}=.06, F_{(1,171)}=14.82, p<.01\right)$, but not general job satisfaction $\left(\Delta R^{2}=.01, F_{(1,}\right.$ $171)=2.33, n s)$. The nature of the interaction with proactive personality with psychological and structural empowerment in the prediction of satisfaction with quality of care can be seen in Figures 9 and 10, respectively.

A similar pattern exists between psychological and structural empowerment with proactive personality in the prediction of satisfaction with quality of care. Empowerment can enhance satisfaction with quality of care for those individuals with low levels of proactive personality, but shows smaller influence for those with high levels of proactive personality. Again it appears that empowerment and proactive personality have a compensatory relationship in the prediction of satisfaction with quality of care. These results do not support the expected relationships outlined in Hypothesis 2 that when both empowerment and proactive personality are high, we would see exponentially higher levels of job satisfaction. Instead, the relationship between proactive personality and satisfaction with quality of care is positive for those low on empowerment. However, there is no relationship between proactive personality and satisfaction with quality of care when empowerment is high. If either empowerment or proactive personality was high, satisfaction with quality of care was high. Satisfaction with quality of care only suffered 
when both empowerment and proactive personality were both low.

To investigate Hypothesis 3, that proactive personality would interact with empowerment to affect stress outcomes; the main effects of procedural and distributive justices were entered in the initial step of each analysis as control variables. Proactive personality and empowerment were entered in Step 2, and the interaction term was entered in Step 3. Analyses were run for both psychological and structural empowerment.

For Hypothesis 3, a general measure of stress and emotional exhaustion were regressed onto control variables, proactive personality, empowerment, and interaction terms. Results for Hypothesis 3 are provided in Tables 11-14. Proactive personality and psychological empowerment did not interact significantly in the prediction of stress $\left(\Delta R^{2}\right.$ $\left.=.00, F_{(1,170)}=.05, n s\right)$ or emotional exhaustion $\left(\Delta R^{2}=.00, F_{(1,170)}=.59, n s\right)$.

Similarly, the interaction between proactive personality and structural empowerment were ineffective in the prediction of stress $\left(\Delta R^{2}=.00, F_{(1,170)}=.42, n s\right)$ or emotional exhaustion $\left(\Delta R^{2}=.00, F_{(1,170)}=.07, n s\right)$. These results do not support Hypothesis 3.

To investigate Hypothesis 4, that proactive personality would interact with empowerment to affect strain; the main effects of procedural and distributive justice were entered in the initial step of each analysis as control variables. Proactive personality and empowerment were entered in Step 2, and the interaction term was entered in Step 3. Analyses were run for both psychological and structural empowerment in the prediction of strain. Results for Hypothesis 4 are provided in Tables 15 and 16. In the prediction of strain, proactive personality did not interact significantly with psychological empowerment $\left(\Delta R^{2}=.00, F_{(1,170)}=.67, n s\right)$ or structural empowerment $\left(\Delta R^{2}=.00, F_{(1,}\right.$ 
170) $=.06, n s)$. Therefore, Hypothesis 4 was not supported.

Proactive personality-political skill interaction. The questions of interest for Hypotheses 5-8 concerned the extent to which political skill interacts with proactive personality in the prediction of organizational outcomes (e.g., performance, job satisfaction, stress, strain). To investigate Hypothesis 5, that proactive personality would interact with political skill to affect job performance; the main effect of conscientiousness was entered in the initial step of each analysis as the control variable. Proactive personality and political skill were entered in Step 2, and the interaction term was entered in Step 3.

For Hypothesis 5, two indices of performance including a general measure of job task performance and a more context specific measure of perceived effectiveness were regressed onto control variables, proactive personality, political skill, and interaction terms. Results for Hypothesis 5 are provided in Tables 17 and 18. A significant interaction was found between proactive personality and political skill in the prediction of job task performance $\left(\Delta R^{2}=.06, F_{(1,248)}=21.77, p<.01\right)$, but not perceived effectiveness $\left(\Delta R^{2}=.01, F_{(1,171)}=2.58, n s\right)$. The nature of the interaction between proactive personality and political skill in the prediction of job task performance can be seen in Figure 11.

As seen in Figure 11, proactive personality interacts with political skill in the prediction of job task performance. A high level of political skill is related to high levels of job task performance regardless of proactive personality level. In general those low on both political skill and proactive personality showed lower levels of performance. Whereas those high on either political skill or proactive personality were performing 
Action Orientation 91

relatively well. Additionally, those high on both proactive personality and political skill performed relatively the same as those high on either one or the other. This relationship is not consistent with what was expected in Hypothesis 5 that high levels of both proactive personality and political skill would lead to higher levels of performance. However, the compensatory relationship is consistent with previous results and not counter to theory.

To investigate Hypothesis 6 , that proactive personality would interact with political skill to affect job satisfaction; the main effect of core self-evaluations was entered in the initial step of each analysis as a control variable. Proactive personality and political skill were entered in Step 2, and the interaction term was entered in Step 3. Two indices of satisfaction including a general measure of job satisfaction and a more context specific measure of satisfaction with quality of care were regressed onto control variables, proactive personality, political skill, and interaction terms.

Results for Hypothesis 6 are provided in Tables 19 and 20. I found a significant interaction between proactive personality and political skill in the prediction of satisfaction with quality of care $\left(\Delta R^{2}=.06, F_{(1,171)}=13.91, p<.01\right)$, but not general job satisfaction $\left(\Delta R^{2}=.00, F_{(1,171)}=.68, n s\right)$. The nature of the interaction with proactive personality with political skill in the prediction of satisfaction with quality of care can be seen in Figure 12.

Interestingly, the results shown in Figure 12 show that the relationship between proactive personality and satisfaction with quality of care is positive for those low on political skill. Alternatively, the relationship between proactive personality and satisfaction with quality of care is fairly flat for those high on political skill. Political skill and proactive personality appear to compensate for each other. Thus, reduced 
Action Orientation

satisfaction with quality of care is only evident when both political skill and proactive personality are low. Hypotheses 6 is not supported because higher levels proactive personality and political skill do not lead to exponentially greater satisfaction, but proactive personality can compensate for lower political skill.

To investigate Hypothesis 7, that proactive personality would interact with political skill to affect stress outcomes; the main effects of procedural and distributive justice were entered in the initial step of each analysis as control variables. Proactive personality and political skill were entered in Step 2, and the interaction term was entered in Step 3.

For Hypothesis 7, a general measure of stress and emotional exhaustion were regressed onto control variables, proactive personality, political skill, and interaction terms. Results for Hypothesis 7 are provided in Tables 21 and 22. There were no significant interactions between proactive personality and political skill in the prediction of stress $\left(\Delta R^{2}=.00, F_{(1,170)}=.01, n s\right)$ or emotional exhaustion $\left(\Delta R^{2}=.00, F_{(1,170)}=.00\right.$, $n s)$. Thus, Hypothesis 7 was not supported.

To investigate Hypothesis 8 , that proactive personality would interact with political skill to affect strain; the main effects of procedural and distributive justice were entered in the initial step of each analysis as control variables. Proactive personality and political skill were entered in Step 2, and the interaction term was entered in Step 3. Results for Hypothesis 8 are provided in Table 23. In the prediction of strain, proactive personality did not interact significantly with political skill $\left(\Delta R^{2}=.00, F_{(1,170)}=.42, n s\right)$. Therefore, Hypothesis 8 was not supported.

Empowerment-political skill interaction. The questions of interest for Hypotheses 
Action Orientation 93

9-12 concerned the extent to which political skill interacts with empowerment in the prediction of organizational outcomes (e.g., performance, job satisfaction, stress, strain).

To investigate Hypothesis 9, that empowerment would interact with political skill to affect job performance; the main effect of conscientiousness was entered in the initial step of each analysis as the control variable. Empowerment and political skill were entered in Step 2, and the interaction term was entered in Step 3. Analyses were run for both psychological and structural empowerment.

For Hypothesis 9, two indices of performance including a general measure of job task performance and a more context specific measure of perceived effectiveness were regressed onto control variables, political skill and empowerment, and interaction terms. Results for Hypothesis 9 are provided in Tables 24-27. I did not find a significant interaction between psychological empowerment and political skill in the prediction of job task performance $\left(\Delta R^{2}=.01, F_{(1,248)}=1.74, n s\right)$ or perceived effectiveness $\left(\Delta R^{2}=\right.$ $\left..01, F_{(1,171)}=2.23, n s\right)$. However, I found a significant interaction between structural empowerment and political skill in the prediction of job task performance $\left(\Delta R^{2}=.03, F\right.$ $(1,171)=6.03, p<.01)$, but not perceived effectiveness $\left(\Delta R^{2}=.01, F_{(1,171)}=.08, n s\right)$. The nature of the interaction with perceived effectiveness can be seen in Figure 13.

As seen in Figures 13, structural empowerment interacts with political skill in the prediction of task performance. As seen in Figure 13, political skill and empowerment are able to compensate for one another. Only when both political skill and empowerment are low does task performance reduce. Because it was proposed that higher levels of empowerment and political skill would lead to exponentially better results, these results do not show support for Hypothesis 9. However, they do provide a compelling and 
consistent support for a compensatory model.

To investigate Hypothesis 10, that empowerment would interact with political skill to affect job satisfaction; the main effect of core self-evaluations was entered in the initial step of each analysis as a control variable. Empowerment and political skill were entered in Step 2, and the interaction term was entered in Step 3. Analyses were run for both psychological and structural empowerment.

For Hypothesis 10, two indices of satisfaction including a general measure of job satisfaction and a more context specific measure of satisfaction with quality of care were regressed onto control variables, political skill, empowerment, and interaction terms. Results for Hypothesis 10 are provided in Tables 28-31. There was not a significant interaction between political skill and psychological empowerment in the prediction of general job satisfaction $\left(\Delta R^{2}=.00, F_{(1,171)}=.09, n s\right)$ or satisfaction with quality of care $\left(\Delta R^{2}=.00, F_{(1,171)}=.87, n s\right)$. I did not find a significant interaction between structural empowerment and political skill in the prediction of general job satisfaction $\left(\Delta R^{2}=.00, F\right.$ $(1,171)=.11, n s)$ or satisfaction with quality of care $\left(\Delta R^{2}=.02, F_{(1,171)}=3.58, n s\right)$.

To investigate Hypothesis 11, that empowerment would interact with political skill to affect stress; the main effects of procedural and distributive justice were entered in the initial step of each analysis as control variables. Empowerment and political skill were entered in Step 2, and the interaction term was entered in Step 3. Analyses were run for both psychological and structural empowerment.

For Hypothesis 11, a general measure of stress and emotional exhaustion were regressed onto control variables, political skill, empowerment, and interaction terms. Results for Hypothesis 11 are provided in Tables 32-35. Psychological empowerment 
Action Orientation 95 and political skill did not interact significantly in the prediction of stress $\left(\Delta R^{2}=.00, F_{(1,}\right.$ $170)=.26, n s)$ or emotional exhaustion $\left(\Delta R^{2}=.00, F_{(1,170)}=.03, n s\right)$. Similarly, the interactions between structural empowerment and political skill were ineffective in the prediction of stress $\left(\Delta R^{2}=.00, F_{(1,170)}=.13, n s\right)$ or emotional exhaustion $\left(\Delta R^{2}=.00, F\right.$ $(1,170)=.57, n s)$. Thus, Hypothesis 11 was not supported.

To investigate Hypothesis 12, that empowerment would interact with political skill to affect strain; the main effects of procedural and distributive justice were entered in the initial step of each analysis as control variables. Empowerment and political skill were entered in Step 2, and the interaction term was entered in Step 3. Analyses were run for both psychological and structural empowerment in the prediction of strain. Results for Hypothesis 12 are provided in Tables 36 and 37. In the prediction of strain, political did not interact significantly with psychological empowerment $\left(\Delta R^{2}=.00, F_{(1,170)}=.25\right.$, $n s)$ or structural empowerment $\left(\Delta R^{2}=.00, F_{(1,170)}=.05, n s\right)$. Therefore, Hypothesis 12 was not supported.

Summary of results. Table 38 provides a summary of the observed results across analyses. As seen in the results, the combination of proactive personality and empowerment did not influence occupational health outcomes (i.e., stress, strain, emotional exhaustion). Further proactive personality did not significantly interact with political skill in the prediction of occupational health outcomes. And empowerment did not significantly interact with political skill in the prediction of occupational health outcomes. However, task performance and perceived effectiveness could be explained by an interaction between proactive personality and empowerment (both structural and psychological). Task performance and perceived effectiveness was best when both 
Action Orientation 96

empowerment and proactive personality were high. However, it seems that being high on either empowerment or proactive personality results in almost equal results. Therefore, proactive personality and empowerment can compensate for each other. However, when both proactive personality and empowerment are low, performance is reduced.

This same pattern is observed in the prediction of satisfaction with quality of care by proactive personality and structural empowerment (both psychological and structural empowerment). High levels of either empowerment or proactive personality will provide high levels of satisfaction, but being low on both is particularly detrimental to satisfaction with quality of care. However, being high on both empowerment and proactive personality provides small increases in satisfaction over and above the results from being high on just one factor.

Political skill interacted with structural empowerment in the prediction of task performance. In that, being high on either political skill or empowerment leads to higher task performance. In general, those that are low on both political skill and empowerment showed lower levels of performance.

Finally, political skill interacted with proactive personality in the prediction of task performance and satisfaction with quality of care. Political skill and proactive personality were able to compensate for one another to produce high task performance and satisfaction.

\section{Additional Research Questions}

Several additional research questions were examined as part of this research study that included three-way interactions. In general, exploratory analyses should be interpreted with caution, especially those that run counter to theory (Aiken \& West, 
Action Orientation 97

1991). It is possible that the observations are idiosyncratic to the sample. Further there is a high experiment-wise error rate or inflated alpha that results from conducting large number of tests (Aiken \& West).

For exploratory purposes, three-way interactions were tested by regressing each dependent variable (e.g., performance, job satisfaction, stress, and strain) onto control variables in the first step, proactive personality, empowerment, and political skill were entered in the second step, each of the two-way interactions were entered into the third step, and finally the three-way interaction was entered in the fourth step. Analyses were run for both psychological and structural empowerment.

Results show several significant interactions. As seen in Table 39, proactive personality, structural empowerment and political skill interacted in the prediction of job task performance $\left(\Delta R^{2}=.02, F_{(1,167)}=6.26, p<.01\right)$. The nature of this interaction can be examined in Figure 14. I have plotted the interaction of structural empowerment and proactive personality at low (-2 SD) and high (+2 SD) levels of political skill. At times the values on the Y-axis were outside of the original scale. However this is seen as a common problem in plotting 3-way interactions and it is suggested to simply change the scale to view the relationships (Dawson, 2010).

As shown in Figure 14, there is a disordinal interaction between political skill and proactive personality at low level of structural empowerment. As political skill increases, the relationship between proactive personality and job task performance changes from positive to negative for those low levels of structural empowerment. The observed relationship is consistent with fit theory (Kristof-Brown, Zimmerman, \& Johnson, 2005). In essence, an individual's characteristics (i.e., high proactive personality) and the 
Action Orientation 98

context (i.e., low structural empowerment) are particularly detrimental for those high on political skill and results in lowered performance.

Table 40 shows the results for the three-way interaction among proactive personality, structural empowerment and political skill in the prediction of satisfaction with quality of care $\left(\Delta R^{2}=.02, F_{(1,167)}=4.76, p<.05\right)$. The nature of this interaction can be examined in Figure 15. As political skill increases, the relationship between proactive personality and satisfaction with quality of care is changes from slightly negative to slightly positive for those with high levels of structural empowerment. For those low on structural empowerment, the relationship between proactive personality and satisfaction with quality of care becomes negative as political skill increases. In general, those with low levels of structural empowerment were substantially less satisfied than those with high levels of empowerment, regardless of proactive personality or political skill. As political skill increases, the relationship between proactive personality and satisfaction with quality of care becomes more negative for those individuals showing low levels of structural empowerment. This shows the integral value of structural empowerment in the workplace. Individual personality factors (i.e., proactive personality) and skills (political skill) are not only unable to mitigate lack of structural empowerment; it is particularly unsatisfying for people high on these traits.

Interactions with Autonomy

In addition to the three-way interaction among study variables, it was expected that the expression of the constructs within this study would be best expressed when the position provides for autonomous working conditions. Therefore, the two constructs of work methods autonomy and decision-making autonomy were collected as a potential 
moderating influence in the analyses. Work-methods autonomy and decision-making autonomy were combined with each pair of research variables to explore three-way interactions. A number of three-way interactions were identified.

Table 41 shows the results for the significant three-way interaction among proactive personality, political skill, with decision-making autonomy in the prediction of job task performance $\left(\Delta R^{2}=.02, F_{(1,167)}=5.24, p<.05\right)$. The nature of this interaction can be examined in Figure 16. As shown in the figure, the relationship between proactive personality and job task performance increases in a positive direction as decision-making autonomy increases for those with low levels of political skill, but reverts to a slightly negative association for those with high levels of political skill. This relationship is counter-intuitive to what one might expect given the positive association between performance with political skill and proactive personality. It would be assumed that greater levels of autonomy would allow these characteristics to flourish and produce a positive impact on performance. However, for those with low levels of proactive personality, high levels of political skill and decision-making helped to enhance performance.

Structural empowerment interacted with proactive personality and decisionmaking autonomy in the prediction of job satisfaction $\left(\Delta R^{2}=.02, F_{(1,167)}=3.95, p<\right.$ $.05)$. These results are provided in Table 42. Figure 17 provides a graphical depiction for the nature of the relationships. The relationship between proactive personality and job satisfaction reverts from a negative association to a positive association as decisionmaking autonomy increases for those high on structural empowerment. Thus, decisionmaking autonomy can profoundly impact job satisfaction in a positive way for those 
Action Orientation 100 employees having a high proactive personality working in a context that provides high levels of structural empowerment. All three elements are integral.

Proactive personality, political skill, and decision-making autonomy interacted in the prediction of job satisfaction $\left(\Delta R^{2}=.02, F_{(1,167)}=4.13, p<.05\right)$. Results are shown in Table 43, while the nature of this interaction can be examined in Figure 18. Based on these results, the relationship between proactive personality and job satisfaction changes from negative to positive for those high on political skill as decision-making autonomy increases. The relationship between proactive personality and job satisfaction is relatively stable regardless of decision-making autonomy for those low on political skill.

As seen in Table 44, proactive personality, structural empowerment and workmethods autonomy interacted in the prediction of emotional exhaustion $\left(\Delta R^{2}=.03, F_{(1)}\right.$ $\left.{ }_{166)}=5.99, p<.05\right)$. Figure 19 illustrates the interaction. For those low on structural empowerment, the relationship between proactive personality and emotional exhaustion changed from positive to no relationship as work-methods autonomy increased. However, the relationship between proactive personality and exhaustion changed from positive to negative or those high on structural empowerment as work-methods autonomy increases.

Specifically, proactive personality is positively related to emotional exhaustion for those in high structurally empowered environments at low level of work-methods autonomy. However, as autonomy increases this relationship shifts and becomes negative. As might be expected, higher levels of work-methods autonomy is able to alleviate emotional exhaustion when proactive personality and structural empowerment are high. 
Action Orientation 101

Table 45 shows the results for the three-way interaction among proactive personality, psychological empowerment and work methods autonomy in the prediction of emotional exhaustion $\left(\Delta R^{2}=.02, F_{(1,166)}=3.94, p<.05\right)$. The nature of this interaction can be examined in Figure 20. As shown in the figure, for those with low levels of psychological empowerment, the relationship between proactive personality and emotional exhaustion remains relatively stable as work-methods autonomy increases. However, the relationship between proactive personality and emotional exhaustion changes from a strong positive relationship to a negative relationship as work methods autonomy increases for those with high levels of psychological empowerment. This shows that work-methods autonomy is able to ameliorate or inhibit exhaustion for those that have a proactive personality and experience high levels of psychological empowerment.

Table 46 shows the results for the three-way interaction among proactive personality, psychological empowerment and work-methods autonomy in the prediction of strain $\left(\Delta R^{2}=.02, F_{(1,166)}=6.17, p<.01\right)$. The nature of this interaction can be examined in Figure 21. As shown in the figure, for those with low levels of psychological empowerment, the relationship between proactive personality and strain is relatively unchanged as work-methods autonomy increases. However, the relationship between proactive personality and strain changes from a strong positive relationship to a negative relationship as work methods autonomy increases for those with high levels of psychological empowerment. This shows that work-methods autonomy is able to ameliorate or minimize strain for those that have a proactive personality and experience high levels of psychological empowerment. 
Action Orientation 102

Summary of autonomy research question findings. As part of the research

questions, I also investigated the three-way interaction of research variables of proactive personality, empowerment, and political skill with two types of autonomy: work-methods autonomy and decision-making autonomy. Results indicated that autonomy played an important role in understanding the relationships between study variables in the prediction of outcome variables.

First, job task performance was explained by a three-way interaction between proactive personality, political skill, and decision-making autonomy. Essentially, those high on political skill reported higher performance regardless of decision-making autonomy or proactive personality levels. However, when political skill was low both higher levels of proactive personality and decision-making autonomy can increase reported performance.

Second, job satisfaction was explained by an interaction with proactive personality, structural empowerment, and decision-making autonomy. Decision-making autonomy increases job satisfaction for those high on structural empowerment and proactive personality. Job satisfaction is also explained by the interaction between proactive personality, political skill, and decision-making autonomy. Interestingly, decision-making autonomy is able to enhance job satisfaction for those employees having a high political skill and proactive personality.

Third, emotional exhaustion is explained by a number of interactions. Proactive personality and work-methods autonomy interacted with both psychological and structural empowerment in the prediction of emotional exhaustion. Work-methods autonomy was able to lower exhaustion for individuals high on proactive personality and 
Action Orientation 103

empowerment, but raised exhaustion for those low on proactive personality and high on empowerment. Also, decision-making autonomy combined with high levels of political skill and psychological empowerment helped reduce emotional exhaustion.

Fifth, proactive personality and work-methods autonomy interacted with psychological in the prediction of strain. Higher levels of work methods autonomy is able to reduce strain levels when proactive personality and psychological empowerment are high, but it can increase strain when proactive personality is high and empowerment is low.

Additional analysis with control variables. As part of the exploratory analysis, it was requested by the dissertation committee that I evaluate my results for analyses without the inclusion of control variables. As suggested by Becker (2005), it is important to evaluate results with and without control variables because differing results may suggest further study of control variables in the phenomenon of interest. In general results were consistent. However, in dropping the control variables from the analysis, I found a significant interaction between psychological empowerment and political skill in the prediction of job task performance $\left(\Delta R^{2}=.01, F_{(1,249)}=3.74, p<.05\right)$ and perceived effectiveness $\left(\Delta R^{2}=.02, F_{(1,173)}=3.93, p<.05\right)$. These relationships were not significant when I controlled for conscientiousness. Figures 22 and 23 provide an illustration of the relationships. As shown, results are consistent with previous observed relationships that political skill and psychological empowerment have a moderate compensatory relationship in the prediction of task performance and perceived effectiveness.

In addition to dropping control variables, the committee asked that I evaluate the 
potential interactions between personality control variables with political skill. This resulted in a significant interaction between political skill and core self-evaluation in the prediction of job satisfaction $\left(\Delta R^{2}=.03, F_{(1,172)}=5.39, p<.05\right)$ and satisfaction with quality of care $\left(\Delta R^{2}=.02, F_{(1,249)}=4.42, p<.05\right)$. Figures 24 and 25 provide graphical representations of these relationships respectively. As seen in the figures, those high on core self-evaluation or political skill show higher levels of job satisfaction or satisfaction with quality of care. Those low on both show lower levels of satisfaction.

Also, political skill interacted with conscientiousness in the prediction of job satisfaction $\left(\Delta R^{2}=.01, F_{(1,250)}=3.80, p<.05\right)$, satisfaction with quality of care $\left(\Delta R^{2}=\right.$ $\left..02, F_{(1,172)}=3.76, p<.05\right)$, and strain $\left(\Delta R^{2}=.02, F_{(1,250)}=4.20, p<.05\right)$. Figures 26 through 28 provide graphical representations of these relationships respectively. Essentially, conscientiousness and political skill compensate for one another. For those high on either conscientiousness or political skill they showed high levels of job satisfaction and satisfaction with quality of care, but low levels of strain. Only when both conscientiousness and political skill were low did individuals report low levels of satisfactory or high levels of strain. 
Action Orientation 105

\section{CHAPTER 7}

\section{DISCUSSION}

An action-orientation within the workforce, whether originating from the individual employee (i.e., proactive personality) or driven by organizational contextual features (i.e., empowerment), has been discussed extensively within the organizational management literature (e.g., Aspinwall \& Taylor, 1997; Bateman \& Crant, 1993; Bodner et al., 2009; Campbell, 2000; Chan, 2006; Crant, 1995, 2000; Crant \& Bateman, 2000; Kizilos, 1990; Leach et al., 2003; Liden et al., 2000; Major et al., 2006; Parker \& Collins, 2010; Parker \& Sprigg, 1999; Parker et al., 2006; Robert et al., 2000; Seibert et al., 1999; Seibert et al., 2001; Spreitzer, 1995a; Spreitzer et al., 1997; Thomas \& Tymon, 1994; Thomas \& Velthouse, 1990; Thompson, 2005; Wilkinson, 1998). Yet investigations examining the interplay between proactive personality and empowerment are largely nonexistent despite considerable conceptual and theoretical overlap between the constructs. This is disappointing in view of the overwhelming agreement among researchers regarding the importance in examining the interplay between the situation and individual characteristics (e.g., Mischel, 1977; Mischel \& Shoda, 1995; Motowidlo, Hooper, \& Jackson, 2006; Snyder, 1975; Tett \& Guterman, 2000).

In the following sections of this chapter, I review the results from the hypothesized relationships and provide general interpretation of these findings. Additionally, I review the observed relationships that were found in experimental threeway interaction analyses to provide further interpretation into results. Based on the results from this study, I outline research contributions and provide practical applications of the findings to organizational practice. I specify limitations of the current study and identify 
Action Orientation 106

future research endeavors that can be motivated by the results. Finally, I provide a general conclusion of the research study.

Two-Way Interactions

As evidenced by R-square changes for the interaction terms, results support twoway moderating relationships between pairs of the following variables: proactive personality, empowerment, and political skill in the prediction of important organizational outcomes. Whereas the typical interaction effects in general research account for approximately $1 \%-3 \%$ of the variance (Aiken \& West, 1991), the interactions for predicting a number of organizational outcomes in this study accounted for $4 \%-6 \%$ of the variance. This is especially optimistic given the expectation that a number of interactions go undetected due to small sample size, unreliability in predictor variables, and range restriction in predictor variables (Aguinis \& Stone-Romero, 1997). Given the strong support garnered for the interactions, these concerns are lessened.

I found that empowerment moderates the relationship between proactive personality and a number of outcomes (i.e., job task performance, perceived effectiveness, and satisfaction with quality of care). The relationship between proactive personality and job task performance is moderated by psychological empowerment. Being high on either psychological empowerment or proactive personality leads to higher levels of job task performance. Those low on both psychological empowerment and proactive personality had lower levels of job task performance. Similarly, the relationship between proactive personality and perceived effectiveness is moderated by psychological empowerment. Perceived effectiveness is high when psychological empowerment or proactive personality is high. Perceived effectiveness is low when one is low on both 
psychological empowerment and proactive personality.

Structural empowerment also moderated the relationship between proactive personality and job task performance. Those high on structural empowerment or proactive personality showed high levels of reported job task performance. Yet those high on both structural empowerment and proactive personality did no better on job task performance than those high on just structural empowerment or proactive personality. Likewise, the relationship between proactive personality and perceived effectiveness is moderated by structural empowerment. Those high on structural empowerment (or proactive personality) showed high levels of perceived effectiveness. Those low on structural empowerment and proactive personality had reduced perceived effectiveness.

Psychological empowerment moderated the relationship between proactive personality and satisfaction with quality of care. Essentially, psychological empowerment and proactive personality could compensate for one another. Those high on psychological empowerment or proactive personality have higher levels of satisfaction with quality of care. Those low on both psychological empowerment and proactive personality had reduced levels of satisfaction with quality of care.

Structural empowerment acts similarly to psychological empowerment in the predication of satisfaction with quality of care with proactive personality. Essentially, an individual who is high on either structural empowerment or proactive personality has greater satisfaction with quality of care. Those low on both proactive personality and empowerment showed lower levels of satisfaction with quality of care.

In summary, it appears that empowerment (either structural or psychological empowerment) and proactive personality compensate for one another. Therefore being 
Action Orientation 108

high on either proactive personality or empowerment leads to positive outcomes (e.g., higher performance, perceived effectiveness, satisfaction with quality of care). However, being high on both empowerment (structural or psychological empowerment) and proactive personality does not lead to exponentially higher results. Instead, being high on any one of these variables, or both, leads to positive outcomes.

Political skill moderated the relationship proactive personality has with job task performance and satisfaction with quality of care. Political skill and proactive personality are compensatory in that being high on either will lead to greater task performance. Being low on both proactive personality and political skill leads to lower task performance. The relationship between proactive personality and satisfaction with quality of care was slightly negative for those high on political skill and slightly positive for those low in political skill. Essentially, being high on both political skill and proactive personality led to slightly less satisfaction with quality of care than being high on just political skill. In making sense of this relationship, there is no clear explanation. However, the exploratory three-way interactions provide some insight. For instance, the relationship between proactive personality and satisfaction with quality of care is positive for those low on structural empowerment when political skill is low. As political skill increases, the relationship between proactive personality and satisfaction with quality of care decreases for those low on structural empowerment. Thus, it could be that the disconnect between an individual's characteristics (i.e., high proactive personality) and the context (i.e., low structural empowerment) is particularly unsatisfying for those high on political skill. This emphasizes the fit between individual characteristics and the organizational context (Kristof-Brown et al., 2005). 
Action Orientation 109

Political skill also moderated the relationship empowerment has with job task performance and satisfaction with quality of care. Specifically, political skill and structural empowerment were able to compensate for one another in the prediction of job task performance. However, being high on both structural empowerment and political skill had only modest increases from being high on either one or the other.

Similarly, being high on both political skill and structural empowerment provided little additional value over being high on either one or the other in the prediction of satisfaction with quality of care. Structural empowerment and political skill also compensated for each other in the prediction of satisfaction with quality of care, such that being high on either led to higher satisfaction, yet being high on both provided only moderate increases in satisfaction compared to being high on just structural empowerment or political skill.

Despite these significant results, it is important to note that no support was found for the prediction of stress, emotional exhaustion, strain, nor job satisfaction based on the interactions among proactive personality, empowerment, and political skill. The lack of support for these relationships does not appear to be caused by range restriction in these variables. Indeed, stress, strain, emotional exhaustion, and job satisfaction showed large levels of variance. In the case of these variables, the influence of proactive personality, empowerment, and political skill added little over justice variables, especially procedural justice. The more clear association between stress and strain with organizational justice constructs may explain this. For instance, pain and hurt might be thought of as the most immediate outcomes engendered from injustice (Krehbiel \& Cropanzano, 2000).

Fairness Heuristic Theory (Lind, 2001) may help explain the processes at work 
Action Orientation 110 when employees are emotionally attached to their roles, status, and organizational identities. Because the premise of the relational model focuses on the relationship between fairness perceptions and organizational trust, which in turn satisfies social/psychological needs, it is well poised to explain occupational health and stress outcomes (Ford, Truxillo, \& Bauer, 2009). As supported by Greenberg (2006), justice variables have a great potential to explain occupational stress and strain within the nursing industry. It may be that the constructs of proactive personality and empowerment are more distal predictors of stress and strain.

Stress and strain may be more easily explained by variables that capture greater variability. Although justice researchers have focused very little on organizational injustice (see Greenberg, 2006 for an exception), researchers suggest that stressful reactions to different types of injustice leads to various unhealthy consequences (Siegrist, 1996). The justice variables lend themselves to describe degrees of positive and negative tendencies by an organization. For instance, respondents can interpret lower levels of procedural or distributive justice in a negative way. Given that fairness would be considered a basic right for employees, stress and strain are relevant outcomes of importance to justice variables. On the other hand, proactive personality and/or empowerment may be considered "nice to have" rather than "need to have".

Proactive personality, empowerment, and to a lesser degree political skill primarily explain variance in positive to neutral constructs. For instance, having lower levels of proactivity, empowerment, or political skill does not evoke the same amount of emotional response as having low levels of justice. The constructs being studied here (proactive personality, empowerment, and political skill) are largely targeting what might 
Action Orientation 111

be considered the positive-orientation of individuals and the organizational context.

Additionally, the antecedent variables in the study may actually enhance stress.

For instance, by definition political skill requires self-monitoring and self-regulation.

The theory of self-regulation depletion (Muraven \& Baumeister, 2000) suggests that

when individuals engage in self-regulation, this requires effort and exertion, which can be draining. Self-control requires one to inhibit urges and desires, which can require high levels of exertion (Barkley, 1997). Based on this rationale, political skill may actually enhance levels of emotional exhaustion, stress, and strain rather than abate these responses. I suspect that the relationship between political skill and OHP outcomes is moderated by another variable (e.g., coping, emotional stability, introversion). A potential moderator would be necessary to explain why there is no relationship between political skill and various OHP outcomes (i.e., stress and strain).

Similarly, it may be that proactive personality and empowerment create additional demands that cause stress, which results in a depletion of resources. Several theories suggest that stress is linked to resource availability, which is not modeled in this study. For example, conservation of resources theory (Hobfoll, 1988, 1989) posits that resource loss is more than that of resource gain. Proactivity and empowerment may be thought of as a drain on resources because it requires the exertion of additional efforts. Although it may lead to enhanced satisfaction, the manifestations of stress on the body may still be present without the necessary resources. Meijman and Mulder's Effort-Recovery Model (1998) posits that exerted effort leads to psychological, behavioral, and subjective responses. When one stops exerting effort, recovery occurs. When one neglects to cease their work-task activities, responses accumulate and recovery fails to occur, which may 
Action Orientation 112

result in negative health outcomes. It may be that proactivity and empowerment allow little opportunity for recovery.

Additionally, it is important to note that researchers have recently conceptualized proactive coping within the workplace, which is thought to help reduce or inhibit stress and strain on the job (Schwarzer \& Taubert, 2002). Proactive coping consists of "efforts undertaken in advance of a potentially stressful event to prevent it or to modify its form before it occurs" (Aspinwall \& Taylor, 1997, p. 417). Fritz (2009) found that higher levels of situational constraints were associated with higher levels of proactive behavior. Time pressure and situational constraints at work can be changed through proactive behaviors. Therefore, proactivity might be used as a strategy to combat pressures, but also invoke stress (Fritz \& Sonnentag, 2009).

Proactive coping involves the collection of resources and skills to prepare or inhibit a stressor (Aspinwall, 2005). One must have the ability to identify a potential threat, strategize the resources necessary to eliminate or reduce the threat, and the skill to obtain the required resources in order to successfully engage in proactive coping (Schwarzer \& Taubert, 2002). Future research should investigate the relationship of proactive coping with proactive personality, empowerment, and political skill. For example, it may be that empowerment coupled with proactive coping leads to reduced stress, while empowerment without proactive coping leads to increased stress. Three-Way Interactions

Although three-way interactions were not hypothesized, the demonstrated relationships may provide greater understanding in the interdependence among proactive personality, empowerment, and political skill. Political skill was able to moderate the 
Action Orientation 113

proactive personality-empowerment relationship in the prediction of job task performance and satisfaction with quality of care. When there is a fit between the three variables (i.e., proactivity, structural empowerment and political skill are all high), this enhances task performance and satisfaction with quality of care.

A similar trend was noticed in the prediction of job task performance and satisfaction with quality of care. Essentially, the relationship between proactive personality and performance or satisfaction is positive for those low on structural empowerment when political skill is low. As political skill increases, the relationship between proactive personality and performance or satisfaction decreases for those low on structural empowerment. This supports the premise that an individual's characteristics (i.e., high proactive personality) and the context (i.e., low structural empowerment) is particularly detrimental for those high on political skill and can lead to lowered performance and/or satisfaction. This is consistent with fit theory (Kristof-Brown et al., 2005).

Further, the role of autonomy (work-method autonomy and decision-making autonomy) on the relationships between proactive personality, empowerment, and political skill is highlighted in the exploratory three-way interactions. Decision-making autonomy was able to moderate the proactive personality-political skill relationship in the predication of job satisfaction. The relationship between proactive personality and job satisfaction changed from negative to positive as decision-making autonomy increased for those with high levels of political skill.

Work-methods autonomy played a role in explaining the proactive personalityempowerment relationship in predicting emotional exhaustion and strain. For instance, 
Action Orientation 114

the relationship between emotional exhaustion and proactive personality decreased as work-methods autonomy increased for those high on structural or psychological empowerment. Similarly, the relationship between strain and proactive personality is lowered as work-methods autonomy is increased for those high on structural or psychological empowerment. These exploratory analyses provide a clearer view of the dynamic relationships that exist within the action-oriented criteria in the workplace. Implications for Research

All in all, the research of this dissertation advance the literature across a number of growing research areas (e.g., proactive personality, empowerment, and political skill). Although, each of the constructs is relatively new within the organizational behavior literature, they have established themselves within the field as viable and worthwhile constructs with great potential. Therefore, the research results contribute to the existing literature, while informing future research.

A considerable contribution of the research is the investigation of potential moderators to proactive personality, empowerment, and political skill in the prediction of attitudinal and behavioral work outcomes. In general proactive personality and political skill are portrayed in a positive light with little emphasis placed on identifying boundary conditions. Given the observed results of the three-way interactions, an understanding of political skill can be important to more accurately understand the multiple influences that impact organizational outcomes. For instance, one may incorrectly assume that high levels of proactive personality and political skill will lead to positive outcomes. However, empowerment is an important moderator. At low levels of empowerment, high levels of proactive personality and political skill can be potentially detrimental. Therefore, these 
results expand the relatively limited research dedicated to moderators to proactivity within the workplace.

In addition, considering the relative newness of the political skill literature, the investigation of political skill as a moderator provides added value to the usefulness of this political skill construct as an organizational variable of interest. Results suggest that political skill can compensate for lower levels of proactive personality or empowerment. The benefits of proactivity and empowerment are good, but they can be slightly enhanced with employees who also possess political skill. These results are important because it adds to our understanding of how political skill combines and works in collaboration with other traits and contextual variables. Therefore, it contributes to the rather limited nomological network (Cronbach \& Meehl, 1955) for political skill. This research provides the theoretical support for the hypothesized relationships between political skill and empowerment or proactive personality, while also offering some support for the empirical investigation.

Similarly, the examination of structural and psychological empowerment is a meaningful contribution of this dissertation. Although structural and psychological empowerment are theoretically linked, they have very rarely been evaluated together in research (see Laschinger et al., 2001 for an exception). As seen in the results of this study, structural empowerment and psychological empowerment worked similarly in their relationships with moderators in the prediction of outcome variables. It is interesting to note that in the three-way interactions, psychological empowerment interacted with political skill and proactive personality to a greater extent than did structural empowerment. The only time that structural empowerment interacted with 
Action Orientation 116 proactive personality and political skill is in the prediction of job task performance. Alternatively, psychological empowerment interacted with political skill and proactive personality in the prediction of perceived effectiveness, job satisfaction, and satisfaction with quality of care. It could be that structural empowerment is a more distal predictor and psychological empowerment acts as a proximal predictor. This would be consistent with the model of structural empowerment put forth by Kanter (1979). Implications for Practice

The research results provide more advanced and detailed views to guide organizational efforts focused on proactive personality and empowerment. Considering that the relationship between proactive personality and empowerment and their interplay are largely ignored, the results from this research not only fill an empirical gap within the two literatures, but also provide practical implications. The results inform organizational decision-makers to the relative importance of contextual and interpersonal trait characteristics, which can be used to design strategic organizational human resource programs.

Proactive personality is able to compensate for lower levels of empowerment in predicting some organizational outcomes. This suggests that a selection program designed to assess an employee's inclination to take initiative would promote action within the workforce. Additionally, empowerment appears to be able to compensate for lower levels of proactive personality in the prediction of effective organizational outcomes; thus, this could be used to motivate interventions targeted at job redesign and/or cultural interventions.

Given this information, an organization may use Attraction-Selection-Attrition 
Theory (Schneider, 1987) to promote an action-orientation within the workforce. By designing a context that attracts proactive employees and selecting employees with proactive personalities, an organization is likely to develop a culture that supports and promotes an action-orientation within the workplace.

Empowerment as a moderator has several potential implications for organizational culture interventions. For instance, employee involvement can be enhanced by organizations that emphasize cascading power, information rewards, and worker discretion (Lawler, 1992). Additionally, leadership is linked to empowerment within the workplace. Positive leader-member exchanges and external leader behavior are shown to enhance empowerment (Chen et al., 2007; Liden et al., 2000). Managerial training and mentoring could influence feelings of empowerment within a unit or team (Kirkman \& Rosen, 1999). Team human resource policies and social structure were also related to empowerment (Kirkman \& Rosen, 1999). Finally, work characteristics, newcomer performance expectations, and social exchanges help to increase empowerment within the workplace (Chen \& Klimoski, 2003). Therefore, changing the structural components of the job to enhance autonomy or providing clear performance expectations could lead to enhanced empowerment. All in all, the empowerment within a workplace can be enhanced in many ways. Thus, organizations have a number of interventions from which to choose that have great potential.

Similarly, there are several practical implications for the discovery of a moderating mechanism of political skill. Implications from this research offer organizations avenues for enhancing the effectiveness of action within the workplace. First, political skill is considered an individual trait that is expressed inherently within 
Action Orientation 118

individuals; therefore, this would suggest that selection methods could be used to select employees that exhibit high levels of political skill. This could be evaluated in a traditional self-report personality measure or could be evaluated using a creative situational-judgment test. Alternatively, an assessment center format that incorporates a political skill dimension would be an option for those occupations with candidate counts that are smaller.

Second, political skill is viewed as dynamic (Ferris et al., 2000). It is expected that an employee's level of political skill can be heightened over time with greater amounts of experience and/or with broader exposure to various situations. It has been proposed that intense training can be used to enhance employee political skill (Ferris, Davidson, et al., 2005), which would suggest that developmental assessment centers might be effective in improving the likely beneficial outcomes of proactive personality and empowerment.

Finally, it is also possible that onboarding, socialization, and/or mentoring programs would benefit from the inclusion of the political skill construct. Socialization research suggests that social acceptance and self-efficacy are important mediators to realizing beneficial organizational outcomes (Bauer et al., 2007). Given that political skill enhances an employee's ability to understand and influence others at work in order to attain personal or organizational goals (Ferris, Treadway, et al., 2005), it is expected that political skill is a potentially relevant and important socialization component that will enhance self-efficacy and social acceptance. Employees that are politically skilled are seen as socially astute with the ability to change in response to situational demands effectively (Ferris et al., 2007). They are seen as sincere, inspire support, exude self- 
Action Orientation 119

confidence, develop trust and influence others (Ferris et al., 2007; Liu et al., 2007).

Similarly, the Theory of Reasoned Action (Ajzen \& Fishbein, 1970) that is used to explain mentoring programs would link to political skill. This theory emphasizes that employees need to make complex decisions and utilize information that is available at the time in a rational manner to arrive at behavioral decisions. Mentoring programs are designed to promote career advancement and organizational adjustment by enhancing decision-making, providing support, and offering information on inside organizational politics and procedures (Blass \& Ferris, 2007; Chao, Walz, \& Gardner, 1992; Green \& Bauer, 1995). Because political skill incorporates dimensions of social astuteness, interpersonal influence, and networking ability (Ferris et al., 2007), it has a clear association with mentoring activities. Therefore, it might be expected that general training related to political skill and savvy would be included into organizational mentoring programs.

Potential Limitations and Future Research Directions

There are several potential limitations to this research. First, the research analysis included HLM to control for the potential nested nature of the data. However, this analysis was not possible with the actual data due to a lack of "matched" respondent data to supervisor data. Therefore, a follow-up study that controls for the levels in the analysis would be beneficial.

In hindsight, I should have gathered data from nurse educators and nurse executives rather than screen them out of the data collection. The perspectives from nurses in different settings and levels would have likely provided some interesting points for comparison. By including respondents from different settings, I may have obtained a 
Action Orientation 120

more comprehensive and detailed account of action orientation within the workplace.

Additionally, this research does not include any group-level constructs for examination. The investigation of group level phenomena is often highlighted as providing a more holistic and realistic examination (Bryk \& Raudenbush, 1992). Therefore, including climate and culture environmental variables measured at the group level would offer a more robust examination of the constructs and their interplay.

Given that the results indicate that empowerment does interact with individual proactive personality, future research should examine potential group level variables. For example, the investigation of empowerment and/or climate variables at the group level would provide more confidence that empowerment can be influenced contextually. It could be that empowerment reflects environmental reality and/or potentially an individual's interpretation of reality. Therefore, future research examining group-level constructs of the organizational context would be a logical next step following this research.

Further, when examining organizational- or group-level data of contextual features, it will be important to examine the strength of the context. As pointed out by Meyer, Dalal, and Hermida (2010), a strong context is likely to be "good" or "bad" and it is up to researchers to determine the factors that lead to beneficial and/or detrimental responses. They explain that situational strength is the homogenization of observed behaviors and strong situations are more likely in occupations and industries wherein mistakes and errors carry an increased risk of negative outcomes, like nursing and healthcare. However, a strong situation may be stressful or overly constraining (Ryan \& Deci, 2000) and result in a reduced employee well-being (Meyer et al., 2010). Therefore, 
Action Orientation 121

situational strength might enhance standardization and reduce errors while at the same time detracting from occupational health. Thus, group-level analysis in this area would benefit from examining both the positive and the negative associated with a context. For instance, it is possible for an environment to be both standardized and empowering. This would suggest that empowerment would be a critical success factor for occupations that require large amounts of standardization and structure. As such, examining situational strength and empowerment in a variety of groups and occupations would provide a meaningful extension to the literature.

Although the research design tested provides two data collection administrations, there is a limitation in that longitudinal examinations are omitted. The benefits of a longitudinal analysis include increased statistical power and the capability to estimate a greater range of conditional probabilities (Solon, 1989). It would be beneficial to followup this research to include outcome variables that would necessitate a longitudinal design, for example, turnover. Similarly, strain is considered an outcome of stress (Hurrell, Nelson, \& Simmons, 1998). Therefore, collecting data regarding stress and strain at the same time using a cross-sectional methodology is a limitation of the study that would be drastically improved with a longitudinal design.

A number of the exploratory three-way interactions suggest that a fit between the context (i.e., empowerment), personal dispositions (i.e., proactive personality), and skills (i.e., political skill) is important to realizing organizational outcomes. This type of interaction is consistent with the fit literature that suggests a misfit between the individual and the context could have unwelcomed results (Schneider, Kristof-Brown, Goldstein, \& Smith, 1997). 
Action Orientation 122

Data collection method was a limitation within the study. The registry served as the point of comparison for evaluating response rates. Additionally, these data served to examine differences between respondents and non-respondents. However, based on the recruiting methods, sampling could be non-representative. Emails were sent to labor union list serves and participants were recruited from conferences. There is potential that those who read union list serve emails and/or attend professional conferences differ from the general population of nurses. It may be that those who read listserves are higher on proactivity. Similarly, those that attend or engage in union conferences and activities may be higher on political skill. Also, this unclear knowledge of who actually received the emails makes the true response rate unknown. Additionally, nurses may differ from other occupational subjects in their awareness of stress and strain related outcomes. It could be that nurses are more reticent to say they experience strain given that they are surrounded with patients that experience suffering, illness, and general lack of wellness. It could be that a nurse's own experiences are minimized when using patients as a referent other comparison. Therefore, the sampling strategy may jeopardize the generalizability of the results (Cook, Campbell, \& Day, 1979).

Although I attempted to minimize common method bias by separating measures in time, input variables (e.g., proactive personality, psychological empowerment, and political skill) and output variables (e.g., perceived effectiveness, task performance, job satisfaction, stress, strain) were collected at the same time by the same respondent in a number of instances. Supervisor responses would provide greater interpretation for a number of outcome variables, especially perceived effectiveness and job performance. Additionally, it would be beneficial to collect outcomes variables that are needed from 
Action Orientation 123

the respondent (e.g., stress and strain) at a different point in time from research variables (i.e., proactive personality, empowerment, political skill).

These methodological limitations raise concerns related to common method bias (Podsakoff et al., 2003). The correlations between two measures may be inflated because both were obtained from the same person at the same point in time using the same datacollection technique. However, inflated correlations between input and outcome variables reduce power to detect interactions (Evans, 1985). Thus, I feel confident that commonmethod variance is not solely responsible for the observed results. Despite this, it would have been preferable to obtain performance measures from supervisors. Further, it would have been optimal to obtain self-report measures of job satisfaction, stress, and strain in at a separate time from proactive personality, empowerment, and political skill.

Finally, future research would benefit from the expanded evaluation of structural and psychological empowerment. Kanter's structural empowerment model (Kanter, 1979) specifies a mediating relationship between structural and psychological empowerment. Specifically, Kanter proposes that psychological empowerment results from structural empowerment in the prediction of organizational outcomes such as job strain and work satisfaction. This was supported in research by Laschinger and colleagues (Laschinger et al., 2001).

Additional analysis involving a moderated-mediation analysis would be a meaningful extension this research effort. This would involve a model where psychological empowerment mediates the relationship between structural empowerment and organizational outcomes. Political skill would moderate the relationship between psychological empowerment and outcomes. Proactive personality would moderate the 
Action Orientation 124

relationship between structural empowerment and psychological empowerment. Using structural equation modeling, the moderated mediation path model would provide a meaningful addition to the empowerment literature by adding further strength to the modeled relationship between psychological and structural empowerment proposed by Kanter (1979) while simultaneously testing two key moderating influences.

Conclusion

Overall this study provides several meaningful additions to the organizational literature dedicated to action-orientation. By examining both proactive personality and empowerment, along with potential moderators, the results of this study provide a holistic examination of the personal and contextual processes at work related to actionorientation. In addition, the inclusion of a broad range of organizational outcome variables offers a substantive examination of important applied considerations to practitioners. Implications from these results can inform organizational interventions for practitioners and continuing areas for exploration for future research endeavors. As such, this dissertation sets the stage for understanding the interplay of individual differences with the organizational context and how these can affect both attitudes and behaviors in organizations. 
Table 1. Overview of Measure by Source and Data Collection Timing

\begin{tabular}{|c|c|c|}
\hline Measure & \# Items & Data Collection Timing \\
\hline Demographics & & Time 1 \\
\hline Proactive Personality (Input) & 10 & Time 1 \\
\hline Empowerment (Moderator) & 12 & Time 1 \\
\hline Work Methods Autonomy (control) & 3 & Time 1 \\
\hline Conscientiousness (Control) & 4 & Time 1 \\
\hline Job Satisfaction (Mediator) & 5 & Time 1 \\
\hline Stress (Outcome) & 15 & Time 1 \\
\hline Strain: General (Outcome) & 7 & Time 1 \\
\hline Strain: Emotional Exhaustion (Outcome) & 8 & Time 1 \\
\hline Political Skill (Moderator) & 6 & Time 1 \\
\hline Task Performance (Outcome) & 6 & Time 1 \\
\hline Organizational Justice (Control) & 11 & Time 2 \\
\hline Core Self-Evaluations (Control) & 12 & Time 2 \\
\hline Perceived Overqualification (Moderator) * & 4 & Time 2 \\
\hline Leader-Member Exchange (Mediator) $*$ & 11 & Time 2 \\
\hline Structural Empowerment (Input) & 21 & Time 2 \\
\hline Self-Monitoring (Moderator)* & 7 & Time 2 \\
\hline Role breadth self-efficacy (Mediator)* & 10 & Time 2 \\
\hline Turnover intentions (Outcome)* & 2 & Time 2 \\
\hline Job Enlargement/Role breadth (Mediator)* & 3 & Time 2 \\
\hline Organizational Commitment $*$ & 6 & Time 2 \\
\hline Proactive - OCB (Outcome)* & 11 & Time 2 \\
\hline Satisfaction with Quality of Care (Outcome) & 3 & Time 2 \\
\hline Perceived Effectiveness (Outcome) & 5 & Time 2 \\
\hline Decision-making Autonomy (Moderator) & 3 & Time 2 \\
\hline
\end{tabular}

Note. * Designates variables that are not included in the dissertation design 
Action Orientation 126

Table 2. Means, Standard Deviations, Reliability Estimates, and Correlations for Study Variables

\begin{tabular}{|c|c|c|c|c|c|c|c|c|c|}
\hline Variable & Mean & $\mathrm{sd}$ & 1 & 2 & 3 & 4 & 5 & 6 & 7 \\
\hline $\begin{array}{l}\text { 1. Procedural } \\
\text { Justice }^{8}\end{array}$ & 4.96 & 1.20 & $(.90)$ & & & & & & \\
\hline $\begin{array}{l}\text { 2. Distributive } \\
\text { Justice }^{8}\end{array}$ & 5.16 & 1.76 & $.65^{* * 1}$ & $(.98)$ & & & & & \\
\hline 3. $\mathrm{CSE}^{8}$ & 5.46 & .89 & $.40^{* * 1}$ & $.28^{* * 1}$ & $(.86)$ & & & & \\
\hline 4. Experience & 13.27 & 5.78 & $-.02^{2}$ & $.04^{2}$ & $-.08^{2}$ & $(.--)$ & & & \\
\hline $\begin{array}{l}\text { 5. Conscien- } \\
\text { tiousness }^{8}\end{array}$ & 5.78 & 1.01 & $.08^{1}$ & $.17^{* 1}$ & $.34^{* * 1}$ & $-.01^{3}$ & $(.72)$ & & \\
\hline $\begin{array}{l}\text { 6. Job } \\
\text { Satisfaction }\end{array}$ & 5.56 & 1.29 & $.53^{* * 1}$ & $.40^{* * 1}$ & $.39^{* * 1}$ & $-.07^{3}$ & $.15^{* 4}$ & $(.91)$ & \\
\hline 7. Strain ${ }^{8}$ & 3.83 & 1.43 & $-.34^{* * 1}$ & $-.21^{* * 1}$ & $-.45^{* * 1}$ & $.05^{3}$ & $-.19^{* * 4}$ & $-.47^{* * 4}$ & $(.87)$ \\
\hline $\begin{array}{l}\text { 8. Emotional } \\
\text { Exhaustion }^{8}\end{array}$ & 3.35 & 1.41 & $-.42^{* * 1}$ & $-.30^{* * 1}$ & $-.41^{* * 1}$ & $.06^{3}$ & $-.13^{* 4}$ & $-.71^{* * 4}$ & $.70^{* * 4}$ \\
\hline $\begin{array}{l}\text { 9. Task } \\
\text { Performance }^{8}\end{array}$ & 6.55 & .61 & $.12^{1}$ & $.13^{1}$ & $.15^{* 1}$ & $-.08^{3}$ & $.20^{* * 4}$ & $.30^{* * 4}$ & $-.05^{4}$ \\
\hline 10. Stress ${ }^{9}$ & 1.70 & .67 & $-.38^{* * 1}$ & $-.28^{* * 1}$ & $-.23^{* * 1}$ & $-.06^{3}$ & $.00^{4}$ & $-.48^{* * 4}$ & $.55^{* * 4}$ \\
\hline $\begin{array}{l}\text { 11. Proactive } \\
\text { Personality }^{8}\end{array}$ & 5.55 & .81 & $.10^{1}$ & $.08^{1}$ & $.24^{* * 1}$ & $.08^{3}$ & $.16^{* 4}$ & $.23^{* * 4}$ & $-.07^{4}$ \\
\hline 12. Pych Emp ${ }^{8}$ & 5.75 & .75 & $.50^{* * 1}$ & $.39^{* * 1}$ & $.25^{* * 1}$ & $.19^{* 3}$ & $.13^{* 4}$ & $.62^{* * 4}$ & $-.25^{* * 4}$ \\
\hline $\begin{array}{l}\text { 13. Political } \\
\text { Skill }^{8}\end{array}$ & 5.70 & .76 & $.22^{* * 1}$ & $.16^{* 1}$ & $.20^{* * 1}$ & $-.12^{3}$ & $.10^{4}$ & $.19^{* * 4}$ & $-.07^{4}$ \\
\hline $\begin{array}{l}\text { 14. Perceived } \\
\text { Effectiveness }^{8}\end{array}$ & 6.16 & .70 & $.22^{* * 1}$ & $.24^{* * 1}$ & $.35^{* * 1}$ & $-.07^{2}$ & $.19^{* 1}$ & $.38^{* * 1}$ & $-.16^{* 1}$ \\
\hline $\begin{array}{l}\text { 15. Structural } \\
\text { Emp }^{10}\end{array}$ & 3.32 & .65 & $.61^{* * 1}$ & $.54^{* * 1}$ & $.38^{* * 1}$ & $-.03^{2}$ & $.23^{* * 1}$ & $.46^{* * 1}$ & $-.26^{* * 1}$ \\
\hline 16. $Q$ of $C^{8}$ & 6.43 & .77 & $.28^{* * 1}$ & $.17^{* 1}$ & $.37^{* * 1}$ & $-.11^{2}$ & $.23^{* * 1}$ & $.43^{* * 1}$ & $-.22^{* * 1}$ \\
\hline 17. Age & 42.26 & 11.46 & $-.03^{1}$ & $-.11^{1}$ & $-.02^{1}$ & $.73^{* * 3}$ & $.10^{4}$ & $-.00^{4}$ & $.08^{4}$ \\
\hline 18. Florida & .48 & .50 & $-.06^{1}$ & $-.12^{1}$ & $.17^{* 1}$ & $.29^{* * 3}$ & $.11^{4}$ & $-.07^{4}$ & $-.10^{4}$ \\
\hline 19. Oregon & .27 & .44 & $.01^{1}$ & $-.04^{1}$ & $-.16^{* 1}$ & $-.08^{3}$ & $-.05^{4}$ & $.01^{4}$ & $.09^{4}$ \\
\hline 20. Missouri & .25 & .44 & $.05^{1}$ & $.17^{* 1}$ & $-.03^{1}$ & $-.26^{* * 3}$ & $-.08^{4}$ & $.07^{4}$ & $.03^{4}$ \\
\hline 21. Gender & .11 & .32 & $.00^{1}$ & $-.09^{1}$ & $.01^{1}$ & $-.06^{3}$ & $-.16^{* 4}$ & $-.08^{4}$ & $-.10^{4}$ \\
\hline 22. Caucasian & .90 & .30 & $-.02^{1}$ & $-.07^{1}$ & $.01^{1}$ & $-.01^{3}$ & $-.13 *^{4}$ & $-.08^{4}$ & $.12^{4}$ \\
\hline 23. Education & 1.91 & .79 & $.01^{3}$ & $.07^{3}$ & $.21^{* * 3}$ & $.24^{* * 3}$ & $.01^{6}$ & $.12^{6}$ & $-.11^{6}$ \\
\hline 24. Tenure & 6.56 & 6.43 & $.03^{5}$ & $-.01^{5}$ & $-.06^{5}$ & $.44^{* * 3}$ & $.04^{1}$ & $-.02^{1}$ & $-.04^{1}$ \\
\hline $\begin{array}{l}\text { 25. FT } \\
\text { Experience }\end{array}$ & 13.61 & 11.17 & $-.07^{7}$ & $-.02^{7}$ & $-.20^{7}$ & $.86^{* * 5}$ & $-.03^{5}$ & $-.01^{5}$ & $.05^{5}$ \\
\hline $\begin{array}{l}\text { 26. } \mathrm{PT} \\
\text { Experience }\end{array}$ & 4.26 & 6.57 & $-.12^{7}$ & $-.01^{7}$ & $.17^{7}$ & $.16^{7}$ & $.15^{7}$ & $-.13^{7}$ & $-.03^{7}$ \\
\hline 27. WMA & 5.31 & 1.39 & $.44^{* * 1}$ & $.35^{* * 1}$ & $.22^{* * 1}$ & $.14^{3}$ & $.07^{4}$ & $.77^{* * 4}$ & $-.22^{* * 4}$ \\
\hline 28. DMA & 5.43 & 1.39 & $.65^{* * 1}$ & $.46^{* * 1}$ & $.63^{* * 1}$ & $.08^{2}$ & $.10^{1}$ & $.47^{* * 1}$ & $-.30^{* * 1}$ \\
\hline
\end{tabular}




\begin{tabular}{|c|c|c|c|c|c|c|c|c|c|}
\hline Variable & Mean & $\mathrm{sd}$ & 8 & 9 & 10 & 11 & 12 & 13 & 14 \\
\hline $\begin{array}{l}\text { 1. Procedural } \\
\text { Justice }^{8}\end{array}$ & 4.96 & 1.20 & & & & & & & \\
\hline $\begin{array}{l}\text { 2. Distributive } \\
\text { Justice }^{8}\end{array}$ & 5.16 & 1.76 & & & & & & & \\
\hline 3. $\mathrm{CSE}^{8}$ & 5.46 & .89 & & & & & & & \\
\hline 4. Experience & 13.27 & 5.78 & & & & & & & \\
\hline $\begin{array}{l}\text { 5. Conscien- } \\
\text { tiousness }^{8}\end{array}$ & 5.78 & 1.01 & & & & & & & \\
\hline $\begin{array}{l}\text { 6. Job } \\
\text { Satisfaction }^{8}\end{array}$ & 5.56 & 1.29 & & & & & & & \\
\hline 7. Strain ${ }^{8}$ & 3.83 & 1.43 & & & & & & & \\
\hline $\begin{array}{l}\text { 8. Emotional } \\
\text { Exhaustion }^{8}\end{array}$ & 3.35 & 1.41 & $(.91)$ & & & & & & \\
\hline $\begin{array}{l}\text { 9. Task } \\
\text { Performance }\end{array}$ & 6.55 & .61 & $-.21^{* * 4}$ & (.89) & & & & & \\
\hline 10. Stress ${ }^{9}$ & 1.70 & .67 & $.68^{* * 4}$ & $-.09^{4}$ & $(.84)$ & & & & \\
\hline $\begin{array}{l}\text { 11. Proactive } \\
\text { Personality }^{8}\end{array}$ & 5.55 & .81 & $-.11^{4}$ & $.41^{* * 4}$ & $-.09^{4}$ & (.89) & & & \\
\hline 12. Pych Emp ${ }^{8}$ & 5.75 & .75 & $-.38^{* * 4}$ & $.30^{* * 4}$ & $-.32^{* * 4}$ & $.43^{* * 4}$ & $(.87)$ & & \\
\hline $\begin{array}{l}\text { 13. Political } \\
\text { Skill }^{8}\end{array}$ & 5.70 & .76 & $-.14^{* 4}$ & $.44^{* * 4}$ & $-.10^{4}$ & $.48^{* * 4}$ & $.38^{* * 4}$ & $(.78)$ & \\
\hline $\begin{array}{l}\text { 14. Perceived } \\
\text { Effectiveness }^{8}\end{array}$ & 6.16 & .70 & $-.33^{* * 1}$ & $.39^{* * 1}$ & $-.21^{* * 1}$ & $.37^{* * 1}$ & $.34^{* * 1}$ & $.41^{* * 1}$ & $(.75)$ \\
\hline $\begin{array}{l}\text { 15. Structural } \\
\text { Emp }^{10}\end{array}$ & 3.32 & .65 & $-.37^{* * 1}$ & $.19^{* 1}$ & $-.28^{* * 1}$ & $.17^{* 1}$ & $.45^{* * 1}$ & $.32^{* * 1}$ & $.34^{* * 1}$ \\
\hline 16. $\mathrm{Q}$ of $\mathrm{C}^{8}$ & 6.43 & .77 & $-.34^{* * 1}$ & $.51^{* * 1}$ & $-.21^{* * 1}$ & $.35^{* * 1}$ & $.40^{* * 1}$ & $.42^{* * 1}$ & $.60^{* * 1}$ \\
\hline 17. Age & 42.26 & 11.46 & $.08^{4}$ & $.01^{4}$ & $-.03^{4}$ & $.16^{* 4}$ & $.13^{* 4}$ & $-.06^{4}$ & $-.02^{1}$ \\
\hline 18. Florida & .48 & .50 & $.02^{4}$ & $.03^{4}$ & $.09^{4}$ & $.06^{4}$ & $-.00^{4}$ & $.02^{4}$ & $-.11^{1}$ \\
\hline 19. Oregon & .27 & .44 & $-.02^{4}$ & $-.10^{4}$ & $-.04^{4}$ & $-.09^{4}$ & $-.04^{4}$ & $-.02^{4}$ & $-.04^{1}$ \\
\hline 20. Missouri & .25 & .44 & $.01^{4}$ & $.06^{4}$ & $-.06^{4}$ & $.02^{4}$ & $.04^{4}$ & $-.01^{4}$ & $.17^{* 1}$ \\
\hline 21. Gender & .11 & .32 & $.01^{4}$ & $-.00^{4}$ & $.06^{4}$ & $.10^{4}$ & $-.12^{4}$ & $.00^{4}$ & $-.02^{1}$ \\
\hline 22. Caucasian & .90 & .30 & $.07^{4}$ & $.02^{4}$ & $.02^{4}$ & $.02^{4}$ & $-.06^{4}$ & $-.09^{4}$ & $-.04^{1}$ \\
\hline 23. Education & 1.91 & .79 & $-.15^{* 6}$ & $.05^{6}$ & $-.14^{* 6}$ & $.22^{* * 6}$ & $.14^{* 6}$ & $.17^{* * 6}$ & $.10^{3}$ \\
\hline 24. Tenure & 6.56 & 6.43 & $.04^{1}$ & $-.08^{1}$ & $.07^{1}$ & $.01^{1}$ & $.08^{1}$ & $-.03^{1}$ & $-.12^{5}$ \\
\hline $\begin{array}{l}\text { 25. FT } \\
\text { Experience }\end{array}$ & 13.61 & 11.17 & $.03^{5}$ & $-.07^{5}$ & $.01^{5}$ & $.10^{5}$ & $.16^{5}$ & $-.12^{5}$ & $-.13^{7}$ \\
\hline $\begin{array}{l}\text { 26. } \mathrm{PT} \\
\text { Experience }\end{array}$ & 4.26 & 6.57 & $.09^{7}$ & $.06^{7}$ & $.18^{7}$ & $.03^{7}$ & $-.01^{7}$ & $.15^{7}$ & $.08^{7}$ \\
\hline 27. WMA & 5.31 & 1.39 & $-.27^{* * 4}$ & $.13^{* 4}$ & $-.29^{* * 4}$ & $.27^{* * 4}$ & $.75^{* * 4}$ & $.16^{* * 4}$ & $.13^{1}$ \\
\hline 28. DMA & 5.43 & 1.39 & $-.32^{* * 1}$ & $.07^{1}$ & $-.31^{* * 1}$ & $.12^{1}$ & $.56^{* * 1}$ & $.19^{* * 1}$ & $.29^{* * 1}$ \\
\hline
\end{tabular}


Action Orientation 128

\begin{tabular}{|c|c|c|c|c|c|c|c|c|c|}
\hline Variable & Mean & sd & 15 & 16 & 17 & 18 & 19 & 20 & 21 \\
\hline $\begin{array}{l}\text { 1. Procedural } \\
\text { Justice }^{8}\end{array}$ & 4.96 & 1.20 & & & & & & & \\
\hline $\begin{array}{l}\text { 2. Distributive } \\
\text { Justice }^{8}\end{array}$ & 5.16 & 1.76 & & & & & & & \\
\hline 3. $\mathrm{CSE}^{8}$ & 5.46 & .89 & & & & & & & \\
\hline 4. Experience & 13.27 & 5.78 & & & & & & & \\
\hline $\begin{array}{l}\text { 5. Conscien- } \\
\text { tiousness }\end{array}$ & 5.78 & 1.01 & & & & & & & \\
\hline $\begin{array}{l}\text { 6. Job } \\
\text { Satisfaction }\end{array}$ & 5.56 & 1.29 & & & & & & & \\
\hline 7. Strain ${ }^{8}$ & 3.83 & 1.43 & & & & & & & \\
\hline $\begin{array}{l}\text { 8. Emotional } \\
\text { Exhaustion }^{8}\end{array}$ & 3.35 & 1.41 & & & & & & & \\
\hline $\begin{array}{l}\text { 9. Task } \\
\text { Performance }^{8}\end{array}$ & 6.55 & .61 & & & & & & & \\
\hline 10. Stress ${ }^{9}$ & 1.70 & .67 & & & & & & & \\
\hline $\begin{array}{l}\text { 11. Proactive } \\
\text { Personality }^{8}\end{array}$ & 5.55 & .81 & & & & & & & \\
\hline 12. Pych Emp ${ }^{8}$ & 5.75 & .75 & & & & & & & \\
\hline $\begin{array}{l}\text { 13. Political } \\
\text { Skill }^{8}\end{array}$ & 5.70 & .76 & & & & & & & \\
\hline $\begin{array}{l}\text { 14. Perceived } \\
\text { Effectiveness }\end{array}$ & 6.16 & .70 & & & & & & & \\
\hline $\begin{array}{l}\text { 15. Structural } \\
\text { Emp }^{10}\end{array}$ & 3.32 & .65 & $(.89)$ & & & & & & \\
\hline 16. $Q$ of $C^{8}$ & 6.43 & .77 & $.33^{* * 1}$ & (.94) & & & & & \\
\hline 17. Age & 42.26 & 11.46 & $-.06^{1}$ & $-.04^{1}$ & & & & & \\
\hline 18. Florida & .48 & .50 & $-.02^{1}$ & $-.00^{1}$ & $.21^{* * 4}$ & & & & \\
\hline 19. Oregon & .27 & .44 & $-.01^{1}$ & $-.11^{1}$ & $.01^{4}$ & $-.58^{* * 4}$ & & & \\
\hline 20. Missouri & .25 & .44 & $.04^{1}$ & $.12^{1}$ & $-.25^{* * 4}$ & $-.56^{* * 4}$ & $-.35^{* * 4}$ & & \\
\hline 21. Gender & .11 & .32 & $-.05^{1}$ & $-.12^{1}$ & $.03^{4}$ & $-.16^{* 4}$ & $.13^{* 4}$ & $.05^{4}$ & \\
\hline 22. Caucasian & .90 & .30 & $-.04^{1}$ & $.05^{1}$ & $-.01^{4}$ & $-.10^{4}$ & $-.09^{4}$ & $.20^{* * 4}$ & $.08^{4}$ \\
\hline 23. Education & 1.91 & .79 & $.12^{3}$ & $.16^{* 3}$ & $.10^{6}$ & $-.08^{6}$ & $.05^{6}$ & $.04^{6}$ & $.10^{6}$ \\
\hline 24. Tenure & 6.56 & 6.43 & $-.01^{5}$ & $-.12^{5}$ & $.40^{* * 1}$ & $.09^{1}$ & $.03^{1}$ & $-.14^{1}$ & $-.05^{1}$ \\
\hline $\begin{array}{l}\text { 25. FT } \\
\text { Experience }\end{array}$ & 13.61 & 11.17 & $-.01^{7}$ & $-.13^{7}$ & $.75^{* * 5}$ & $.42^{* * 5}$ & $-.18^{5}$ & $-.30^{* * 5}$ & $.03^{5}$ \\
\hline $\begin{array}{l}\text { 26. } \mathrm{PT}_{-} \\
\text {Experience }\end{array}$ & 4.26 & 6.57 & $-.10^{7}$ & $.06^{7}$ & $.11^{7}$ & $-.05^{7}$ & $-.03^{7}$ & $.08^{7}$ & $.17^{7}$ \\
\hline 27. WMA & 5.31 & 1.39 & $.36^{* * 1}$ & $.17^{* 1}$ & $.15^{* 4}$ & $.00^{4}$ & $-.03^{4}$ & $.03^{4}$ & $-.01^{4}$ \\
\hline 28. DMA & 5.43 & 1.39 & $.46^{* * 1}$ & $.22^{* 1}$ & $.07^{1}$ & $-.08^{1}$ & $.13^{1}$ & $-.04^{1}$ & $-.04^{1}$ \\
\hline
\end{tabular}


Action Orientation 129

\begin{tabular}{|c|c|c|c|c|c|c|c|c|c|}
\hline Variable & Mean & $\mathrm{sd}$ & 22 & 23 & 24 & 25 & 26 & 27 & 28 \\
\hline $\begin{array}{l}\text { 1. Procedural } \\
\text { Justice }^{8}\end{array}$ & 4.96 & 1.20 & & & & & & & \\
\hline $\begin{array}{l}\text { 2. Distributive } \\
\text { Justice }^{8}\end{array}$ & 5.16 & 1.76 & & & & & & & \\
\hline 3. $\mathrm{CSE}^{8}$ & 5.46 & .89 & & & & & & & \\
\hline 4. Experience & 13.27 & 5.78 & & & & & & & \\
\hline $\begin{array}{l}\text { 5. Conscien- } \\
\text { tiousness }\end{array}$ & 5.78 & 1.01 & & & & & & & \\
\hline $\begin{array}{l}\text { 6. Job } \\
\text { Satisfaction }\end{array}$ & 5.56 & 1.29 & & & & & & & \\
\hline 7. Strain ${ }^{8}$ & 3.83 & 1.43 & & & & & & & \\
\hline $\begin{array}{l}\text { 8. Emotional } \\
\text { Exhaustion }^{8}\end{array}$ & 3.35 & 1.41 & & & & & & & \\
\hline $\begin{array}{l}\text { 9. Task } \\
\text { Performance }^{8}\end{array}$ & 6.55 & .61 & & & & & & & \\
\hline 10. Stress ${ }^{9}$ & 1.70 & .67 & & & & & & & \\
\hline $\begin{array}{l}\text { 11. Proactive } \\
\text { Personality }^{8}\end{array}$ & 5.55 & .81 & & & & & & & \\
\hline 12. Pych Emp ${ }^{8}$ & 5.75 & .75 & & & & & & & \\
\hline $\begin{array}{l}\text { 13. Political } \\
\text { Skill }^{8}\end{array}$ & 5.70 & .76 & & & & & & & \\
\hline $\begin{array}{l}\text { 14. Perceived } \\
\text { Effectiveness }^{8}\end{array}$ & 6.16 & .70 & & & & & & & \\
\hline $\begin{array}{l}\text { 15. Structural } \\
\text { Emp }^{10}\end{array}$ & 3.32 & .65 & & & & & & & \\
\hline 16. $\mathrm{Q}$ of $\mathrm{C}^{8}$ & 6.43 & .77 & & & & & & & \\
\hline 17. Age & 42.26 & 11.46 & & & & & & & \\
\hline 18. Florida & .48 & .50 & & & & & & & \\
\hline 19. Oregon & .27 & .44 & & & & & & & \\
\hline 20. Missouri & .25 & .44 & & & & & & & \\
\hline 21. Gender & .11 & .32 & & & & & & & \\
\hline 22. Caucasian & .90 & .30 & & & & & & & \\
\hline 23. Education & 1.91 & .79 & $.02^{6}$ & & & & & & \\
\hline 24. Tenure & 6.56 & 6.43 & $.02^{1}$ & $-.07^{1}$ & & & & & \\
\hline $\begin{array}{l}\text { 25. FT } \\
\text { Experience }\end{array}$ & 13.61 & 11.17 & $.04^{5}$ & $.18^{5}$ & $.41^{* * 5}$ & & & & \\
\hline $\begin{array}{l}\text { 26. } \mathrm{PT}_{-} \\
\text {Experience }\end{array}$ & 4.26 & 6.57 & $.11^{7}$ & $.19^{7}$ & $.25^{* 7}$ & $-.06^{7}$ & & & \\
\hline 27. WMA & 5.31 & 1.39 & $.05^{4}$ & $.13^{* 4}$ & $.16^{* * 6}$ & $.16^{5}$ & $.05^{7}$ & & \\
\hline 28. DMA & 5.43 & 1.39 & $-.06^{1}$ & $.10^{3}$ & $.12^{3}$ & $-.03^{7}$ & $-.08^{7}$ & & \\
\hline
\end{tabular}


Action Orientation 130

Table 3. Regression Analyses Testing Proactive Personality and Psychological Empowerment Interaction with Task Performance

\begin{tabular}{|c|c|c|c|c|c|c|}
\hline \multirow{2}{*}{ Variables } & \multicolumn{2}{|c|}{ Step 1} & \multicolumn{2}{|c|}{ Step 2} & \multicolumn{2}{|c|}{ Step 3} \\
\hline & $\mathrm{b}$ & $\left(\mathrm{SE}_{\mathrm{b}}\right)$ & $\mathrm{b}$ & $\left(\mathrm{SE}_{\mathrm{b}}\right)$ & $\mathrm{b}$ & $\left(\mathrm{SE}_{\mathrm{b}}\right)$ \\
\hline Constant & $5.84 * *$ & $(.22)$ & $6.08 * *$ & $(.20)$ & $6.18 * *$ & $(.21)$ \\
\hline Conscientiousness & $.12 * *$ & $(.04)$ & .08 & $(.04)$ & .07 & $(.04)$ \\
\hline Proactive Personality & & & $.20 * *$ & $(.04)$ & $.20 * *$ & $(.04)$ \\
\hline Psychological Empowerment & & & $.09 *$ & $(.04)$ & $.08^{*}$ & $(.04)$ \\
\hline $\begin{array}{l}\text { Proactive Personality } \mathrm{x} \\
\text { Psychological Empowerment }\end{array}$ & & & & & $-.08 *$ & $(.04)$ \\
\hline Model $\mathrm{R}^{2}$ & $.04 * *$ & & $.20 * *$ & & $.22 * *$ & \\
\hline Step $\Delta \mathrm{R}^{2}$ & & & $.16 * *$ & & $.02 *$ & \\
\hline
\end{tabular}

Note. $* \mathrm{p}<.05 ; * * \mathrm{p}<.01$. 
Action Orientation 131

Table 4. Regression Analyses Testing Proactive Personality and Structural Empowerment Interaction with Task Performance

\begin{tabular}{|c|c|c|c|c|c|c|}
\hline \multirow{2}{*}{ Variables } & \multicolumn{2}{|c|}{ Step 1} & \multicolumn{2}{|c|}{ Step 2} & \multicolumn{2}{|c|}{ Step 3} \\
\hline & b & $\left(\mathrm{SE}_{\mathrm{b}}\right)$ & b & $\left(\mathrm{SE}_{\mathrm{b}}\right)$ & b & $\left(\mathrm{SE}_{\mathrm{b}}\right)$ \\
\hline Constant & $5.85 * *$ & $(.28)$ & $6.26 * *$ & $(.27)$ & $6.32 * *$ & $(.26)$ \\
\hline Conscientiousness & $.12 * *$ & $(.05)$ & .05 & $(.05)$ & .05 & $(.04)$ \\
\hline Proactive Personality & & & $.26^{* *}$ & $(.04)$ & $.25^{* *}$ & $(.04)$ \\
\hline Structural Empowerment & & & .06 & $(.05)$ & .07 & $(.04)$ \\
\hline $\begin{array}{l}\text { Proactive Personality } \mathrm{x} \\
\text { Structural Empowerment }\end{array}$ & & & & & $-.13 * *$ & $(.04)$ \\
\hline Model $\mathrm{R}^{2}$ & $.04 * *$ & & $.22 * *$ & & $.27 * *$ & \\
\hline Step $\Delta \mathrm{R}^{2}$ & & & $.19 * *$ & & $.05 * *$ & \\
\hline
\end{tabular}

Note. $* \mathrm{p}<.05 ; * * \mathrm{p}<.01$. 
Action Orientation 132

Table 5. Regression Analyses Testing Proactive Personality and Psychological Empowerment Interaction with Perceived Effectiveness

\begin{tabular}{|c|c|c|c|c|c|c|}
\hline \multirow{2}{*}{ Variables } & \multicolumn{2}{|c|}{ Step 1} & \multicolumn{2}{|c|}{ Step 2} & \multicolumn{2}{|c|}{ Step 3} \\
\hline & $\mathrm{b}$ & $\left(\mathrm{SE}_{\mathrm{b}}\right)$ & $\mathrm{b}$ & $\left(\mathrm{SE}_{\mathrm{b}}\right)$ & $\mathrm{b}$ & $\left(\mathrm{SE}_{\mathrm{b}}\right)$ \\
\hline Constant & $5.39 * *$ & $(.31)$ & $5.76^{* *}$ & $(.29)$ & $6.01 * *$ & $(.29)$ \\
\hline Conscientiousness & $.13 * *$ & $(.05)$ & .07 & $(.05)$ & .04 & $(.05)$ \\
\hline Proactive Personality & & & $.18 * *$ & $(.05)$ & $.18 * *$ & $(.05)$ \\
\hline Psychological Empowerment & & & $.14 *$ & $(.05)$ & $.13 *$ & $(.05)$ \\
\hline $\begin{array}{l}\text { Proactive Personality } \mathrm{x} \\
\text { Psychological Empowerment }\end{array}$ & & & & & $-.14^{*}$ & $(.05)$ \\
\hline Model $\mathrm{R}^{2}$ & $.04 * *$ & & $.19 * *$ & & $.23 * *$ & \\
\hline Step $\Delta \mathrm{R}^{2}$ & & & $.15^{* *}$ & & $.04 * *$ & \\
\hline
\end{tabular}

Note. $* \mathrm{p}<.05 ; * * \mathrm{p}<.01$. 
Action Orientation 133

Table 6. Regression Analyses Testing Proactive Personality and Structural Empowerment Interaction with Perceived Effectiveness

\begin{tabular}{|c|c|c|c|c|c|c|}
\hline \multirow{2}{*}{ Variables } & \multicolumn{2}{|c|}{ Step 1} & \multicolumn{2}{|c|}{ Step 2} & \multicolumn{2}{|c|}{ Step 3} \\
\hline & b & $\left(\mathrm{SE}_{\mathrm{b}}\right)$ & $\mathrm{b}$ & $\left(\mathrm{SE}_{\mathrm{b}}\right)$ & $\mathrm{b}$ & $\left(\mathrm{SE}_{\mathrm{b}}\right)$ \\
\hline Constant & $5.39 * *$ & $(.31)$ & $3.91 * *$ & $(.29)$ & $5.95 * *$ & $(.29)$ \\
\hline Conscientiousness & $.13^{* *}$ & $(.05)$ & .05 & $(.05)$ & .04 & $(.05)$ \\
\hline Proactive Personality & & & $.21 * *$ & $(.05)$ & $.21 * *$ & $(.05)$ \\
\hline Structural Empowerment & & & $.19^{* *}$ & $(.05)$ & $.19 * *$ & $(.05)$ \\
\hline $\begin{array}{l}\text { Proactive Personality } \mathrm{x} \\
\text { Structural Empowerment }\end{array}$ & & & & & $-.10^{*}$ & $(.04)$ \\
\hline $\begin{array}{l}\text { Model } \mathrm{R}^{2} \\
\text { Step } \Delta \mathrm{R}^{2}\end{array}$ & $.04 * *$ & & $\begin{array}{l}.22^{* *} \\
.18^{* *} \\
\end{array}$ & & $\begin{array}{l}.24 * * \\
.02 *\end{array}$ & \\
\hline
\end{tabular}

Note. $* \mathrm{p}<.05 ; * * \mathrm{p}<.01$. 
Action Orientation 134

Table 7. Regression Analyses Testing Proactive Personality and Psychological Empowerment Interaction with Job Satisfaction

\begin{tabular}{|c|c|c|c|c|c|c|}
\hline \multirow[b]{2}{*}{ Variables } & \multicolumn{2}{|c|}{ Step 1} & \multicolumn{2}{|c|}{ Step 2} & \multicolumn{2}{|c|}{ Step 3} \\
\hline & $\mathrm{b}$ & $\left(\mathrm{SE}_{\mathrm{b}}\right)$ & $\mathrm{b}$ & $\left(\mathrm{SE}_{\mathrm{b}}\right)$ & $\mathrm{b}$ & $\left(\mathrm{SE}_{\mathrm{b}}\right)$ \\
\hline Constant & $2.49 * *$ & $(.57)$ & $3.59 * *$ & $(.47)$ & $3.69 *$ & $(.48)$ \\
\hline Core Self-Evaluations & $.57 * *$ & $(.10)$ & $.36 * *$ & $(.09)$ & $.36 * *$ & $(.09)$ \\
\hline Proactive Personality & & & -.07 & $(.08)$ & -.07 & $(.08)$ \\
\hline Psychological Empowerment & & & $.76^{* *}$ & $(.08)$ & $.75^{* *}$ & $(.08)$ \\
\hline $\begin{array}{l}\text { Proactive Personality x } \\
\text { Psychological Empowerment }\end{array}$ & & & & & -.10 & $(.07)$ \\
\hline $\begin{array}{l}\text { Model } \mathrm{R}^{2} \\
\text { Step } \Delta \mathrm{R}^{2}\end{array}$ & $.15 * *$ & & $\begin{array}{l}.47 * * \\
.32 * *\end{array}$ & & $\begin{array}{l}.47 * * \\
.01\end{array}$ & \\
\hline
\end{tabular}

Note. $* \mathrm{p}<.05 ; * * \mathrm{p}<.01$. 
Action Orientation 135

Table 8. Regression Analyses Testing Proactive Personality and Structural Empowerment Interaction with Job Satisfaction

\begin{tabular}{|c|c|c|c|c|c|c|}
\hline \multirow{2}{*}{ Variables } & \multicolumn{2}{|c|}{ Step 1} & \multicolumn{2}{|c|}{ Step 2} & \multicolumn{2}{|c|}{ Step 3} \\
\hline & b & $\left(\mathrm{SE}_{\mathrm{b}}\right)$ & $\mathrm{b}$ & $\left(\mathrm{SE}_{\mathrm{b}}\right)$ & $\mathrm{b}$ & $\left(\mathrm{SE}_{\mathrm{b}}\right)$ \\
\hline Constant & $2.49 * *$ & $(.57)$ & $3.85 * *$ & $(.58)$ & $3.85 * *$ & $(.57)$ \\
\hline Core Self-Evaluations & $.57 * *$ & $(.10)$ & $.32 * *$ & $(.10)$ & $.32 * *$ & $(.10)$ \\
\hline Proactive Personality & & & $.18^{*}$ & $(.08)$ & $.17^{*}$ & $(.08)$ \\
\hline Structural Empowerment & & & $.46^{* *}$ & $(.09)$ & $.47 * *$ & $(.09)$ \\
\hline $\begin{array}{l}\text { Proactive Personality } \mathrm{x} \\
\text { Structural Empowerment }\end{array}$ & & & & & -.12 & $(.08)$ \\
\hline $\begin{array}{l}\text { Model } \mathrm{R}^{2} \\
\text { Step } \Delta \mathrm{R}^{2}\end{array}$ & $.15 * *$ & & $\begin{array}{l}.28 * * \\
.14 * *\end{array}$ & & $\begin{array}{l}.29 * * \\
.01\end{array}$ & \\
\hline
\end{tabular}

Note. $* \mathrm{p}<.05 ; * * \mathrm{p}<.01$. 
Action Orientation 136

Table 9. Regression Analyses Testing Proactive Personality and Psychological Empowerment Interaction with Satisfaction with Quality of Care

\begin{tabular}{|c|c|c|c|c|c|c|}
\hline \multirow{2}{*}{ Variables } & \multicolumn{2}{|c|}{ Step 1} & \multicolumn{2}{|c|}{ Step 2} & \multicolumn{2}{|c|}{ Step 3} \\
\hline & b & $\left(\mathrm{SE}_{\mathrm{b}}\right)$ & b & $\left(\mathrm{SE}_{\mathrm{b}}\right)$ & b & $\left(\mathrm{SE}_{\mathrm{b}}\right)$ \\
\hline Constant & $4.69 * *$ & $(.34)$ & $5.21 * *$ & $(.33)$ & $5.34 * *$ & $(.32)$ \\
\hline Core Self-Evaluations & $.32 * *$ & $(.06)$ & $.23 * *$ & $(.06)$ & $.21 * *$ & $(.06)$ \\
\hline Proactive Personality & & & $.13^{*}$ & $(.05)$ & $.13^{*}$ & $(.05)$ \\
\hline Psychological Empowerment & & & $.20 * *$ & $(.06)$ & $.18 * *$ & $(.05)$ \\
\hline $\begin{array}{l}\text { Proactive Personality x } \\
\text { Psychological Empowerment }\end{array}$ & & & & & $-.14 * *$ & $(.05)$ \\
\hline $\begin{array}{l}\text { Model } \mathrm{R}^{2} \\
\text { Step } \Delta \mathrm{R}^{2}\end{array}$ & $.14^{* *}$ & & $\begin{array}{l}.26^{* *} \\
.13^{* *}\end{array}$ & & $\begin{array}{l}.30 * * \\
.04 * *\end{array}$ & \\
\hline
\end{tabular}

Note. $* \mathrm{p}<.05 ; * * \mathrm{p}<.01$. 
Action Orientation 137

Table 10. Regression Analyses Testing Proactive Personality and Structural Empowerment Interaction with Satisfaction with Quality of Care

\begin{tabular}{|c|c|c|c|c|c|c|}
\hline \multirow{2}{*}{ Variables } & \multicolumn{2}{|c|}{ Step 1} & \multicolumn{2}{|c|}{ Step 2} & \multicolumn{2}{|c|}{ Step 3} \\
\hline & $\mathrm{b}$ & $\left(\mathrm{SE}_{\mathrm{b}}\right)$ & $\mathrm{b}$ & $\left(\mathrm{SE}_{\mathrm{b}}\right)$ & $\mathrm{b}$ & $\left(\mathrm{SE}_{\mathrm{b}}\right)$ \\
\hline Constant & $4.69 * *$ & $(.34)$ & $5.34 * *$ & $(.35)$ & $5.33 * *$ & $(.34)$ \\
\hline Core Self-Evaluations & $.32 * *$ & $(.06)$ & $.20 * *$ & $(.06)$ & $.21 * *$ & $(.06)$ \\
\hline Proactive Personality & & & $.19 * *$ & $(.05)$ & $.18^{* *}$ & $(.05)$ \\
\hline Structural Empowerment & & & $.15^{* *}$ & $(.06)$ & $.16^{* *}$ & $(.05)$ \\
\hline $\begin{array}{l}\text { Proactive Personality } \mathrm{x} \\
\text { Structural Empowerment }\end{array}$ & & & & & $-.18 * *$ & $(.05)$ \\
\hline $\begin{array}{l}\text { Model } \mathrm{R}^{2} \\
\text { Step } \Delta \mathrm{R}^{2}\end{array}$ & $.14 * *$ & & $\begin{array}{l}.24 * * \\
.10 * * \\
\end{array}$ & & $\begin{array}{l}.30 * * \\
.06^{* *}\end{array}$ & \\
\hline
\end{tabular}

Note. $* \mathrm{p}<.05 ; * * \mathrm{p}<.01$. 
Action Orientation 138

Table 11. Regression Analyses Testing Proactive Personality and Psychological Empowerment Interaction with Stress

\begin{tabular}{|c|c|c|c|c|c|c|}
\hline \multirow{2}{*}{ Variables } & \multicolumn{2}{|c|}{ Step 1} & \multicolumn{2}{|c|}{ Step 2} & \multicolumn{2}{|c|}{ Step 3} \\
\hline & $\mathrm{b}$ & $\left(\mathrm{SE}_{\mathrm{b}}\right)$ & $\mathrm{b}$ & $\left(\mathrm{SE}_{\mathrm{b}}\right)$ & $b$ & $\left(\mathrm{SE}_{\mathrm{b}}\right)$ \\
\hline Constant & $2.95 * *$ & $(.22)$ & $2.53 * *$ & $(.25)$ & $2.53 * *$ & $(.25)$ \\
\hline Procedural Justice & $-.24 * *$ & $(.06)$ & $-.17 * *$ & $(.06)$ & $-.17 * *$ & $(.06)$ \\
\hline Distributive Justice & -.03 & $(.04)$ & -.02 & $(.04)$ & -.02 & $(.04)$ \\
\hline Proactive Personality & & & -.00 & $(.06)$ & -.00 & $(.06)$ \\
\hline Psychological Empowerment & & & $-.19 * *$ & $(.06)$ & $-.19 * *$ & $(.06)$ \\
\hline Proactive Personality $\mathrm{x}$ & & & & & .01 & $(.05)$ \\
\hline Psychological Empowerment & & & & & & \\
\hline Model $\mathrm{R}^{2}$ & $.18 * *$ & & $.23 * *$ & & $.23 * *$ & \\
\hline Step $\Delta \mathrm{R}^{2}$ & & & $.05 * *$ & & .00 & \\
\hline
\end{tabular}

Note. $* \mathrm{p}<.05 ; * * \mathrm{p}<.01$. 
Action Orientation 139

Table 12. Regression Analyses Testing Proactive Personality and Structural Empowerment Interaction with Stress

\begin{tabular}{|c|c|c|c|c|c|c|}
\hline \multirow{2}{*}{ Variables } & \multicolumn{2}{|c|}{ Step 1} & \multicolumn{2}{|c|}{ Step 2} & \multicolumn{2}{|c|}{ Step 3} \\
\hline & b & $\left(\mathrm{SE}_{\mathrm{b}}\right)$ & $\mathrm{b}$ & $\left(\mathrm{SE}_{\mathrm{b}}\right)$ & $\mathrm{b}$ & $\left(\mathrm{SE}_{\mathrm{b}}\right)$ \\
\hline Constant & $2.95 * *$ & $(.22)$ & $2.78 * *$ & $(.29)$ & $2.78 * *$ & $(.29)$ \\
\hline Procedural Justice & $-.24 * *$ & $(.06)$ & $-.22 * *$ & $(.06)$ & $-.22 * *$ & $(.06)$ \\
\hline Distributive Justice & -.03 & $(.04)$ & -.02 & $(.04)$ & -.02 & $(.04)$ \\
\hline Proactive Personality & & & -.07 & $(.05)$ & -.07 & $(.05)$ \\
\hline Structural Empowerment & & & -.05 & $(.07)$ & -.05 & $(.07)$ \\
\hline Proactive Personality x & & & & & .03 & $(.05)$ \\
\hline Structural Empowerment & & & & & & \\
\hline Model R ${ }^{2}$ & $.17 * *$ & & $.17 * *$ & & $.17 * *$ & \\
\hline Step $\Delta \mathrm{R}^{2}$ & & & .01 & & .00 & \\
\hline
\end{tabular}

Note. $* \mathrm{p}<.05 ; * * \mathrm{p}<.01$. 
Action Orientation 140

Table 13. Regression Analyses Testing Proactive Personality and Psychological Empowerment Interaction with Emotional Exhaustion

\begin{tabular}{|c|c|c|c|c|c|c|}
\hline \multirow{2}{*}{ Variables } & \multicolumn{2}{|c|}{ Step 1} & \multicolumn{2}{|c|}{ Step 2} & \multicolumn{2}{|c|}{ Step 3} \\
\hline & $\mathrm{b}$ & $\left(\mathrm{SE}_{\mathrm{b}}\right)$ & b & $\left(\mathrm{SE}_{\mathrm{b}}\right)$ & $\mathrm{b}$ & $\left(\mathrm{SE}_{\mathrm{b}}\right)$ \\
\hline Constant & $5.78 * *$ & $(.41)$ & $5.13 * *$ & $(.46)$ & $5.11 * *$ & $(.47)$ \\
\hline Procedural Justice & $-.45 * *$ & $(.11)$ & $-.34 * *$ & $(.11)$ & $-.34 * *$ & $(.11)$ \\
\hline Distributive Justice & -.04 & $(.07)$ & -.02 & $(.07)$ & -.02 & $(.07)$ \\
\hline Proactive Personality & & & .09 & $(.10)$ & .09 & $(.10)$ \\
\hline Psychological Empowerment & & & $-.33 * *$ & $(.12)$ & $-.31 * *$ & $(.12)$ \\
\hline Proactive Personality $\mathrm{x}$ & & & & & .07 & $(.09)$ \\
\hline Psychological Empowerment & & & & & & \\
\hline Model $\mathrm{R}^{2}$ & $.18 * *$ & & $.21 * *$ & & $.22 * *$ & \\
\hline Step $\Delta \mathrm{R}^{2}$ & & & $.04 *$ & & .00 & \\
\hline
\end{tabular}

Note. $* \mathrm{p}<.05 ; * * \mathrm{p}<.01$. 
Action Orientation 141

Table 14. Regression Analyses Testing Proactive Personality and Structural Empowerment Interaction with Emotional Exhaustion

\begin{tabular}{|c|c|c|c|c|c|c|}
\hline \multirow[b]{2}{*}{ Variables } & \multicolumn{2}{|c|}{ Step 1} & \multicolumn{2}{|c|}{ Step 2} & \multicolumn{2}{|c|}{ Step 3} \\
\hline & b & $\left(\mathrm{SE}_{\mathrm{b}}\right)$ & b & $\left(\mathrm{SE}_{\mathrm{b}}\right)$ & b & $\left(\mathrm{SE}_{\mathrm{b}}\right)$ \\
\hline Constant & $5.78 * *$ & $(.41)$ & $5.13 * *$ & $(.52)$ & $5.14 * *$ & $(.52)$ \\
\hline Procedural Justice & $-.45 * *$ & $(.11)$ & $-.36 * *$ & $(.12)$ & $-.36 * *$ & $(.12)$ \\
\hline Distributive Justice & -.04 & $(.07)$ & -.01 & $(.07)$ & -.01 & $(.08)$ \\
\hline Proactive Personality & & & -.01 & $(.09)$ & -.01 & $(.09)$ \\
\hline Structural Empowerment & & & $-.25 *$ & $(.13)$ & $-.25 *$ & $(.13)$ \\
\hline Proactive Personality x & & & & & -.02 & $(.09)$ \\
\hline Structural Empowerment & & & & & & \\
\hline Model R ${ }^{2}$ & $.18 * *$ & & $.20 * *$ & & $.20 * *$ & \\
\hline Step $\Delta \mathrm{R}^{2}$ & & & .02 & & .00 & \\
\hline
\end{tabular}

Note. $* \mathrm{p}<.05 ; * * \mathrm{p}<.01$. 
Action Orientation 142

Table 15. Regression Analyses Testing Proactive Personality and Psychological Empowerment Interaction with Strain

\begin{tabular}{|c|c|c|c|c|c|c|}
\hline \multirow{2}{*}{ Variables } & \multicolumn{2}{|c|}{ Step 1} & \multicolumn{2}{|c|}{ Step 2} & \multicolumn{2}{|c|}{ Step 3} \\
\hline & $\mathrm{b}$ & $\left(\mathrm{SE}_{\mathrm{b}}\right)$ & $\mathrm{b}$ & $\left(\mathrm{SE}_{\mathrm{b}}\right)$ & $\mathrm{b}$ & $\left(\mathrm{SE}_{\mathrm{b}}\right)$ \\
\hline Constant & $5.88 * *$ & $(.43)$ & $5.41 * *$ & $(.49)$ & $5.40 * *$ & $(.49)$ \\
\hline Procedural Justice & $-.41 * *$ & $(.11)$ & $-.33 *$ & $(.12)$ & $-.34 *$ & $(.12)$ \\
\hline Distributive Justice & .02 & $(.08)$ & .03 & $(.08)$ & .03 & $(.08)$ \\
\hline Proactive Personality & & & .08 & $(.11)$ & .09 & $(.11)$ \\
\hline Psychological Empowerment & & & -.24 & $(.13)$ & -.23 & $(.13)$ \\
\hline Proactive Personality $\mathrm{x}$ & & & & & .10 & $(.10)$ \\
\hline Psychological Empowerment & & & & & & \\
\hline Model $\mathrm{R}^{2}$ & $.12 * *$ & & $.13 * *$ & & $.14 * *$ & \\
\hline Step $\Delta \mathrm{R}^{2}$ & & & .02 & & .00 & \\
\hline
\end{tabular}

Note. $* \mathrm{p}<.05 ; * * \mathrm{p}<.01$. 
Action Orientation 143

Table 16. Regression Analyses Testing Proactive Personality and Structural Empowerment Interaction with Strain

\begin{tabular}{|c|c|c|c|c|c|c|}
\hline \multirow{2}{*}{ Variables } & \multicolumn{2}{|c|}{ Step 1} & \multicolumn{2}{|c|}{ Step 2} & \multicolumn{2}{|c|}{ Step 3} \\
\hline & b & $\left(\mathrm{SE}_{\mathrm{b}}\right)$ & $\mathrm{b}$ & $\left(\mathrm{SE}_{\mathrm{b}}\right)$ & $\mathrm{b}$ & $\left(\mathrm{SE}_{\mathrm{b}}\right)$ \\
\hline Constant & $5.88 * *$ & $(.43)$ & $5.52 * *$ & $(.55)$ & $5.51 * *$ & $(.55)$ \\
\hline Procedural Justice & $-.41 * *$ & $(.11)$ & $-.36 * *$ & $(.12)$ & $-.36 * *$ & $(.12)$ \\
\hline Distributive Justice & .02 & $(.08)$ & .04 & $(.08)$ & .04 & $(.08)$ \\
\hline Proactive Personality & & & .01 & $(.10)$ & -.01 & $(.10)$ \\
\hline Structural Empowerment & & & -.14 & $(.13)$ & -.15 & $(.13)$ \\
\hline Proactive Personality $\mathrm{x}$ & & & & & .02 & $(.10)$ \\
\hline Structural Empowerment & & & & & & \\
\hline Model $\mathrm{R}^{2}$ & $.12 * *$ & & $.12 * *$ & & $.12 * *$ & \\
\hline Step $\Delta \mathrm{R}^{2}$ & & & .01 & & .00 & \\
\hline
\end{tabular}

Note. $* \mathrm{p}<.05 ; * * \mathrm{p}<.01$. 
Action Orientation 144

Table 17. Regression Analyses Testing Proactive Personality and Political Skill Interaction with Task Performance

\begin{tabular}{|c|c|c|c|c|c|c|}
\hline \multirow{2}{*}{ Variables } & \multicolumn{2}{|c|}{ Step 1} & \multicolumn{2}{|c|}{ Step 2} & \multicolumn{2}{|c|}{ Step 3} \\
\hline & $\mathrm{b}$ & $\left(\mathrm{SE}_{\mathrm{b}}\right)$ & $b$ & $\left(\mathrm{SE}_{\mathrm{b}}\right)$ & b & $\left(\mathrm{SE}_{\mathrm{b}}\right)$ \\
\hline Constant & $5.84 * *$ & $(.22)$ & $6.08 * *$ & $(.20)$ & $6.24 * *$ & $(.19)$ \\
\hline Conscientiousness & $.12 * *$ & $(.04)$ & $.08 *$ & $(.03)$ & .07 & $(.03)$ \\
\hline Proactive Personality & & & $.14^{* *}$ & $(.04)$ & $.12^{*}$ & $(.04)$ \\
\hline Political Skill & & & $.19 * *$ & $(.04)$ & $.19 * *$ & $(.04)$ \\
\hline $\begin{array}{l}\text { Proactive Personality x } \\
\text { Political Skill }\end{array}$ & & & & & $-.13^{* *}$ & $(.03)$ \\
\hline Model $\mathrm{R}^{2}$ & $.04 * *$ & & $.26^{* *}$ & & $.32 * *$ & \\
\hline Step $\Delta \mathrm{R}^{2}$ & & & $.22 * *$ & & $.06 * *$ & \\
\hline
\end{tabular}

Note. $* \mathrm{p}<.05 ; * * \mathrm{p}<.01$. 
Action Orientation 145

Table 18. Regression Analyses Testing Proactive Personality and Political Skill Interaction with Perceived Effectiveness

\begin{tabular}{|c|c|c|c|c|c|c|}
\hline \multirow{2}{*}{ Variables } & \multicolumn{2}{|c|}{ Step 1} & \multicolumn{2}{|c|}{ Step 2} & \multicolumn{2}{|c|}{ Step 3} \\
\hline & $\mathrm{b}$ & $\left(\mathrm{SE}_{\mathrm{b}}\right)$ & $\mathrm{b}$ & $\left(\mathrm{SE}_{\mathrm{b}}\right)$ & b & $\left(\mathrm{SE}_{\mathrm{b}}\right)$ \\
\hline Constant & $5.39 * *$ & $(.31)$ & $5.69 * *$ & $(.29)$ & $5.78 * *$ & $(.29)$ \\
\hline Conscientiousness & $.13^{* *}$ & $(.05)$ & .08 & $(.05)$ & .07 & $(.05)$ \\
\hline Proactive Personality & & & $.13^{*}$ & $(.05)$ & .12 & $(.05)$ \\
\hline Political Skill & & & $.21 * *$ & $(.06)$ & $.20 * *$ & $(.06)$ \\
\hline $\begin{array}{l}\text { Proactive Personality x } \\
\text { Political Skill }\end{array}$ & & & & & -.06 & $(.04)$ \\
\hline Model $\mathrm{R}^{2}$ & $.04 * *$ & & $.20 * *$ & & $.21 * *$ & \\
\hline Step $\Delta \mathrm{R}^{2}$ & & & $.17 * *$ & & .01 & \\
\hline
\end{tabular}

Note. $* \mathrm{p}<.05 ; * * \mathrm{p}<.01$. 
Action Orientation 146

Table 19. Regression Analyses Testing Proactive Personality and Political Skill Interaction with Job Satisfaction

\begin{tabular}{lcccccc}
\hline \multicolumn{1}{c}{ Variables } & \multicolumn{2}{c}{ Step 1 } & \multicolumn{2}{c}{ Step 2 } & \multicolumn{2}{c}{ Step 3 } \\
& $\mathrm{b}$ & $\left(\mathrm{SE}_{\mathrm{b}}\right)$ & $\mathrm{b}$ & $\left(\mathrm{SE}_{\mathrm{b}}\right)$ & $\mathrm{b}$ & $\left(\mathrm{SE}_{\mathrm{b}}\right)$ \\
\hline Constant & $2.49^{* *}$ & $(.57)$ & $2.89^{* *}$ & $(.58)$ & $2.92^{* *}$ & $(.58)$ \\
Core Self-Evaluations & $.57^{* *}$ & $(.10)$ & $.48^{* *}$ & $(.11)$ & $.50^{* *}$ & $(.11)$ \\
& & & & & & \\
Proactive Personality & & & .12 & $(.10)$ & .16 & $(.10)$ \\
Political Skill & & & .27 & $(.11)$ & .09 & $(.11)$ \\
& & & & & & \\
Proactive Personality $\mathrm{x}$ & & & & & & \\
Political Skill & & & & & & \\
& & & & & & \\
Model $\mathrm{R}^{2}$ & $.15^{* *}$ & & $.18^{* *}$ & & .06 & \\
Step $\Delta \mathrm{R}^{2}$ & & & $.03^{* *}$ & & .00 & \\
\hline
\end{tabular}

Note. ${ }^{*} \mathrm{p}<.05 ; * * \mathrm{p}<.01$. 
Action Orientation 147

Table 20. Regression Analyses Testing Proactive Personality and Political Skill Interaction with Satisfaction with Quality of Care

\begin{tabular}{|c|c|c|c|c|c|c|}
\hline \multirow{2}{*}{ Variables } & \multicolumn{2}{|c|}{ Step 1} & \multicolumn{2}{|c|}{ Step 2} & \multicolumn{2}{|c|}{ Step 3} \\
\hline & b & $\left(\mathrm{SE}_{\mathrm{b}}\right)$ & b & $\left(\mathrm{SE}_{\mathrm{b}}\right)$ & b & $\left(\mathrm{SE}_{\mathrm{b}}\right)$ \\
\hline Constant & $4.69 * *$ & $(.34)$ & $5.10 * *$ & $(.33)$ & $5.16^{* *}$ & $(.32)$ \\
\hline Core Self-Evaluations & $.32 * *$ & $(.06)$ & $.25 * *$ & $(.06)$ & $.26 * *$ & $(.06)$ \\
\hline Proactive Personality & & & .12 & $(.06)$ & .08 & $(.06)$ \\
\hline Political Skill & & & $.17 * *$ & $(.06)$ & $.15 * *$ & $(.06)$ \\
\hline $\begin{array}{l}\text { Proactive Personality x } \\
\text { Political Skill }\end{array}$ & & & & & $-.15 * *$ & $(.04)$ \\
\hline Model $\mathrm{R}^{2}$ & $.14 * *$ & & $.24 * *$ & & $.30 * *$ & \\
\hline Step $\Delta \mathrm{R}^{2}$ & & & $.11 * *$ & & $.06 * *$ & \\
\hline
\end{tabular}

Note. $* \mathrm{p}<.05 ; * * \mathrm{p}<.01$. 
Action Orientation 148

Table 21. Regression Analyses Testing Proactive Personality and Political Skill Interaction with Stress

\begin{tabular}{|c|c|c|c|c|c|c|}
\hline \multirow{2}{*}{ Variables } & \multicolumn{2}{|c|}{ Step 1} & \multicolumn{2}{|c|}{ Step 2} & \multicolumn{2}{|c|}{ Step 3} \\
\hline & $\mathrm{b}$ & $\left(\mathrm{SE}_{\mathrm{b}}\right)$ & $\mathrm{b}$ & $\left(\mathrm{SE}_{\mathrm{b}}\right)$ & $\mathrm{b}$ & $\left(\mathrm{SE}_{\mathrm{b}}\right)$ \\
\hline Constant & $2.95 * *$ & $(.22)$ & $2.93 * *$ & $(.23)$ & $2.92 * *$ & $(.23)$ \\
\hline Procedural Justice & $-.24 * *$ & $(.06)$ & $-.24 * *$ & $(.06)$ & $-.24 * *$ & $(.06)$ \\
\hline Distributive Justice & -.03 & $(.04)$ & -.03 & $(.04)$ & -.03 & $(.04)$ \\
\hline Proactive Personality & & & -.08 & $(.06)$ & -.08 & $(.06)$ \\
\hline Political Skill & & & -.02 & $(.06)$ & .02 & $(.06)$ \\
\hline $\begin{array}{l}\text { Proactive Personality x } \\
\text { Political Skill }\end{array}$ & & & & & -.00 & $(.05)$ \\
\hline Model R ${ }^{2}$ & $.18 * *$ & & $.19^{* *}$ & & $.19^{* *}$ & \\
\hline Step $\Delta \mathrm{R}^{2}$ & & & .01 & & .00 & \\
\hline
\end{tabular}

Note. $* \mathrm{p}<.05 ; * * \mathrm{p}<.01$. 
Action Orientation 149

Table 22. Regression Analyses Testing Proactive Personality and Political Skill Interaction with Emotional Exhaustion

\begin{tabular}{|c|c|c|c|c|c|c|}
\hline \multirow{2}{*}{ Variables } & \multicolumn{2}{|c|}{ Step 1} & \multicolumn{2}{|c|}{ Step 2} & \multicolumn{2}{|c|}{ Step 3} \\
\hline & $\mathrm{b}$ & $\left(\mathrm{SE}_{\mathrm{b}}\right)$ & $\mathrm{b}$ & $\left(\mathrm{SE}_{\mathrm{b}}\right)$ & $\mathrm{b}$ & $\left(\mathrm{SE}_{\mathrm{b}}\right)$ \\
\hline Constant & $5.78 * *$ & $(.41)$ & $5.73 * *$ & $(.42)$ & $5.72 * *$ & $(.43)$ \\
\hline Procedural Justice & $-.45 * *$ & $(.11)$ & $-.44 * *$ & $(.11)$ & $-.44 * *$ & $(.11)$ \\
\hline Distributive Justice & -.04 & $(.07)$ & -.04 & $(.07)$ & -.04 & $(.07)$ \\
\hline Proactive Personality & & & .01 & $(.11)$ & -.01 & $(.11)$ \\
\hline Political Skill & & & -.05 & $(.12)$ & -.05 & $(.12)$ \\
\hline $\begin{array}{l}\text { Proactive Personality x } \\
\text { Political Skill }\end{array}$ & & & & & .00 & $(.08)$ \\
\hline Model $\mathrm{R}^{2}$ & $.18 * *$ & & $.19 * *$ & & $.19 * *$ & \\
\hline Step $\Delta \mathrm{R}^{2}$ & & & .01 & & .00 & \\
\hline
\end{tabular}

Note. $* \mathrm{p}<.05 ; * * \mathrm{p}<.01$. 
Action Orientation 150

Table 23. Regression Analyses Testing Proactive Personality and Political Skill Interaction with Strain

\begin{tabular}{|c|c|c|c|c|c|c|}
\hline \multirow{2}{*}{ Variables } & \multicolumn{2}{|c|}{ Step 1} & \multicolumn{2}{|c|}{ Step 2} & \multicolumn{2}{|c|}{ Step 3} \\
\hline & $\mathrm{b}$ & $\left(\mathrm{SE}_{\mathrm{b}}\right)$ & $\mathrm{b}$ & $\left(\mathrm{SE}_{\mathrm{b}}\right)$ & $\mathrm{b}$ & $\left(\mathrm{SE}_{\mathrm{b}}\right)$ \\
\hline Constant & $5.88 * *$ & $(.43)$ & $5.93 * *$ & $(.44)$ & $5.96 * *$ & $(.45)$ \\
\hline Procedural Justice & $-.41 * *$ & $(.11)$ & $-.42 * *$ & $(.11)$ & $-.42 * *$ & $(.11)$ \\
\hline Distributive Justice & .02 & $(.08)$ & .01 & $(.08)$ & .01 & $(.08)$ \\
\hline Proactive Personality & & & -.04 & $(.11)$ & -.05 & $(.12)$ \\
\hline Political Skill & & & .07 & $(.12)$ & .07 & $(.12)$ \\
\hline $\begin{array}{l}\text { Proactive Personality x } \\
\text { Political Skill }\end{array}$ & & & & & -.06 & $(.09)$ \\
\hline Model $\mathrm{R}^{2}$ & $.12 * *$ & & $.12 * *$ & & $.12 * *$ & \\
\hline Step $\Delta \mathrm{R}^{2}$ & & & .00 & & .00 & \\
\hline
\end{tabular}

Note. $* \mathrm{p}<.05 ; * * \mathrm{p}<.01$. 
Action Orientation 151

Table 24. Regression Analyses Testing Psychological Empowerment and Political Skill Interaction with Task Performance

\begin{tabular}{|c|c|c|c|c|c|c|}
\hline \multirow{2}{*}{ Variables } & \multicolumn{2}{|c|}{ Step 1} & \multicolumn{2}{|c|}{ Step 2} & \multicolumn{2}{|c|}{ Step 3} \\
\hline & $\mathrm{b}$ & $\left(\mathrm{SE}_{\mathrm{b}}\right)$ & $\mathrm{b}$ & $\left(\mathrm{SE}_{\mathrm{b}}\right)$ & $\mathrm{b}$ & $\left(\mathrm{SE}_{\mathrm{b}}\right)$ \\
\hline Constant & $5.84 * *$ & $(.22)$ & $6.04 * *$ & $(.20)$ & $6.12 * *$ & $(.34)$ \\
\hline Conscientiousness & $.12 * *$ & $(.04)$ & $.09 *$ & $(.03)$ & .08 & $(.03)$ \\
\hline Psychological Empowerment & & & $.11 *$ & $(.04)$ & $.10^{*}$ & $(.05)$ \\
\hline Political Skill & & & $.23 * *$ & $(.04)$ & $.23 * *$ & $(.05)$ \\
\hline $\begin{array}{l}\text { Psychological Empowerment x } \\
\text { Political Skill }\end{array}$ & & & & & -.04 & $(.03)$ \\
\hline Model $\mathrm{R}^{2}$ & $.04 * *$ & & $.25^{* *}$ & & $.25^{* *}$ & \\
\hline Step $\Delta \mathrm{R}^{2}$ & & & $.21 * *$ & & .01 & \\
\hline
\end{tabular}

Note. $* \mathrm{p}<.05 ; * * \mathrm{p}<.01$. 
Action Orientation 152

Table 25. Regression Analyses Testing Structural Empowerment and Political Skill Interaction with Task Performance

\begin{tabular}{|c|c|c|c|c|c|c|}
\hline \multirow{2}{*}{ Variables } & \multicolumn{2}{|c|}{ Step 1} & \multicolumn{2}{|c|}{ Step 2} & \multicolumn{2}{|c|}{ Step 3} \\
\hline & $\mathrm{b}$ & $\left(\mathrm{SE}_{\mathrm{b}}\right)$ & $b$ & $\left(\mathrm{SE}_{\mathrm{b}}\right)$ & $b$ & $\left(\mathrm{SE}_{\mathrm{b}}\right)$ \\
\hline Constant & $5.85 * *$ & $(.28)$ & $6.06^{* *}$ & $(.27)$ & $6.16^{* *}$ & $(.26)$ \\
\hline Conscientiousness & $.12 * *$ & $(.05)$ & .09 & $(.05)$ & .08 & $(.05)$ \\
\hline Structural Empowerment & & & .04 & $(.05)$ & .05 & $(.05)$ \\
\hline Political Skill & & & $.25 * *$ & $(.05)$ & $.24 * *$ & $(.05)$ \\
\hline $\begin{array}{l}\text { Proactive Personality x } \\
\text { Structural Empowerment }\end{array}$ & & & & & $-.11 *$ & $(.04)$ \\
\hline Model $\mathrm{R}^{2}$ & $.04 * *$ & & $.20 * *$ & & $.23 * *$ & \\
\hline Step $\Delta \mathrm{R}^{2}$ & & & $.17 * *$ & & $.03 *$ & \\
\hline
\end{tabular}

Note. $* \mathrm{p}<.05 ; * * \mathrm{p}<.01$. 
Action Orientation 153

Table 26. Regression Analyses Testing Psychological Empowerment and Political Skill Interaction with Perceived Effectiveness

\begin{tabular}{|c|c|c|c|c|c|c|}
\hline \multirow{2}{*}{ Variables } & \multicolumn{2}{|c|}{ Step 1} & \multicolumn{2}{|c|}{ Step 2} & \multicolumn{2}{|c|}{ Step 3} \\
\hline & $\mathrm{b}$ & $\left(\mathrm{SE}_{\mathrm{b}}\right)$ & $\mathrm{b}$ & $\left(\mathrm{SE}_{\mathrm{b}}\right)$ & b & $\left(\mathrm{SE}_{\mathrm{b}}\right)$ \\
\hline Constant & $5.39 * *$ & $(.31)$ & $5.68 * *$ & $(.28)$ & $5.85 * *$ & $(.30)$ \\
\hline Conscientiousness & $.13 * *$ & $(.05)$ & .08 & $(.05)$ & .06 & $(.05)$ \\
\hline Psychological Empowerment & & & $.14 * *$ & $(.05)$ & $.14^{*}$ & $(.05)$ \\
\hline Political Skill & & & $.23 * *$ & $(.05)$ & $.23 * *$ & $(.05)$ \\
\hline $\begin{array}{l}\text { Psychological Empowerment x } \\
\text { Political Skill }\end{array}$ & & & & & -.07 & $(.05)$ \\
\hline Model $\mathrm{R}^{2}$ & $.04 * *$ & & $.23 * *$ & & $.24 * *$ & \\
\hline Step $\Delta \mathrm{R}^{2}$ & & & $.19 * *$ & & .01 & \\
\hline
\end{tabular}

Note. $* \mathrm{p}<.05 ; * * \mathrm{p}<.01$. 
Action Orientation 154

Table 27. Regression Analyses Testing Structural Empowerment and Political Skill Interaction with Perceived Effectiveness

\begin{tabular}{|c|c|c|c|c|c|c|}
\hline \multirow{2}{*}{ Variables } & \multicolumn{2}{|c|}{ Step 1} & \multicolumn{2}{|c|}{ Step 2} & \multicolumn{2}{|c|}{ Step 3} \\
\hline & $\mathrm{b}$ & $\left(\mathrm{SE}_{\mathrm{b}}\right)$ & b & $\left(\mathrm{SE}_{\mathrm{b}}\right)$ & b & $\left(\mathrm{SE}_{\mathrm{b}}\right)$ \\
\hline Constant & $5.39 * *$ & $(.31)$ & $3.75^{* *}$ & $(.29)$ & $5.77 * *$ & $(.41)$ \\
\hline Conscientiousness & $.13 * *$ & $(.05)$ & .07 & $(.05)$ & .07 & $(.05)$ \\
\hline Structural Empowerment & & & $.16^{* *}$ & $(.05)$ & $.16^{* *}$ & $(.05)$ \\
\hline Political Skill & & & $.24 * *$ & $(.05)$ & $.23 * *$ & $(.05)$ \\
\hline $\begin{array}{l}\text { Structural Empowerment x } \\
\text { Political Skill }\end{array}$ & & & & & -.01 & $(.05)$ \\
\hline Model $\mathrm{R}^{2}$ & $.04 * *$ & & $.22 * *$ & & $.22 * *$ & \\
\hline Step $\Delta \mathrm{R}^{2}$ & & & $.18 * *$ & & .01 & \\
\hline
\end{tabular}

Note. $* \mathrm{p}<.05 ; * * \mathrm{p}<.01$. 
Action Orientation 155

Table 28. Regression Analyses Testing Psychological Empowerment and Political Skill Interaction with Job Satisfaction

\begin{tabular}{|c|c|c|c|c|c|c|}
\hline \multirow{2}{*}{ Variables } & \multicolumn{2}{|c|}{ Step 1} & \multicolumn{2}{|c|}{ Step 2} & \multicolumn{2}{|c|}{ Step 3} \\
\hline & $\mathrm{b}$ & $\left(\mathrm{SE}_{\mathrm{b}}\right)$ & b & $\left(\mathrm{SE}_{\mathrm{b}}\right)$ & $\mathrm{b}$ & $\left(\mathrm{SE}_{\mathrm{b}}\right)$ \\
\hline Constant & $2.49 * *$ & $(.57)$ & $3.63 * *$ & $(.47)$ & $3.61 *$ & $(.48)$ \\
\hline Core Self-Evaluations & $.57 * *$ & $(.10)$ & $.36 * *$ & $(.09)$ & $.36^{* *}$ & $(.09)$ \\
\hline Psychological Empowerment & & & $.75 * *$ & $(.08)$ & $.75 * *$ & $(.08)$ \\
\hline Political Skill & & & -.05 & $(.08)$ & -.05 & $(.08)$ \\
\hline $\begin{array}{l}\text { Psychological Empowerment x } \\
\text { Political Skill }\end{array}$ & & & & & -.05 & $(.08)$ \\
\hline $\begin{array}{l}\text { Model } \mathrm{R}^{2} \\
\text { Step } \Delta \mathrm{R}^{2}\end{array}$ & $.15^{* *}$ & & $\begin{array}{l}.46^{* *} \\
.31 * * \\
\end{array}$ & & $\begin{array}{l}.46^{* *} \\
.00\end{array}$ & \\
\hline
\end{tabular}

Note. $* \mathrm{p}<.05 ; * * \mathrm{p}<.01$. 
Action Orientation 156

Table 29. Regression Analyses Testing Structural Empowerment and Political Skill Interaction with Job Satisfaction

\begin{tabular}{|c|c|c|c|c|c|c|}
\hline \multirow{2}{*}{ Variables } & \multicolumn{2}{|c|}{ Step 1} & \multicolumn{2}{|c|}{ Step 2} & \multicolumn{2}{|c|}{ Step 3} \\
\hline & $\mathrm{b}$ & $\left(\mathrm{SE}_{\mathrm{b}}\right)$ & b & $\left(\mathrm{SE}_{\mathrm{b}}\right)$ & b & $\left(\mathrm{SE}_{\mathrm{b}}\right)$ \\
\hline Constant & $2.49 * *$ & $(.57)$ & 3.69 & $(.57)$ & 3.68 & $(.58)$ \\
\hline Core Self-Evaluations & $.57 * *$ & $(.10)$ & $.35 * *$ & $(.10)$ & $.35 * *$ & $(.10)$ \\
\hline Structural Empowerment & & & $.46 * *$ & $(.09)$ & $.46^{* *}$ & (.09) \\
\hline Political Skill & & & .10 & $(.09)$ & .09 & $(.09)$ \\
\hline $\begin{array}{l}\text { Structural Empowerment x } \\
\text { Political Skill }\end{array}$ & & & & & -.03 & $(.09)$ \\
\hline Model $\mathrm{R}^{2}$ & $.15 * *$ & & $.27 * *$ & & $.27 * *$ & \\
\hline Step $\Delta \mathrm{R}^{2}$ & & & $.12 * *$ & & .00 & \\
\hline
\end{tabular}

Note. $* \mathrm{p}<.05 ; * * \mathrm{p}<.01$. 
Action Orientation 157

Table 30. Regression Analyses Testing Psychological Empowerment and Political Skill Interaction with Satisfaction with Quality of Care

\begin{tabular}{|c|c|c|c|c|c|c|}
\hline \multirow{2}{*}{ Variables } & \multicolumn{2}{|c|}{ Step 1} & \multicolumn{2}{|c|}{ Step 2} & \multicolumn{2}{|c|}{ Step 3} \\
\hline & $\mathrm{b}$ & $\left(\mathrm{SE}_{\mathrm{b}}\right)$ & $\mathrm{b}$ & $\left(\mathrm{SE}_{\mathrm{b}}\right)$ & $\mathrm{b}$ & $\left(\mathrm{SE}_{\mathrm{b}}\right)$ \\
\hline Constant & $4.69 * *$ & $(.34)$ & $5.21 * *$ & $(.32)$ & $5.26 * *$ & $(.33)$ \\
\hline Core Self-Evaluations & $.32 * *$ & $(.06)$ & $.22 * *$ & $(.06)$ & $.22 * *$ & $(.06)$ \\
\hline Psychological Empowerment & & & $.19 * *$ & $(.05)$ & $.19 * *$ & $(.05)$ \\
\hline Political Skill & & & $.17 * *$ & $(.05)$ & $.17 * *$ & $(.05)$ \\
\hline $\begin{array}{l}\text { Psychological Empowerment x } \\
\text { Political Skill }\end{array}$ & & & & & -.04 & $(.05)$ \\
\hline Model $\mathrm{R}^{2}$ & $.14 * *$ & & $.28 * *$ & & $.28 * *$ & \\
\hline Step $\Delta \mathrm{R}^{2}$ & & & $.14 * *$ & & .01 & \\
\hline
\end{tabular}

Note. $* \mathrm{p}<.05 ; * * \mathrm{p}<.01$. 
Action Orientation 158

Table 31. Regression Analyses Testing Structural Empowerment and Political Skill Interaction with Satisfaction with Quality of Care

\begin{tabular}{|c|c|c|c|c|c|c|}
\hline \multirow{2}{*}{ Variables } & \multicolumn{2}{|c|}{ Step 1} & \multicolumn{2}{|c|}{ Step 2} & \multicolumn{2}{|c|}{ Step 3} \\
\hline & $\mathrm{b}$ & $\left(\mathrm{SE}_{\mathrm{b}}\right)$ & $b$ & $\left(\mathrm{SE}_{\mathrm{b}}\right)$ & $\mathrm{b}$ & $\left(\mathrm{SE}_{\mathrm{b}}\right)$ \\
\hline Constant & $4.69 * *$ & $(.34)$ & $5.24 * *$ & $(.34)$ & $5.24 * *$ & $(.34)$ \\
\hline Core Self-Evaluations & $.32 * *$ & $(.06)$ & $.22 * *$ & $(.06)$ & $.22 * *$ & $(.06)$ \\
\hline Structural Empowerment & & & $.13^{*}$ & $(.06)$ & $.13^{*}$ & $(.06)$ \\
\hline Political Skill & & & $.21 * *$ & $(.05)$ & $.19 * *$ & $(.05)$ \\
\hline $\begin{array}{l}\text { Structural Empowerment x } \\
\text { Political Skill }\end{array}$ & & & & & -.10 & $(.05)$ \\
\hline $\begin{array}{l}\text { Model } \mathrm{R}^{2} \\
\text { Step } \Delta \mathrm{R}^{2}\end{array}$ & $.14 * *$ & & $\begin{array}{l}.25^{* *} \\
.12^{* *} \\
\end{array}$ & & $\begin{array}{l}.26^{* *} \\
.02\end{array}$ & \\
\hline
\end{tabular}

Note. $* \mathrm{p}<.05 ; * * \mathrm{p}<.01$. 
Action Orientation 159

Table 32. Regression Analyses Testing Psychological Empowerment and Political Skill Interaction with Stress

\begin{tabular}{|c|c|c|c|c|c|c|}
\hline \multirow{2}{*}{ Variables } & \multicolumn{2}{|c|}{ Step 1} & \multicolumn{2}{|c|}{ Step 2} & \multicolumn{2}{|c|}{ Step 3} \\
\hline & $\mathrm{b}$ & $\left(\mathrm{SE}_{\mathrm{b}}\right)$ & $\mathrm{b}$ & $\left(\mathrm{SE}_{\mathrm{b}}\right)$ & $\mathrm{b}$ & $\left(\mathrm{SE}_{\mathrm{b}}\right)$ \\
\hline Constant & $2.95 * *$ & $(.22)$ & $2.54 * *$ & $(.25)$ & $2.53 * *$ & $(.25)$ \\
\hline Procedural Justice & $-.24 * *$ & $(.06)$ & $-.17 *$ & $(.06)$ & $-.16^{*}$ & $(.06)$ \\
\hline Distributive Justice & -.03 & $(.04)$ & -.02 & $(.04)$ & -.02 & $(.04)$ \\
\hline Psychological Empowerment & & & $-.20 * *$ & $(.06)$ & $-.21 * *$ & $(.06)$ \\
\hline Political Skill & & & .02 & $(.06)$ & .02 & $(.06)$ \\
\hline $\begin{array}{l}\text { Psychological Empowerment x } \\
\text { Political Skill }\end{array}$ & & & & & -.03 & $(.05)$ \\
\hline Model $\mathrm{R}^{2}$ & $.17 * *$ & & $.21 * *$ & & $.21 * *$ & \\
\hline Step $\Delta \mathrm{R}^{2}$ & & & $.05 * *$ & & .00 & \\
\hline
\end{tabular}

Note. $* \mathrm{p}<.05 ; * * \mathrm{p}<.01$. 
Action Orientation 160

Table 33. Regression Analyses Testing Structural Empowerment and Political Skill Interaction with Stress

\begin{tabular}{|c|c|c|c|c|c|c|}
\hline \multirow{2}{*}{ Variables } & \multicolumn{2}{|c|}{ Step 1} & \multicolumn{2}{|c|}{ Step 2} & \multicolumn{2}{|c|}{ Step 3} \\
\hline & $\mathrm{b}$ & $\left(\mathrm{SE}_{\mathrm{b}}\right)$ & $\mathrm{b}$ & $\left(\mathrm{SE}_{\mathrm{b}}\right)$ & $\mathrm{b}$ & $\left(\mathrm{SE}_{\mathrm{b}}\right)$ \\
\hline Constant & $2.95 * *$ & $(.22)$ & $2.78 * *$ & $(.29)$ & $2.79 * *$ & $(.29)$ \\
\hline Procedural Justice & $-.24 * *$ & $(.06)$ & $-.22 * *$ & $(.06)$ & $-.21 * *$ & $(.06)$ \\
\hline Distributive Justice & -.03 & $(.04)$ & -.02 & $(.04)$ & -.06 & $(.04)$ \\
\hline Structural Empowerment & & & -.06 & $(.07)$ & -.06 & $(.07)$ \\
\hline Political Skill & & & -.02 & $(.06)$ & -.02 & $(.06)$ \\
\hline $\begin{array}{l}\text { Structural Empowerment x } \\
\text { Political Skill }\end{array}$ & & & & & -.02 & $(.06)$ \\
\hline Model $\mathrm{R}^{2}$ & $.18 * *$ & & $.18 * *$ & & $.18 * *$ & \\
\hline Step $\Delta \mathrm{R}^{2}$ & & & .01 & & .00 & \\
\hline
\end{tabular}

Note. $* \mathrm{p}<.05 ; * * \mathrm{p}<.01$. 
Action Orientation 161

Table 34. Regression Analyses Testing Psychological Empowerment and Political Skill Interaction with Emotional Exhaustion

\begin{tabular}{lcccccc}
\hline \multicolumn{1}{c}{ Variables } & \multicolumn{2}{c}{ Step 1 } & \multicolumn{2}{c}{ Step 2 } & \multicolumn{2}{c}{ Step 3 } \\
& $\mathrm{b}$ & $\left(\mathrm{SE}_{\mathrm{b}}\right)$ & $\mathrm{b}$ & $\left(\mathrm{SE}_{\mathrm{b}}\right)$ & $\mathrm{b}$ & $\left(\mathrm{SE}_{\mathrm{b}}\right)$ \\
\hline Constant & $5.78^{* *}$ & $(.41)$ & $5.18^{* *}$ & $(.47)$ & $5.19^{* *}$ & $(.46)$ \\
& & & & & & \\
Procedural Justice & $-.45^{* *}$ & $(.11)$ & $-.35^{* *}$ & $(.11)$ & $-.35^{* *}$ & $(.11)$ \\
Distributive Justice & -.04 & $(.07)$ & -.02 & $(.07)$ & -.02 & $(.07)$ \\
& & & & & & \\
Psychological Empowerment & & & $-.29 * *$ & $(.11)$ & $-.29 * *$ & $(.11)$ \\
Political Skill & & & .02 & $(.10)$ & .02 & $(.10)$ \\
& & & & & & \\
Psychological Empowerment x & & & & & .02 & $(.09)$ \\
Political Skill & & & & & & \\
& & & & & & \\
Model $\mathrm{R}^{2}$ & $.18^{* *}$ & & $.21 * *$ & & $.21 * *$ & \\
Step $\Delta \mathrm{R}^{2}$ & & & $.03 *$ & & .00 & \\
\hline
\end{tabular}

Note. $* \mathrm{p}<.05 ; * * \mathrm{p}<.01$. 
Action Orientation 162

Table 35. Regression Analyses Testing Proactive Personality and Structural Empowerment Interaction with Emotional Exhaustion

\begin{tabular}{|c|c|c|c|c|c|c|}
\hline \multirow{2}{*}{ Variables } & \multicolumn{2}{|c|}{ Step 1} & \multicolumn{2}{|c|}{ Step 2} & \multicolumn{2}{|c|}{ Step 3} \\
\hline & $\mathrm{b}$ & $\left(\mathrm{SE}_{\mathrm{b}}\right)$ & $\mathrm{b}$ & $\left(\mathrm{SE}_{\mathrm{b}}\right)$ & $\mathrm{b}$ & $\left(\mathrm{SE}_{\mathrm{b}}\right)$ \\
\hline Constant & $5.78 * *$ & $(.41)$ & $5.12 * *$ & $(.52)$ & $5.13 * *$ & $(.52)$ \\
\hline Procedural Justice & $-.45 * *$ & $(.11)$ & $-.35 * *$ & $(.12)$ & $-.35 * *$ & $(.12)$ \\
\hline Distributive Justice & -.04 & $(.07)$ & -.01 & $(.07)$ & -.01 & $(.07)$ \\
\hline Proactive Personality & & & $-.25 *$ & $(.13)$ & -.24 & $(.13)$ \\
\hline Structural Empowerment & & & -.02 & $(.10)$ & -.04 & $(.10)$ \\
\hline Proactive Personality $\mathrm{x}$ & & & & & -.07 & $(.10)$ \\
\hline Structural Empowerment & & & & & & \\
\hline Model R ${ }^{2}$ & $.18 * *$ & & $.20 * *$ & & $.20 * *$ & \\
\hline Step $\Delta \mathrm{R}^{2}$ & & & .02 & & .00 & \\
\hline
\end{tabular}

Note. $* \mathrm{p}<.05 ; * * \mathrm{p}<.01$. 
Action Orientation 163

Table 36. Regression Analyses Testing Psychological Empowerment and Political Skill Interaction with Strain

\begin{tabular}{|c|c|c|c|c|c|c|}
\hline \multirow{2}{*}{ Variables } & \multicolumn{2}{|c|}{ Step 1} & \multicolumn{2}{|c|}{ Step 2} & \multicolumn{2}{|c|}{ Step 3} \\
\hline & $\mathrm{b}$ & $\left(\mathrm{SE}_{\mathrm{b}}\right)$ & $\mathrm{b}$ & $\left(\mathrm{SE}_{\mathrm{b}}\right)$ & $\mathrm{b}$ & $\left(\mathrm{SE}_{\mathrm{b}}\right)$ \\
\hline Constant & $5.88 * *$ & $(.43)$ & $5.49 * *$ & $(.49)$ & $5.51 * *$ & $(.49)$ \\
\hline Procedural Justice & $-.41 * *$ & $(.11)$ & $-.35 * *$ & $(.12)$ & $-.36 * *$ & $(.12)$ \\
\hline Distributive Justice & .02 & $(.08)$ & .03 & $(.08)$ & .03 & $(.08)$ \\
\hline Psychological Empowerment & & & $-.23 *$ & $(.12)$ & -.22 & $(.12)$ \\
\hline Political Skill & & & .11 & $(.11)$ & .11 & $(.11)$ \\
\hline $\begin{array}{l}\text { Psychological Empowerment x } \\
\text { Political Skill }\end{array}$ & & & & & .05 & $(.10)$ \\
\hline Model $\mathrm{R}^{2}$ & $.12 * *$ & & $.14 * *$ & & $.14 * *$ & \\
\hline Step $\Delta \mathrm{R}^{2}$ & & & .02 & & .00 & \\
\hline
\end{tabular}

Note. $* \mathrm{p}<.05 ; * * \mathrm{p}<.01$. 
Action Orientation 164

Table 37. Regression Analyses Testing Structural Empowerment and Political Skill Interaction with Strain

\begin{tabular}{|c|c|c|c|c|c|c|}
\hline \multirow{2}{*}{ Variables } & \multicolumn{2}{|c|}{ Step 1} & \multicolumn{2}{|c|}{ Step 2} & \multicolumn{2}{|c|}{ Step 3} \\
\hline & $\mathrm{b}$ & $\left(\mathrm{SE}_{\mathrm{b}}\right)$ & $\mathrm{b}$ & $\left(\mathrm{SE}_{\mathrm{b}}\right)$ & $\mathrm{b}$ & $\left(\mathrm{SE}_{\mathrm{b}}\right)$ \\
\hline Constant & $5.88 * *$ & $(.43)$ & $5.55 * *$ & $(.55)$ & $5.54 * *$ & $(.55)$ \\
\hline Procedural Justice & $-.41 * *$ & $(.11)$ & $-.37 * *$ & $(.12)$ & $-.36 * *$ & $(.12)$ \\
\hline Distributive Justice & .02 & $(.08)$ & .04 & $(.08)$ & .04 & $(.08)$ \\
\hline Structural Empowerment & & & -.16 & $(.13)$ & -.16 & $(.13)$ \\
\hline Political Skill & & & .07 & $(.11)$ & -.07 & $(.11)$ \\
\hline $\begin{array}{l}\text { Structural Empowerment x } \\
\text { Political Skill }\end{array}$ & & & & & .02 & $(.10)$ \\
\hline Model $\mathrm{R}^{2}$ & $.12 * *$ & & $.12 * *$ & & $.12 * *$ & \\
\hline Step $\Delta \mathrm{R}^{2}$ & & & .01 & & .00 & \\
\hline
\end{tabular}

Note. $* \mathrm{p}<.05 ; * * \mathrm{p}<.01$. 
Action Orientation 165

Table 38. Summary Table of Observed Significant Main Effects and Interactions

\begin{tabular}{|c|c|c|c|c|c|c|c|}
\hline \multirow{2}{*}{$\begin{array}{c}\text { Main Effects } \\
\& \\
\text { Interactions }{ }^{1}\end{array}$} & \multicolumn{7}{|c|}{ Dependent Variables } \\
\hline & Perform & Effect & Job Sat & $\begin{array}{l}\text { Satisfaction } \\
\text { with } Q \text { of } C\end{array}$ & Stress & Strain & $\begin{array}{r}\text { Emotional } \\
\text { Exhaustion }\end{array}$ \\
\hline $\begin{array}{l}\text { Proactive } \\
\text { Personality }\end{array}$ & $\mathrm{X}$ & $\mathrm{X}$ & $\mathrm{X}$ & $\mathrm{X}$ & & & \\
\hline $\begin{array}{l}\text { Psychological } \\
\text { Empowerment }\end{array}$ & $\mathrm{X}$ & $\mathrm{X}$ & $\mathrm{X}$ & $\mathrm{X}$ & $\mathrm{X}$ & $\mathrm{X}$ & $\mathrm{X}$ \\
\hline $\begin{array}{l}\text { Structural } \\
\text { Empowerment }\end{array}$ & $\mathrm{X}$ & $\mathrm{X}$ & $\mathrm{X}$ & $\mathrm{X}$ & $\mathrm{X}$ & $X$ & $X$ \\
\hline Political Skill & $\mathrm{X}$ & $\mathrm{X}$ & $\mathrm{X}$ & $\mathrm{X}$ & & & $X$ \\
\hline $\begin{array}{l}\text { Proactive } \\
\text { Personality x } \\
\text { Psychological } \\
\text { Empowerment }\end{array}$ & X; H1 & $\mathrm{X}$ & $\mathrm{H} 2$ & $X$ & H3 & $\mathrm{H} 4$ & \\
\hline $\begin{array}{l}\text { Proactive } \\
\text { Personality x } \\
\text { Structural } \\
\text { Empowerment }\end{array}$ & X; H1 & $\mathrm{X}$ & $\mathrm{H} 2$ & $X$ & $\mathrm{H} 3$ & H4 & \\
\hline $\begin{array}{l}\text { Proactive } \\
\text { Personality x } \\
\text { Political Skill } \\
\end{array}$ & X; H5 & & H6 & $\mathrm{X}$ & $\mathrm{H} 7$ & $\mathrm{H} 8$ & \\
\hline $\begin{array}{l}\text { Psychological } \\
\text { Empowerment } \\
\text { x Political } \\
\text { Skill }\end{array}$ & H9 & & H10 & & H11 & H12 & \\
\hline $\begin{array}{l}\text { Structural } \\
\text { Empowerment } \\
\text { x Political } \\
\text { Skill } \\
\end{array}$ & X; H9 & & H10 & & H11 & H12 & \\
\hline
\end{tabular}

\footnotetext{
${ }^{1}$ Main Effects were derived from the correlation analysis, while the interaction summaries are derived from the regression analysis. The results were significant, but not consistent with hypothesized relationships; Perform $=$ Performance; Effect $=$ Effectiveness; Job Sat $=$ Job Satisfaction; Satisfaction with $\mathrm{Q}$ of $\mathrm{C}=$ Satisfaction with Quality of Care.
} 
Action Orientation 166

Table 39. Regression Analyses Testing Proactive Personality, Structural Empowerment, and Political Skill Interaction with Job Task Performance

\begin{tabular}{|c|c|c|c|c|c|c|c|c|}
\hline \multirow{2}{*}{ Variables } & \multicolumn{2}{|c|}{ Step 1} & \multicolumn{2}{|c|}{ Step 2} & \multicolumn{2}{|c|}{ Step 3} & \multicolumn{2}{|c|}{ Step 4} \\
\hline & $\mathrm{b}$ & $\left(\mathrm{SE}_{\mathrm{b}}\right)$ & $\mathrm{b}$ & $\left(\mathrm{SE}_{\mathrm{b}}\right)$ & $\mathrm{b}$ & $\left(\mathrm{SE}_{\mathrm{b}}\right)$ & $\mathrm{b}$ & $\left(\mathrm{SE}_{\mathrm{b}}\right)$ \\
\hline Constant & $5.85 * *$ & $(.28)$ & $6.23 * *$ & $(.26)$ & $6.49 * *$ & $(.25)$ & $6.48 * *$ & $(.24)$ \\
\hline $\begin{array}{l}\text { Conscien- } \\
\text { tiousness }\end{array}$ & $.12 * *$ & $(.05)$ & .06 & $(.05)$ & .04 & $(.04)$ & .03 & $(.04)$ \\
\hline $\begin{array}{l}\text { Proactive } \\
\text { Personality } \\
\text { (PP) }\end{array}$ & & & $.18 * *$ & $(.05)$ & $.15^{* *}$ & $(.05)$ & $.14 * *$ & $(.05)$ \\
\hline $\begin{array}{l}\text { Structural } \\
\text { Empowerment } \\
\text { (Str Emp) }\end{array}$ & & & .04 & $(.04)$ & .04 & $(.04)$ & -.02 & $(.05)$ \\
\hline $\begin{array}{l}\text { Political Skill } \\
\text { (PS) }\end{array}$ & & & $.16^{* *}$ & $(.05)$ & $.14 * *$ & $(.05)$ & $.11 *$ & $(.08)$ \\
\hline PP x Str Emp & & & & & -.04 & $(.05)$ & -.03 & $(.05)$ \\
\hline PP x PS & & & & & $-.16^{* *}$ & $(.04)$ & $-.11 * *$ & $(.04)$ \\
\hline Str Emp x PS & & & & & -.01 & $(.05)$ & .04 & $(.05)$ \\
\hline $\begin{array}{l}\text { PP x PS x Str } \\
\text { Emp }\end{array}$ & & & & & & & $.10 * *$ & $(.04)$ \\
\hline $\begin{array}{l}\text { Model } \mathrm{R}^{2} \\
\text { Step } \Delta \mathrm{R}^{2}\end{array}$ & $.04 * *$ & & $\begin{array}{l}.27 * * \\
.23 * *\end{array}$ & & $\begin{array}{l}.38^{* *} \\
.11^{* *}\end{array}$ & & $\begin{array}{l}.40 * * \\
.02 * *\end{array}$ & \\
\hline
\end{tabular}

Note. $* \mathrm{p}<.05 ; * * \mathrm{p}<.01$. 
Action Orientation 167

Table 40. Regression Analyses Testing Proactive Personality, Structural Empowerment, and Political Skill Interaction with Satisfaction with Quality of Care

\begin{tabular}{|c|c|c|c|c|c|c|c|c|}
\hline \multirow{2}{*}{ Variables } & \multicolumn{2}{|c|}{ Step 1} & \multicolumn{2}{|c|}{ Step 2} & \multicolumn{2}{|c|}{ Step 3} & \multicolumn{2}{|c|}{ Step 4} \\
\hline & $\mathrm{b}$ & $\left(\mathrm{SE}_{\mathrm{b}}\right)$ & $\mathrm{b}$ & $\left(\mathrm{SE}_{\mathrm{b}}\right)$ & $\mathrm{b}$ & $\left(\mathrm{SE}_{\mathrm{b}}\right)$ & $\mathrm{b}$ & $\left(\mathrm{SE}_{\mathrm{b}}\right)$ \\
\hline Constant & $4.69 * *$ & $(.34)$ & $5.36 * *$ & $(.34)$ & $5.39 * *$ & $(.33)$ & $5.22 * *$ & $(.33)$ \\
\hline $\begin{array}{l}\text { Core Self- } \\
\text { Evaluations }\end{array}$ & $.32 * *$ & $(.06)$ & $.20 * *$ & $(.06)$ & $.21 * *$ & $(.06)$ & $.24 * *$ & $(.06)$ \\
\hline $\begin{array}{l}\text { Proactive } \\
\text { Personality } \\
\text { (PP) }\end{array}$ & & & $.12 *$ & $(.06)$ & .09 & $(.06)$ & .08 & $(.06)$ \\
\hline $\begin{array}{l}\text { Psychological } \\
\text { Empowerment } \\
\text { (Psyc Emp) }\end{array}$ & & & $.13^{*}$ & $(.06)$ & $.13^{*}$ & $(.05)$ & .06 & $(.06)$ \\
\hline $\begin{array}{l}\text { Political Skill } \\
\text { (PS) }\end{array}$ & & & $.15^{*}$ & $(.06)$ & $.13^{*}$ & $(.06)$ & .10 & $(.06)$ \\
\hline $\begin{array}{l}\text { PP x Psyc } \\
\text { Emp }\end{array}$ & & & & & $-.13 *$ & $(.06)$ & $-.12 *$ & $(.06)$ \\
\hline $\begin{array}{l}\text { PP x PS } \\
\text { Psyc Emp x } \\
\text { PS }\end{array}$ & & & & & $\begin{array}{l}-.11 * \\
.04\end{array}$ & $\begin{array}{l}(.05) \\
(.06)\end{array}$ & $\begin{array}{l}-.06 \\
.01\end{array}$ & $\begin{array}{l}(.05) \\
(.06)\end{array}$ \\
\hline $\begin{array}{l}\text { PP x PS x } \\
\text { Psyc Emp }\end{array}$ & & & & & & & $.11 *$ & $(.05)$ \\
\hline $\begin{array}{l}\text { Model } \mathrm{R}^{2} \\
\text { Step } \Delta \mathrm{R}^{2}\end{array}$ & $.14 * *$ & & $\begin{array}{l}.27 * * \\
.13 * *\end{array}$ & & $\begin{array}{l}.34^{* *} \\
.08^{* *}\end{array}$ & & $\begin{array}{l}.36 * * \\
.02 *\end{array}$ & \\
\hline
\end{tabular}

Note. $* \mathrm{p}<.05 ; * * \mathrm{p}<.01$. 
Action Orientation 168

Table 41. Regression Analyses Testing Proactive Personality, Political Skill, with Decision-Making Autonomy Interaction with Job Task Performance

\begin{tabular}{|c|c|c|c|c|c|c|c|c|}
\hline \multirow{2}{*}{ Variables } & \multicolumn{2}{|c|}{ Step 1} & \multicolumn{2}{|c|}{ Step 2} & \multicolumn{2}{|c|}{ Step 3} & \multicolumn{2}{|c|}{ Step 4} \\
\hline & $\mathrm{b}$ & $\left(\mathrm{SE}_{\mathrm{b}}\right)$ & $\mathrm{b}$ & $\left(\mathrm{SE}_{\mathrm{b}}\right)$ & $\mathrm{b}$ & $\left(\mathrm{SE}_{\mathrm{b}}\right)$ & $\mathrm{b}$ & $\left(\mathrm{SE}_{\mathrm{b}}\right)$ \\
\hline Constant & $5.85^{* *}$ & $(.28)$ & $4.91 * *$ & $(.46)$ & $5.35 * *$ & $(.43)$ & $5.35 * *$ & (.42) \\
\hline $\begin{array}{l}\text { Core Self- } \\
\text { Evaluations }\end{array}$ & $.12 * *$ & $(.05)$ & .07 & $(.04)$ & .05 & $(.04)$ & .04 & $(.04)$ \\
\hline $\begin{array}{l}\text { Proactive } \\
\text { Personality } \\
\text { (PP) }\end{array}$ & & & $.19 * *$ & $(.05)$ & $.14^{*}$ & $(.05)$ & $.16 * *$ & $(.05)$ \\
\hline $\begin{array}{l}\text { Political Skill } \\
\text { (PS) }\end{array}$ & & & $.23 * *$ & $(.07)$ & $.18 * *$ & $(.06)$ & $.20 * *$ & $(.06)$ \\
\hline $\begin{array}{l}\text { Decision } \\
\text { Making } \\
\text { Autonomy } \\
\text { (DM Aut) }\end{array}$ & & & -.02 & $(.04)$ & .00 & $(.04)$ & .03 & $(.03)$ \\
\hline$P P \times P S$ & & & & & $-.19 * *$ & $(.03)$ & $-.19 * *$ & $(.04)$ \\
\hline PP x DM Aut & & & & & .07 & $(.05)$ & .03 & $(.05)$ \\
\hline PS x DM Aut & & & & & .02 & $(.05)$ & .02 & $(.05)$ \\
\hline $\begin{array}{l}\text { PP x DM Aut } \\
x \text { PS }\end{array}$ & & & & & & & $-.09 *$ & $(.04)$ \\
\hline Model $\mathrm{R}^{2}$ & $.04 * *$ & & $.27 * *$ & & $.39 * *$ & & $.41 * *$ & \\
\hline Step $\Delta \mathrm{R}^{2}$ & & & $.24 * *$ & & $.12 * *$ & & $.02 *$ & \\
\hline
\end{tabular}

Note. $* \mathrm{p}<.05 ; * * \mathrm{p}<.01$. 
Action Orientation 169

Table 42. Regression Analyses Testing Proactive Personality, Structural Empowerment, with Decision-Making Autonomy Interaction with Job Satisfaction

\begin{tabular}{|c|c|c|c|c|c|c|c|c|}
\hline \multirow{2}{*}{ Variables } & \multicolumn{2}{|c|}{ Step 1} & \multicolumn{2}{|c|}{ Step 2} & \multicolumn{2}{|c|}{ Step 3} & \multicolumn{2}{|c|}{ Step 4} \\
\hline & $\mathrm{b}$ & $\left(\mathrm{SE}_{\mathrm{b}}\right)$ & $\mathrm{b}$ & $\left(\mathrm{SE}_{\mathrm{b}}\right)$ & $\mathrm{b}$ & $\left(\mathrm{SE}_{\mathrm{b}}\right)$ & $\mathrm{b}$ & $\left(\mathrm{SE}_{\mathrm{b}}\right)$ \\
\hline Constant & $2.49 * *$ & $(.57)$ & 4.22 & $(.56)$ & 4.33 & $(.57)$ & 4.18 & $(.57)$ \\
\hline $\begin{array}{l}\text { Core Self- } \\
\text { Evaluations }\end{array}$ & $.57 * *$ & $(.10)$ & $.23 *$ & $(.10)$ & $.25^{*}$ & $(.10)$ & $.28 * *$ & $(.10)$ \\
\hline $\begin{array}{l}\text { Proactive } \\
\text { Personality } \\
\text { (PP) }\end{array}$ & & & $.18^{*}$ & $(.08)$ & $.17^{*}$ & $(.08)$ & .08 & $(.11)$ \\
\hline $\begin{array}{l}\text { Structural } \\
\text { Empowerment } \\
\text { (Str Emp) }\end{array}$ & & & $.33 * *$ & $(.10)$ & $.39 * *$ & $(.10)$ & $.32 * *$ & $(.10)$ \\
\hline $\begin{array}{l}\text { Decision } \\
\text { Making } \\
\text { Autonomy } \\
\text { (DM Aut) }\end{array}$ & & & $.36 * *$ & $(.09)$ & $.27 * *$ & $(.10)$ & $.27 * *$ & $(.10)$ \\
\hline $\begin{array}{l}\text { PP x Str Emp } \\
\text { PP x DM Aut } \\
\text { Str Emp x DM } \\
\text { Aut }\end{array}$ & & & & & $\begin{array}{r}-.09 \\
.08 \\
.18\end{array}$ & $\begin{array}{l}(.09) \\
(.09) \\
(.10)\end{array}$ & $\begin{array}{r}-.17 \\
.18 \\
-.16\end{array}$ & $\begin{array}{l}(.09) \\
(.11) \\
(.10)\end{array}$ \\
\hline $\begin{array}{l}\text { PP x DM Aut } \\
\text { x Str Emp }\end{array}$ & & & & & & & $.21 *$ & $(.10)$ \\
\hline $\begin{array}{l}\text { Model } \mathrm{R}^{2} \\
\text { Step } \Delta \mathrm{R}^{2}\end{array}$ & $.15 * *$ & & $\begin{array}{l}.34 * * \\
.19 * *\end{array}$ & & $\begin{array}{l}.36 * * \\
.02\end{array}$ & & $\begin{array}{r}.38 * * \\
.02 *\end{array}$ & \\
\hline
\end{tabular}

Note. $* \mathrm{p}<.05 ; * * \mathrm{p}<.01$. 
Action Orientation 170

Table 43. Regression Analyses Testing Proactive Personality, Political Skill, with Decision-Making Autonomy Interaction with Job Satisfaction

\begin{tabular}{|c|c|c|c|c|c|c|c|c|}
\hline \multirow{2}{*}{ Variables } & \multicolumn{2}{|c|}{ Step 1} & \multicolumn{2}{|c|}{ Step 2} & \multicolumn{2}{|c|}{ Step 3} & \multicolumn{2}{|c|}{ Step 4} \\
\hline & $\mathrm{b}$ & $\left(\mathrm{SE}_{\mathrm{b}}\right)$ & $\mathrm{b}$ & $\left(\mathrm{SE}_{\mathrm{b}}\right)$ & $\mathrm{b}$ & $\left(\mathrm{SE}_{\mathrm{b}}\right)$ & $\mathrm{b}$ & $\left(\mathrm{SE}_{\mathrm{b}}\right)$ \\
\hline Constant & $2.49 * *$ & $(.57)$ & $3.89 * *$ & $(.57)$ & $3.90 * *$ & $(.58)$ & $3.58 * *$ & $(.59)$ \\
\hline $\begin{array}{l}\text { Core Self- } \\
\text { Evaluations }\end{array}$ & $.57 * *$ & $(.10)$ & $.31 * *$ & $(.10)$ & $.32 * *$ & $(.11)$ & $.38 * *$ & $(.11)$ \\
\hline $\begin{array}{l}\text { Proactive } \\
\text { Personality } \\
\text { (PP) }\end{array}$ & & & $.19 *$ & $(.10)$ & .16 & $(.10)$ & .10 & $(.10)$ \\
\hline $\begin{array}{l}\text { Political Skill } \\
\text { (PS) }\end{array}$ & & & .03 & $(.10)$ & .02 & $(.10)$ & -.01 & $(.10)$ \\
\hline $\begin{array}{l}\text { Decision } \\
\text { Making } \\
\text { Autonomy } \\
\text { (DM Aut) }\end{array}$ & & & $.48 * *$ & (.09) & $.48 * *$ & $(.00)$ & $.39 * *$ & $(.10)$ \\
\hline $\begin{array}{l}\text { PP } \times \text { PS } \\
\text { PP x DM Aut } \\
\text { PS x DM Aut }\end{array}$ & & & & & $\begin{array}{r}-.08 \\
.04 \\
-.01\end{array}$ & $\begin{array}{l}(.08) \\
(.10) \\
(.10)\end{array}$ & $\begin{array}{r}-.11 \\
.15 \\
-.01\end{array}$ & $\begin{array}{l}(.07) \\
(.11) \\
(.10)\end{array}$ \\
\hline $\begin{array}{l}\text { PP x DM Aut } \\
x \text { PS }\end{array}$ & & & & & & & $.22 * *$ & $(.09)$ \\
\hline $\begin{array}{l}\text { Model } \mathrm{R}^{2} \\
\text { Step } \Delta \mathrm{R}^{2}\end{array}$ & $.15^{* *}$ & & $\begin{array}{l}.30^{* *} \\
.15^{* *}\end{array}$ & & $\begin{array}{l}.30 * * \\
.01\end{array}$ & & $\begin{array}{l}.33 * * \\
.03 * *\end{array}$ & \\
\hline
\end{tabular}

Note. $* \mathrm{p}<.05 ; * * \mathrm{p}<.01$. 
Action Orientation 171

Table 44. Regression Analyses Testing Proactive Personality, Structural Empowerment, and Work-Methods Autonomy Interaction with Emotional Exhaustion

\begin{tabular}{|c|c|c|c|c|c|c|c|c|}
\hline \multirow{2}{*}{ Variables } & \multicolumn{2}{|c|}{ Step 1} & \multicolumn{2}{|c|}{ Step 2} & \multicolumn{2}{|c|}{ Step 3} & \multicolumn{2}{|c|}{ Step 4} \\
\hline & $\mathrm{b}$ & $\left(\mathrm{SE}_{\mathrm{b}}\right)$ & $\mathrm{b}$ & $\left(\mathrm{SE}_{\mathrm{b}}\right)$ & $\mathrm{b}$ & $\left(\mathrm{SE}_{\mathrm{b}}\right)$ & $\mathrm{b}$ & $\left(\mathrm{SE}_{\mathrm{b}}\right)$ \\
\hline Constant & $5.78 * *$ & $(.41)$ & $5.12 * *$ & $(.55)$ & $4.99 * *$ & $(.56)$ & $4.99 * *$ & $(.56)$ \\
\hline $\begin{array}{l}\text { Procedural } \\
\text { Justice }\end{array}$ & $-.45 * *$ & $(.11)$ & $-.35 * *$ & $(.12)$ & $-.33 * *$ & $(.12)$ & $-.34 * *$ & $(.12)$ \\
\hline $\begin{array}{l}\text { Distributive } \\
\text { Justice }\end{array}$ & -.04 & $(.07)$ & -.01 & $(.07)$ & -.01 & $(.08)$ & -.00 & $(.07)$ \\
\hline $\begin{array}{l}\text { Proactive } \\
\text { Personality } \\
\text { (PP) }\end{array}$ & & & -.00 & $(.10)$ & .00 & $(.10)$ & .07 & $(.10)$ \\
\hline $\begin{array}{l}\text { Structural } \\
\text { Empowerment } \\
\text { (Str Emp) }\end{array}$ & & & $-.25^{*}$ & $(.13)$ & $-.28 *$ & $(.13)$ & -.21 & $(.13)$ \\
\hline $\begin{array}{l}\text { Work } \\
\text { Methods } \\
\text { Autonomy } \\
\text { (WM Aut) }\end{array}$ & & & -.01 & $(.11)$ & .00 & $(.11)$ & .06 & $(.11)$ \\
\hline $\begin{array}{l}\text { Str Emp x PP } \\
\text { PP x WM Aut } \\
\text { WM Aut x Str } \\
\text { Emp }\end{array}$ & & & & & $\begin{array}{r}-.04 \\
-.08 \\
.12\end{array}$ & $\begin{array}{l}(.10) \\
(.10) \\
(.11)\end{array}$ & $\begin{array}{r}.02 \\
-.17 \\
.12\end{array}$ & $\begin{array}{l}(.10) \\
(.11) \\
(.11)\end{array}$ \\
\hline $\begin{array}{l}\text { Str Emp x } \\
\text { WM Aut x PP }\end{array}$ & & & & & & & $-.24^{*}$ & $(.10)$ \\
\hline $\begin{array}{l}\text { Model } \mathrm{R}^{2} \\
\text { Step } \Delta \mathrm{R}^{2}\end{array}$ & $.18 * *$ & & $\begin{array}{l}.20 * * \\
.02\end{array}$ & & $\begin{array}{l}.20 * * \\
.01\end{array}$ & & $\begin{array}{l}.23 * * \\
.03 *\end{array}$ & \\
\hline
\end{tabular}

Note. $* \mathrm{p}<.05 ; * * \mathrm{p}<.01$. 
Action Orientation 172

Table 45. Regression Analyses Testing Proactive Personality, Psychological

Empowerment, and Work-Methods Autonomy Interaction with Emotional Exhaustion

\begin{tabular}{|c|c|c|c|c|c|c|c|c|}
\hline \multirow{2}{*}{ Variables } & \multicolumn{2}{|c|}{ Step 1} & \multicolumn{2}{|c|}{ Step 2} & \multicolumn{2}{|c|}{ Step 3} & \multicolumn{2}{|c|}{ Step 4} \\
\hline & $\mathrm{b}$ & $\left(\mathrm{SE}_{\mathrm{b}}\right)$ & $\mathrm{b}$ & $\left(\mathrm{SE}_{\mathrm{b}}\right)$ & $\mathrm{b}$ & $\left(\mathrm{SE}_{\mathrm{b}}\right)$ & $\mathrm{b}$ & $\left(\mathrm{SE}_{\mathrm{b}}\right)$ \\
\hline Constant & $5.78 * *$ & $(.41)$ & $5.23 * *$ & $(.46)$ & $5.37 * *$ & $(.47)$ & $5.34 * *$ & $(.46)$ \\
\hline $\begin{array}{l}\text { Procedural } \\
\text { Justice }\end{array}$ & $-.45 * *$ & $(.11)$ & $-.35 * *$ & $(.11)$ & $-.38 * *$ & $(.11)$ & $-.38 * *$ & $(.11)$ \\
\hline $\begin{array}{l}\text { Distributive } \\
\text { Justice }\end{array}$ & -.04 & $(.07)$ & -.03 & $(.07)$ & -.01 & $(.07)$ & -.01 & $(.07)$ \\
\hline $\begin{array}{l}\text { Proactive } \\
\text { Personality } \\
\text { (PP) }\end{array}$ & & & .10 & $(.10)$ & .15 & $(.10)$ & $.27 *$ & $(.17)$ \\
\hline $\begin{array}{l}\text { Psychological } \\
\text { Empowerment } \\
\text { (Psy Emp) }\end{array}$ & & & $-.56 * *$ & $(.16)$ & $-.54 * *$ & $(.17)$ & $-.46^{* *}$ & $(.16)$ \\
\hline $\begin{array}{l}\text { Work } \\
\text { Methods } \\
\text { Autonomy } \\
\text { (WM Aut) }\end{array}$ & & & .32 & $(.14)$ & .15 & $(.16)$ & .12 & $(.16)$ \\
\hline $\begin{array}{l}\text { Psy Emp x PP } \\
\text { PP x WM Aut } \\
\text { WM Aut x } \\
\text { Psy Emp }\end{array}$ & & & & & $\begin{array}{r}.21 \\
-.12 \\
-.18\end{array}$ & $\begin{array}{l}(.14) \\
(.14) \\
(.09)\end{array}$ & $\begin{array}{r}.17 \\
-.21 \\
-.27\end{array}$ & $\begin{array}{l}(.14) \\
(.16) \\
(.09)\end{array}$ \\
\hline $\begin{array}{l}\text { Psy Emp x } \\
\text { WM Aut x PP }\end{array}$ & & & & & & & $-.19 *$ & $(.09)$ \\
\hline $\begin{array}{l}\text { Model } \mathrm{R}^{2} \\
\text { Step } \Delta \mathrm{R}^{2}\end{array}$ & $.18 * *$ & & $\begin{array}{l}.24 * * \\
.06 * *\end{array}$ & & $\begin{array}{l}.26 * * \\
.02\end{array}$ & & $\begin{array}{l}.28 * * \\
.02 *\end{array}$ & \\
\hline
\end{tabular}

Note. $* \mathrm{p}<.05 ; * * \mathrm{p}<.01$. 
Action Orientation 173

Table 46. Regression Analyses Testing Proactive Personality, Psychological

Empowerment, and Work-Methods Autonomy Interaction with Strain

\begin{tabular}{|c|c|c|c|c|c|c|c|c|}
\hline \multirow{2}{*}{ Variables } & \multicolumn{2}{|c|}{ Step 1} & \multicolumn{2}{|c|}{ Step 2} & \multicolumn{2}{|c|}{ Step 3} & \multicolumn{2}{|c|}{ Step 4} \\
\hline & $\mathrm{b}$ & $\left(\mathrm{SE}_{\mathrm{b}}\right)$ & $\mathrm{b}$ & $\left(\mathrm{SE}_{\mathrm{b}}\right)$ & $\mathrm{b}$ & $\left(\mathrm{SE}_{\mathrm{b}}\right)$ & $\mathrm{b}$ & $\left(\mathrm{SE}_{\mathrm{b}}\right)$ \\
\hline Constant & $5.88 * *$ & $(.43)$ & $5.43 * *$ & $(.50)$ & $5.45 * *$ & $(.51)$ & $5.41 * *$ & $(.50)$ \\
\hline $\begin{array}{l}\text { Procedural } \\
\text { Justice }\end{array}$ & $-.41 * *$ & $(.11)$ & $-.33 * *$ & $(.12)$ & $-.35^{* *}$ & $(.12)$ & $-.34 * *$ & $(.12)$ \\
\hline $\begin{array}{l}\text { Distributive } \\
\text { Justice }\end{array}$ & .02 & $(.08)$ & .03 & $(.08)$ & .03 & $(.08)$ & .04 & $(.08)$ \\
\hline $\begin{array}{l}\text { Proactive } \\
\text { Personality } \\
\text { (PP) }\end{array}$ & & & .09 & $(.11)$ & .10 & $(.11)$ & $.26^{*}$ & $(.13)$ \\
\hline $\begin{array}{l}\text { Psychological } \\
\text { Empowerment } \\
\text { (Psy Emp) }\end{array}$ & & & -.27 & $(.17)$ & -.24 & $(.18)$ & -.13 & $(.18)$ \\
\hline $\begin{array}{l}\text { Work } \\
\text { Methods } \\
\text { Autonomy } \\
\text { (WM Aut) }\end{array}$ & & & .04 & $(.15)$ & -.01 & $(.18)$ & .01 & $(.18)$ \\
\hline $\begin{array}{l}\text { Psy Emp x PP } \\
\text { PP x WM Aut } \\
\text { WM Aut x } \\
\text { Psy Emp }\end{array}$ & & & & & $\begin{array}{r}.14 \\
-.07 \\
-.04\end{array}$ & $\begin{array}{l}(.15) \\
(.15) \\
(.10)\end{array}$ & $\begin{array}{r}.14 \\
-.28 \\
.00\end{array}$ & $\begin{array}{l}(.15) \\
(.17) \\
(.10)\end{array}$ \\
\hline $\begin{array}{l}\text { Psy Emp x } \\
\text { WM Aut x PP }\end{array}$ & & & & & & & $-.25 * *$ & $(.10)$ \\
\hline $\begin{array}{l}\text { Model } \mathrm{R}^{2} \\
\text { Step } \Delta \mathrm{R}^{2}\end{array}$ & $.12 * *$ & & $\begin{array}{l}.14 * * \\
.02\end{array}$ & & $\begin{array}{l}.14^{* *} \\
.01\end{array}$ & & $\begin{array}{l}.17 * * \\
.03 * *\end{array}$ & \\
\hline
\end{tabular}

Note. $* \mathrm{p}<.05 ; * * \mathrm{p}<.01$. 
Figure 1. Model of Relationships between Proactive Personality, Empowerment and Political Skill

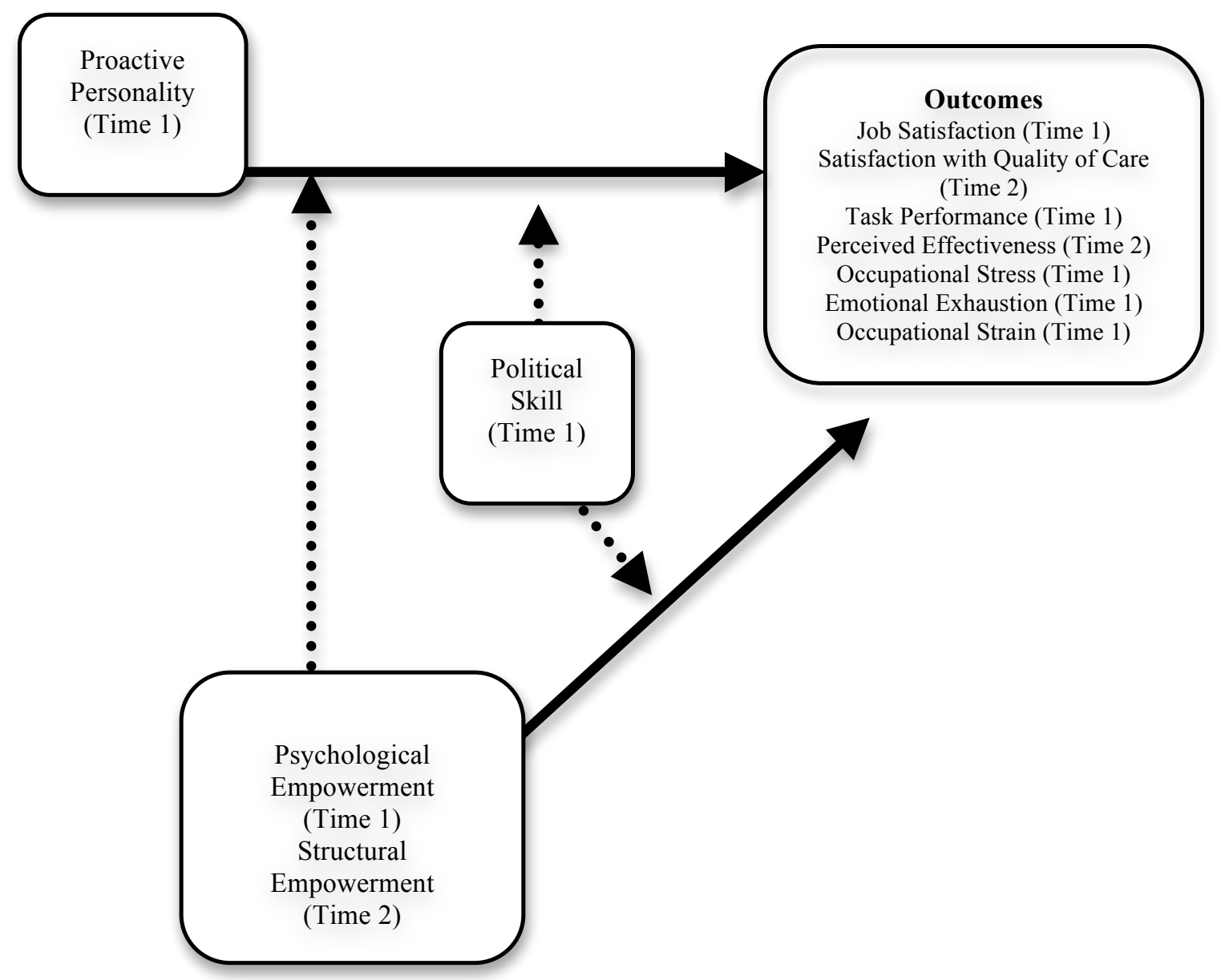


Figure 2. Model of Empowerment as Moderator of Proactive Personality-Outcome Relationships

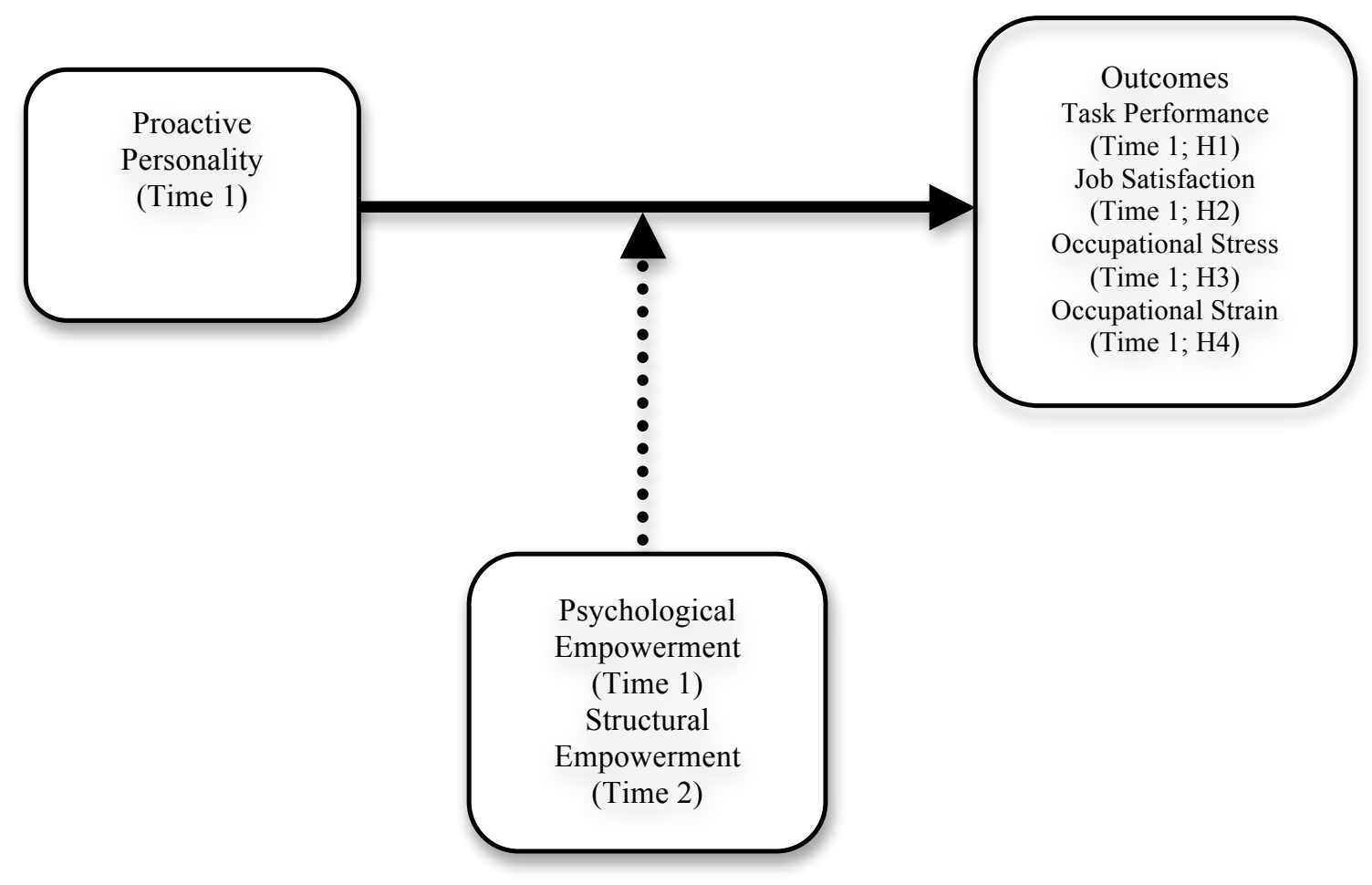


Figure 3. Model of Political Skill as Moderator of Proactive Personality-Outcome Relationships

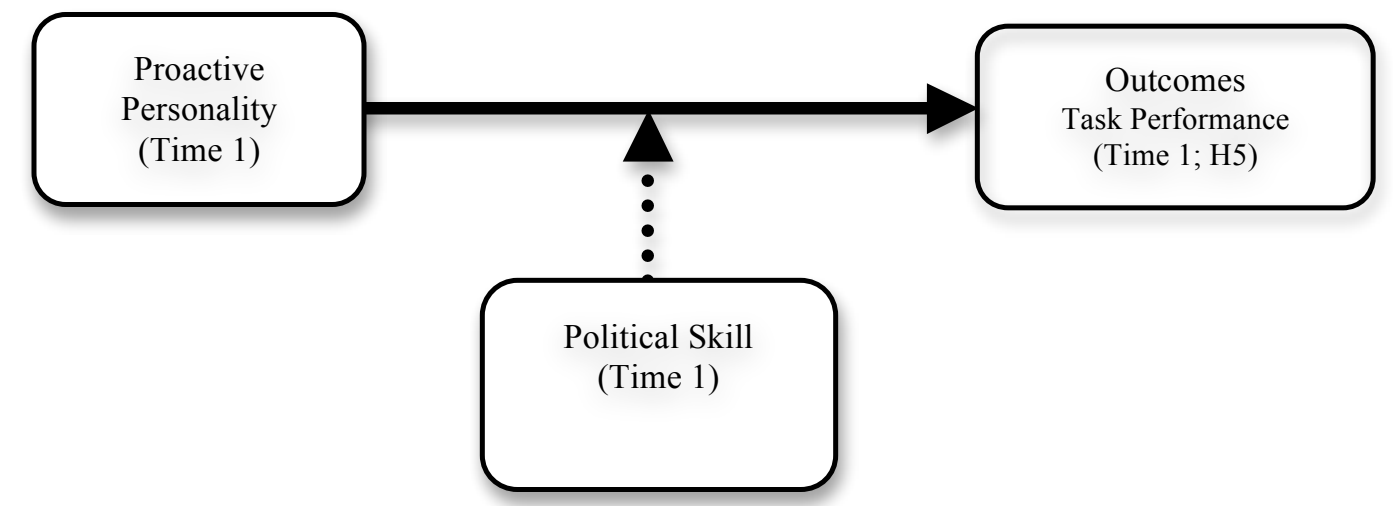


Figure 4. Model of Political Skill as Moderator of Empowerment-Outcome Relationships

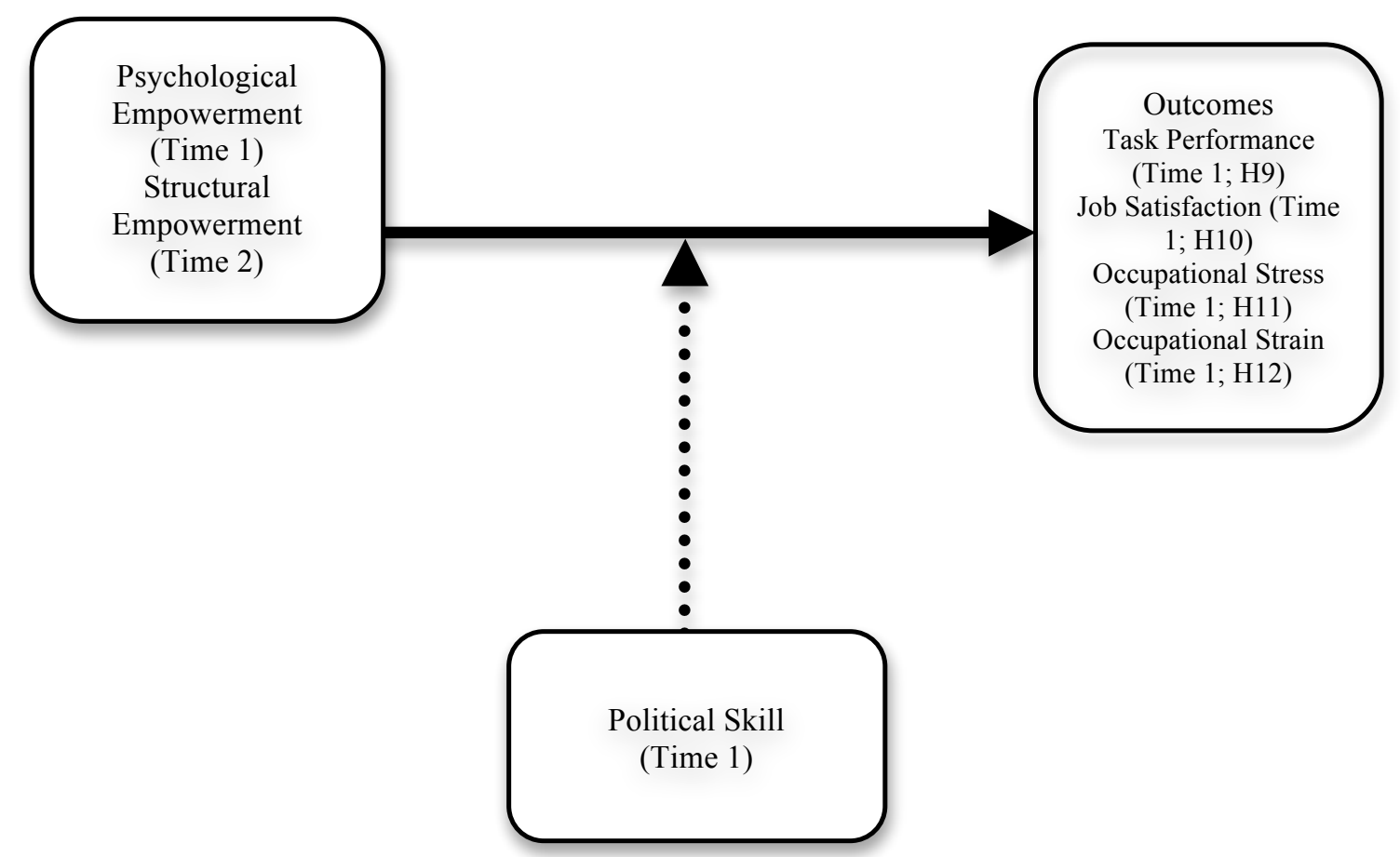


Figure 5. Proactive Personality by Psychological Empowerment with Job Task Performance

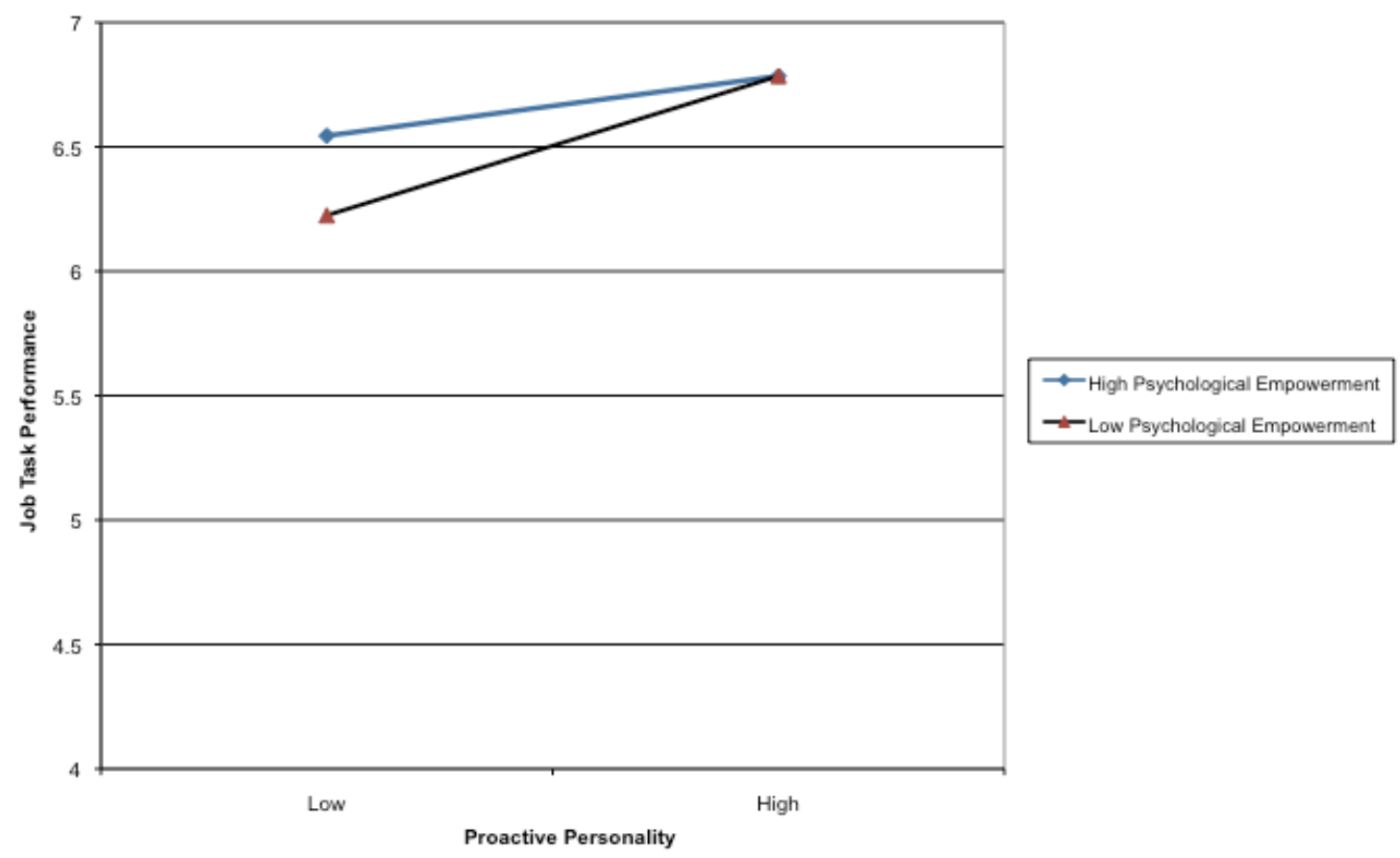


Action Orientation 179

Figure 6. Proactive Personality by Psychological Empowerment with Perceived Effectiveness

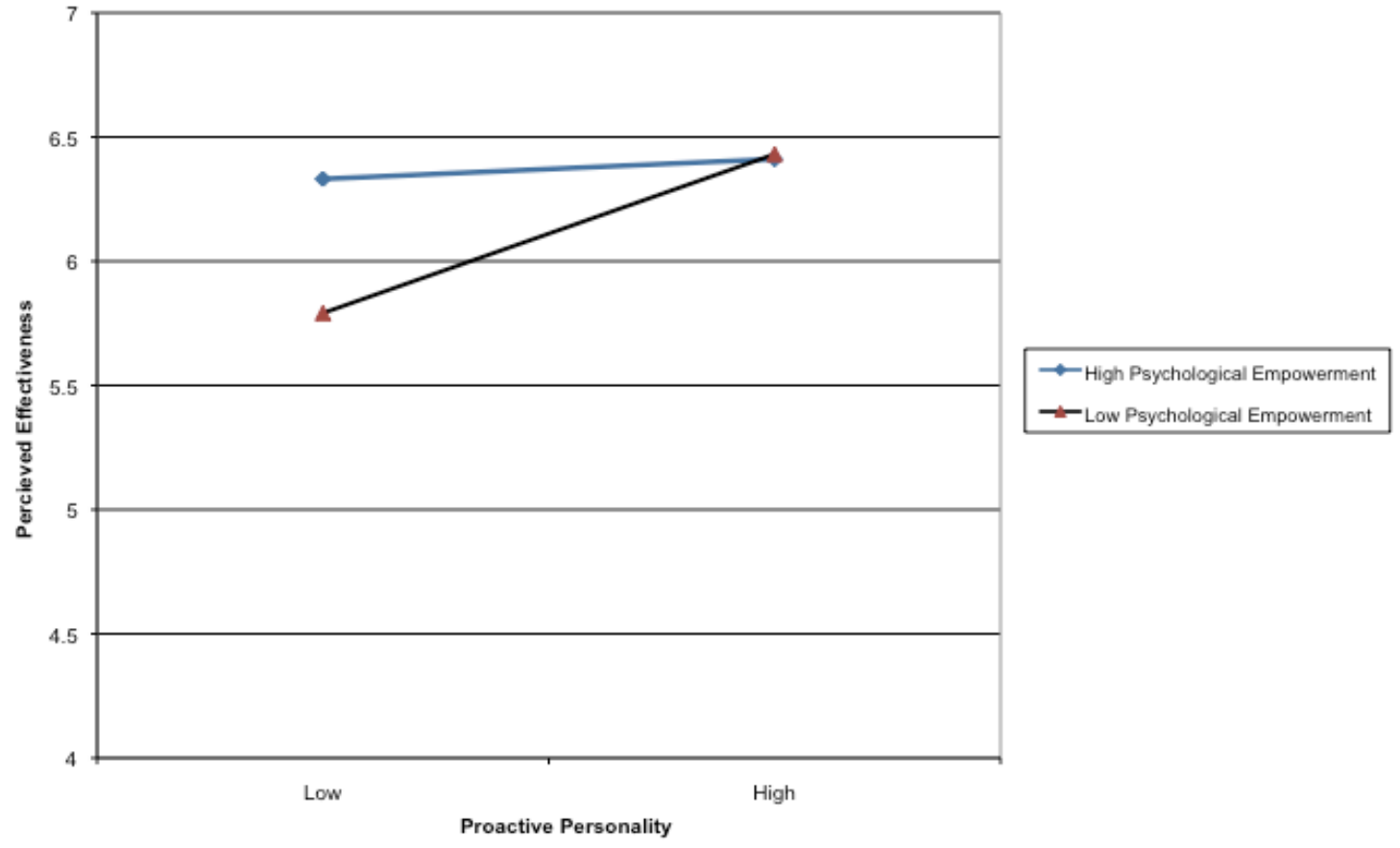


Action Orientation 180

Figure 7. Proactive Personality by Structural Empowerment with Job Task Performance

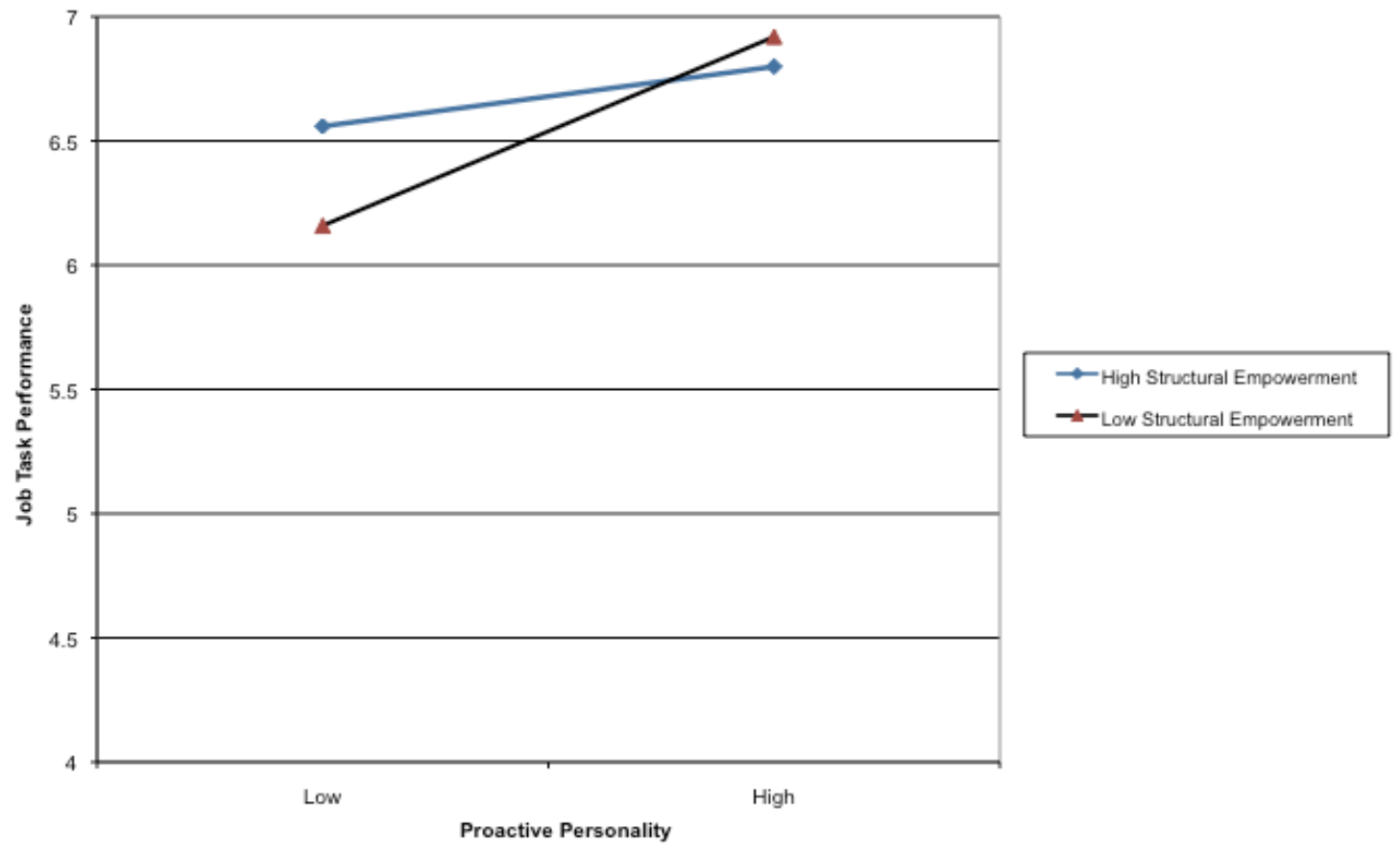


Action Orientation 181

Figure 8. Proactive Personality by Structural Empowerment with Perceived Effectiveness

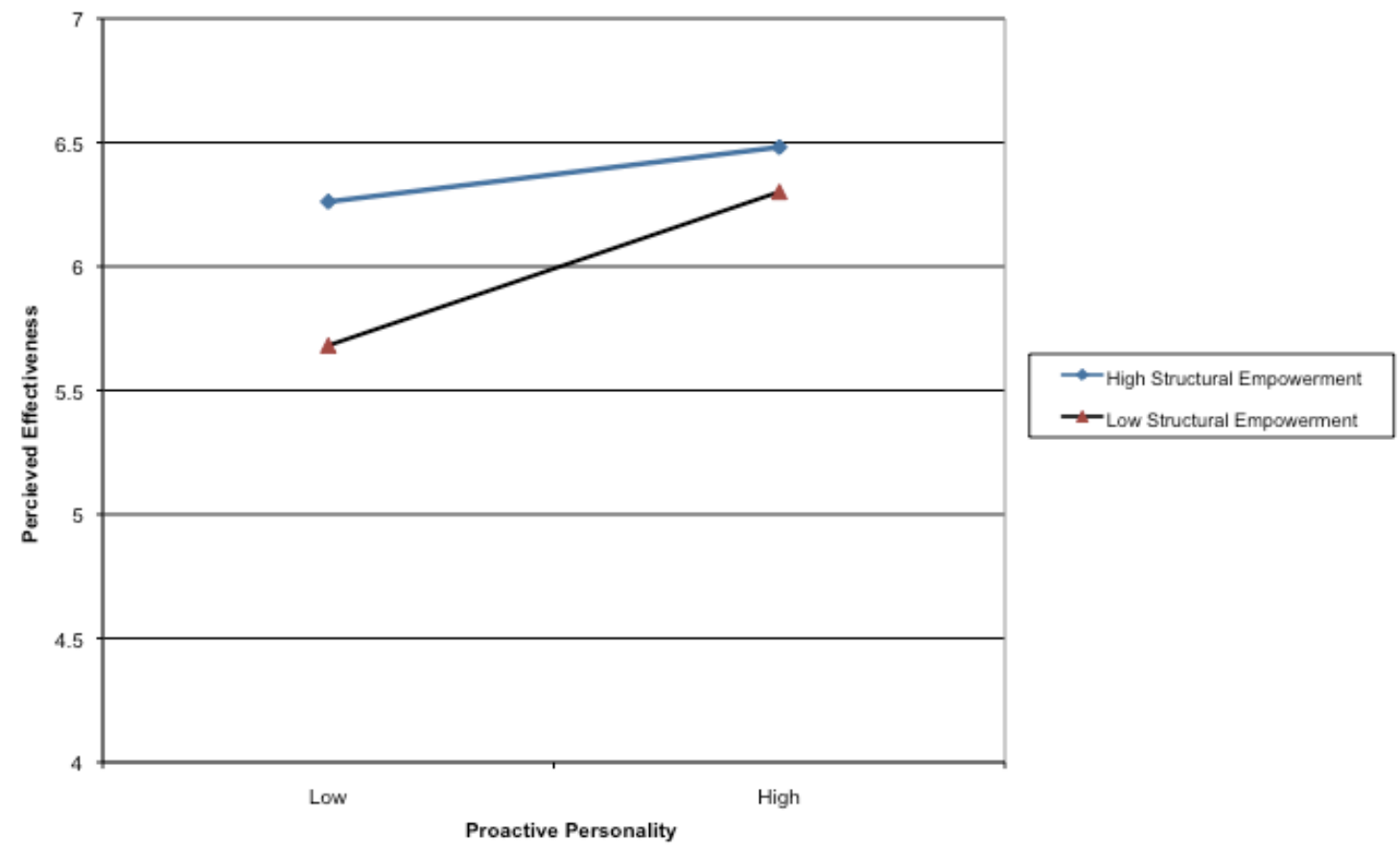


Action Orientation 182

Figure 9. Proactive Personality by Psychological Empowerment with Satisfaction Quality of Care

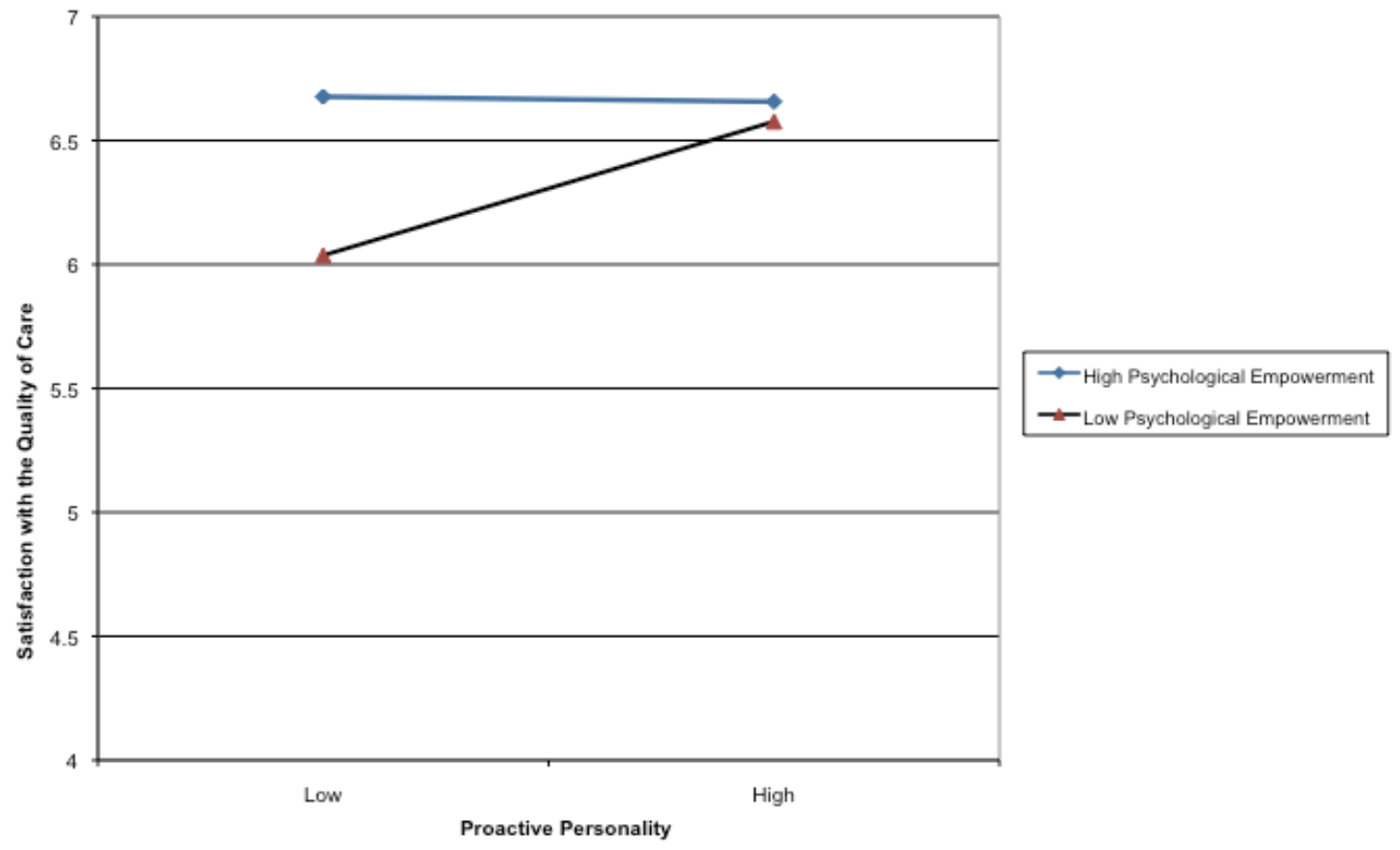


Action Orientation 183

Figure 10. Proactive Personality by Structural Empowerment with Satisfaction with Quality of Care

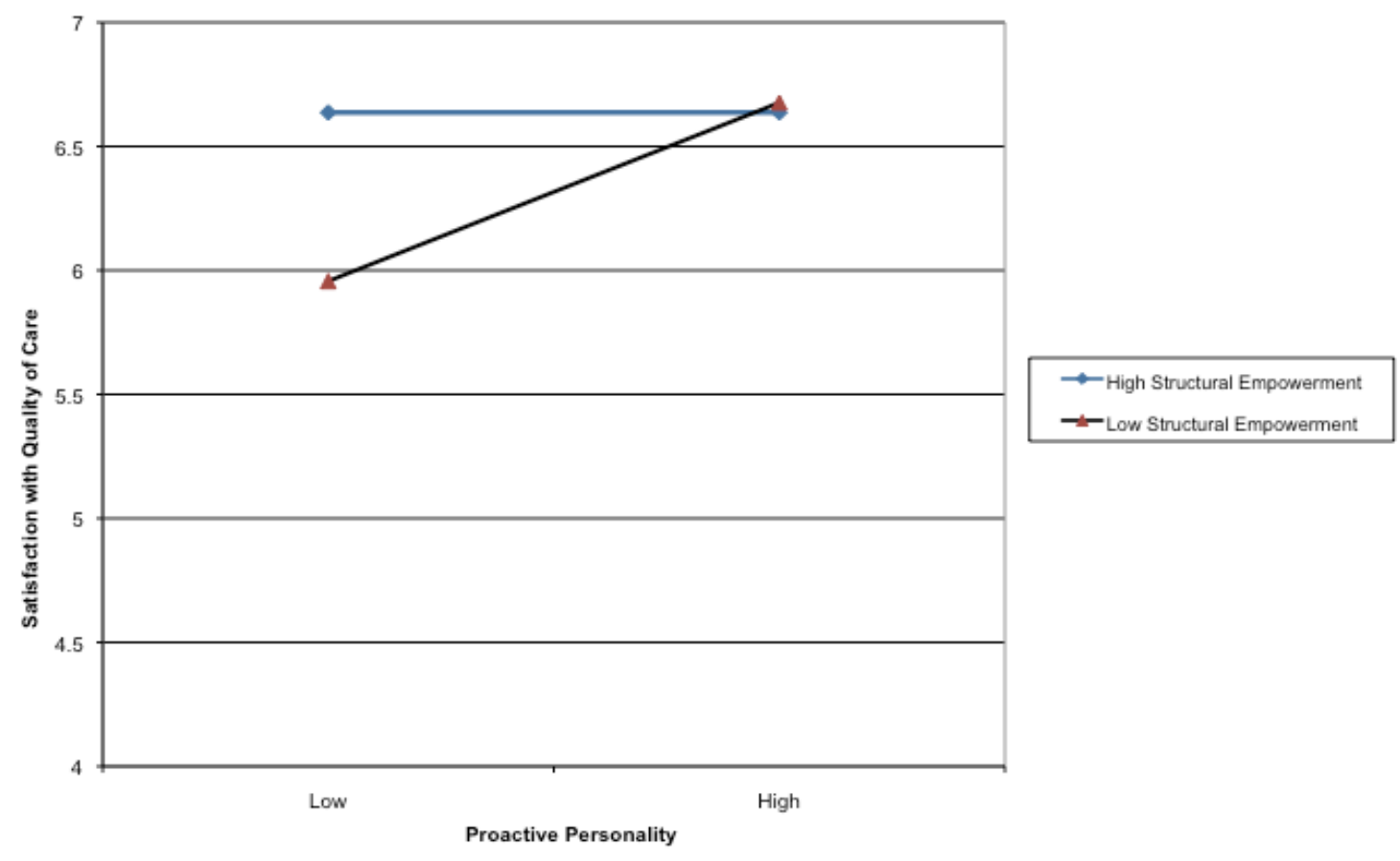


Action Orientation 184

Figure 11. Proactive Personality by Political Skill with Job Task Performance

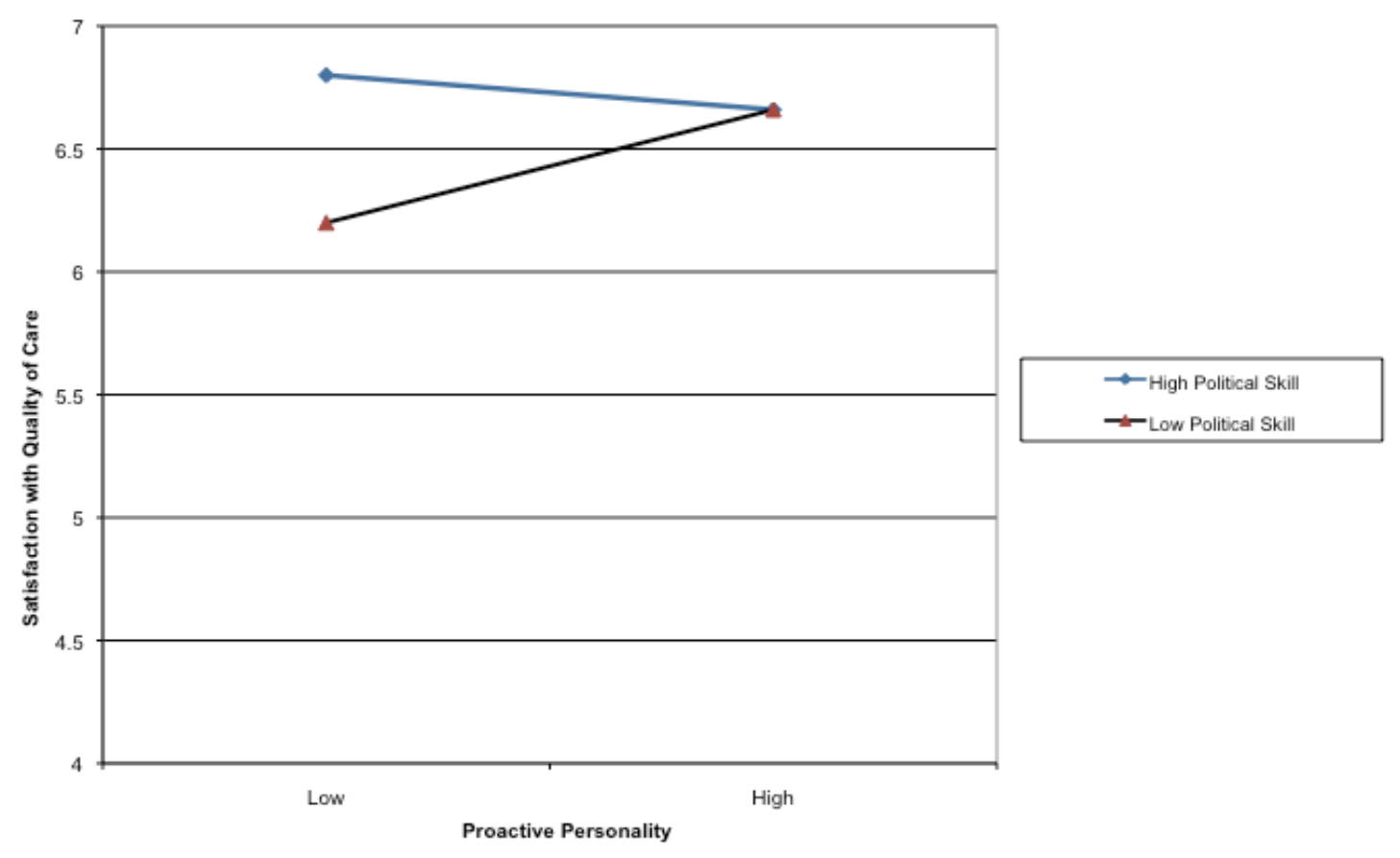


Action Orientation 185

Figure 12. Proactive Personality by Political Skill with Satisfaction with Quality of Care

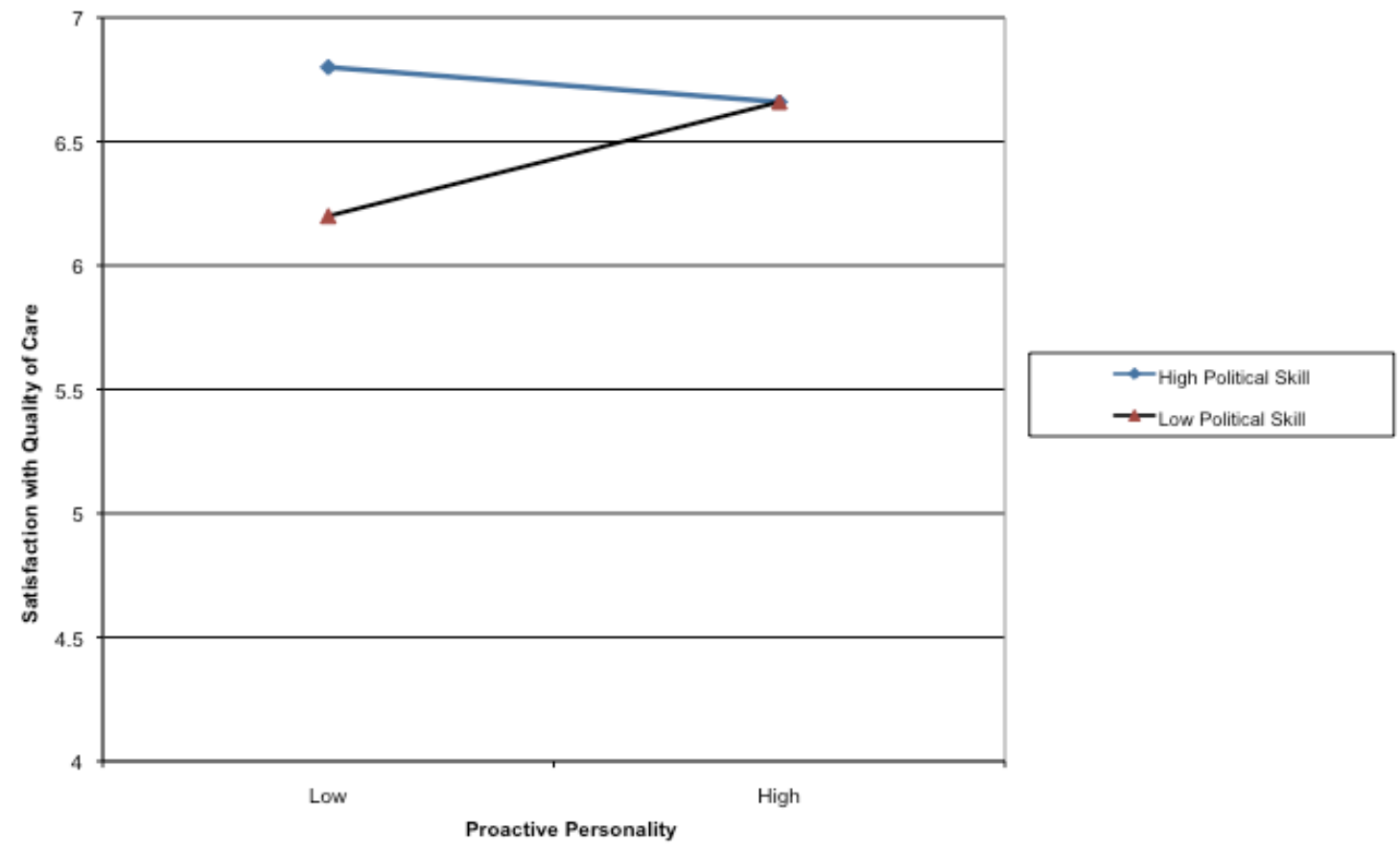


Action Orientation 186

Figure 13. Structural Empowerment by Political Skill with Job Task Performance

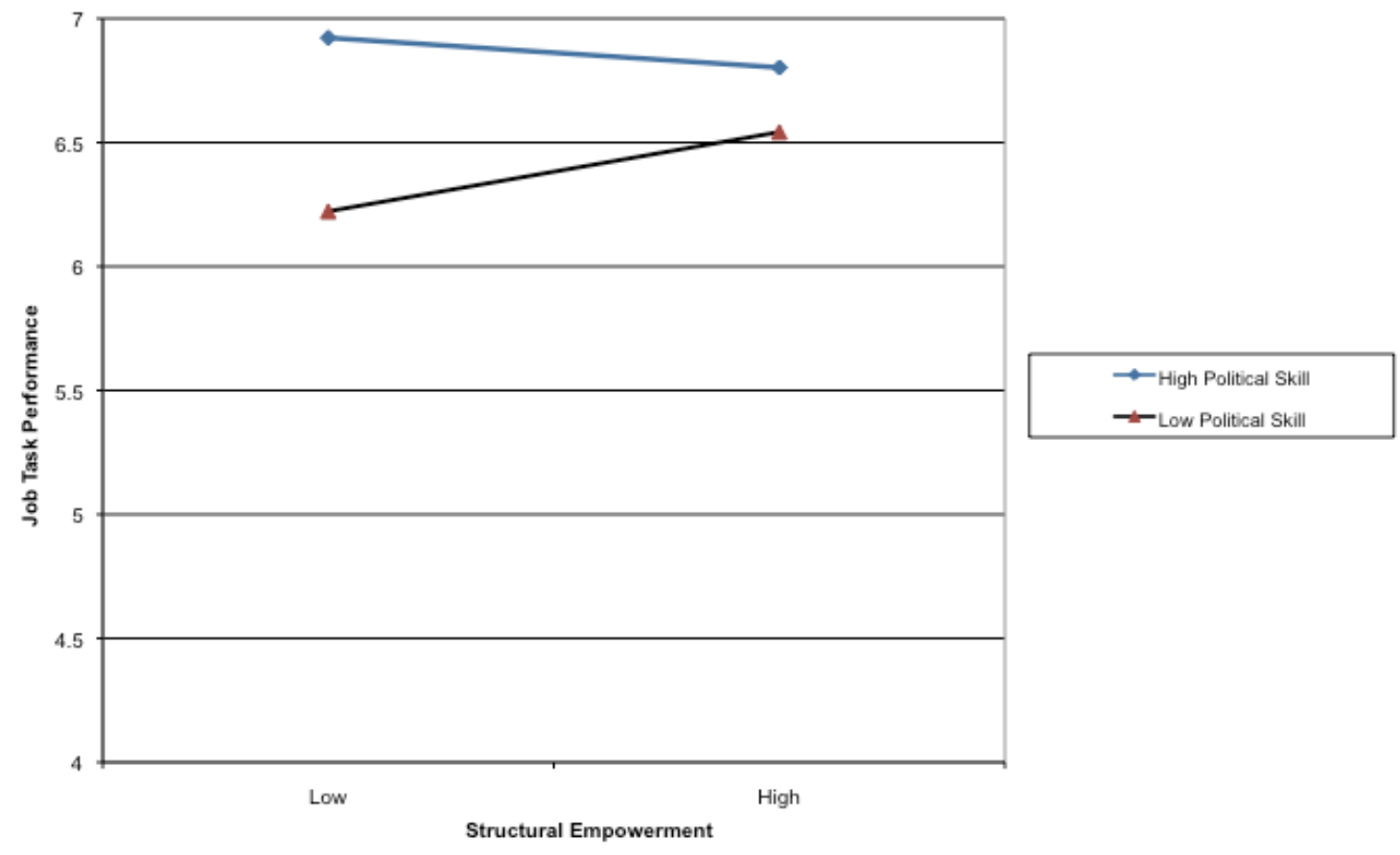


Figure 14. Proactive Personality, Structural Empowerment, and Political Skill with Job Task Performance

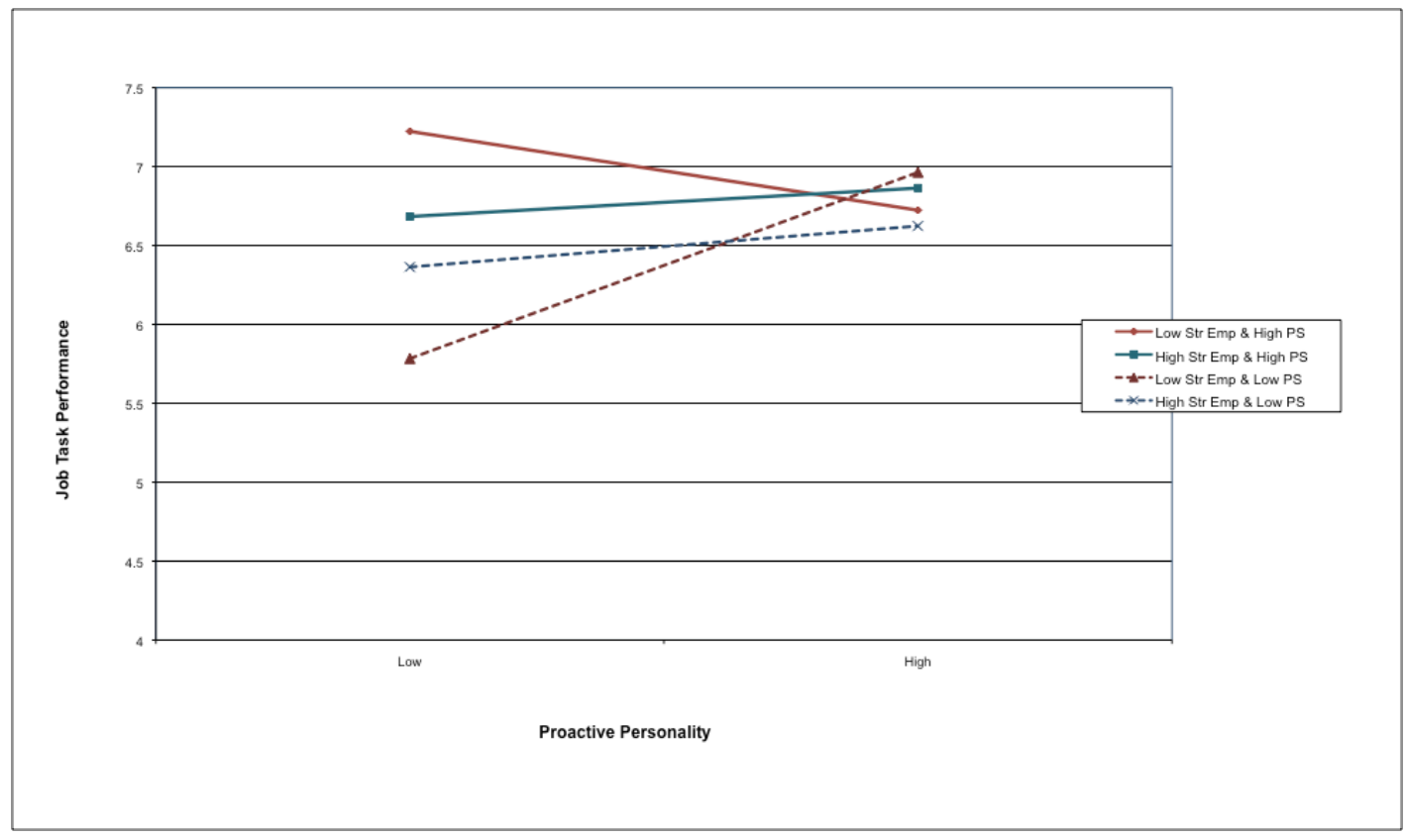


Figure 15. Proactive Personality, Structural Empowerment, and Political Skill with Satisfaction with Quality of Care

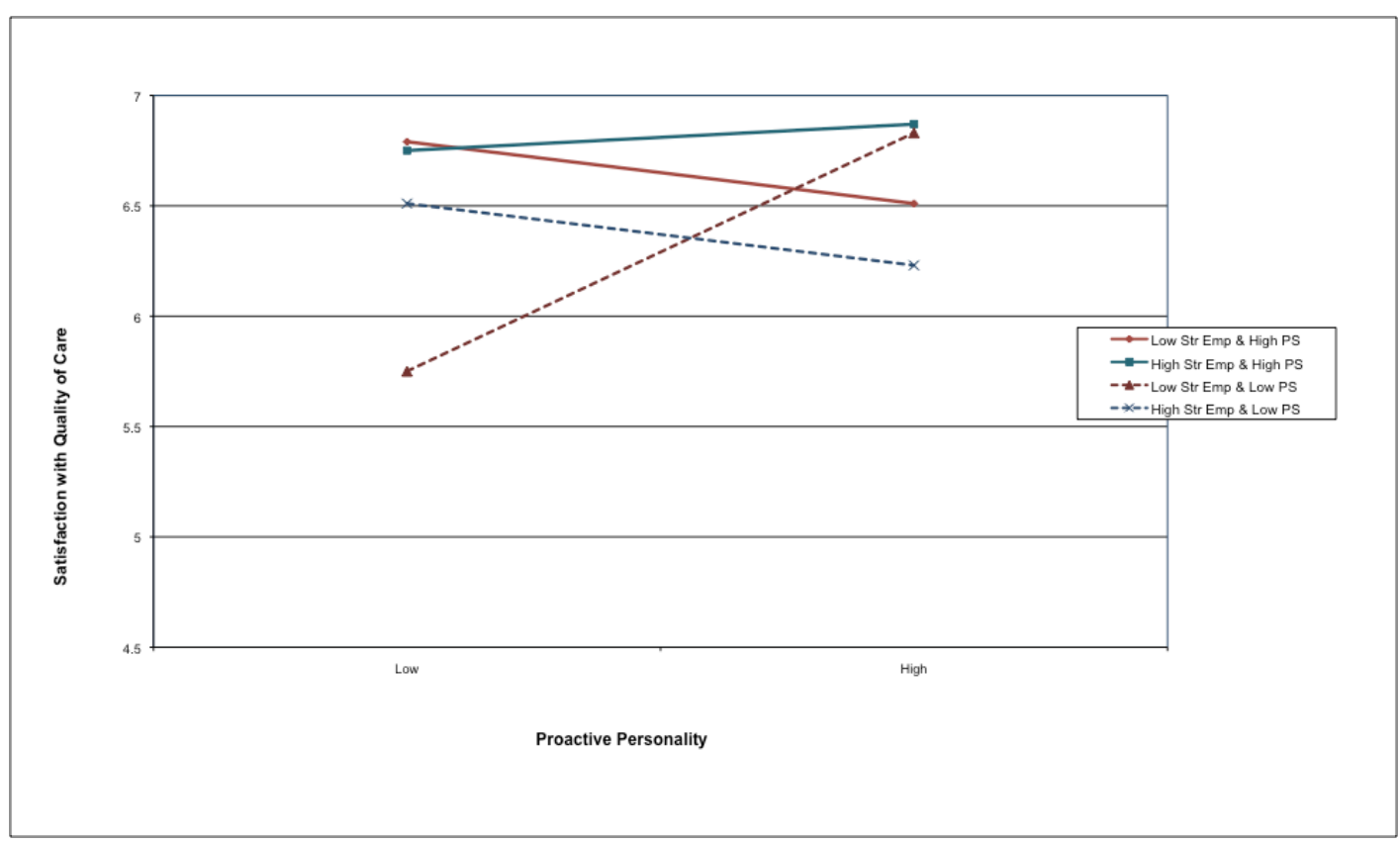


Figure 16. Proactive Personality, Political Skill, and Decision-Making Autonomy with Job Task Performance

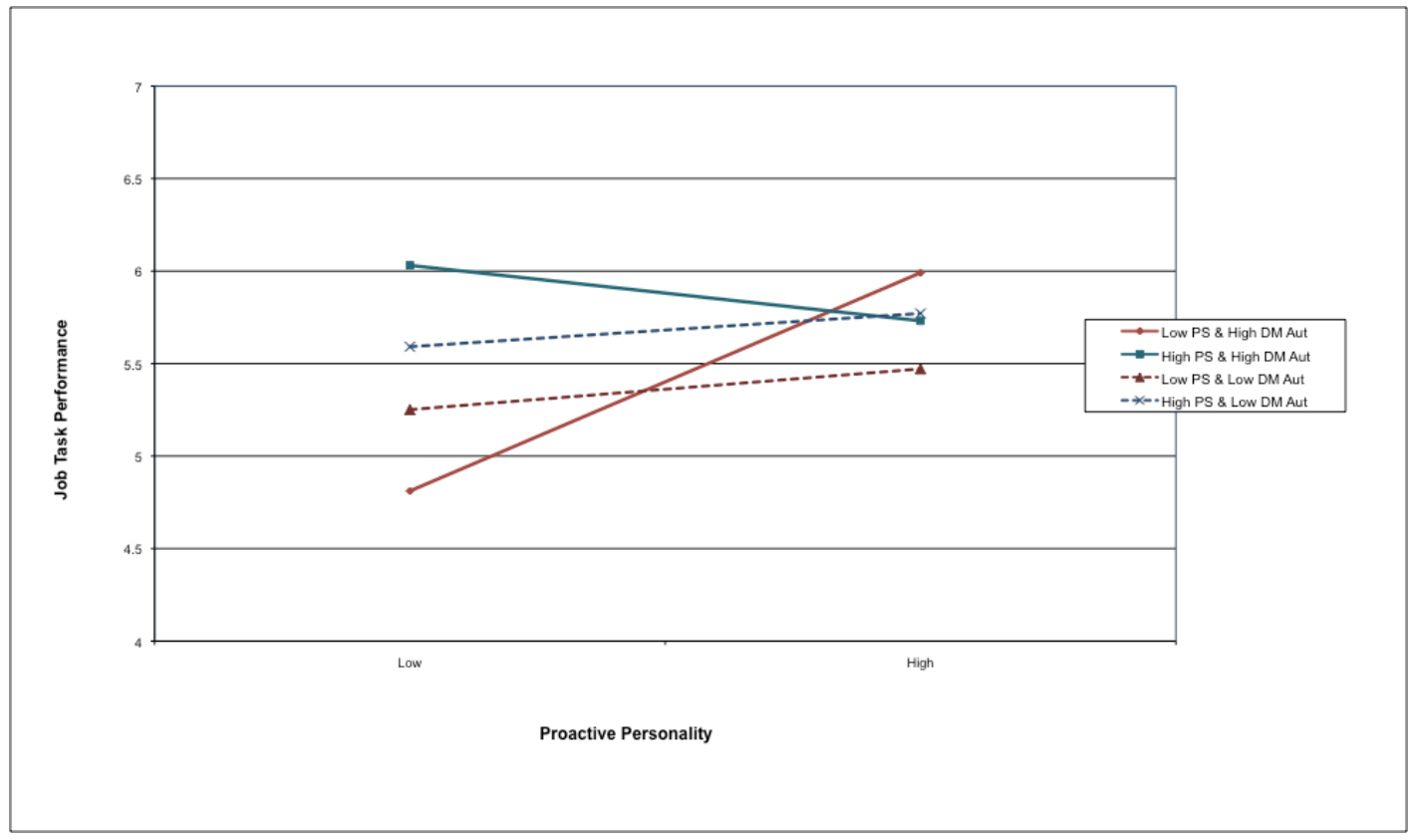


Figure 17. Proactive Personality, Structural Empowerment, and Decision-Making Autonomy with Job Satisfaction

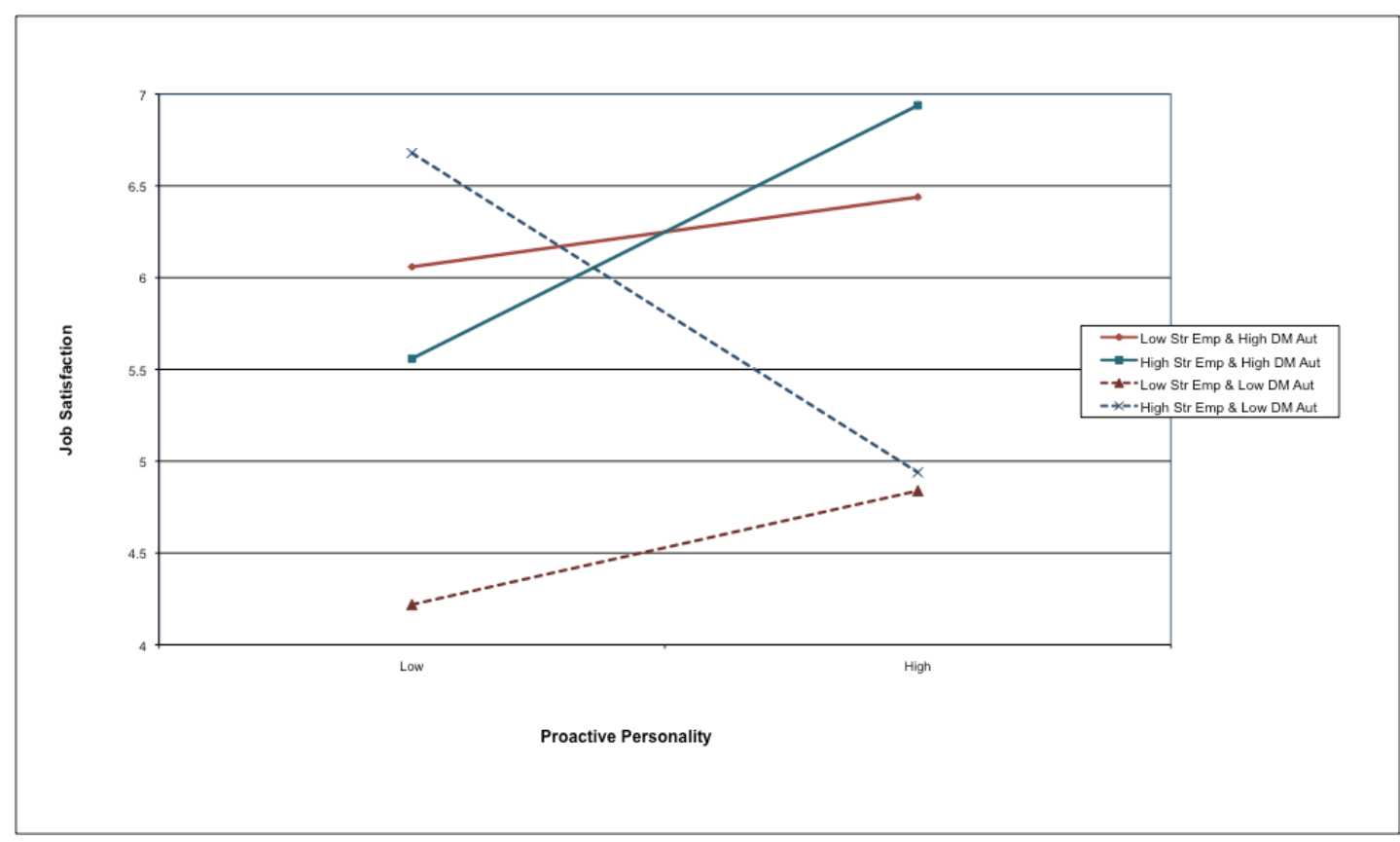


Figure 18. Proactive Personality, Political Skill, and Decision-Making Autonomy with Job Satisfaction

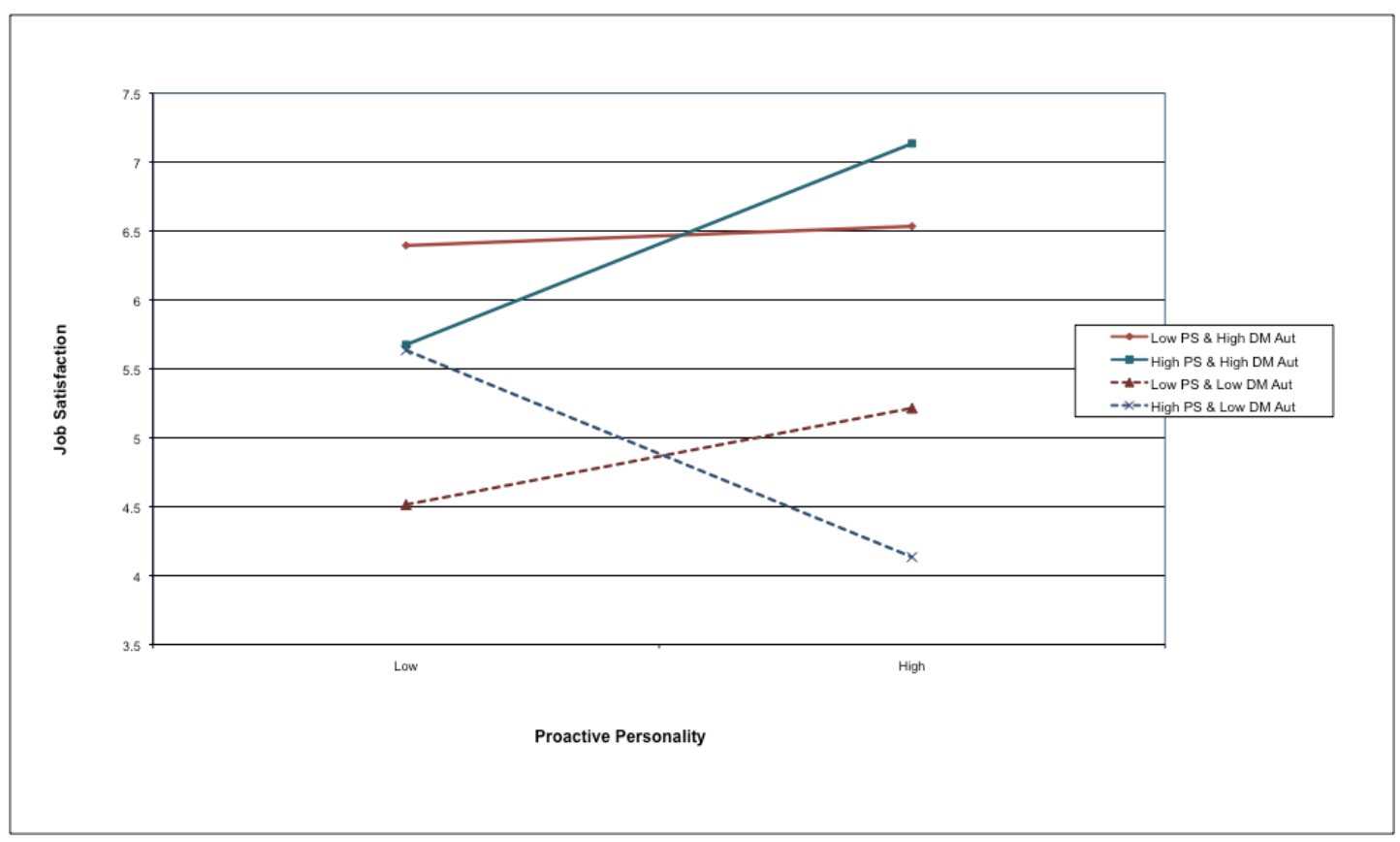


Figure 19. Proactive Personality, Structural Empowerment, and Work Methods Autonomy with Emotional Exhaustion

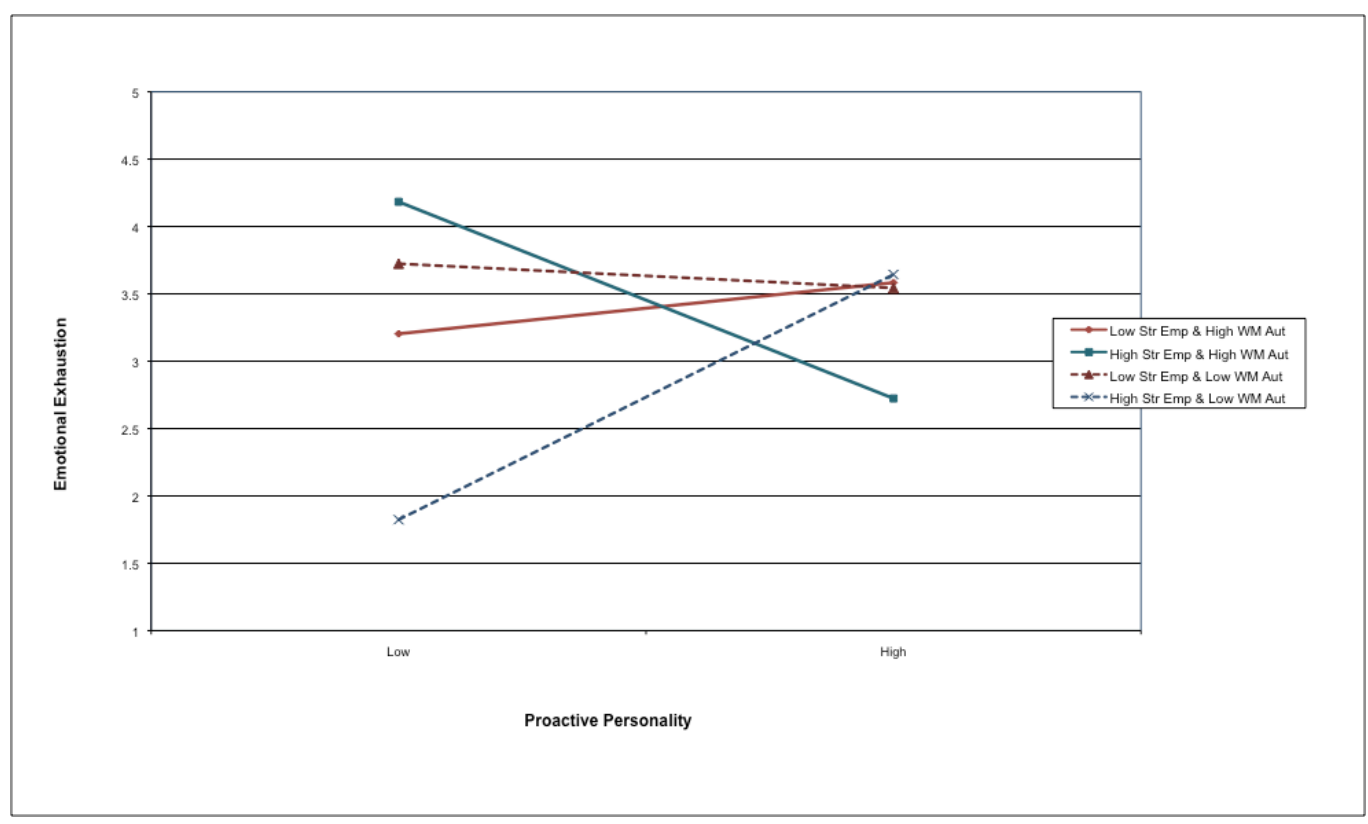


Figure 20. Proactive Personality, Psychological Empowerment, and Work Methods Autonomy with Emotional Exhaustion

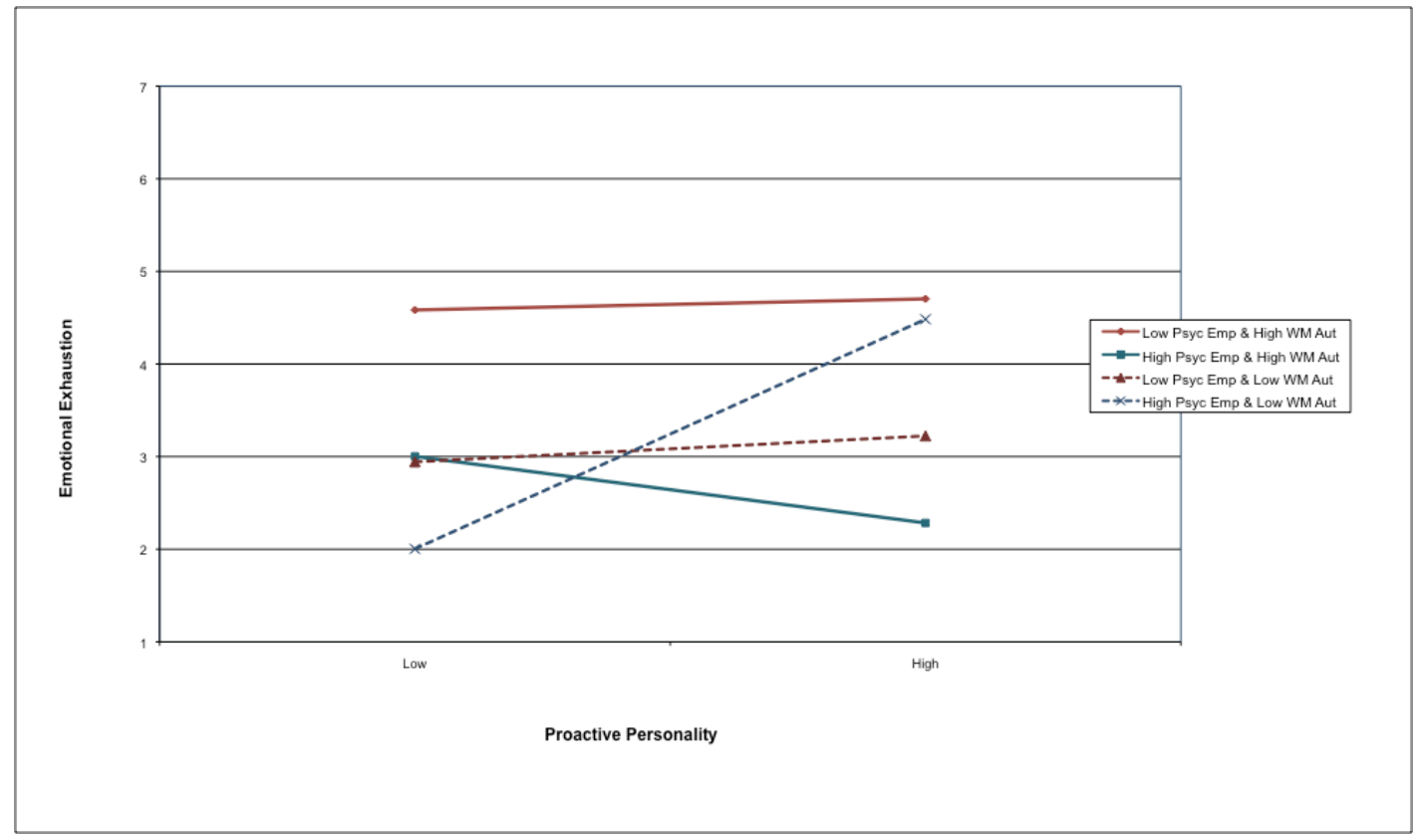


Action Orientation 194

Figure 21. Proactive Personality, Psychological Empowerment, and Work Methods Autonomy with Strain

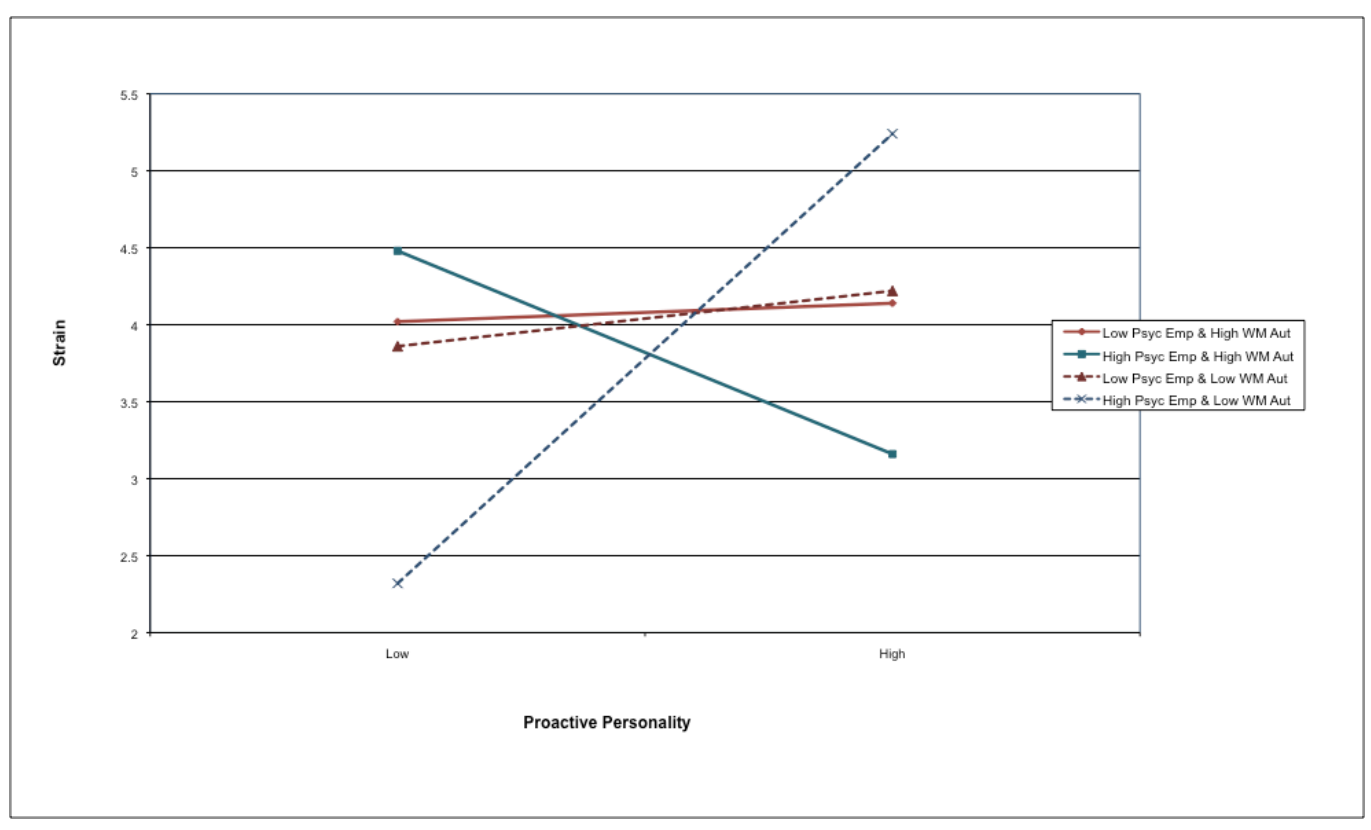


Action Orientation 195

Figure 22. Psychological Empowerment by Political Skill with Job Task Performance

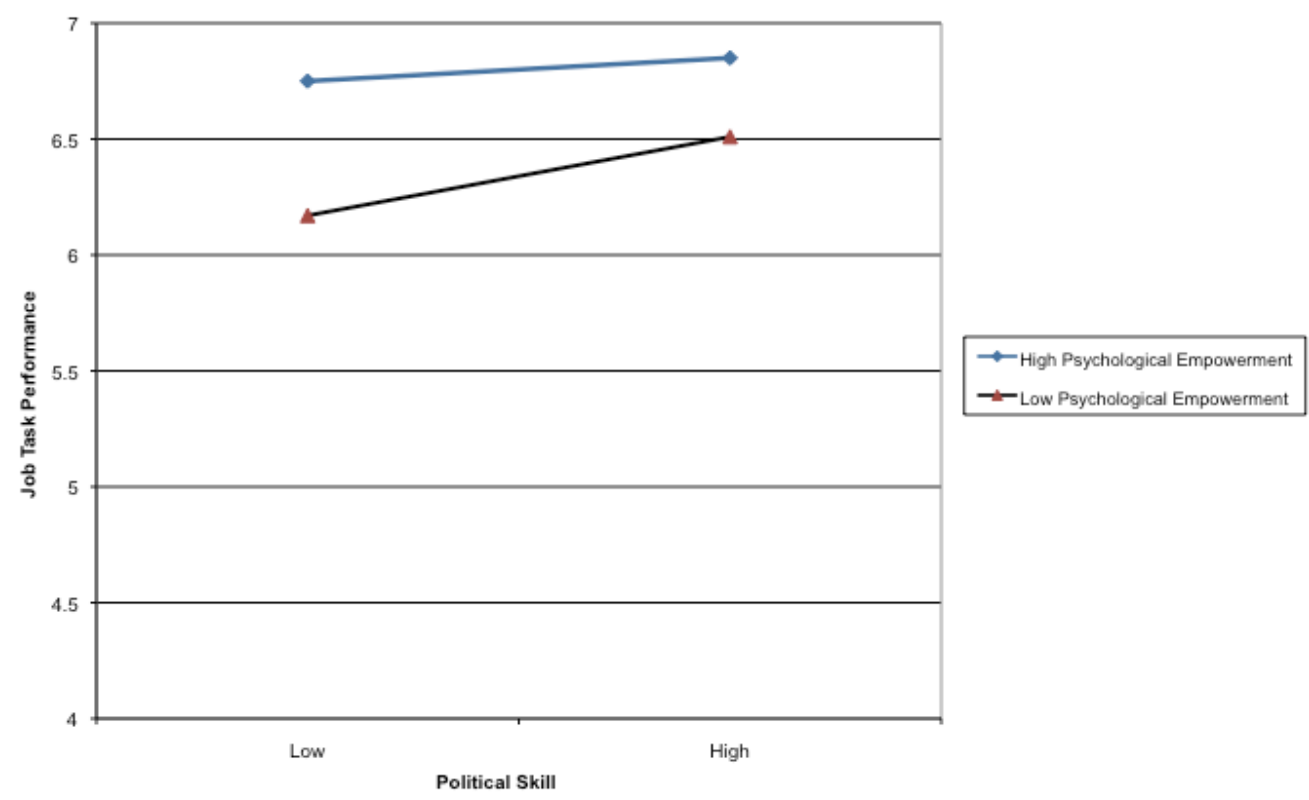


Action Orientation 196

Figure 23. Psychological Empowerment by Political Skill with Perceived Effectiveness

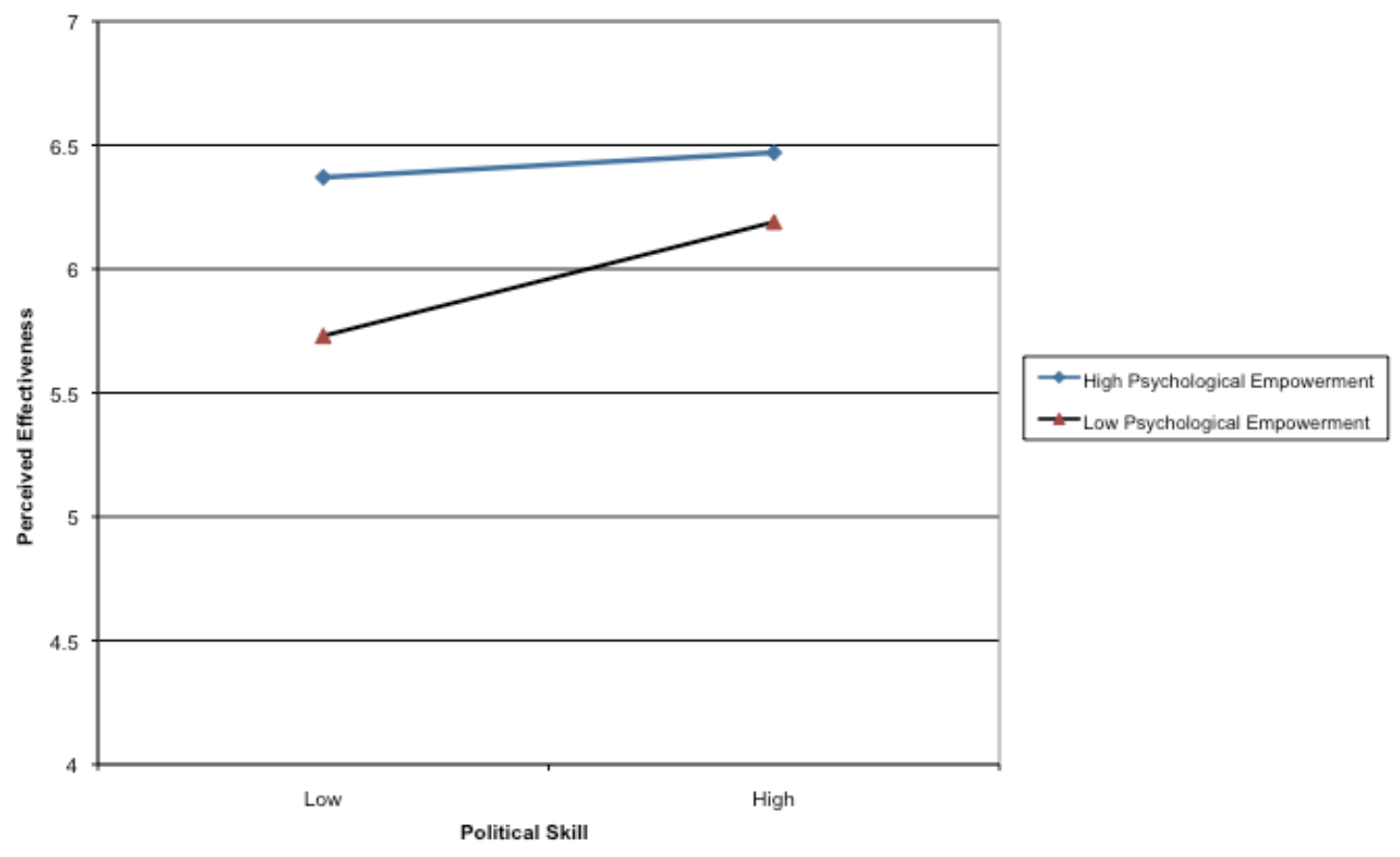


Figure 24. Core Self Evaluation by Political Skill with Job Satisfaction

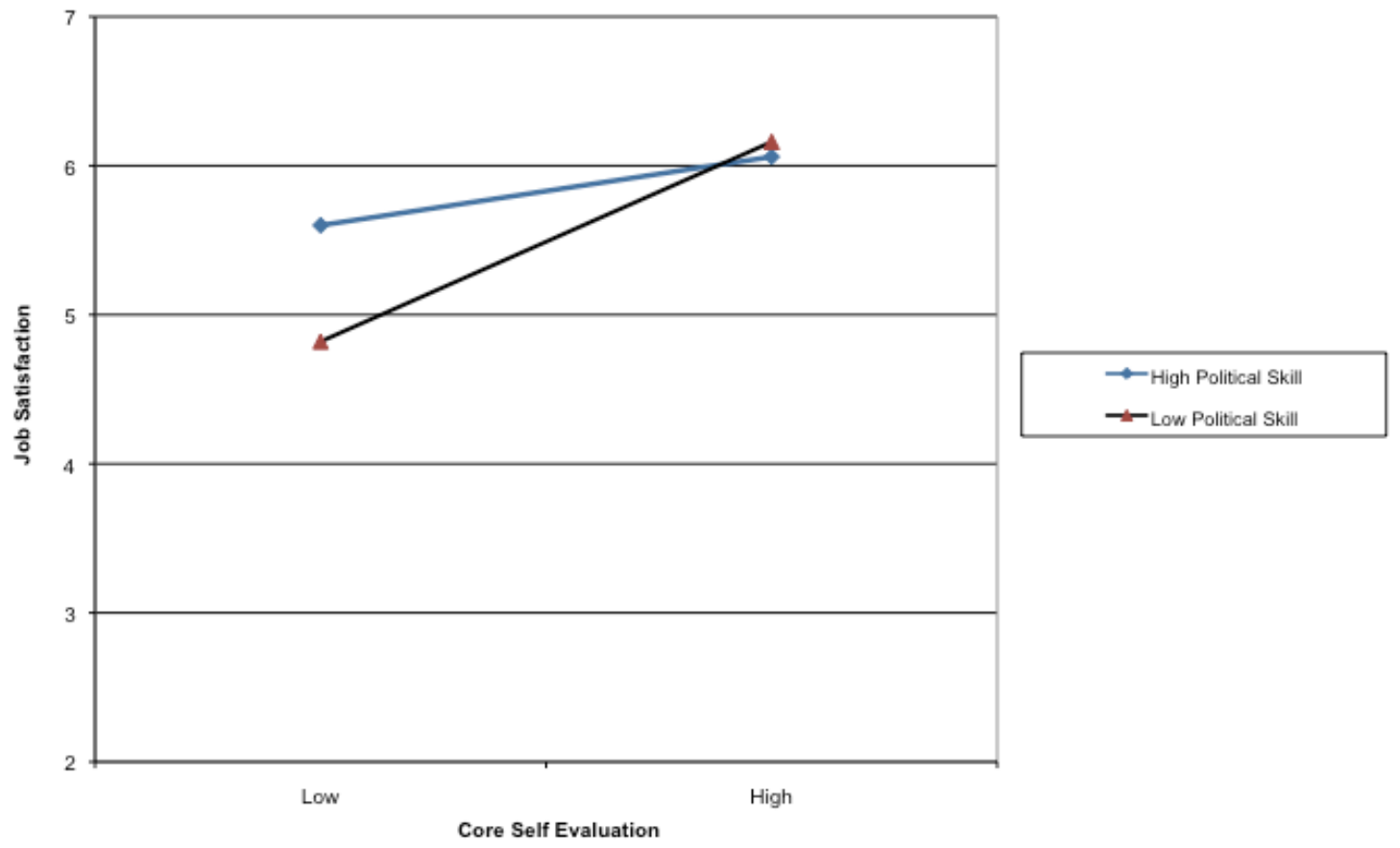


Action Orientation 198

Figure 25. Core Self Evaluation by Political Skill with Satisfaction with Quality of Care

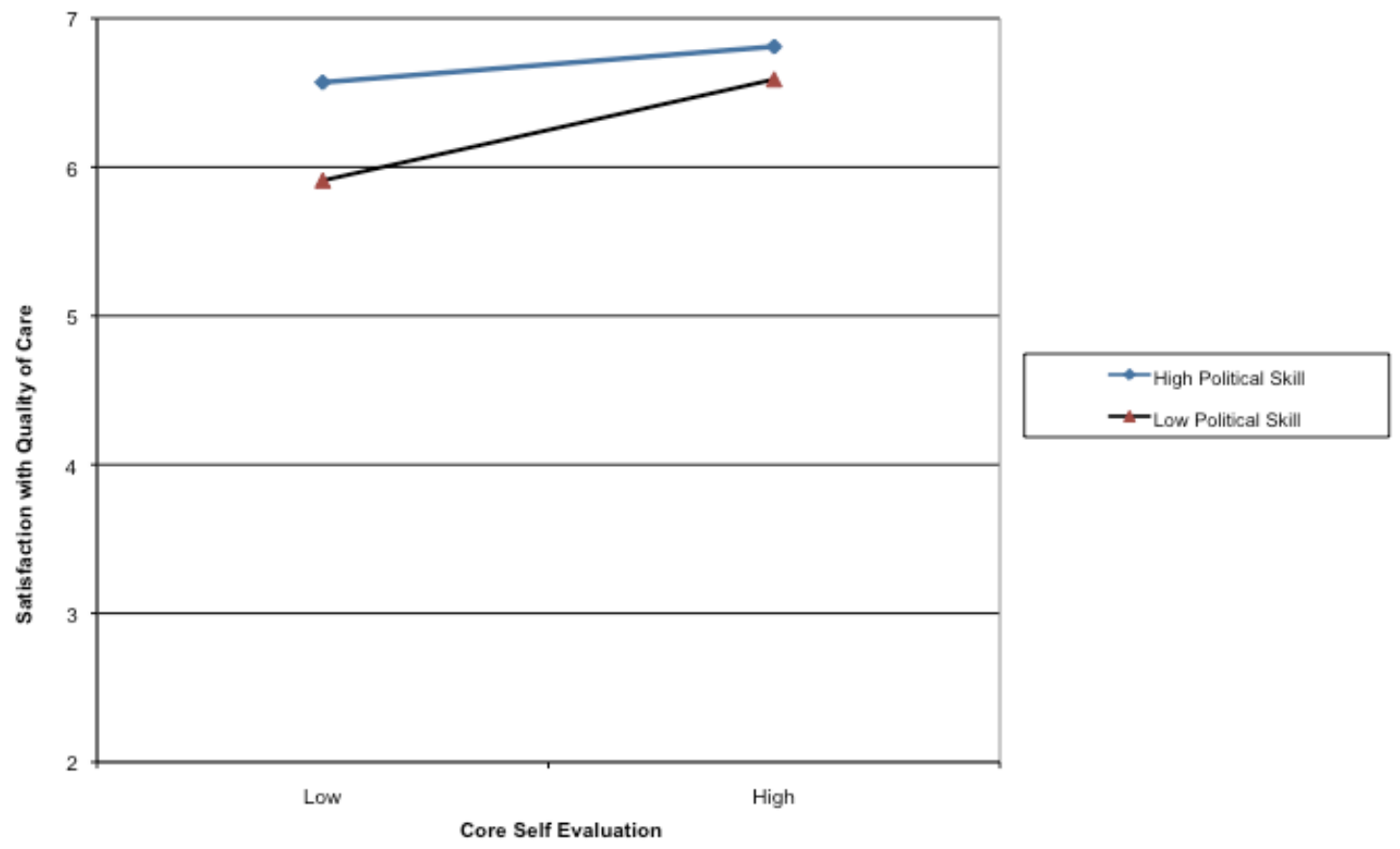


Action Orientation 199

Figure 26. Conscientiousness by Political Skill with Job Satisfaction

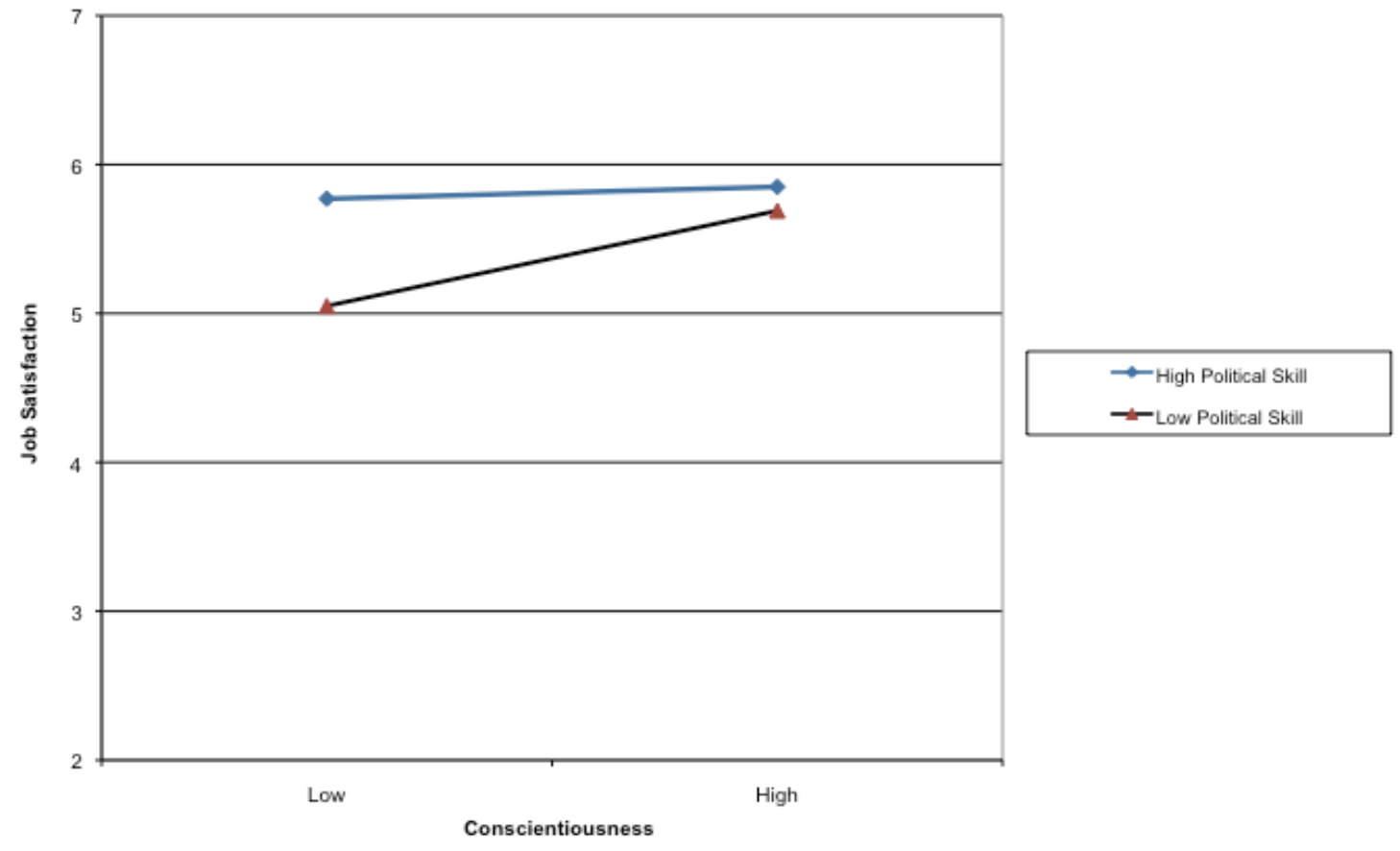


Action Orientation 200

Figure 27. Conscientiousness by Political Skill with Satisfaction with Quality of Care

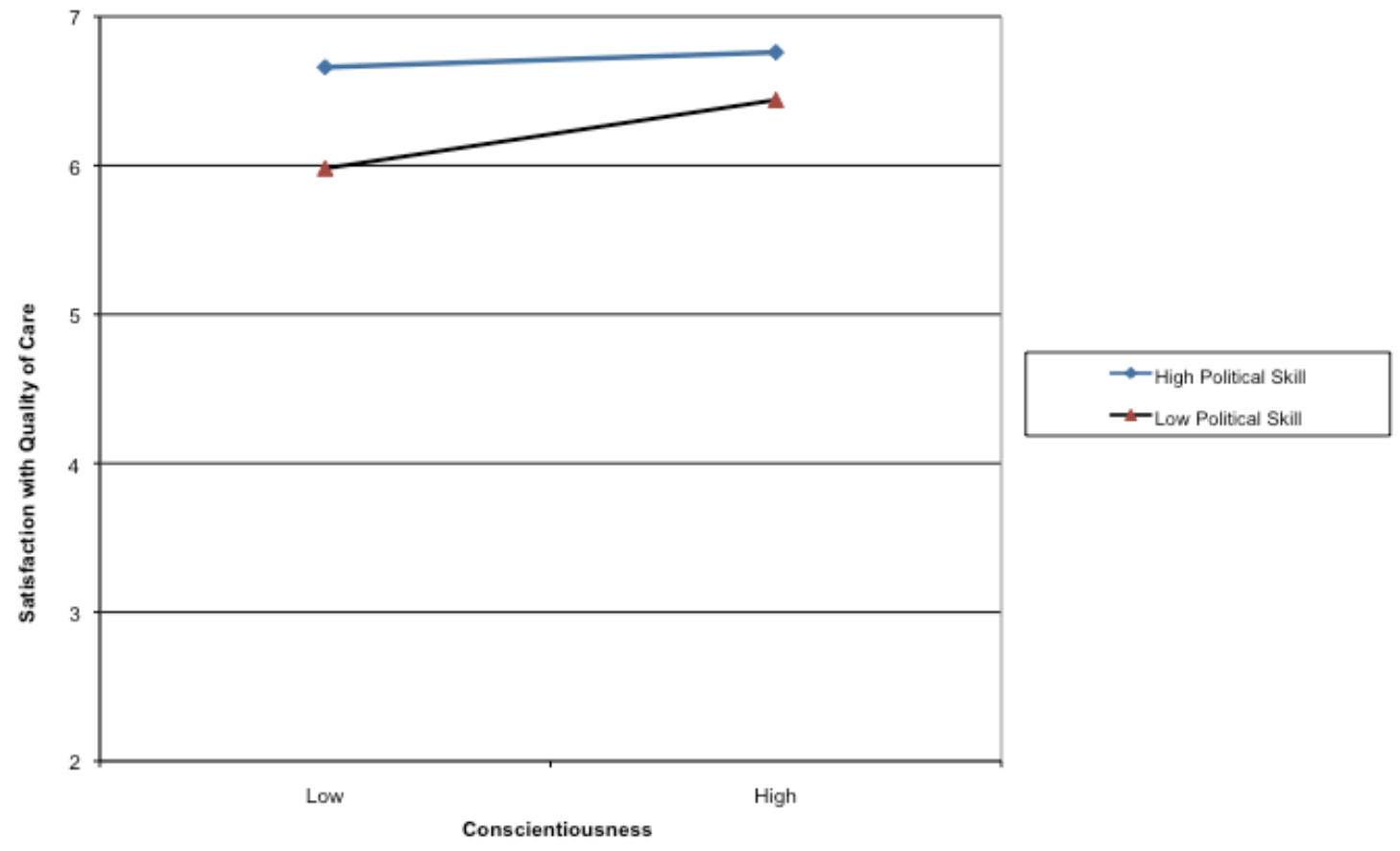


Figure 28. Conscientiousness by Political Skill with Strain

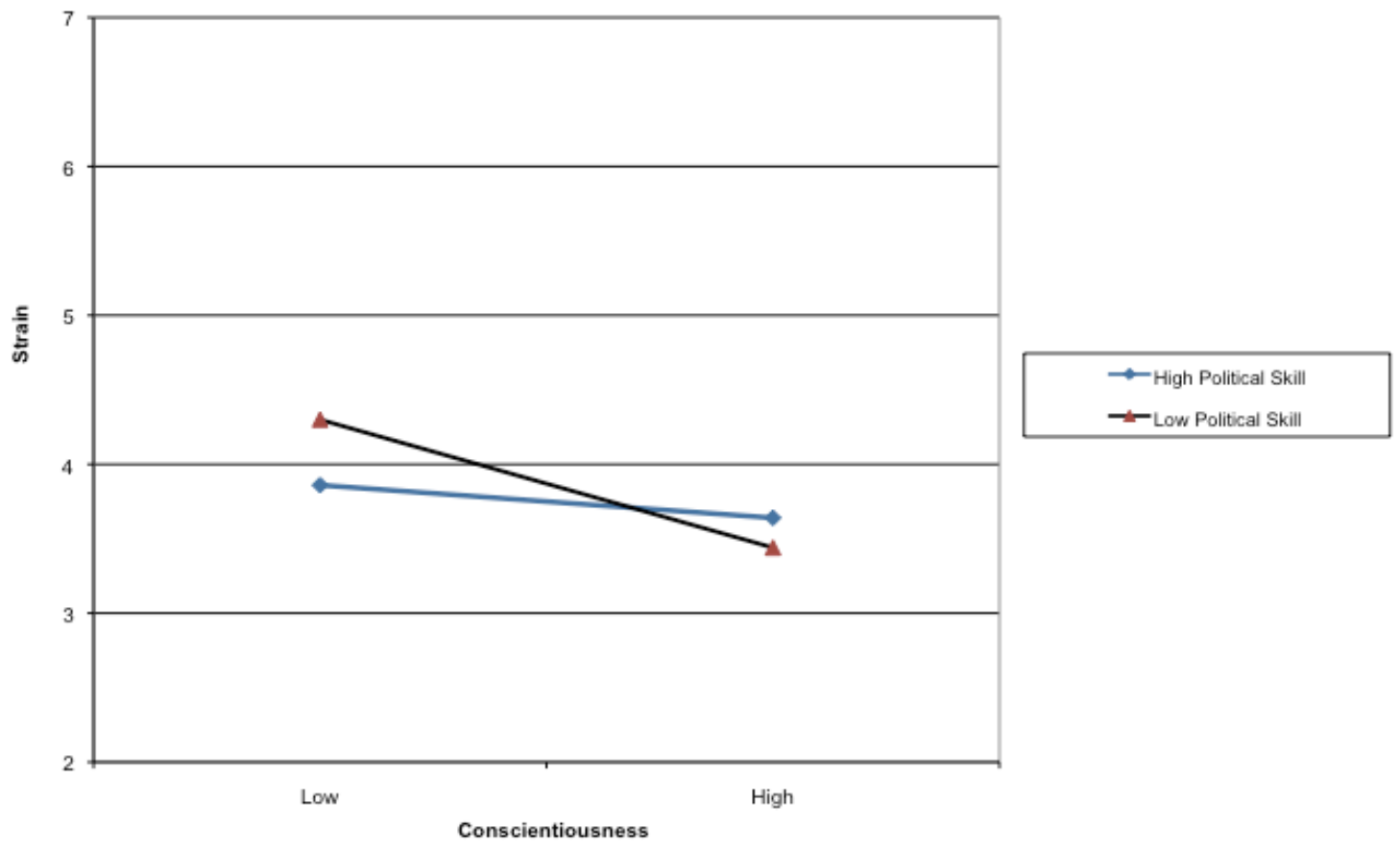


Action Orientation 202

\section{REFERENCES}

Abramson, L., Seligman, M., \& Teasdale, J. (1978). Learned helplessness in humans: Critique and reformulation. Journal of Abnormal Psychology, 87, 49-74.

Aguinis, H., \& Stone-Romero, E. (1997). Methodological artifacts in moderated multiple regression and their effects on statistical power. Journal of Applied Psychology, 82(1), 192.

Ahearn, K., Ferris, G., Hochwarter, W., Douglas, C., \& Ammeter, A. (2004). Leader political skill and team performance. Journal of Management, 30, 309-327.

Ahearne, M., Mathieu, J., \& Rapp, A. (2005). To empower or not to empower your sales force? An empirical examination of the influence of leadership empowerment behavior on customer satisfaction and performance. Journal of Applied Psychology, 90, 945-955.

Aiken, L., \& West, S. (1991). Multiple regression: Testing and interpreting interactions. New York: Sage.

Ajzen, I., \& Fishbein, M. (1970). The prediction of behaviour from attitudinal and normative beliefs. Journal of Personality and Social Psychology, 6(4), 466-487.

Alge, B., Ballinger, G., Tangirala, S., \& Oakley, J. (2006). Information privacy in organizations: Empowering creative and extrarole performance. Journal of Applied Psychology, 91, 221-232.

Amason, A. (1996). Distinguishing the effects of functional and dysfunctional conflict on strategic decision making: Resolving a paradox for top management teams. Academy of Management Journal, 39, 123-148.

Ammeter, A., Douglas, C., Gardner, W., Hochwarter, W., \& Ferris, G. (2002). Toward a 
Action Orientation 203

political theory of leadership. The Leadership Quarterly, 13, 751-796.

Arnold, J., Arad, S., Rhoades, J., \& Drasgow, F. (2000). The empowering leadership questionnaire: The construction and validation of a new scale for measuring leader behaviors. Journal of Organizational Behavior, 21, 249-269.

Ashford, S., Blatt, R., \& Vandewalle, D. (2003). Reflections on the looking glass: A review of research on feedback-seeking behavior in organizations. Journal of Management, 29, 773-799.

Ashford, S., Rothbard, N., Piderit, S., \& Dutton, J. (1998). Out on a limb: The role of context and impression management in issue selling. Administrative Science Quarterly, 43, 23-57.

Ashford, S., \& Tsui, A. (1991). Self-regulation for managerial effectiveness: The role of active feedback seeking. Academy of Management Journal, 34, 251-280.

Ashford, S.J., \& Black, J.S. (1996). Proactivity during organizational entry: The role of desire for control. Journal of Applied Psychology, 81, 199-214.

Ashford, S.J., \& Cummings, L.L. (1983). Feedback as an individual resource: Personal strategies for creating information. Organizational Behavior and Human Performance, 32, 370-389.

Ashforth, B. (1989). The experience of powerlessness in organizations. Organizational Behavior and Human Decision Processes, 43, 207-242.

Ashforth, B. (1990). The organizationally induced helplessness syndrome: A preliminary model. Canadian Journal of Administrative Sciences, 7, 30-36.

Aspinwall, L. (2005). The psychology of future-oriented thinking: From achievement to proactive coping, adaption, and aging. Motivation and Emotion, 29, 203-235. 
Action Orientation 204

Aspinwall, L., \& Taylor, S. (1997). A stitch in time: Self-regulation and proactive coping. Psychological Bulletin, 121, 417-436.

Bacharach, S. (1989). Organizational theories: Some criteria for evaluation. Academy of Management Review, 14, 496-515.

Bandura, A. (1977). Social learning theory. Englewood Cliffs, NJ: Prentice Hall.

Bandura, A. (1986). Social foundations of thought and action. Englewood Cliffs, NJ: Prentice Hall.

Bandura, A. (1991). Social cognitive theory of self-regulation. Organizational Behavior and Human Decision Processes, 50, 248-287.

Bandura, A. (1997). Self-efficacy: The exercise of control. New York, NY: W. H. Freeman.

Bandura, A., \& Locke, E.A. (2003). Negative self-efficacy and goal effects revisited. Journal of Applied Psychology, 88, 87-99.

Barker, J. (1993). Tightening the iron cage: Concertive control in self-managing teams. Administrative Science Quarterly, 38, 408-437.

Barkley, R.A. (1997). Adhd and the nature of self-control. New York, NY: Guilford Press.

Bateman, T., \& Crant, J. (1993). The proactive component of organizational behavior: A measure and correlates. Journal of Organizational Behavior, 14, 103-118.

Bauer, T.N., Bodner, T., Erdogan, B., Truxillo, D.M., \& Tucker, J.S. (2007). Newcomer adjustment during organizational socialization: A meta-analytic review of antecedents, outcomes, and methods. Journal of Applied Psychology, 92, 707721. 
Action Orientation 205

Becherer, R., \& Maurer, J. (1999). The proactive personality disposition and entrepreneurial behavior among small company presidents. Journal of Small Business Management, 37, 28-37.

Becker, T.E. (2005). Potential problems in the statistical control of variables in organizational research: A qualitative analysis with recommendations. Organizational Research Methods, 8, 274-289.

Begley, T. (1998). Coping strategies as predictors of employee distress and turnover after an organizational consolidation: A longitudinal analysis. Journal of Occupational and Organizational Psychology, 71, 305-330.

Bell, N.E., \& Staw, B.M. (1989). People as sculptors versus sculpture: The role of personality and personal control in organizations. In M. B. Arthur, D. T. Hall \& B. S. Lawrence (Eds.), The handbook of career theory (pp. 232-251). Cambridge: Cambridge University Press.

Bing, M.N., Minor, I., Davison, H.K., \& Novicevic, M. (2009). Meta-analysis of the research on political skill and job performance. Paper presented at the 24th Annual Society for Industrial and Organizational Psychology Conference, New Orleans, LA.

Blass, F., \& Ferris, G. (2007). Leader reputation: The role of mentoring, political skill, contextual learning, and adaptation. Human Resource Management, 46, 5-19.

Blau, J., \& Alba, R. (1982). Empowering nets of participation. Administrative Science Quarterly, 27, 363-379.

Bodner, T., Cadiz, D., Drown, D., \& Mccune, E. (2009). Proactive personality metaanalysis: Relationships with performance and job satisfaction. Paper presented at 
Action Orientation 206 the 24th Annual Society for Industrial and Organizational Psychology Conference Bookman, A., \& Morgan, S. (1988). Women and the politics of empowerment. Philadelphia, PA: Temple University Press.

Bowen, D.E., \& Lawler, E.E. (2006). The empowerment of service workers: What, why, how, and when. Sloan Management Review, 33(3), 31-39.

Brayfield, A.H., \& Rothe, H.F. (1951). An index of job satisfaction. Journal of Applied Psychology, 35, 307-311.

Brief, A., \& Nord, W. (1990). Work and meaning: Definitions and interpretations. In A. Brief \& W. Nord (Eds.), Meanings of occupational work: A collection of essays (pp. 1-19). Lexington, MA.

Brockner, J., \& Wiesenfeld, B. (1993). Living on the edge (of social and organizational psychology): The effects of job layoffs on those who remain. In J. K. Murnighan (Ed.), Social psychology in organizations: Advances in theory and research (pp. 119-140). Englewood Cliffs, NJ: Prentice-Hall.

Brown, D. (1992). Why participative management won't work here. Management Review, 8, 42-46.

Bryk, A.S., \& Raudenbush, S.W. (1992). Hierarchical linear models. Newbury Park, CA: Sage.

Buerhaus, P., Auerbach, D.I., \& Staiger, D.O. (2009). The recent surge in nurse employment: Causes and implications. Health Affairs, 28(4), 657-668.

Burke, W. (1986). Leadership as empowering others. In S. Srivastva (Ed.), Executive power (pp. 51-77). San Francisco, CA: Jossey-Bass.

Buss, D.M. (1987). Selection, evocation, and manipulation. Journal of Personality and 
Social Psychology, 53, 1214-1221.

Action Orientation 207

Caldwell, D.F., \& Burger, J.M. (1997). Personality and social influence strategies in the workplace. Personality and Social Psychology Bulletin, 23, 1003-1012.

Campbell, D. (2000). The proactive employee: Managing workplace initiative. The Academy of Management Executive, 14, 52-66.

Chan, D. (2006). Interactive effects of situational judgment effectiveness and proactive personality on work perceptions and work outcomes. Journal of Applied Psychology, 91, 475-481.

Chan, D., \& Schmitt, N. (2000). Interindividual differences in intraindividual changes in proactivity during organizational entry: A latent growth modeling approach to understanding newcomer adaptation. Journal of Applied Psychology, 85, 190-210.

Chao, G.T., Walz, P.M., \& Gardner, P.D. (1992). Formal and informal mentorship: A comparison on mentoring functions and contrast with nonmentored counterparts. Personnel Psychology, 45, 619-636.

Chen, G., Kirkman, B., Kanfer, R., Allen, D., \& Rosen, B. (2007). A multilevel study of leadership. Empowerment, and performance in teams. Journal of Applied Psychology, 92, 331-346.

Chen, G., \& Klimoski, R.J. (2003). The impact of expectations on newcomer performance in teams as mediated by work characteristics, social exchanges, and empowerment. The Academy of Management Journal, 46(5), 591-607.

Cohen, J., \& Cohen, P. (1983). Applied multiple regression/correlation analysis for the behavioral sciences. Hillsdale: Erlbaum.

Colquitt, J. (2001). On the dimensionality of organizational justice: A construct 
Action Orientation 208

validation of a measure. Journal of Applied Psychology, 86, 386-400.

Conger, J., \& Kanungo, R. (1988). The empowerment process: Integrating theory and practice. Academy of Management Review, 13, 471-482.

Connolly, J., \& Viswesvaran, C. (2000). The role of affectivity in job satisfaction: A meta-analysis. Personality and Individual Differences, 29, 265-281.

Cook, T., Campbell, D., \& Day, A. (1979). Quasi-experimentation: Design \& analysis issues for field settings: Houghton Mifflin Boston.

Cooke, W. (1994). Employee participation programs, group-based incentives, and company performance: A union-nonunion comparison. Industrial and Labor Relations Review, 47, 594-610.

Cooper, C. (1998). Introduction. In C. Cooper (Ed.), Theories of organizational stress (pp. 1-5). Oxford: Oxford University Press.

Cooper, C., Liukkonen, P., \& Cartwright, S. (1996). The problem of workplace stress Stress prevention in the workplace: Assessing the costs and benefits to organisations (pp. 1-10). Luxembourg: European Communities.

Cortina, L.M., \& Magley, V.J. (2003). Raising voice, risking retaliation: Events following interpersonal mistreatment in the workplace. Journal of Occupational Health Psychology, 8(4), 247-265.

Crant, J.M. (1995). The proactive personality scale and objective job performance among real estate agents. Journal of Applied Psychology, 80, 532-537.

Crant, J.M. (2000). Proactive behavior in organizations. Journal of Management, 26, 435-462.

Crant, J.M., \& Bateman, T.S. (2000). Charismatic leadership viewed from above: The 
Action Orientation 209

impact of proactive personality. Journal of Organizational Behavior, 21, 63-75.

Cronbach, L., \& Meehl, P. (1955). Construct validation in psychological tests.

Psychological Bulletin, 52(4), 281-302.

Dawson, J. (2010). Interpreting interaction effects Retrieved September 30, 2010, from http://www.jeremydawson.co.uk/slopes.htm

De Dreu, C., \& Weingart, L. (2003). Task versus relationship conflict: A meta-analysis. Journal of Applied Psychology, 88, 741-749.

Dean, J.W., \& Bowen, D.E. (1994). Management theory and total quality: Improving research and practice through theory development. Academy of Management Journal, 19(3), 392-418.

Deci, E., \& Ryan, R. (1985). Intrinsic motivation and self-determination in human behavior. New York, NY: Springer.

Detert, J.R., \& Burris, E.R. (2007). Leadership behavior and employee voice: Is the door really open? Academy of Management Journal, 50, 869-884.

Donnellan, M.B., Oswald, F.L., Brendan, B.M., \& Lucas, R.E. (2006). The mini-ipip scales: Tiny-yet-effective measures of the big five factors of personality. Psychological Assessment, 18, 192-203.

Dutton, J., \& Ashford, S. (1993). Selling issues to top management. Academy of Management Review, 18, 397-428.

Eccles, T. (1993). The deceptive allure of empowerment. Long Range Planning, 26, 1321.

Edwards, J. (1992). A cybernetic theory of stress, coping, and well-being in organizations. Academy of Management Review, 17, 238-274. 
Action Orientation 210

Erdogan, B., \& Bauer, T.N. (2005). Enhancing career benefits of employee practive personality: The role of fit with jobs and organizations. Personnel Psychology, 58, $859-891$

Evangelista, A., \& Sims-Giddens, S. (2008). Gender differences in discipline of nurses in missouri. Western Journal of Nursing Research, 30(4), 501-514.

Evans, M. (1985). A monte carlo study of the effects of correlated method variance in moderated multiple regression analysis. . Organizational Behavior and Human Decision Processes, 36, 305-323.

Feldman, D. (2004). What are we talking about when we talk about theory? Journal of Management, 30, 565-567.

Ferris, G., Davidson, S., \& Perrewe, P. (2005). Political skill at work: Impact on work effectiveness. Mountain View, CA: Davies-Black Publishing.

Ferris, G., \& Judge, T. (1991). Personnel/human resources management: A political influence perspective. Journal of Management, 17, 447-488.

Ferris, G., Perrewé, P., \& Douglas, C. (2002). Social effectiveness in organizations: Construct validity and directions for future research. Journal of Leadership and Organizational Studies, 9, 49-63.

Ferris, G.R., Berkson, H.M., Kaplan, D.M., Gilmore, D.C., Buckley, M.R., Hochwarter, W.A. et al. (1999). Development and initial validation of the political skill inventory. Paper presented at the Academy of Managment, 59th Annual National Meeting.

Ferris, G.R., Perrewé, P.L., Anthony, W.P., \& Gilmore, D.C. (2000). Political skill at work. Organizational Dynamics, 28, 25-37. 
Action Orientation 211

Ferris, G.R., Treadway, D.C., Kolodinsky, R.W., Hochwarter, W.A., Kacmar, K.M., Douglas, C. et al. (2005). Development and validation of the political skill inventory. Journal of Management, 31, 126-152.

Ferris, G.R., Treadway, D.C., Perrewé, P.L., Brouer, R.L., Douglas, C., \& Lux, S. (2007). Political skill in organizations. Journal of Management, 33, 290-320.

Fishbein, M., \& Ajzen, I. (1974). Attitudes toward objects as predictors of single and multiple behavioral criteria. Psychological Review, 81, 59-74.

Fishbein, M., \& Ajzen, I. (1975). Belief, attitude, intention and behavior: An introduction to theory and research. Reading, MA: Addison Wesley.

Florida Center for Nursing (2010). Florida's rn and arnp supply: Growth, demographics, and employment characteristics. Retrieved from www.FLCenterForNursing.org

Ford, D., Truxillo, D., \& Bauer, T. (2009). Rejected but still there: Shifting the focus in applicant reactions to the promotional context. International Journal of Selection and Assessment, 17(4), 402-416.

French, J., \& Raven, B.H. (1959). The bases of social power. In D. Cartwright (Ed.), Studies in social power (pp. 150-167). Ann Arbor, MI: Institute for Social Research.

Frese, M., Fay, D., Hilburger, T., Leng, K., \& Tag, A. (1997). The concept of personal initiative: Operationalization, reliability and validity in two german samples. Journal of Occupational and Organizational Psychology, 70, 139-161.

Frese, M., \& Fray, D. (2001). Personal initiative: An active performance concept for work in the 21st century. Research in Organizational Behavior, 23, 133-188.

Frese, M., Kring, W., Soose, A., \& Zempel, J. (1996). Personal initiative at work: 
Action Orientation 212

Differences between East and West Germany. Academy of Management Journal, 39, 37-63.

Fritz, C., \& Sonnentag, S. (2009). Antecedents of day level proactive behavior: A look at job stressors and positive affect during the workday. Journal of Management, 35, 94-111.

Gecas, V. (1989). The social psychology of self-efficacy. Annual Reviews in Sociology, 15, 291-316.

Gerstner, C.R., \& Day, D.V. (1997). Meta-analytic review of leader-member exchange theory: Correlates and construct issues. Journal of Applied Psychology, 82, 827844.

Gist, M. (1987). Self-efficacy: Implications for organizational behavior and human resource management. Academy of Management Review, 12, 472-485.

Gist, M., \& Mitchell, T. (1992). Self-efficacy: A theoretical analysis of its determinants and malleability. Academy of Management Review, 17, 183-211.

Graen, G. (1976). Role-making processes within complex organizations. In M. D. Dunnette (Ed.), Handbook of industrial and organizational psychology (pp. 12011245). Chicago, IL: Rand McNally.

Graen, G., \& Uhl-Gien, M. (1995). Relationships based approach to leadership: Development of leader-member exchange $(\operatorname{lmx})$ theory of leadership over 25 years: Applying a multi-level multi-domain perspective. The Leadership Quarterly, 6, 219-247.

Grant, A.M., \& Ashford, S.J. (2008). The dynamics of proactivity at work. Research in Organizational Behavior, 28, 3-34. 
Action Orientation 213

Green, S.G., \& Bauer, T.N. (1995). Supervisory mentoring by advisers: Relationships with doctoral student potential, productivity, and commitment. Personnel Psychology, 48, 537-562.

Greenberg, J. (2006). Losing sleep over organizational injustice: Attenuating insomniac reactions to underpayment inequity with supervisory training in interactional justice. Journal of Applied Psychology, 91, 58-69.

Griffin, M., Neal, A., \& Parker, S. (2007). A new model of work role performance: Positive behavior in uncertain and interdependent contexts. The Academy of Management Journal, 50, 327-347.

Hackman, J., \& Oldham, G. (1975). Development of the job diagnostic survey. Journal of Applied Psychology, 60, 159-170.

Hackman, J., \& Oldham, G. (1980). Work redesign reading. MA: Addison-Wesley.

Harackiewicz, J.M., Sansone, C., \& Manderlink, G. (1985). Competence, achievement orientation, and intrinsic motivation: A process analysis. Journal of Personality and Social Psychology, 48, 493-508.

Hardy, C., \& Leiba-O'sullivan, S. (1998). The power behind empowerment: Implications for research and practice. Human Relations, 51, 451-483.

Harris, K.J., Kacmar, K.M., Zivnuska, S., \& Shaw, J.D. (2007). The impact of political skill on impression management effectiveness. Journal of Applied Psychology, $92,278-285$.

Harvey, M., \& Novicevic, M. (2004). The development of political skill and political capital by global leaders through global assignments. The International Journal of Human Resource Management, 15, 1173-1188. 
Action Orientation 214

Harvey, S., Blouin, C., \& Stout, D. (2006). Proactive personality as a moderator of outcomes for young workers experiencing conflict at work. Personality and Individual Differences, 40, 1063-1074.

Hatcher, S., \& Laschinger, H.K.S. (1996). Staff nurses' perceptions of job empowerment and level of burnout: A test of kanter's theory of structural power in organizations. Canadian Journal of Nursing Administration, 9(2), 74-94.

Hertog, D., \& Beischak, F. (2007). Personal initiative, commitment and affect at work. Journal of Occupational and Organization Psychology, 80, 601-622.

Herzberg, F. (1966). Work and nature of man. Cleveland, OH: The Word Publishing Co.

Hinshaw, A.S., \& Atwood, J.R. (1983). Nursing staff turnover, stress and satisfaction: Models, measures, and management. Annual Review of Nursing Research, 1, 133153.

Hirschman, A.O. (1970). Exit, voice, and loyalty: Responses to decline in firms, organizations, and states. Cambridge, MA: Harvard University Press.

Hobfoll, S.E. (1988). The ecology of stress. New York, NY: Hemisphere.

Hobfoll, S.E. (1989). Conservationof resources: A new attempt at conceptualizing stress. American Psychologist, 44, 513-524.

Hough, L. (2003). Emerging trends and needs in personality research and practice: Beyond main effects. In M. R. Barrick \& A. M. Ryan (Eds.), Personality and work (pp. 289-325). San Francisco, CA: Jossey-Bass.

House, R., \& Rizzo, J. (1972). Role conflict and ambiguity as critical variables in a model of organizational behavior. Organizational Behavior and Human Performance, 7, 467-505. 
Action Orientation 215

Hulin, C., \& Judge, T. (2003). Job attitudes. In W. C. Borman, D. R. Ilgen \& R. J. Klimoski (Eds.), Handbook of psychology: Industrial and organizational psychology (Vol. 12, pp. 255-276). Hoboken, NJ: John Wiley \& Sons, Inc.

Hulin, C.L. (2002). Lessons from industrial and organizational psychology. In J. M. Herman \& F. Drasgow (Eds.), The psychology of work (pp. 3-22). Nahway, NJ: Erlbaum.

Hunter, J.E. (1983). A causal analysis of cognitive ability, job knowledge, job performance and supervisory ratings. In F. J. Landy, S. Zedeck \& J. Cleveland (Eds.), Performance measurement and theory (pp. 257-266). Hillsdale, NJ: Erlbaum.

Hunter, S., Brace, S., \& Buckley, G. (1993). The lnter-disciplinary assessment of older people at entry into long-term institutional care lessons for the new commumty care arrangements. Research, Policy and Planning, 11, 2-9.

Hurrell, J.J., Nelson, D., \& Simmons, B. (1998). Measuring job stressors and strains: Where we have been, where we are, and where we need to go. Journal of Occupational Health Psychology, 3, 368-389.

Jex, S., \& Beehr, T. (1991). Emerging theoretical and methodological issues in the study of work-related stress. Research in Personnel and Human Resources Management, 9, 1-365.

Judge, T., Locke, E., Durham, C., \& Kluger, A. (1998). Dispositional effects on job and life satisfaction: The role of core evaluations. Journal of Applied Psychology, 83(1), 17-34.

Judge, T.A., \& Bono, J.E. (2001). Relationship of core self-evaluations traits-self-esteem, 
Action Orientation 216

generalized self-efficacy, locus of control, and emotional stability-with job satisfaction and job performance: A meta-analysis. Journal of Applied Psychology, 86, 80-92.

Judge, T.A., Erez, A., Bono, J.E., \& Thoresen, C.J. (2003). The core self-evaluations scale: Development of a measure. Personnel Psychology, 56, 303-331.

Judge, T.A., \& Hulin, C.L. (1993). Job satisfaction as a reflection of disposition: A multiple source causal analysis. Organizational Behavior and Human Decision Processes, 56, 388-421.

Kanfer, F. (1970). Self-regulation: Research, issues and speculations. In C. N. J. I. Michael (Ed.), Behavior modification in clinical psychology (pp. 178-220). New York, NY: Appleton-Century-Crofts.

Kanter, R. (1977). Men and women of the corporation. New York, NY: Basic Books.

Kanter, R.M. (1979). Power failure in management circuits. Harvard Business Review, $57(4), 65-75$.

Karasek, R. (1979). Job demands, job decision latitude, and mental strain: Implications for job redesign. Administrative Science Quarterly, 24, 285-308.

Karoly, P. (1993). Mechanisms of self-regulation: A systems view. Annual Reviews in Psychology, 44, 23-52.

Katz, D., \& Kahn, R.L. (1978). The social psychology of organizations. New York, NY: Wiley.

Kickul, J., \& Guidry, L.K. (2002). Prospecting for strategic advantage: The proactive entrepreneurial personality and small firm innovation. Journal of Small Business Management, 40, 85-97. 
Action Orientation 217

Kirkman, B.L., \& Rosen, B. (1999). Beyond self-management: Antecedents and consequences of team empowerment. Academy of Management Journal, 42, 5874.

Kizilos, P. (1990). Crazy about empowerment? Training, 27, 47-56.

Knights, D. (1992). Changing spaces: The disruptive impact of a new epistemological location for the study of management. Academy of Management Review, 17, 514536.

Kolodinsky, R., Hochwarter, W., \& Ferris, G. (2004). Nonlinearity in the relationship between political skill and work outcomes: Convergent evidence from three studies. Journal of Vocational Behavior, 65, 294-308.

Krehbiel, P.J., \& Cropanzano, R. (2000). Procedural justice, outcome favorability and emotion. Social Justice Research, 13, 339-360.

Kristof-Brown, A., Zimmerman, R., \& Johnson, E. (2005). Consequences of individuals'fit at work: A meta analysis of person-job, person-organization, person-group, and person-supervisor fit. Personnel Psychology, 58(2), 281-342.

Lacey, A., \& Wright, B. (2009). Occupational employment projections to 2018.

Langer, E. (1983). The psychology of control. Beverly Hills, CA: Sage Publications.

Laschinger, H., \& Finegan, J. (2005). Using empowerment to build trust and respect in the workplace: A strategy for addressing the nursing shortage. Nursing Economics, 23(1), 6-13.

Laschinger, H., Finegan, J., Shamian, J., \& Wilk, P. (2004). A longitudinal analysis of the impact of workplace empowerment on work satisfaction. Journal of Organizational Behavior, 25(4), 527-545. 
Action Orientation 218

Laschinger, H., Finegan, J., Wilk, P., \& Shamian, J. (2000). A confirmatory factor analysis of the cweq, jas, ors: Working paper, University of Western Ontario.

Laschinger, H.K.S., Finegan, J., Shamian, J., \& Wilk, P. (2001). Impact of structural and psychological empowerment on job strain in nursing work settings: Expanding kanter's model. Journal of nursing Administration, 31(5), 260-272.

Laschinger, H.K.S., Wilk, P., Cho, J., \& Greco, P. (2009). Empowerment, engagement and perceived effectiveness in nursing work environments: Does experience matter? Journal of Nursing Management, 17, 636-645.

Lawler, E. (1992). The ultimate advantage: Creating the high-involvement organization. San Francisco, CA: Jossey-Bass.

Lawler III, E. (1986). High-involvement management. Participative strategies for improving organizational performance. San Francisco, CA: Jossey-Bass.

Leach, D., Wall, T., \& Jackson, P. (2003). The effect of empowerment on job knowledge: An empirical test involving operators of complex technology. Journal of Occupational and Organizational Psychology, 76, 27-52.

Lepine, J., \& Van Dyne, L. (1998). Predicting voice behavior in work groups. Journal of Applied Psychology, 83, 853-868.

Levy, D., Collins, B., \& Nail, P. (1998). A new model of interpersonal influence characteristics. Journal of Social Behavior and Personality, 13, 715-734.

Lewin, K. (1936). Principles of topological psychology. New York, NY: McGraw-Hill. Liden, R., \& Graen, G. (1980). Generalizability of the vertical dyad linkage model of leadership. Academy of Management Journal, 23, 451-465.

Liden, R., Wayne, S.J., \& Sparrowe, R. (2000). An examination of the mediating role of 
Action Orientation 219

psychological empowerment on the relations between the job, interpersonal relationships, and work outcomes. Journal of Applied Psychology, 85, 407-416.

Liedtka, J. (1999). Linking competitive advantage with communities of practice. Journal of Management Inquiry, 8, 5-16.

Lim, S., \& Cortina, L.M. (2005). Interpersonal mistreatment in the workplace: The interface and impact of general incivility and sexual harassment. Journal of Applied Psychology, 90(3), 483-496.

Lin, N. (2001). Building a network theory of social capital. In K. Cook \& R. Burt (Eds.), Social capital: Theory and research (pp. 3-29). Piscataway, NJ: Aldine Transaction.

Lind, E.A. (2001). Fairness heuristic theory: Justice judgments as pivotal cognitions in organizational settings. In Greenberg \& R. J. and Cropanzano (Eds.), Advances in organizational justice. (pp. 56-88). Stanford, CA: Stanford University Press.

Liu, Y., Ferris, G., Zinko, R., Perrewè, P., Weitz, B., \& Xu, J. (2007). Dispositional antecedents and outcomes of political skill in organizations: A four-study investigation with convergence. Journal of Vocational Behavior, 71(1), 146-165.

Locke, E. (1976). The nature and causes of job satisfaction. Handbook of industrial and organizational psychology, 1, 1297-1343.

Locke, E. (1991). The motivation sequence, the motivation hub, and the motivation core. Organizational Behavior and Human Decision Processes, 50, 288-299.

Locke, E., Frederick, E., Lee, C., \& Bobko, P. (1984). Effect of self-efficacy, goals, and task strategies on task performance. Journal of Applied Psychology, 69, 241-251. Major, D., Turner, J., \& Fletcher, T. (2006). Linking proactive personality and the big 
Action Orientation 220

five to motivation to learn and development activity. Journal of Applied Psychology, 91, 927-935.

Martinko, M., \& Gardner, W. (1982). Learned helplessness: An alternative explanation for performance deficits. Academy of Management Review, 7, 195-204.

Mathieu, J., Ahearne, M., \& Taylor, S. (2007). A longitudinal cross-level model of leader and salesperson influences on sales force technology use and performance. Journal of Applied Psychology, 92, 528-537.

Matteson, M., \& Ivancevich, J. (1987). Controlling work stress: Effective human resource and management strategies. San Francisco, CA: Jossey-Bass.

Mccrae, R.R., \& Costa, P.T. (1990). Personality in adulthood. New York: The Guilford Press.

Mcdermott, K., Laschinger, H.K.S., \& Shamian, J. (1996). Work empowerment and organizational commitment. Nursing Management, 27(5), 44-48.

Meijman, T., \& Mulder, G. (1998). Psychological aspects of workload. Handbook of work and organizational psychology: Work psychology, 2, 5-33.

Merriam Webster (2008, October 17, 2008). from http://www.merriamwebster.com/dictionary/proactive

Meyer, R., Dalal, R., \& Hermida, R. (2010). A review and synthesis of situational strength in the organizational sciences. Journal of Management, 36(1), 121-140.

Mintzberg, H. (1983). Power in and around organizations. Englewood Cliffs, NJ: Prentice-Hall.

Mischel, W. (1977). The interaction of person and situation. In D. Magnusson \& N. Endler (Eds.), Personality at the crossroads: Current issues in interactional 
psychology. Hillsdale, NJ: Erlbaum.

Mischel, W., \& Shoda, Y. (1995). A cognitive-affective system theory of personality: Reconceptualizing situations, dispositions, dynamics, and invariance in personality structure. Psychological Review, 102, 246-246.

Mitchell, T.R., \& Daniels, D. (2003). Motivation. In W. C. Borman, D. R. Ilgen \& R. J. Klimoski (Eds.), Handbook of psychology: Industrial organizational psychology (Vol. 12, pp. 225-254). Hoboken, NJ: John Wiley \& Sons, Inc.

Morgeson, F.P., \& Humphrey, S.E. (2006). The work design questionnaire (wdq): Developing and validating a comprehensive measure for assessing job design and the nature of work Journal of Applied Psychology, 91, 1321-1339.

Morrison, E.W. (1993). Longitudinal study of effects of information seeking on newcomer socialization. Journal of Applied Psychology, 78, 173-183.

Morrison, E.W. (1994). Role definitions and organizational citizenship behavior: The importance of the employee's perspective. Academy of Management Journal, 37, $1543-1562$.

Morrison, E.W., \& Phelps, C.C. (1999). Taking charge at work: Extrarole efforts to initiate workplace change. Academy of Management Journal, 42, 403-419.

Motowidlo, S.J. (2003). Job performance. In W. C. Borman, D. R. Ilgen \& R. J. Klimoski (Eds.), Handbook of psychology: Industrial and organizational psychology (Vol. 12, pp. 39-53). Hoboken, NJ: John Wiley \& Sons, Inc.

Motowidlo, S.J., Hooper, A.C., \& Jackson, H.L. (2006). Implicit policies about relations between personality traits and behavioral effectiveness in situational judgment items. Journal of Applied Psychology, 91, 749-761. 
Action Orientation 222

Muraven, M., \& Baumeister, R. (2000). Self-regulation and depletion of limited resources: Does self-control resemble a muscle? Psychological Bulletin, 126(2), 247-259.

Nelson, D., \& Simmons, B. (2003). Health psychology and work stress: A more positive approach. In J. C. Quick \& L. E. Tetrick (Eds.), Handbook of occupational health psychology (pp. 97-119). Washington DC: American Psychological Association.

Nolan, M., Walker, G., Nolan, J., Williams, S., Poland, F., Curran, M. et al. (1996). Entry to care: Positive choice or fait accompli? Developing a more proactive nursing response to the needs of older people and their carers. Journal of Advanced Nursing, 24, 265-274.

O*NET (2008a). Details report for: 29-1111.00 - registered nurses. In o*net online. Retrieved from http://online.Onetcenter.Org/link/summary/27-2011.00

O*NET (2008b). Summary report for: 29-1111.00 - registered nurses. In o*net online. Retrieved from http://online.Onetcenter.Org/link/summary/27-2011.00

Oregon Center for Nursing \& Oregon Healthcare Workforce Institute (2010). Oregon health professions: Occupational and county profiles. Retrieved from www.oregoncenterfornursing.org

Oregon Health \& Science University (2010). OHSU school of nursing helps launch oregon assembly for men in nursing, from http://www.ohsu.edu/xd/about/news_events/news/2010/2010-10-04-ohsu-schoolof-nurs.cfm

Orlovsky, C. (2006). Mass nurse retirement expected in 2011: Survey, from http://www.amnhealthcare.com/News.aspx?id=15444 
Action Orientation 223

Parker, S. (2003). Longitudinal effects of lean production on employee outcomes and the mediating role of work characteristics. Journal of Applied Psychology, 88, 620634.

Parker, S., \& Collins, C. (2010). Taking stock: Integrating and differentiating multiple proactive behaviors. Journal of Management, 36(3), 633-663.

Parker, S.K. (1998). Enhancing role breadth self-efficacy: The roles of job enrichment and other organizational interventions. Journal of Applied Psychology, 83, 835852.

Parker, S.K., \& Sprigg, C.A. (1999). Minimizing strain and maximizing learning: The role of job demands, job control, and proactive personality. Journal of Applied Psychology, 84, 925-939.

Parker, S.K., Wall, T.D., \& Jackson, P.R. (1997). "That's not my job": Developing flexible employee work orientations. Academy of Management Journal, 40, 899929.

Parker, S.K., Williams, H.M., \& Turner, N. (2006). Modeling the antecedents of proactive behavior at work. Journal of Applied Psychology, 91, 636-652.

Parkes, K. (1990). Coping, negative affectivity, and the work environment: Additive and interactive predictors of mental health. Journal of Applied Psychology, 75, 399409.

Parkes, K. (1994). Personality and coping as moderators of work stress processes: Models, methods and measures. Work \& Stress, 8, 110-129.

Perrewé, P., Ferris, G., Frink, D., \& Anthony, W. (2000). Political skill: An anecdote for workplace stressors. The Academy of Management Executive, 14, 115-123. 
Action Orientation 224

Pettigrew, A. (1973). The politics of organizational decision-making. New York, NY: Harper Collins Publishers.

Pfeffer, J. (1981). Power in organizations. Boston, MA: Pitman.

Pfeffer, J. (1992). Managing with power. Boston, MA: Harvard Business School Press.

Podsakoff, P.M., Mackenzie, S.B., Lee, J.Y., \& Podsakoff, N.P. (2003). Common method biases in behavioral research: A critical review of the literature and recommended remedies. Journal of Applied Psychology, 88, 879-903.

Princeton University (2003, October 17, 2008). from http://wordnet.princeton.edu/perl/webwn?s=proactive\&sub=Search+WordNet\&o $\underline{2=\& 00=1 \& 07=\& 05=\& 01=1 \& 06=\& 04=\& 03=\& h=}$

Pulakos, E.D., Arad, S., Donovan, M.A., \& Plamondon, K.E. (2000). Adaptability in the workplace: Development of a taxonomy of adaptive performance. Journal of Applied Psychology, 85, 612-624.

Ray, E., \& Miller, K. (1994). Social support, home/work stress, and burnout: Who can help? The Journal of Applied Behavioral Science, 30, 357-373.

Robert, C., Probst, T., Martocchio, J., Drasgow, F., \& Lawler, J. (2000). Empowerment and continuous improvement in the united states, mexico, poland, and india: Predicting fit on the basis of the dimensions of power distance and individualism. Journal of Applied Psychology, 85, 643-658.

Roy, M., \& Steptoe, A. (1994). Daily stressors and social support availability as predictors of depressed mood in male firefighters. Work and Stress, 8, 210-219.

Ryan, R., \& Deci, E. (2000). Self-determination theory and the facilitation of intrinsic motivation, social development, and well-being. American Psychologist, 55(1), 
$68-78$.

Salancik, G.R., \& Pfeffer, J. (1978). A social information processing approach to job attitudes and task design. Administrative Science Quarterly, 23, 224-253.

Schein, E. (1971). Occupational socialization in the professions: The case of role innovation. Journal of Psychiatric Research, 8, 521-530.

Schmidt, F., \& Hunter, J. (1998). The validity and utility of selection methods in personnel psychology: Practical and theoretical implications of 85 years of research findings. Psychological Bulletin, 124, 262-274.

Schmidt, F.L., Hunter, J.E., \& Outerbridge, A.N. (1986). Impact of job experience and ability on job knowledge, work sample performance, and supervisory ratings of job performance. Journal of Applied Psychology, 71, 432-439.

Schneider, B. (1987). The people make the place. Personnel Psychology, 40, 437-453.

Schneider, B. (2000). The psychological life of organizations. In N. M. Ashkanasy, C. P. M. Wilderom \& M. F. Peterson (Eds.), Handbook of organizational culture and climate (pp. xvii-xxi). Thousand Oaks, CA: Sage.

Schneider, B., Kristof-Brown, A., Goldstein, H., \& Smith, D. (1997). What is this thing called fit? In N. A. P. Herriot (Ed.), International handbook of selection and assessment (pp. 393-412). London: Wiley.

Schwarzer, R., \& Taubert, S. (2002). Tenacious goal pursuits and striving toward personal growth: Proactive coping.

Seibert, S.E., Crant, J.M., \& Kraimer, M.L. (1999). Proactive personality and career success. Journal of Applied Psychology, 84, 416-427.

Seibert, S.E., Kraimer, M.L., \& Crant, J.M. (2001). What do proactive people do? A 
Action Orientation 226

longitudinal model linking proactive personality and career success. Personnel Psychology, 54, 845-874.

Semadar, A., Robins, G., \& Ferris, G. (2006). Comparing the validity of multiple social effectiveness constructs in the prediction of managerial job performance. Journal of Organizational Behavior, 27, 443-461.

Shortell, S., Rousseau, D., Gillies, R., Devers, K., \& Simons, T. (1991). Organizational assessment in intensive care units (icus): Construct development, reliability, and validity of the icu nurse-physician questionnaire. Medical Care, 709-726.

Siegrist, J. (1996). Adverse health effects of high-effort/low-reward conditions. Journal of Occupational Health Psychology, 1, 27-41.

Smith, B., \& Zauntra, A. (2002). The role of personality in exposure and reactivity to interpersonal stress in relation to arthritis disease activity and negative affect in women. Health Psychology, 21, 81-88.

Snyder, M., \& Monson, T.C. (1975). Persons, situations and the control of social behavior. Journal of Personality and Social Psychology, 32, 637-644.

Snyder, M., \& Copeland, M. (1989). Self-monitoring processes in organizational settings. In R. A. Giacolone \& P. Rosenfeld (Eds.), Impression management in the organization (pp. 7-19). Hillsdale, NJ: Erlbaum.

Solon, G. (1989). The value of panel data in economic research. New York: John Wiley and Sons.

Spector, P. (1986). Perceived control by employees: A meta-analysis of studies concerning autonomy and participation at work. Human Relations, 39, 10051016. 
Action Orientation 227

Spector, P., \& Brannick, M. (2010). Methodological urban legends: The misuse of statistical control variables. Organizational Research Methods.

Spielberger, C.D., Vagg, P.R., \& Wasala, C.F. (2003). Occupational stress: Job pressures and lack of support. In J. C. Quick \& L. E. Tetrick (Eds.), Handbook of occupational health psychology. Washington, DC: American Psychological Association.

Spreitzer, G.M. (1995a). An empirical examination of a comprehensive model of psychological empowerment in the workplace. American Journal of Community Psychology, 23, 601-629.

Spreitzer, G.M. (1995b). Individual empowerment in the workplace: Dimensions, measurement, and validation. Academy of Management Journal, 38, 1442-1465. Spreitzer, G.M., Kizilos, M.A., \& Nason, S.W. (1997). A dimensional analysis of the relationship between psychological empowerment and effectiveness satisfaction, and strain. Journal of Management, 23, 679-704.

Stanton, J., Balzer, W., Smith, P., Parra, L., \& Ironson, G. (2001). A general measure of work stress: The stress in general scale. Educational and Psychological Measurement, 61, 866-887.

Staw, B., \& Boettger, R. (1990). Task revision: A neglected form of work performance. Academy of Management Journal, 33, 534-559.

Stober, J. (2001). The social desirability scale-17 (sds-17): Convergent validity, discriminant validity, and relationship with age. European Journal of Psychological Assessment, 17, 222-232.

Sutton, R., \& Kahn, R. (1987). Prediction, understanding, and control as antidotes to 
Action Orientation 228

organizational stress. In J. Lorsch (Ed.), Handbook of organizational behavior (pp. 272-285). Englewood Cliffs, NJ: Prentice-Hall.

Terborg, J. (1981). Interactional psychology and research on human behavior in organizations. Academy of Management Review, 6, 569-576.

Tett, R., \& Guterman, H. (2000). Situation trait relevance, trait expression, and crosssituational consistency: Testing a principle of trait activation. Journal of Research in Personality, 34, 397-423.

Thomas, K., \& Tymon, W. (1994). Does empowerment always work: Understanding the role of intrinsic motivation and personal interpretation. Journal of Management Systems, 6, 1-13.

Thomas, K., \& Velthouse, B. (1990). Cognitive elements of empowerment. Academy of Management Review, 15, 666-681.

Thompson, J. (2005). Proactive personality and job performance: A social capital perspective. Journal of Applied Psychology, 90, 1011-1017.

Topping, K., Bremner, W., \& Holmes, E.A. (2000). Social competence: The social construction of the concept. In R. Bar-On \& J. D. A. Parker (Eds.), Handbook of emotional intelligence: Theory, development, assessment, and application at home, school and in the workplace (pp. 28-39). San Francisco, CA: Jossey-Bass.

Treadway, D., Hochwarter, W., Ferris, G., Kacmar, C., Douglas, C., Ammeter, A. et al. (2004). Leader political skill and employee reactions. The Leadership Quarterly, $15,493-513$.

US Department of Health and Human Services (2010). Nurse population: Findings from the 2008 national sample survey of registered nurses. 
Action Orientation 229

Van Der Doef, M., \& Maes, S. (1999). The job demand-control (-support) model and psychological well-being: A review of 20 years of empirical research. Work \& Stress, $13,87-114$.

Van Der Hek, H., \& Plomp, H. (1997). Occupational stress management programmes: A practical overview of published effect studies. Occupational Medicine, 47, 133141.

Van Dyne, L., Cummings, L., \& McLean Parks, J. (1995). Extra-role behaviors: In pursuit of construct and definitional clarity. In L. L. Cummings \& B. M. Staw (Eds.), Research in organizational behavior (Vol. 17, pp. 215-285). Greenwich, CT: JAI Press.

Vancouver, J.B. (2000). Self-regulation in industrial/organiational psychology: A tale of two paradigms. In M. Boekaerts, P. R. Pintrick \& M. Zeidner (Eds.), Handbook of self-regulation (pp. 303-341). San Diego, CA: Academic Press.

Vancouver, J.B., Thompson, D.E., \& Williams, K.Y. (2001). The changing signs in the relationship among self-efficacy, personal goals, and performance. Journal of Applied Psychology, 86, 605-620.

Vroom, V.H. (1964). Work and motivation. New York, NY: Wiley Press.

Wayne, S.J., \& Liden, R.C. (1995). Effects of impression management on performance ratings: A longitudinal study. Academy of Management Journal, 38, 232-260.

Weick, K. (1979). The social psychology of organizing. Reading, MA: Addison Wesley.

Wells, N., Roberts, L., \& Medlin, L.C. (2002). Issues related to staff retention and turnover. Seminars for Nurse Managers, 10(3), 171-179.

Whetten, D. (1989). What constitutes a theoretical contribution? Academy of 
Management Review, 14, 490-495.

White, R. (1959). Motivation reconsidered: The concept of competence. Psychology Review, 66, 297-333.

Wilkinson, A. (1998). Empowerment: Theory and practice. Personnel Review, 27, 40-56.

Williams, L., \& Anderson, S. (1991). Job satisfaction and organizational commitment as predictors of organizational citizenship and in-role behaviors. Journal of Management, 17, 601-617.

Witt, L.A., Burke, L.A., Barrick, M.R., \& Mount, M.K. (2002). The interactive effects of conscientiousness and agreeableness on job performance. Journal of Applied Psychology, 87, 164-169.

Yeo, G.B., \& Neal, A. (2006). An examination of the dynamic relationship between selfefficacy and performance across levels of analysis and levels of specificity. Journal of Applied Psychology, 91, 1088-1101.

Yukl, G., \& Falbe, C.M. (1990). Influence tactics and objectives in upward, downward, and lateral influence attempts. Journal of Applied Psychology, 75, 132-140.

Yukl, G., \& Tracey, J.B. (1992). Consequences of influence tactics used with subordinates, peers, and the boss. Journal of Applied Psychology, 77, 525-535. 
Appendix: Scale Items

Proactive Personality

I am constantly on the lookout for new ways to improve my life

Wherever I have been, I have been a powerful force for constructive change

Nothing is more exciting than seeing my ideas turn into reality

If I see something I don't like, I fix it

No matter what the odds, if I believe in something I will make it happen

I love being a champion for my ideas, even against others' opposition

I excel at identifying opportunities

I am always looking for better ways to do things

If I believe in an idea, no obstacle will prevent me from making it happen

I can spot a good opportunity long before others can

Psychological Empowerment

Meaning

The work I do is very important to me

My job activities are personally meaningful to me

The work I do is meaningful to me

Self-Determination

I have significant autonomy in determining how I do my job

I can decide on my own how to go about doing my work

I have considerable opportunity for independence and freedom in how I do my job

Impact

My impact on what happens in my unit is large

I have a great deal of control over what happens in my unit

I have significant influence over what happens in my unit

Competence

I am confident about my ability to do my job

I am self-assured about my capabilities to perform my work activities

I have the skills necessary for my job 
Political Skill Inventory

I find it easy to envision myself in the position of others.

I am able to make most people feel comfortable and at ease around me.

It is easy for me to develop good rapport with most people.

I understand people very well.

I am good at getting others to respond positively to me.

I usually try to find common ground with others.

In-Role Task Performance

I engage in activities that positively affect my performance evaluation.

I meet formal performance requirements of the job.

I adequately complete assigned duties.

I fulfill responsibilities specified in the job description.

I perform essential job duties.

I perform tasks that are expected of me.

Stress in General

Demanding

Pressured

Hectic

Calm (R)

Relaxed (R)

Many things stressful

Pushed

Irritating

Under control (R)

Nerve-wracking

Hassled

Comfortable (R)

More stressful than I'd like

Smooth running $(\mathrm{R})$

Overwhelming

Strain: Job Induced Tension

My job tends to directly affect my health

I work under a great deal of tension

I have felt fidgety or nervous as a result of my job

If I had a different job, my health would probably improve

Problems associated with my job have kept me awake at night

I have felt nervous before attending meetings in the company

I often "take my job home with me" in the sense that I think about it when doing 
other things

\section{Strain: Emotional Exhaustion Scale}

I feel emotionally drained from my work

I feel used up at the end of the workday

I feel fatigue when I get up in the morning and have to face another day on the job

I feel burned out from my work

I feel frustrated by my job

I feel I'm working too hard on my job

Working directly with people puts too much stress on me

I feel like I'm at the end of my rope

Conscientiousness

I get chores done right away.

I often forget to put things back in their proper place. (R)

I like order.

I make a mess of things. (R)

Core Self-Evaluations Scale

1. I am confident I get the success I deserve in life

2. Sometimes I feel depressed (R)

3. When I try, I generally succeed

4. Sometimes when I fail I feel worthless (R)

5. I complete tasks successfully

6. Sometimes, I do not feel in control of my work (R)

7. Overall, I am satisfied with myself

8. I am filled with doubts about my competence (R)

9. I determine what will happen in my life

10. I do not feel in control of my success in my career (R)

11. I am capable of coping with most of my problems

12. There are times when things look pretty bleak and hopeless to me (R)

Organization Justice

Procedural Justice

I am able to express my views and feelings regarding my unit's procedures

I have influence over the outcomes arrived at by my unit's procedures

My unit's procedures are applied consistently

My unit's procedures are free of bias

My unit's procedures are based on accurate information

I have been able to appeal the outcomes arrived at by my unit's procedures 
My unit's procedures have upheld ethical and moral standards

Distributive Justice

My outcomes (e.g., performance appraisals, promotions) reflect the effort I have put into my work

My outcomes (e.g., performance appraisals, promotions) are appropriate for the work I have completed

My outcomes (e.g., performance appraisals, promotions) reflect what I have contributed to the unit.

My outcomes (e.g., performance appraisals, promotions) are justified, given my performance

\section{Role Breadth Self-Efficacy}

Analyzing a long-term problem to find a solution

Representing your work area in meetings with senior management

Designing new procedures for your work area

Making suggestions to management about ways to improve the working of your section

Contributing to discussions about the company's strategy

Writing a proposal to spend money in your work area

Helping to set targets/goals in your work area

Contacting people outside the company (e.g., suppliers, customers) to discuss

problems

Presenting information to a group of colleagues

Visiting people from other departments to suggest doing things differently 
Job Enlargement

This employee does a range of different things

This employee makes full use of their skills

This employee uses a variety of skills

Turnover Intentions

I often think about quitting.

I will likely start actively looking for a new job in the next year.

Perceived Overqualification

My talents are not fully utilized on my job

My work experience is more than necessary to do my present job

Based on my skills, I am overqualified for the job I hold

Leader Member Exchange

I like my shift manager/charge nurse very much as a person

My shift manager/charge nurse is the kind of person one would like to have as a friend

My shift manager/charge nurse is a lot of fun to work with

My shift manager/charge nurse defends my work actions to a superior, even

without complete knowledge of the issue in question

My shift manager/charge nurse would come to my defense if I were "attacked" by others

My shift manager/charge nurse would defend me to others in the organization if I made an honest mistake

I do work for my shift manager/charge nurse that goes beyond what is specified in my job description.

I am willing to apply extra efforts, beyond those normally required, to further the interests of my work group

I am impressed with my shift manager's/charge nurse's knowledge of his/ her job I respect my shift manager's/charge nurse's knowledge of and competence on the job

I admire my shift manager's/charge nurse's professional skills

\section{Self-monitoring}

I would probably make a good actor.

I'm not always the person I appear to be.

I may deceive people by being friendly when I really dislike them.

In different situations and with different people, I often act like very different persons. 
I have considered being an entertainer.

I guess I put on a show to impress or entertain others.

I can look anyone in the eye and tell a lie with a straight face (if for a right end).

Structural Empowerment

\section{HOW MUCH OF EACH KIND OF OPPORTUNITY DO YOU HAVE IN YOUR PRESENT JOB?}

Challenging work

The chance to gain new skills and knowledge on the job.

Tasks that use all of your own skills and knowledge.

HOW MUCH ACCESS TO INFORMATION DO YOU HAVE IN YOUR PRESENT JOB?

The current state of the hospital.

The values of top management.

The goals of top management.

\section{HOW MUCH ACCESS TO SUPPORT DO YOU HAVE IN YOUR PRESENT JOB?}

Specific information about things you do well.

Specific comments about things you could improve.

Helpful hints or problem solving advice.

HOW MUCH ACCESS TO RESOURCES DO YOU HAVE IN YOUR PRESENT JOB?

Time available to do necessary paperwork.

Time available to accomplish job requirements.

Acquiring temporary help when needed.

IN MY WORK SETTING/JOB:

In your present position, how often are you rewarded for innovation on the job?

In your present position, how much flexibility do you have on the job?

In your present position, how much visibility does your work-related activities within the institution receive?

HOW MUCH OPPORTUNITY DO YOU HAVE FOR THESE ACTIVITIES IN YOUR PRESENT JOB?

Collaborating on patient care with physicians.

Being sought out by peers for help with problems

Being sought out by managers for help with problems

Seeking out ideas from professionals other than physicians, e.g., Physiotherapists, Occupational Therapists, Dieticians. 
Overall empowerment:

Overall, my current work environment empowers me to accomplish my work in an effective manner.

Overall, I consider my workplace to be an empowering environment.

Self-monitoring

I would probably make a good actor.

I'm not always the person I appear to be.

I may deceive people by being friendly when I really dislike them.

In different situations and with different people, I often act like very different persons.

I have considered being an entertainer.

I guess I put on a show to impress or entertain others.

I can look anyone in the eye and tell a lie with a straight face (if for a right end).

Organizational Commitment

I would be very happy to spend the rest of my career with this hospital.

I really feel as if this hospital's problems are my own.

I feel like part of the family at this hospital.

I feel emotionally attached to this hospital.

This hospital has a great deal of personal meaning for me.

I feel a strong sense of belonging to this hospital.

Job Satisfaction

I feel fairly well satisfied with my present job.

I find real enjoyment in my work.

Most days I am enthusiastic about my job

Each day of work seems like it will never end. (R)

I consider my job rather unpleasant. (R)

Organizational Citizenship Behaviors

Proactive

I say things to make people feel good about themselves or the work group

I encourage others to overcome their differences and get along

I treat others fairly

I anticipate what colleagues might need to know \& shares this knowledge

I plan ahead to offer assistance to colleagues facing new challenges

I go out of my way to build supportive links with colleagues

\section{Reactive}

I praise co-workers when they are successful

I support or encourage a co-worker who has personal problem (slightly reworded) 
I help colleagues who have been absent

I help someone without being asked

I talk to other workers before taking actions that might affect them

Perceived Effectiveness

I am almost always able to meet patient care treatment goals.

Given the severity of the patients I treat, my patients experience very good outcomes. I am very good at responding to emergency situations.

I do a good job of meeting family member needs.

Relative to other nurses in my specialty, I do a good job of meeting family member needs.

Satisfaction with quality of care

I was satisfied with the quality of nursing care I gave.

Under the circumstances, I was happy with the quality of care I provided.

The patient care I gave met my standards for good patient care.

Decision-Making Autonomy

1. This job gives me a chance to use my personal initiative or judgment in carrying out the work.

2. This job allows me to make a lot of decisions on my own.

3. This job provides me with significant autonomy in making decisions.

Work Methods Autonomy

1. This job allows me to make decisions about what methods I use to complete my work.

2. This job gives me considerable opportunity for independence and freedom in how I do the work.

3. This job allows me to decide on my own how to go about doing my work. 